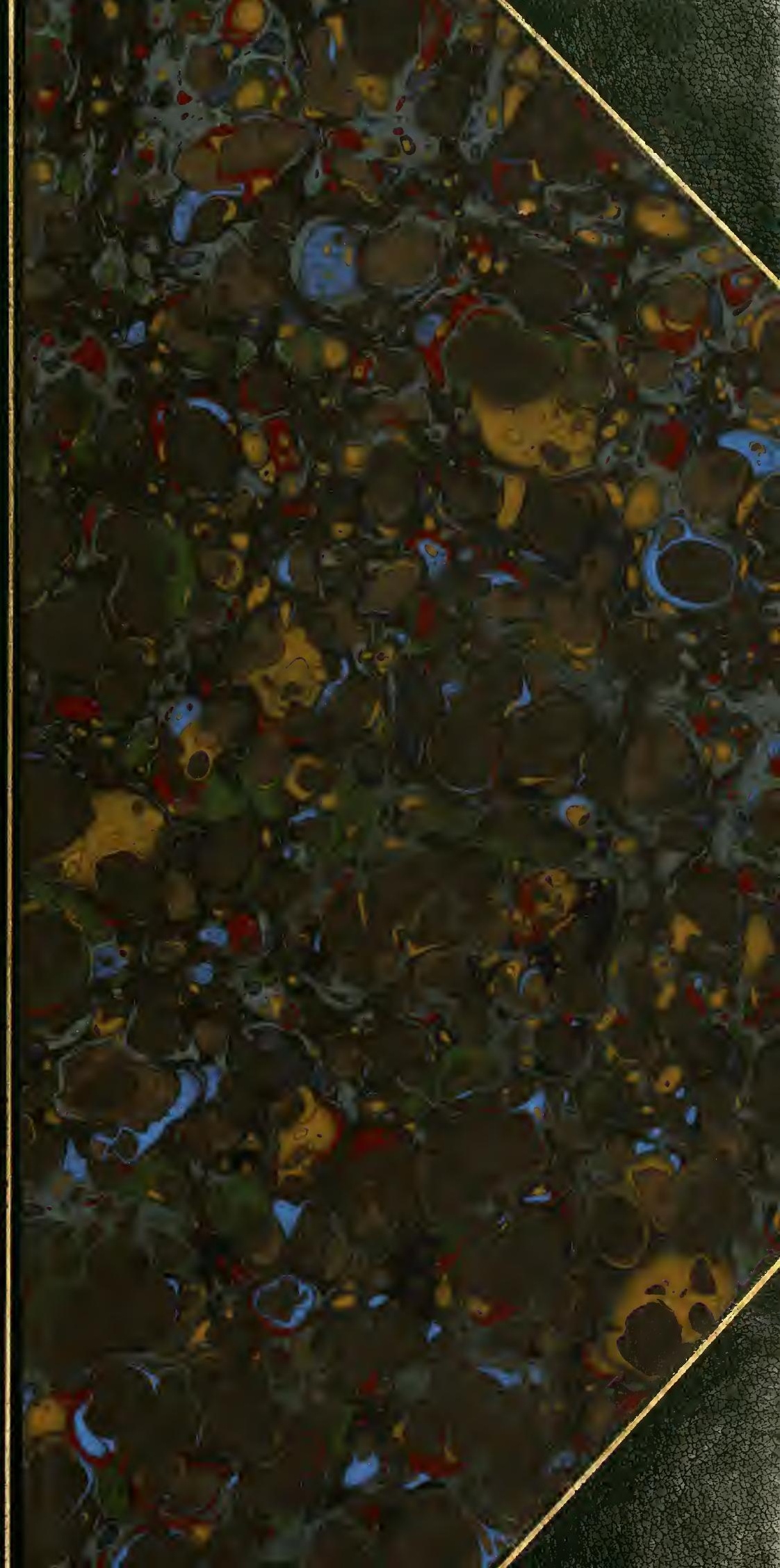





Shi Zne 

F L O R A

BOREALI-AMERICANA. 



\section{Glis areos. \\ FLORA \\ BOREALI-AMERICANA,}

SISTENS CARACTERES PLANTARUM

quas in America septentrionali collegit et detexit

\section{A N D R A M I C H UX,}

Instituti Gallici Scientiarum, necnon Societatis Agriculturæe Caroliniensis socius.

TABULIS ENEIS 5I ORNATA.

\section{TOMUS PRIMUS.}

TYPIS CAROLI CR APELET.

$P A R I S I I S$ I $A R G E N T O R A T I$,

Apud fratres LEVRAULT.

$$
A N N O X I-1805 .
$$





\section{LECTORI BENEVOLO.}

$H_{\text {is ro r a naturalis, scientiarum physica- }}$ rum insignis pars, diu arctis limitibus constricta, rupto demum obice plurimum increvit studiosis agentibus viris quos innata rerum novarum cupido in exteras impulit regiones Quidquid in iis tellus sua sponte profert, seu jamdiu indigenum, seu humaña industria ex vicino solo congregatum, id sedulo observantes alii descripsere et interdum delineavere, alii collegerunt addito præparationis conservatricis opere, futurum in musæis privatis aut publicis ornamentum; alii missis plantarum seminibus et animantibus vivis hortos europæos et aviaria claustra sylvasque numeroso exoticorum agmine ditaverunt. Hos initer peregrinatores scientiæ naturali addictos annumerandus Andreas Michaux qui, ex Persia redux ubi per sexennium plantas perquisierat hucusque incognitas, missus in Americam a rege Ludovico XVI et artium fautore Dangivillæo, post repetitas per annos duodecim ex Carolina ack 
littus hudsonianum itinerationes non sine vitae periculo, collectis indesinenter numerosis plantarum fasciculis, multiplicatis ubique quantum licuit observationibus et descriptionibus, novam et cæteris ditiorem America borealis Floram compendiose profert.

Plures jam prodiere ejusdem plantarum enumerationes botanicæ quibus singulis sua laus debetur. Canadenses descripsit plantas Cornuti, Virginicas Claytonius juvante Gronovio, Carolinianas Catesby cum adjunctis iconibus pictis, easdem prolixior Walterus et nuper Bartramius, americanas in tractu boreali arborescentes aut fruticantes Marshallius. Integram demum hujus regionis Floram inchoavit Forster in indice nomina tantum exhibente descriptionibus et etiam phrasibus omissis.

Quam nunc patris mei floram exhibeo, ea ex manuscripto auctoris non absoluto excerpta, ab eodem perfici. non potuit. Ille enim, ubi primum increbuit botanici in Australasiam insulasque adjacentes futuri itineris fama, prateritæ juventutis memor viriumque conscius, novorum laborum periculorumque non cleterritus metu, jamdiu Asiæ australis invisendæe desiderio incitatus, suam novæe expeditioni 
adjunctionem expostulavit propositi tenax, obtinuitque consentientibus ultro reipublica administris. Manuscripto hujus operis nondum summam imposuerat manum, quod quidem. adhucdum constabat in schedulis quibus singulatim inscripserat prælısoriam novorum gcnerum etspecierum delineationem.

In re herbaria parum ego versatus schedulas illas examini nonnullorum botanicorum subjeci quorum innixus consiliis, editoris munus mihi a proficiscente patre mandatum melius explere possem. Hos inter fuere quibus descriptiuncula singulas species designantes visa sunt passim justo prolixiores quam qua ex toto transirent in phrases specificas, neque eiiam caracteri quorumdam generum nimiis verbis dilatato defuit vituperatio; omnium vero consensu ınaximam operis edendi utilitaten exploratam habui : hunc ideo majoris laboris prodromum typis committere ausus sum.

Quas continet Flora Boreali-Americana plantas, ea fere omnes facilem felicemque in hortis europæis subire possunt culturam ; jamque non paucæ in istis late vigent tum a diversis viatoribus quum et uberius ab ipso auctore introductæ: horticultoribus idcirco pariter ac bo- 
riij LECTORI BENEVOLO.

tanicis gratam et utilem futuranı esse arbitror.

Nequidem europæas plantas omittere voluit auctor non tantum ut Floræ suæ servaret integritatem, sed etiam ea ductus sententia, quod communitas nonnullorum vegetabilium inter diversas remotasque regiones non sine quadam utilitate comperiatur. Plures quidem plantarum species ex Europa in Americam septentrionalem humana industria demigrarunt; multa vero juxta accuratas auctoris observationes patrium in utraque solum jussu naturæ inhabitant.

Mens erat auctori compendiosos generum quæ in suo opere continentur caracteres ex autopsia reformare : vacuam hanc paterni manuscripti partem supplere tentavi, insertis characteribus ex Murrayi systemate rarius ex alio fonte depromptis; quo additamento liber incolis remotarum regionum et peregrinatoribus evaderet commodior.

Linnæanas species qua potuit cura confirmavit auctor. Caracterem plurimarum rursus condidit non vano quidem innovandi studio, sed ea potius mente ut inde tutiorem allegatis denominationibus accerseret fidem. Species non. 
nisi a se visas lectasve in Floram suam adduxit ullas.

Genera ejusdem Ordinis, quantum salvis systematis legibus licuit, sub vexillo affinitatum. commilitant necnon passim in sectiones dispertita sunt, unde ad disquisitum genus clarior breviorque patet aditus.

Cyperacearum et numerosior Graminearum progenies, multiplici hominum animaliumque commodo nata, floristarum exoticorum diutius incuriam passa est immeritam. Harum species sagacibus indefessi nostri viatoris indagationibus debentur benemultæ quarum caracteres accurata analysi elaboravit compendiosos. Ille etiam cryptogamica vegetabilia (omissis fungis) studiose comparavit. Filices ad genera Smithi fuerunt relatæ. Examen Muscorum ad meritissimi Hedwigii normam diligenter institutum est. Lichenum Ordinem et denominationem suppeditavit recentior Acharius.

Nonnullæ quidem, ut audio, ex plantis in Flora Boreali-Americana enumeratis, sub aliis denominationibus recenter prodierunt. Verumtainen auctorem a biennio absentem detectoris jura, multis parta laboribus et periculis, sibi retinere æquum omnibus videbitur. Qua ideo 
seposita parvi momenti lite, statutas in paternis schedis denominationes servare non dubitavi.

\section{MICHAUX.}





\title{
ADDENDA ET CORRIGENDA.
}

\author{
T O M. I.
}

Pag. 44, lin. 13, precox, lege ír micox.

- 45, lin. 18 , precox, lege praecox.

- 56 , lin. 10, Scheuczeri, lege Scheuchzeri.

- 67 , lin. 1, DistichipHy lia, lege Distichophylia.

- 70 , lin. 15 , emarginati, lege emarginatae.

- $9^{\mathrm{I}}$, lin. 8, acuminatis, lege acuminatis:

- ro3, lin. 16, fructicosus, lege fruticosus.

- 113, ANYCHIA merniarioides.... adde: $O_{B}$. Habilus Herniaria hirsutae, fasciculis floralibus confertioribus : calyx clausus, sursum conice angustatus et apice quasi stellatim 5-acuminatus.

- 149, PHYSALIS viscosa.... adde : $O_{B S}$. Antherae pallide luteæ.

-150, AZALEA viscosa.... adde : OBs. Cal. minutus. cor. albido-rosea, angustius tubulosa : stamina breviuscule exerta.

- i7o, CAREX Richardi - est Carex curta recent.

- 171, CAREX Oeder I.... synonymum dele.

- 184 , lin. nlt., in undis, lege in udis.

- 195 , lin. 14 , TILLIANDSIA, lege TILLANDSIA.

— 197, LILIUM CAтеsв жi.... adde : $O_{B} s$. Flos pallide flavus, maculis purpureis parce insignitus.

- 218 , lin. 6 , Mattuschia, lege Mattuschia.

- 311, lin. 1, psytracina, lege psitticina.

- 311 , lin. 6, Pisttaci, lege Psittaci.

T O MI. II.

Pag. 18, lin. 17, BUCKNERA, lege BUCHNERA.

- 21, lin. 17, Newyrck, lege New-Yorck.

- 43, lin. 7, MELACHODENDRON, lege MALACHODENDRON.

- 275 , lin. 22, aULGatum, lege vULGatum. 


\title{
F L O R A
}

\section{BOREALI-AMERICANA.}

\author{
CLA S S I S I. \\ M O N A N D R I A. \\ $M O N O G Y N I A$. \\ H I P P U R I S. $L$.
}

Cal. integer, non manifestus. Petala nulla.

Stigma simplex. Sem. 1.

vulgaris. H. foliis plerumque senis, lineari-

L. bus.

$O_{B S .} \mathrm{Ab}$ europæa panciore foliorum numero in singulo verticillo tantum differt.

HAE. in fossis aquosis Canadæ.

$$
\text { S A L I C O R N I A. } L \text {. }
$$

Cal. ventriculosus, integer. Petala o. Sem. 1.

HERBACEA. S. herbacea, pumila, erecta; spicis

$\boldsymbol{u}$. lineari-oblongis; pedunculo subancipiticompresso, sursum latescente.

$O_{B S .}$ In nostra rami plerumque simpliciter ramulosi;

ramulis totidem spicas constituentibus.

$H_{A B}$. ad ripas sari inundatas flurninis $S$. Laurentii.

$\pi$. 
AMbigua. S. fruticulosa, procumbens seu assurgens, inordinate ramosa.

OBs. Quasi media herbaceam inter et fruticosam. Lins. sed sempervirens et incompte laxa.

$H_{A B}$, in Carolinæ scirpetis maritimis.$$
D I G Y N I A \text {. }
$$$$
\text { B L I T U M. L. }
$$

Cal. 3-fidus. Petala 0. Sem. 1. calyce baccato.

capitatum. B. procumbens : foliis acute trian-

$\boldsymbol{L}$. gulo-hastatis : capitulis alternis, in racemum superne aphyllum approximatis.

$H_{A B}$. in ruderatis \&c. Canadæ; huc ex Europa advena.

\section{A L L I T R I C H E. $L$.}

Cal. o. Petala 2. Caps. 2-locul. 4-perma.

VERra. C. foliis superioribus spathulato-obo-

L. valibus; inferioribus linearibus : floribus omnibus hermaphroditis.

$H_{A B}$. ubique a Canada ad Carolinam.

AUTUMrals? C. foliis omnibus linearibus, cmar-

L. ginatis, approximatis.

$O_{B S .}$ Florentem non vidi.

HAB.ad ripam meridionalem lacus Champlain. 
DIANDRIA. MONOGYNIA.

\section{I A N D R I A. MONOGYNIA.}

ઈ. I. MONOPET, REGULARES.

L I G U S T R U M. $L$.

Cor. 4-fida. Bacca tetrasperma.

VULGARE. L. foliis lanceolatis, acutis : paniculæe $\boldsymbol{L}$. pedicellis oppositis. $\boldsymbol{L}$.

$H_{A B}$, rarius in sylvis, a nova Anglia ad Pensylvaniam.

C H I O N A N T H U S. $L$.

Cor. 4 - fida : laciniis longissimis. Drupae nucleus striatus.

virgivica. C. foliis ovali-lanceolatis, non acu-

L. minatis : racemi ramulis simplicibus, I-3-floris; floribus omnibus pedicellatis: fructu brevi-ovato, subacuto.

OBS. Folia interdum obovalia : juniora pubescentia.

HAB. in maritimis, a Pensylvania ad Carolinam, etiamque in posterioris montosis. 
S. II. MONOP. IRREGULARES.

-A. C A P S U L A B I L O C U L A R I.

$$
\text { V E R O N I C A. L }
$$

Cor. limbo 1-partito, lacinia infima angustiore.

ARvensis. V. pumila, diffusa, pubescens : foliis

I. subrotundo-ovalibus, obtusissimis, obtuse denticulatis : floribus alternis, sessilibus, subspicatis.

$H_{A B}$. in Virginia; huc cum cerealibus allata.

SERPYLLIFOLIA. V. humifusa, radicans : foliis sub-

$\boldsymbol{L}$. orbiculato-ovaliłus, subintegris, glabris : spica foliosa; floribus breviter pedicellatis : capsulie abbreviatæ valvis ciliatis.

$H_{A B}$ a Canada ad Carolinam.

PFRFGrINA. V. pumila, procumbens, glaberrima :

L. foliis obtusissimis, rariter subdentatis; radicalibus obovalibus; inferioribus subpathulatis; superioribus oblanceolatis , alternis, subsessilibus, unifloris.

OBs. Perperam, ni follor, Limnæus V. marilandicam (quæ mea est (distinxit a V. peregrina.

Interdum caules primarii assurgentes.

HAB. in Carolina inferiore \&c. inter oleraceas, cum quibus forsan allata. 
scutellata. V. debilis, diffusa : foliis omnibus

$\boldsymbol{L}$. oppositis, linearibus, acutissimis, remotedenticulatis : spicis axillaribus, divaricato-laxifloris.

$H_{A B}$. juxta rivos ad sinum Huc${ }^{\top}$ sonis defuentes.

Anıgallis. V. radicanti-assurgens, glaberrima,

L. nitida : foliis oblongo-ovalibus, acutis, serratis : spicis axillaribus; pedicellis erectis.

HAB. in Pensylvania; Connceticut.

officinalis. V. repens, conspicue pubens : folis

L. ommibus oppositis, ovalibus, basi breviter angustatis, aqualiter serratis : spicis lateralibus, assurgentibus; floribus subsessilibus : capsula pubente.

HAs. in Virginia et Marilandia

YIRGrica. V. caule simplici, erecto: foliis 4 -ver-

L. ticillatis, argute serratis : spicis confertifloris : corolla tubulata : genitalibus promisse exertis.

Oes. Folia interdun quina; inferiura nommunam subtus pubescentia. Cauli sæpe 1-stachyos, Capo sula ovata, nec emargniata.

HAB, a Pensylvania ad Carolinan : copiosins in $r c$. gionc Illinoenssi. 


\section{G R A T I O L A. L.}

Cor. irregularis, resupinata. Stamina 2 sterilia. Capsula 2-locularis. Cal. 7-phyllus : 2 exterioribus patulis.

Exclusis tetrandris, ad Monnieram referendis.

officinalis. G. assurgens, glaberrima : foliis lanL. ceolatis, sursum acutissimis, rariter den ticulatis : calycis laciniis lineari-lanceolatis, integris : filamentis castratis nullis: capsula calyci subrequali.

OBs. Europæa universe minor. Caules plerumque simplices, rarius opposite ramosi. Certissime nequidem vestigia filamentorum sterilium.

$H_{A B}$. in Virginia et Carolina.

QUADrinentata. G. pumila, assurgens, ramosa, glabra : foliis lanceolatis, acutis, remole 4-dentatis; dentibus exertis; binis ad apicem inde tricuspidatum longioribus: capsula calyce subulato triplo breviore.

OBS. Habitu fere prioris; omnibus partibus minor: Folia suprema interdun tantum bidentata. Pedunculi longiusculi. Filamenta castrata 2, capillaria, remote infra stamina.

$H_{A B}$. in Carolina inferiore.

ANAGALLIDEA. G. erecta, glaberrima: caule 4-gulo: foliis oblongo-ovalibus, rariter denticu. 
DIANDRIA. MONOGYNIA:

latis, flore brevioribus: calyce ebracteato, subulato, puberulo: corolla intus glabra.

G. inaequalis? WALT.

OBS. Folia plerumque obtusa. Carolla pallido-coerulescens.

HAß. in humidis Carolinæ.

pIlosa. G. erecta, ramosa, pilosissima : foliis ovalibus, rariter subrlentatis : floribus subsessilibus, folio brevioribus.

G. peruviana. WALT.

OBS. Canlis subpedalis et infra, cylindraceus cum linea prominula utrinque, pilosissimus; pilis articulatis. Eolia subrngosa, pilosa. Calyx etiam pilosus. Corolla pallido-albida.

$H_{A B}$, in Carolinæ inferioris uliginosis. Maio florens.

\section{J U S T I G I A. $L$.}

Cor. ringens. Caps. hilocularis, ungue clastico. dissiliens. Stamina authera singulari.

pedurcuzosa. J. glabra : caulibus herbaceis, erectis, simplicissimis : foliis erectis, linearilancéolatis, utrinque angustato-acutis : spicis alternis, longissime pedunculatis, conferte paucifloris.

\section{Dianthera americana. LiNn.}

$O_{B S}$. Cáules fistulosi, inferne demersi, reptatrice sni aquis stirpe multiplicandi. Flores dilute violacei.

$\boldsymbol{H}_{A B}$. in littoribus hicme inundatis fuminum Ohis S. Laurentii, Mississipi. 
Humilis. J. glabra : caulibus herbaceis, e stirpe repente assurgentibus : foliis ovali-lanceolatis : spicarum bracteis minutissimis; floribus subbinatim sessilibus : capsula longe stipitata, compressa.

$O_{B S}$. Spicæ longinscule pedunculatæ; floribus distincte approximatis. Calyx longo-subulatus. Corollæ labium superius integrum; inferius tripartitum, laciniis oblongis. Capsula acute mucronata: semina planiuscula.

Affinis J. assurgenti, Lins.

$H_{A B}$. in sylvarum paludibus cæspitosis, a Carolina ad Floridam.

SEXANGULARIS. J. herbacea, assurgens, glabra : L. caule 6-angulato, ramosissimo; ramis paniculatis; ramulis aphyllis, remote alternifloris : foliis ovalibus, plerisque reflexis.

$O_{B S .}$ Radix perennis. Corolla rubelTa.

$H_{A B}$, in urbe Bahamensi Nassau dicta : Maio florens.

$$
\text { E L Y T R A R I A. }
$$

Exurģov, vagina : elytris seu vaginis glumaceis vestita.

Herbæ. Scapi radicales, alterne vaginato-squamosi: spicæ imbricatæ; bracteis coriaceis, sessilibus, 1-floris; bracteolis binis calycis latera, prementibus, lanulosis.

CAL. bractea bracteolisque complexus, co- 
(4)

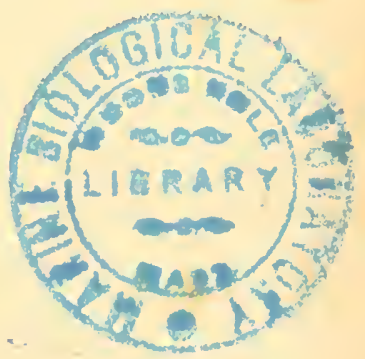




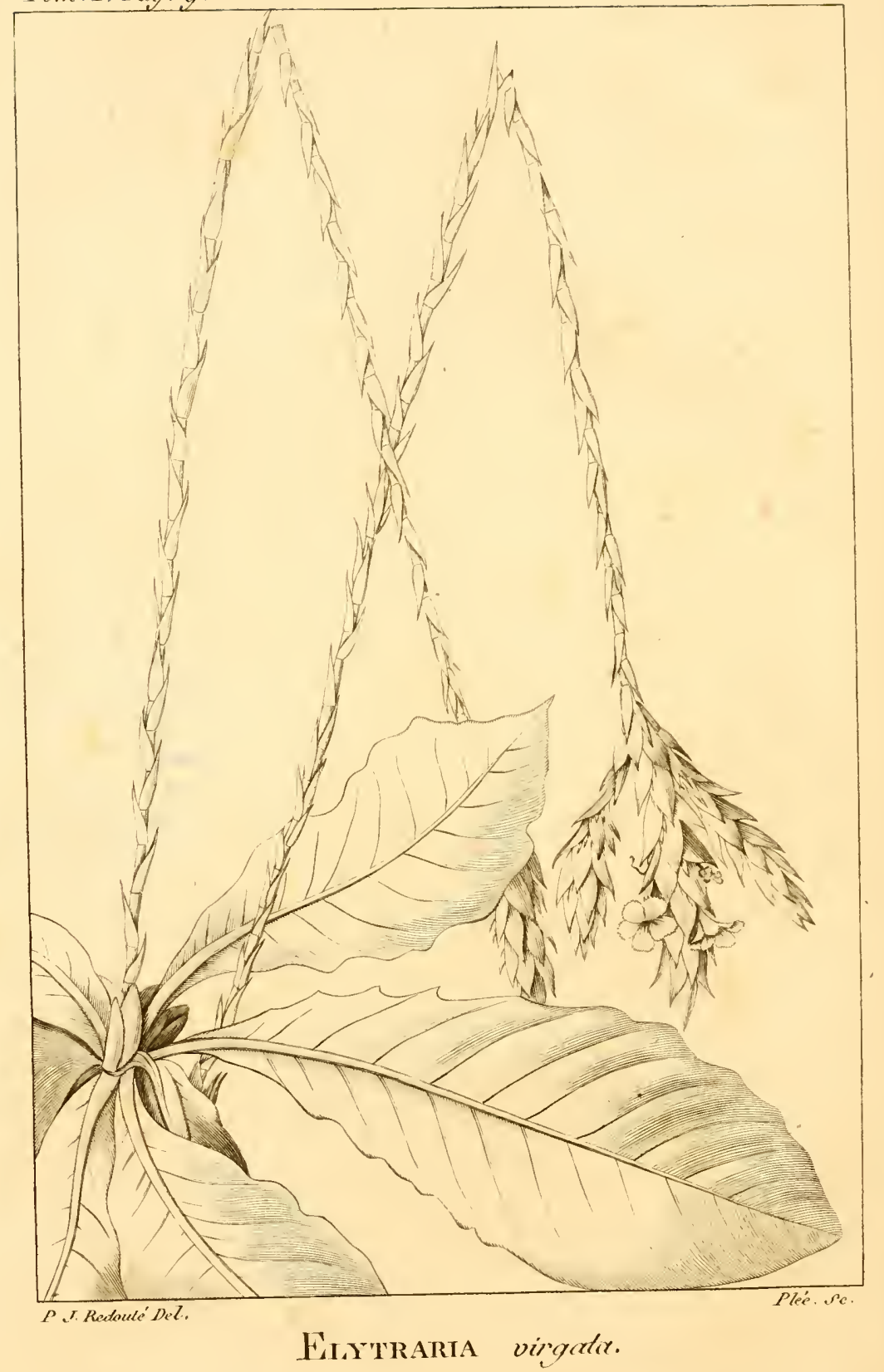


DIANDRIA. MONOGYN1A.

riaceus, profunde 4-partitus : laciniis oblongis; antica bidentato-fissa.

Cor. tubus angustus : faux transverse subclausa : limbus subbilabiato-5-fidus; laciniis subrqualibus, obtuso-ellipticis; duabus superioribus, ascendentibus; tribus inferioribus, patulis.

Stam. inclusa : antheræ oblongx; apposite 2-loculares : filamenta 2 castrata.

PIst. ovarium oblongum : stylus capillaris : stigma hinc in ligulam ovalem, obtusam, recurvam expansum.

CAPS. oblonga, teretiuscula, 2-locularis, 2-valvis, valvis medio semiseptiferis.

SEM. pauca, ad imi dissepimenti axim adnexa, sublenticularia.

$O_{B S}$. Genus Justicie affine.

VIRGATA. E. foliis superne integris; nervis subtus glabellis : scapis longissimis : capsula obtab. 1. tusiuscula.

Tubiflor a caroliniensis. Grex. Syst. 27. OBs. Congener Justicia acaulis. LINN. Suppl. $H_{A B}$ in humidis Carolinæ inferioris. 
-B. C A P S L A U N I L O C U LA R I.

M I C R A N T H E M M.

Mixpos, parvus. Aveos, flos.

Herba pusilla. Folia opposita; nervis longitudinalibus.

Flores minuti, axillares, solitarï, alterni.

CaL. profunde 4-partitus; laciniis subspathulatis; 2 superioribus paulo minoribus.

Cor. vix exerta, subcampanulata : tubus brevissinus, intus glaber : limbus inaqualiter 4-partitus, subbilabiatus; lacinia superiore minore.

Stam. convergentia : filmmenta incurva, basi appendiculata : antheræ rotundatosubdidyma.

PIst. ovarium subglobosum : stylus brevis, subdeclinatus : stigma depresso-capitatum, obliquatum.

CAps. calyce persistente vestita, subglobosa, J-locularis, 2-valvis, polysperma.

SEM. numerosa; placenta basilari undique immediate affixa; ovata, striatula.

OBs. Genus Anagallideum.

oreiculatum. M: glaberimum : caulibus filiformibus, repentibus : foliis orbiculatis, tab. 2. integris, flore longioribus.

Globifera Umbros. Gmez. Syst. 32.

H.AB. in udis opacisque sylvarum Carolinæ et Georgiæ. Augusto florens. 
Tom, 1. Pag. 10 .

Tab. 2.

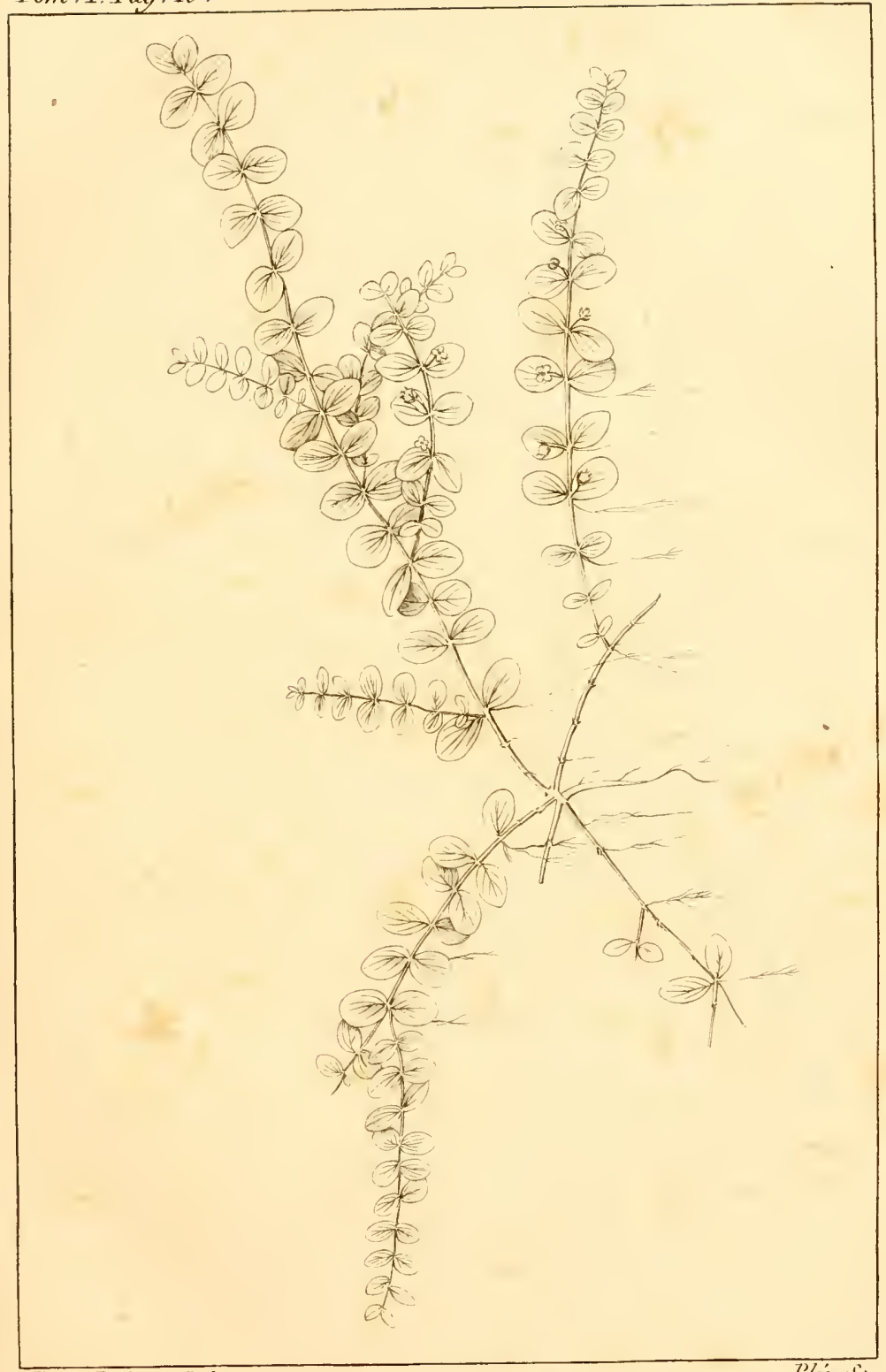

Micrantinemun orliculation. 



\section{P I N G U I C U L A. $L$.}

Cor. ringens, calcarata. Cal. bilabiatus, 5-fidus. Caps. 1-locularis.

Jlation. P. scapo manifeste pubente, superne rigidulo, erecto : calyce glanduloso-pubere : corolla majuscula; tubo conspicue inflato.

$$
\text { P. corulea? WALT'. }
$$

$O_{B S .}$ Folia P. vulgaris : Corolla subquadruplo major, amethysteo rubens.

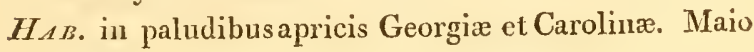
florens.

Acutifolia. P. pusilla, glaberrima : foliis erectorosulaceis, arcte sessilibus, ovalibus, acutissimis.

$O_{B}$. Fructiferam tantum reperii.

H.tE. in sylvis ripariis circa lacus Mistassins. Abeunte Augusto deflorata.

IU te A. P. scapo glabriusculo : corolla majus$W_{\text {ALT. }}$ cula, lutea; laciniis manifeste crenatis; calcare subfiliformi, vix longitudine tubi.

Ors. Folia brevius obovalia, apice magis rotundata.

Cor. saturate lutea.

$H_{A B}$, in pinetis, sylvis sterilioribus Carolinæ inferioris. Aprili florens.

punula. P. scapo brevi, glabello: corolla parvula, dilute violacea; oblongiuscule tu. bulata; calcare tubo breviore.

$I_{A B}$, in humidis apricis Georgix. 


\section{U T R I C U L A R I A. L。}

Cor. ringens, calcarata. Cal. diphyllus, æqualis

Caps. unilocularis.

Cratophylua. U. foliis ad superficiem aque senoverticillatis, pinnatifidis; laciniis capillaceo-multipartitis : spica floribus pedicellatis quasi corymbosa : calcare brevi, conoideo.

$O_{B S}$. Radix U. vulgaris. Foliorum verticillus unicus; supra et infra quem caulis nudus. Flores paulo majores, lutei : calcar conoideo-crassius, acutiusculum, sub labio infcriore approximatum.

$\Pi_{A B}$. in stagnis Carolinæ inferioris.

connura. U. subarrhiza, aphylla : scapo rigido, sessiliter summitate bifloro : corolle majuscula labio inferiore amplissimo; calcare porrecto, longiusculo, acutissime cornuformi.

OBs. Scapus interdum 1-florus.

$H_{A B}$. in Canada, juxta lacus ad originem fluvii Sagney. Julio florens.

SETACEA. U. minuta, aphylla : caule tenui-setaceo, distanter 2-3-floro; floribus longius. cule pedicellatis; calcare longiusculo. $H_{A B}$, in udis subpratensibus Carolinæ inferioris. 
Cor. ringens : labio superiore erecto, plano. Filamenta castrata 2. Semina 4 .

mariana. C. perennis : foliis arcte sessilibus,

L. ovalibus, serratis, subtus pilosis : corymbulis lateralibus et terminalibus, subdichotome multifloris, fastigiatis.

$H_{A B}$. in montosis, a Carolina ad Canadam.

glabella. C. perennis; erecta, glabra : caule 4-gono, fistuloso : foliis inferne angustatis, ovali-lanceolatis : floribus paucioribus, pedicellatis : calycis oblongi dentibus brevibus, aristatis.

$O_{B S}$. Caulis nodi minutissime pubentes; angnli prominuli. Folia uti in congeneribus puncticnlosa, rario-ribus dentibus serrata : inferiora ovalia; superiora gradatim lanceolata.

$H_{A B}$. in rupibus ripariis fluvii Tennassée, juxta Nashville.

pulegiomes. C? annua, tota puberula : foliis

L. lanceolato-ovalibus, in petiolum angustatis, paucidentatis : floribus verticillatis : calycis labio inferiore biseto, setis ciliatis.

$H_{A B}$, in montosis Americæ septentrionalis. 
L Y C O P U S. $L$.

Cor.4-fida : lacinia unica emarginata. Stamina distantia. Semina 4, retusa.

EUROPzUS : $\beta$. L. foliis inferioribus incisis; su-

L. perioribus lanceolatis, serratis : calycibus subspinescenti-acuminatis.

$H_{A B}$. in Canada.

vikginicus. L. foliis lato-lanceolatis, serratis, basi

$\boldsymbol{L}$. integra angustatis : calycibus brevissimis, muticis.

HAB. a nova Anglia ad Carolinam.

UNIFLORUS. L. pusillus, radice tuberosa : caulibus simplicibus : foliis ovalibus, obtusis, obsolete dentatis : axillis unifloris.

$H_{A B}$ ad Lacus $S$-Joannis et Mistassins.

$$
\text { S A L V I A. L. }
$$

Cor. inæqualis. Filamenta transverse pedicello affixa.

Lyrata. S. erecta, hirsuta : foliis radicalibus

L. lyrato-sinuosis, obtusis : caulibus simplicibus, subdiphyllis : spica remote interrupta : calycibus 5-fido-spinescentibus : corollis promisse exertis.

$O B S$. Folia radicalia modo subintegra, modo lyratosinuata, modo etiam subpinnatifido-lyrata; laciniis repandis sinuatisve. Corolla longa, coerulea; labio superiore brevissimo. Filamentula antherica utrinque loculifera!

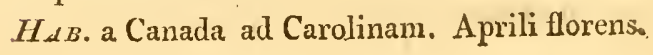


DIA NDRIA. MONOGYNIA.

URTICIFolia. S. foliis rhomboideo-ovalibus, utrin-

L. que acutis, inæqualiter serratis, subtus crebro-puncticulosis : spica nuda; verticillis remotis : calycibus puberulis, brevitrifidis.

$H_{A B}$. in remotis occidentalibus Virginiz et Carolinx.

coccrnea. S. suffruticosa : foliis ovali-cordatis,

$\boldsymbol{L}$. acutis, denticulatis, molliter incano-tomentosis : spicæ verticillis subnudis : calyce oblongo, trifido : corolla longa : genitalibus exertis.

$H_{\mathcal{A B}}$. juxta fluvios et in insulis Florida.

ANG USTIFolia. S. erecta, glabra : foliis longo-linearibus, integriusculis, lavibus : spicis nudis : calyce pubente, brevissime trifido: corolla longiuscule excrta.

$O_{B S .}$ Elatior; foliis inferioribus lanceolatis, serratis: spicæ e verticillis subsexfloris. Calycis dentes rotuntdati; superiore subintegro. Corolla tubo exerta, azurea. Stylus, uti præcedentis, barbatus.

H.AB. in apricis sylvaticis Georgia meridionalis ; rariox in Carolina. Jumio florens. 


\section{O NA R D A. L.}

Cor. labio superiore lineari, filamenta involvente. Sem. 4.

coccrnea. M. foliis late subcordato-ovalibus; calycibus imberbibus : corollis maximis, coccineis.

M. didyma. Linn.

$H_{A B}$. in rivulis excelsorum montium Carolinæ sep. tentrionalis. Septembri florens.

Lutea. M. foliis lanceolatis, leviter serratis, partim ciliatis : floribus verticillatis; calycibus summitate barbatis; corollis luteis.

\section{M. punctata. LinN.}

$O_{B S}$. Omnium specierum corolla punctata.

$H_{A B}$. a Virginia ad Floridam.

ALLOPHYLLA. M. foliis oblongis, acute serratis: capitulo terminali : calycibus ad limbum barbatis : corollis graciliter elongatis, carneis.

$O_{B S}$. Foliorum figura, serratura, pubescentia \&c。 adeo variant, ut ex hujus varietatibus species plures statuerint !

$H_{A B}$. in America septentrionali.

cilata. M. hirsutie canescens : foliis oblongo-

L. ovalibus, sensim acuminatis : floribus verticillatis; bracteis pusillis, ciliatis : calycibus villosis, valde inæqualiter bilabiatis : corollis parvulis, albis.

$H_{A B}$. in montosis Virginiæ \&c. 
Cor. inæqualis : labio inferiore multifido, capillari, Eemen 1. perfectum.

Caradensis. C. foliis ample cordato-ovalibus : ca-

$\boldsymbol{z}$. lycis dentibus brevi-subulatis, tubo vix aqualibus.

$H_{A B}$. in sylvis umbrosis montium Alleghanis. Au= gusto florens.

TUBErosa. C. radice tuberosa : foliis subrhombeoovalibus, utrinque angustato-acutis : calycis dentibus setaceis, tubo longioribus. $H_{A B}$. in umbrosis humidisque sylvarum Carolinæ. Septembri florens.

§. III, POLY PETALE.

C I R C A E A. L.

Cor. dipetala. Cal. diphyllus, superus. Sem.2.

LUtetrana : C. erecta : foliis ovalibus, (rarius canadensis. cordatis) leviter dentatis : spicis virgatis :

L. fructibus reflexis, conspicue hispidis.

$H_{A B}$. in America septentrionali.

a trins. C. pumila, procumbens : foliis brevi-

L. cordatis, remotiuscule acuteque serratis : spica filiformi : fructibus patulis, parcius breviusque pubentibus.

$H_{A B}$, in Canada.

I. 
CLASS I S III.

\section{T R I A N D R I A.}

\section{$M O N O G Y N I A$.}

๑. I. OVARIO INFFRO.

V A L E R I A N A. L.

Cor. 1-petala, basi hinc gibba. Capsula 1-locularis, 1-sperma, papposa.

pauciflora. V. caulibus simplicibus, erectis: foliis radicalibus pinnatis; caulinis trifoliatis; foliolis ovalibus, acutis, serratis : panicula laxa, pauciflora.

HAB. in montosis umbrosis Tennassée prope FlinnCreek. Junio florens.

$$
\text { F E D I A. G.ERT. }
$$

Cal. 1-phyllus, 5-pluri-dentatus. Cor. 1-petala, limbo-5-fido, regulari et irregulari. Stam. 2-3. Ovarium inferum; stylus simplex. Caps. coronata; 3-locularis; loculamento unico fertili.

radiata. F. assurgens, pubens : foliis spathulatooblongis, subintegris : fructu pubescente, sub4-gono, apice nudo.

Valeriana locusta : radiata. Linn.

$H A B$. in apricis Carolinæ inferioris. 



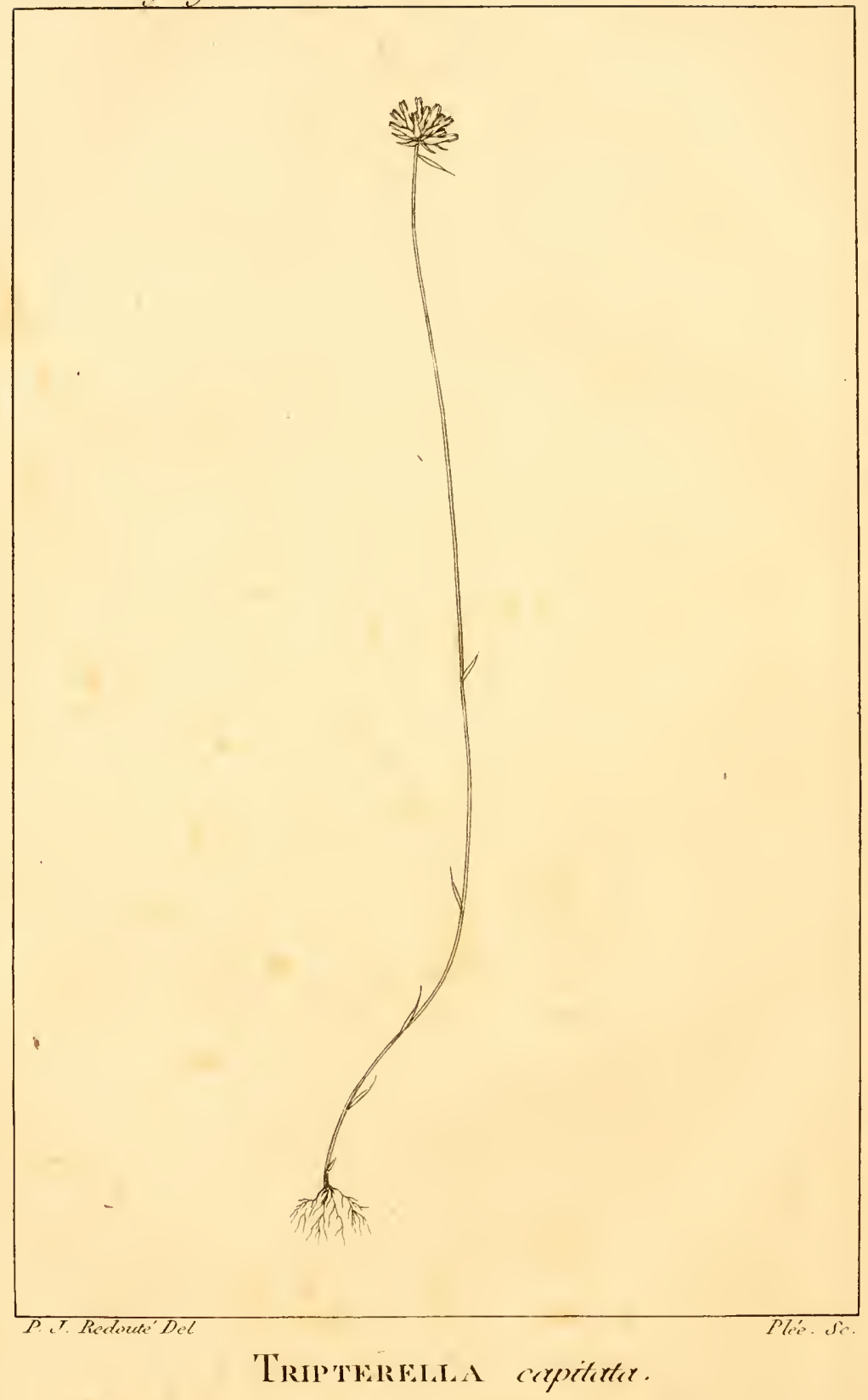


T R I P T E R E L L A.

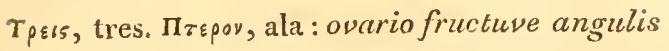
subalato-exstantibus.

Herbulæ simplices, quasi subaphyllæ. Folia sparsa, sessilia. Flosculi terminales.

CaL. oblongus, triqueter, supra basim solidam tubulosus, angulis anguste alatimve extantibus : limbus brevis, exfidus; lacinulis dentibusve alternis, minutis.

Sтам. inclusa, infra denticulos inserta ; antheræ subsessiles, remote biloculares. Pist. ovarium inferum : stylus altitudine staminum, 3-angulus : stigmata 3 , brevia, crassiuscula, obtusa.

CAps. marcido flore terminata, triquetra, membranacea, 3-locularis, polysperma. Ser. ad axim altero apice adnexa, oblonga, teretia, striatula.

$O B S$. Genus Burmannie affine.

capitata. T. debili-setacea : foliis subulatis : floribus in capitulo terminali fasciculatis: tab. 3. calyce angulis subaptero.

Vorelia capilata? Gmel. Syst. 10\%.

$H_{A B}$, in udis Carolinæ ctiamque Cayennæ. 
E L O D E A.

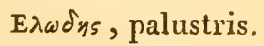

Herbulæ aquatiles. Folia verticillata, simplicia. Flores sparsi, solitarii, spathilla longa inferue involucrati.

CaL. limbus quasi filo pedicellatus, petaloideus, patens , 6-partitus; lacinulis oblongo-ovalibus.

Stam. lacinulis tribus exterioribus opposita, iis subbreviora : filamenta crassa : antheræ terminales, cordatæ.

Pist. ovarium ad caulem sessile, inferum, superne attenuatum quasi in filum longum, terminatum limbo; cujus in centro stigmata tria, ligulata, bifida.

Fruct. . .

$O_{B} s$. Genus Hydrocharideum? forsan potius trigynum.

Canadensis. E. foliis ternis, oblongis, obtusiusculis.

$O_{B S}$. In hac specie pariter ac in Guyannensi, folia (armato oculo) subtiliter serrulata.

$H_{A B}$, in rivulis Canadæ.

H E R I T I E R A. Grel.

Foliatio iridea. Florescentia fasciculato-paniculata.

CaL. lanuginoso-tomentosus, intus glaber, petaloideus, oblongo-subcampanulatus, 

Tom. 1. Pay. 21.

Tab.4.

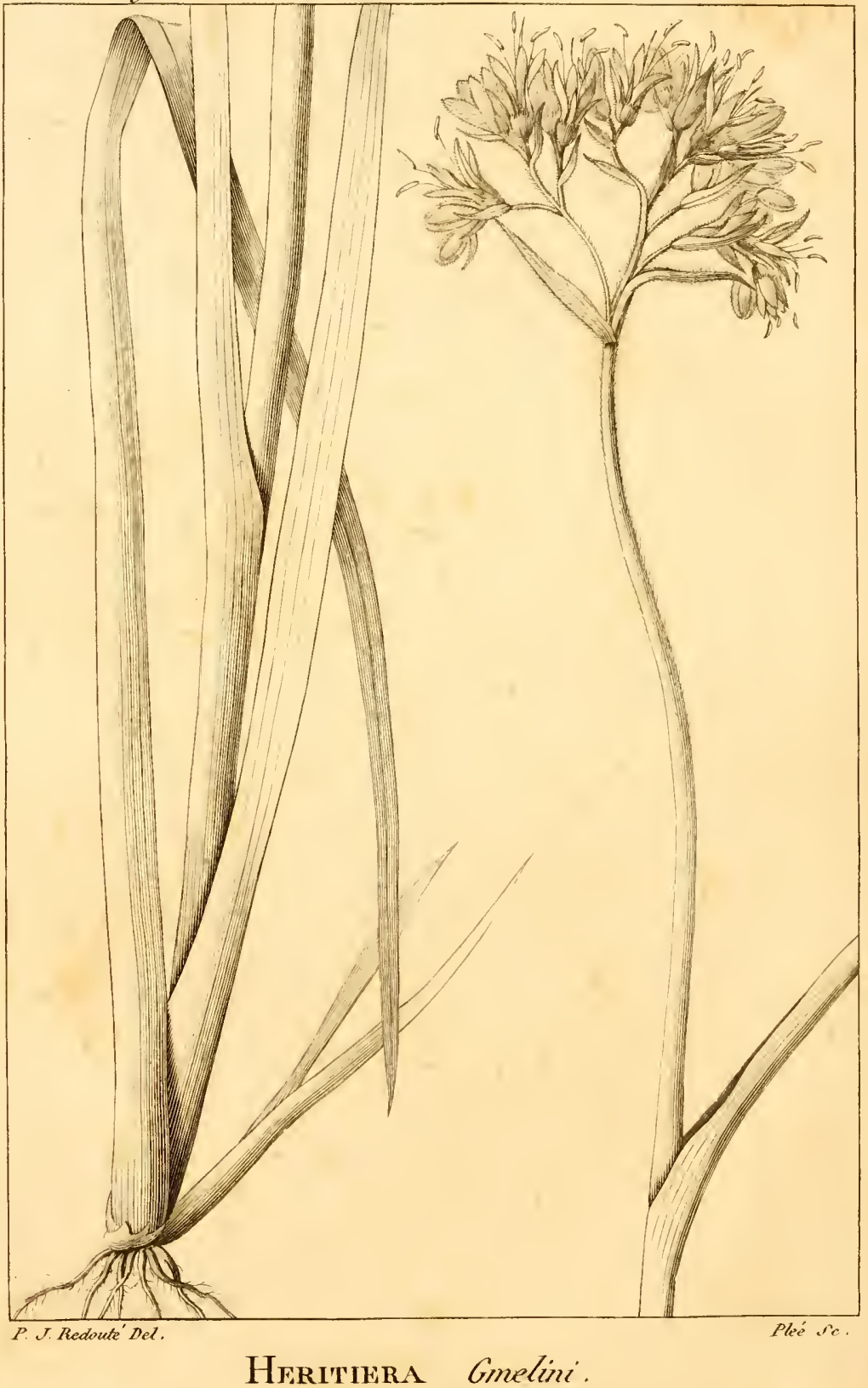


TRIANDRIA. MONOGYNIA.

6-fidus : laciniis tribus linearibus; tribus alternis, interioribus, lanceolatis.

StaM. erecta, subexerta, imis laciniis interioribus inserta : filamenta setacea : antheræ angusto-oblonga.

PisT. ovarium inferum, subrotundo-trigonum : stylus triqueter, exertus : stigma minutum, subtrilobulatum.

CAps. marcido limbo coronata, quasi tricocco-triquetra ; 3-locularis, oligosperma; angulis dehiscens, valvis septo medio ad axim connexis.

SEM. sibi invicem incumbentia, suborbiculata, anguste marginata ; prona facie concavula et a minuto subcentrali tuberculo quasi radiatim rugellosa.

OBs. Genus Dilatri affine.

Grelini. H. foliis angusto-irideis, acutis, erectis : panicula subcorymbiformi, confertab. 4. tim fasciculosa; floribus tomentosis.

H. tinctorum. Bull. des sc. $\mathbf{n}^{\circ}$. $\mathbf{9}$.

$O_{B S}$. Radix fibrosa, rubens. Folia caule solito breviora : caulis seu scapus simplex, subbipedalis.

$H_{A B}$. in paludibus et uliginosis a Carolina maritima ad Floridam. Junio floreus. 
I R I S. $L$.

Cor. 6-petala, inæqualis, petalis alternis geniculatopatentibus. Stigmata petaliformia, cucullatobilabiata.

VERNa. I. pusilla : foliis lineari-gladiatis : caule $\boldsymbol{L}$, brevissimo; vaginis quasi linearibus, distichis; summis florem limbo imberbi exerto involucrantibus.

$H_{A B}$, in Virginia et Kentucky.

cristata. 1. pumila, I-2-flora : calycis tubo seAIt. taceo; laciniis 3 fascia subtrifariam undulato-crenata.

$O_{B S}$. Folia latiuscule lanceolato-gladiata. Caulis brevissimus ; vaginarum binis superioribus manifeste majoribus et latiuscule lanceolatis.

$\Pi_{A B}$. in umbrosis altorum montium Carolinæ.

virginica. I. caule anguste folioso, hinc acuto, L. subtrifloro : calycis laciniis 3 fascia mucido-tomentosa : capsula oblonga, angulis sulcatis.

\section{I. hexagona. WALT.}

$O_{B S .}$ Elatior; caule compresso. Bractea quasi lineari lanceolatæ. Limbus calycis coerulescens, purpureovenosus. Capsula trigona, angulis sulco exaratis.

$H_{A B}$. palustris in Virginia et Carolina. A Maio ad Julium florens. 
TRIANDRIA. MONOGTNIA.

Ø. II. OVARIO LIBÉRO.

X. Y R I S. $L$.

Cor.5-petala, aqualis, crenata. Glumce 2-valves

in capitulum. Caps. supera.

BREVIFolta. X. foliis subbiuncialibus, fere subulato-gladiatis : scapo gracili, teretiusculo, subrequali : capitulo parvo, globoso. $H_{A B}$. in pratensibus udis Georgix inferioris.

Jupicar. X. foliis subæquilate lineari-gramineis, obtusiusculis : scapo infra capitulum anci. piti-dilatato : squamis rotundato-obtusis. HAB. a Marilandia ad Floridam.

C O M M E L I N A. L.

Cor. 6-petala. Nectaria tria, cruciata; filamentis propriis inserta.

rongifolia. C. stricte elatior, tota conspicue pubescens : foliis longissime lanceolatis; vaginis ad faucem rufo-barbatissimis : bracteis subsessiliter aggregato-terminalibus : calyce subrqualiter tripetaloideo. C. Virginica? Linn.

$O_{B S .}$ Caulis $2-2 \frac{\mathrm{I}}{2}$ pedalis, firmus, erectus, crassus. Folia subsemipedalia et ultra. Bractex extensione subreniformes : calyx coeruleus. Semina subelliptica, compressa.

$H_{A B}$, in umbrosis sylvarum Virginix et Carolina. Iulio florens. 
24 TRIANDRIA. MONOGYNIA.

ANGustifolia. C. assurgens, debilis, glabriuscula, dipetaloidea : foliis lineari-lanceolatis, acutissimis, planis : bracteis pedunculatis, solitariis, extensione brevi-cordatis.

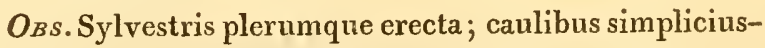
culis, vel ab imo simpliciter ramosis : culta vero solito procumbens. Flores coerulescentes. Semina cylindracea.

Accedit synonymon Pluckneti a Linnæe ad C. virginicam relatum.

$H_{A B}$. in campestribus Carolinæ. Maio florens.

\section{E P T A N T H U.}

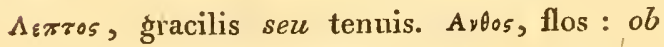
gracilitatem tubi teneritatemque calycis.

Herbæ aquatiles : Folia alterna, basi vaginantia. Flos solitarius, axillaris seu quasi ex imo petiolo erumpens.

Spatha I-flora, hinc dehiscens.

CAL. petaloideus : tubus gracilis, longissimus : limbus adusque faucem 6-partitus; laciniis subacqualibus, oblongis.

STAr. calycis laciniis juxta faucem inserta : filamenta latiuscule oblonga : antheræ lineares.

PIST. ovarium imo tubo arcte involutum, oblongum : stylus longitudine tubi, supra faucem latescens in tubulum apice glandulari et quasi fimbriolato hiantem. 


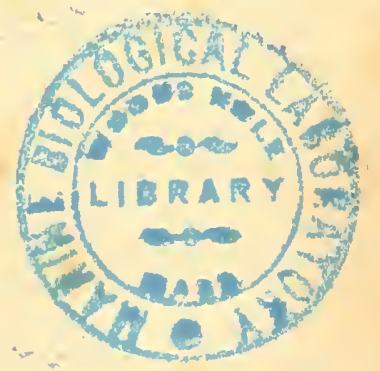




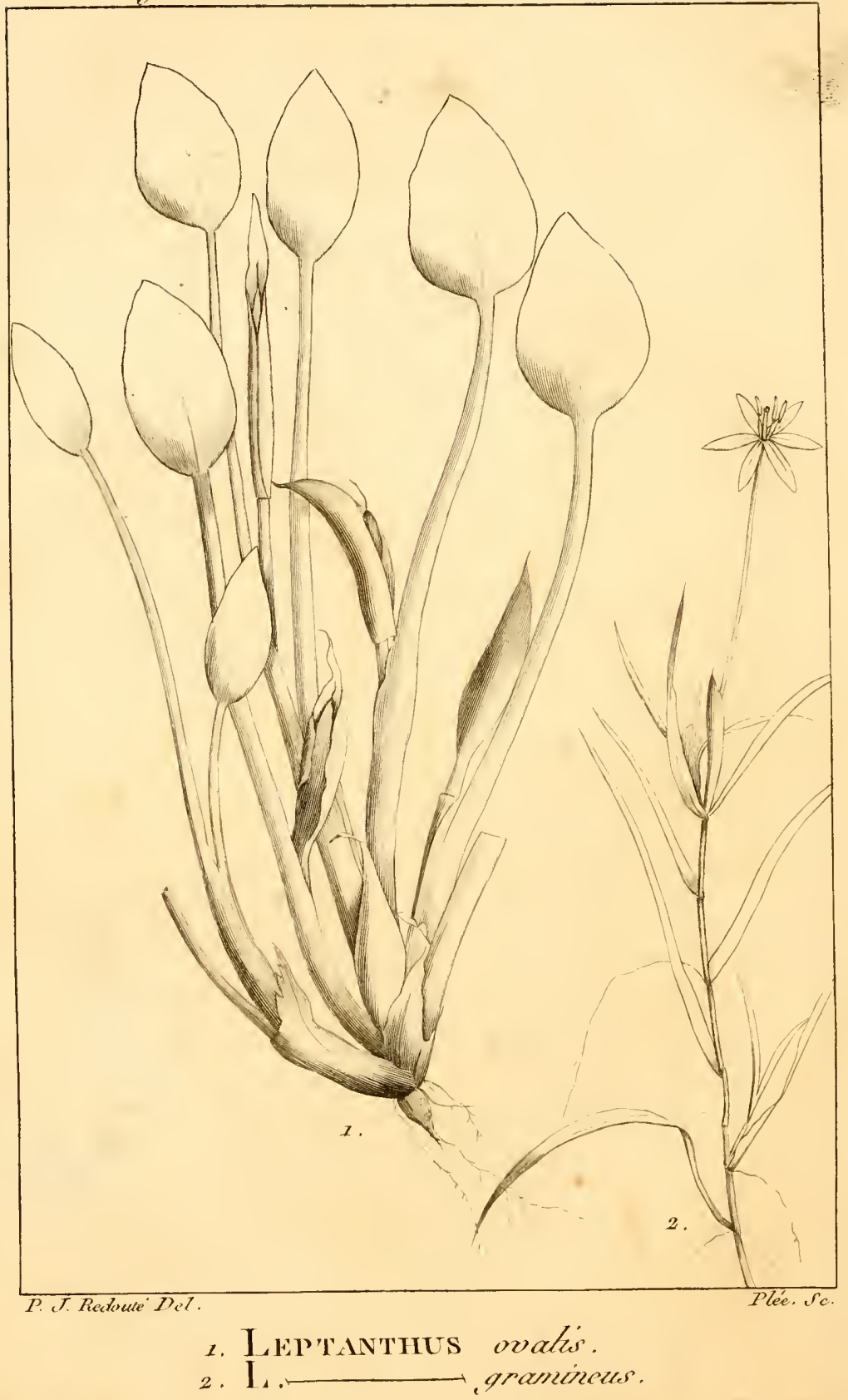


TRIANDRIA. MONOGYNIA. 25

CAPS. spatha involuta et tubo calycis membranaceo obvestita; oblonga, subtrigona, 3-locularis, polysperma ; angulis dehiscens; septis angustissimis, valvarum mediis.

Sem. numerosa, duplici serie axilia, ovata, longitudinaliter striata.

OBs. Genus affine Ponteder Iæ.

ovalis. L. ramulis subradicalibus, unifoliis, tab.5. unifloris : folio longe petiolato, ovali: fig. 1. flore ex imo petiolo erumpente.

$H_{A B}$. in paludosis Illinoensibus. Augusto florens.

gramineus. L. caule gracili, fluitante, dichototab.5. mo : foliis impetiolatis, angusto-lineafig. 2. ribus.

OBs. Habitus Potamogeti graminei.

$H_{A B}$. in flumine Ohio, juxta Louisville. Florens Julio.

RENIFORMIS. L. foliis orbiculato-reniformibus : staminibus duobus tertio multo minoribus.

Heteranthera. Act Philadelp. vol.4, pag. 173. $H_{A B}$, in Pensylvania et Virginia. 


\section{A Y A C A. Aubl.}

Cal.6-partitus, laciniis tribus petaloideis. Caps. 1 -lucularis, 5 -valvis, valvis 2 -spermis.

Aubletr. M. foliis confertissimis, setaceo-subulatis : pedunculis brevibus.

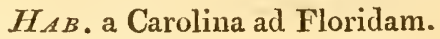

\section{S T I P U L I C I D A.}

i.e. Stipulis incisis.

Herbulæ perennes. Caulis dichotomus; ramis floriferis aphyllis. Folia opposita; stipulæ setaceo-multifidæ. Flores minuti.

CaL. profunde 5-partitus : laciniis oblongoovalibus, margine membranaceis.

Cor. petala 5, calyci subrequalia, cuneatooblonga, erecta.

Sram. petalis breviora : filamenta capillarisetacea; disco ovariffero, uti petala, adnexa : antherre subsagittato-oblonga.

Pist. ovarium subrotundum : stylus brevis, stigmata tria, approximato-erecta.

CAps. calyce vestita, ovata, I-locularis, 3-valvis.

Serr. pauca; receptaculo basilari, brevissimo, filamentoso adnexa.

$O_{B S .}$ Huc Holostevm cordatum. Linn.

SETACEA. S. glabra, erecta, setaceo-ramosissima: 
Tom.x. Pay. 26 .

Tab. 6 .

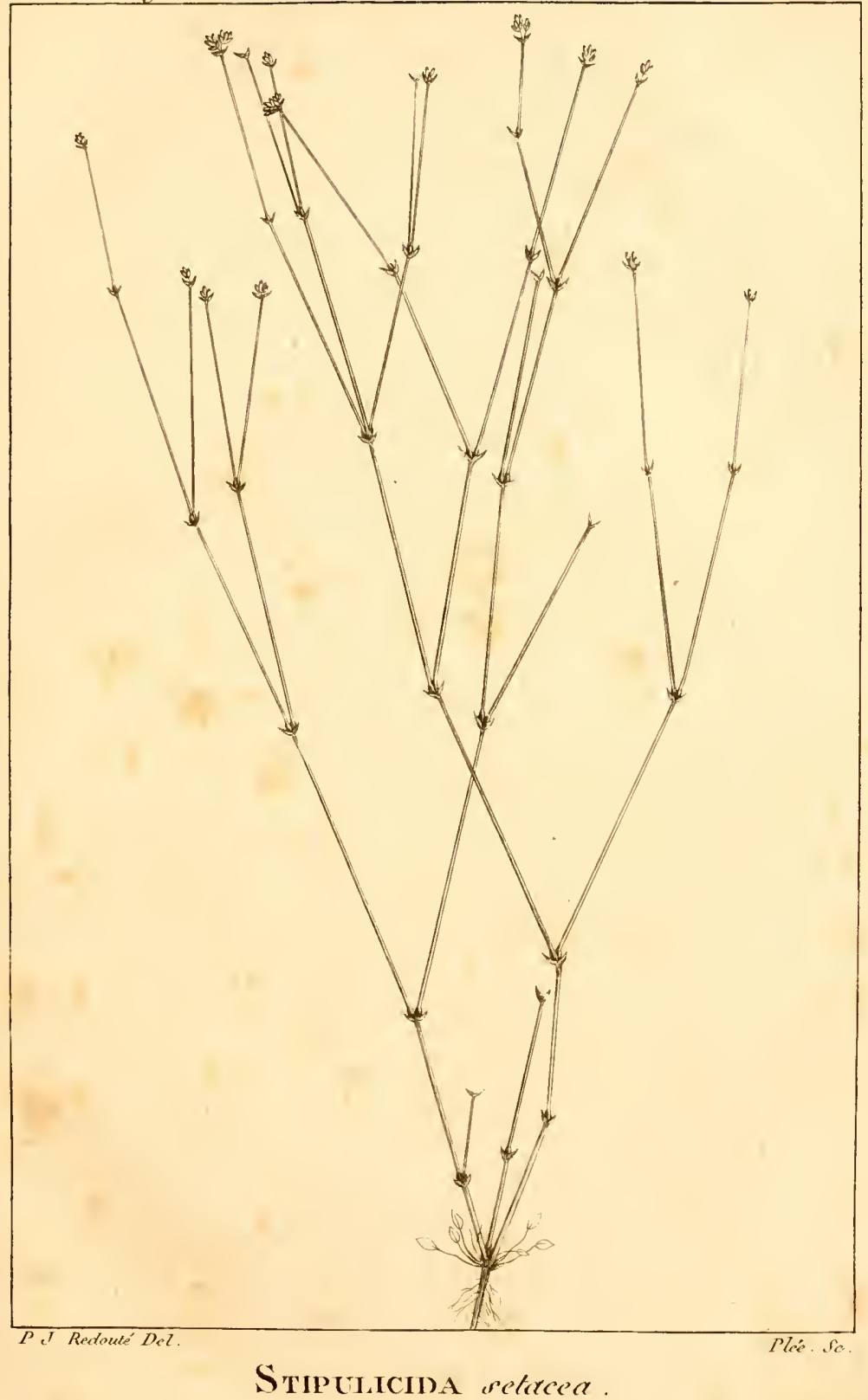



TRIA NDRIA. MONOGYNIA.

foliis juxta radicem paucissimis, spathu1ab. 6. latis: floribus terminalibus, ternatim quinatimve fasciculatis.

$H_{A B}$. in sabulosis aridis Carolinæ.

ઈ. III. C Y P E R A C E IE.

C Y P E R U S. $\boldsymbol{L}$.

Glumae paleaceæ, distiche imbricatæ. Cal. o. Stigmata 3. Sem, villis destitutum.

articulatus. C. aphyllus, elatior : culmo tereti,

x. sub prementibus digitis quasi articuloso: umbella composita; spiculis subfasciculatis, longo-linearibus, erectis.

$H_{A B}$. in Carolina.

Hydra. C. radice repente, tuberifera : foliis radicalibus, recurvatis : culmo triquetro, lavigato : umbella simplici; spiculis ad summitates proxime alternis, subfasciculatis, patentibus, lanceolatolinearibus, conspicue compressis, saturate castaneis.

$O_{B S}$. Tuberibus per agros facillime renascens, maximo colonum Indiæ occidentalis damno!

$H_{A B}$. in cultis Virginiæ, Carolinæ, Floridx.

elavicomus. C. majusculus, basi foliosus; involucro longissimo, reflexo : umbella com- 
posita ; ramulis ab ipsa basi floridis ; spicillis patentibus, flavis, oblongis, 7 -floris.

$O_{b s}$. Culmus triqueter : involucrum sub5-phyllum : umbella confertiuscula; umbellulæ secundariæ ex ramulis simplicibus, ab ipsa basi spicatim spicilliferis : spiculæ squamis obtusis, margine scariosis. $H_{A B}$, in Carolina.

virens. C. majusculus, nitidus : involucrolongissimo : umbella composita, subnuda; ramis summitate divaricato-ramulosis: spiculis fasciculatis, virentibus, ovalibus, plano-compressis.

$O_{B S}$. Glaber : culmus acutissime triqueter : involucrum polyphyllum : spiculæ copiosæ, undique versæ, breviuscule ovales.

$H_{A B}$. in Carolina.

stRigosus. C. magnus : foliis radicalibus : culmo L. 3-quetro : involucro longissimo : umbella composita ; spiculis copiosis, subteretisubulatis, spicatis, undique patentissimis. $H_{A} B$. in Carolina.

\section{K Y L L I N G I A. Rottв.}

Gluma 2-valvis, inæqualis, 1-flora. Cal. major 2-valvis, flores capitati.

гUмila. K. subtriuncialis, glabra : foliis angusto-planis : involucro triphyllo, plano, patulo : capitulo simpliciusculo, subglo- 
TRIANDRIA. MONOGYNIA.

boso: glumis minutis; valvulis exterio ribus æqualibus, interiores superantibus : staminibus 2 : stylo bifido.

$H_{A B}$, in Shavanensium regione, ad amnem Scioto.

maculata. K. involucro triphyllo, patentissimo: capitulis tribus, subglobosis, arete glomerato-sessilibus : glumis oblongis; valvulis exterioribus interiores superantibus, cuneato-lanceolatis, infra apicem macula gemina purpurea solito insigni. tis : stamine unico : stylo bifido.

$O_{B s}$. Affinis K. tricipiti; cui plures species distinctæ, etiam diversi generis, perperam referuntur.

HAB, in Carolina.

ovUlaris. K. spicis umbellatis, sessilibus pedunculatisque, globoso-ovoideis : glumis rectis, lanceolatis; valvulis exterioribus ovalibus : staminibus 3 : stylo 3-partito.

$H_{A B}$, in Georgia et Carolina. 
Glumce paleaceæ undique imbricatæ. Cal. o. Stigs mata 3. Semen. villis palea brevioribus cinctum.

S. I. M ONOSTACHYI.

Quadrangulatus. S. aphyllus; culmis stricte erectis, acute quadrangulatis : spica longocylindrica; squamis rotundato-obtusis. $O_{B S \text {. Affinis S. mutato. }}$ $H_{A B}$, in Carolina.

TUBERculosus. S. aphyllus, erectus : spica turgide ovata, subacuta; squamis subrotundis, obtusis : semine setis ipso longioribus stipato et tuberculo crassiore terminato.

$H_{A B}$. in Carolina inferiore.

capillaceus. S. perpusillus : culmis foliisque omnium tenuissime capillaceis, flaccidis: spica oblongo - ovoidea, acuta, imbricata; squamis paucis, oblongis, castaneis. $O_{B S}$. Affinis S. aciculari, sed distinctus. $H_{A B}$. in nova Anglia.

\section{\$. II. POLY T T C HYI. -A. А Р Н Y L L I.}

rRIQUETER. S. culmo aphyllo, triquetro : spicuL. lis infra mucronem his longiorem sessiliter conglomeratis, oblongo-ovatis, rufis. $H_{A B}$. in Carolina inferiore. 
TRIA NDRIA. MONOGYNI

LAcUstris. S. elatior, aphyllus : culmis tereti-

L. bus : spiculis solitarie gregatimque pedunculatis, ovatis, rufis : squamis latoovalibus, dorso prominule puncticulosis, margine suberosis.

HAB. in Canada, ad lacum Champlain.

-B. FOL I O S I.

- - ad radicem tantum.

puberulus. S. foliis radicalibus, angustissimis, longis : umbella terminali, sparsa; ramulis $\mathbf{1 - 4 - s t a c h y i s ~ : ~ s p i c u l i s ~ c r a s s i u s - ~}$ cule ovatis; squamis minutim pubentibus, lato-ovalibus : stylo fimbriato, bifido.

$\mathrm{O}_{B S}$. Affinis S. dichotomo.

$H_{A B}$. in Carolina et Georgia.

Castaneus. S. foliis radicalibus, angustissimis, longis, stricte erectis, rigidulis : culmo subtereti, striato : umbella terminali, bracteis pluribus erectis involucrata, ramulis I-4-stachyis: spiculis subrotundo-ovatis, lucide nigricanti-castaneis; squamis suborbiculatis, pauciusculis : stylo fimbriato, bifido.

$H_{A B}$. in Florida.

mucronulatus. S. foliis radicalibus, planis : culmo nudo, subancipiti : umbella composita : 
laxa : spiculis minusculis, oblongo-ovatis, glabris; squamis lanceolatis; carina prominula, discolore, in minutum mucronem desinente : setulis sub genitalibus seu semine, nullis : stylo glabro, 3-fido.

$O_{B S}$. Affinis S. dichotomo, sub quo plures adhucdum militant species in posterum sane distinguendæ! $H_{A B}$. in montibus Carolinæ.

- ${ }^{* *}$ etiam et in culmo.

Maritrmus: S. culmo acutissime triquetro, folioso: macrosta- bracteis pluribus, longissimis : spicis seschyus. silibus pedunculatisque, crassius ovatis, ferrugineiş; squamis mucrone abrupto et subulato quasi aristatis.

$O_{B S}$. Spiculæ quam in europæa multo crassiores.

$\boldsymbol{H}_{A B}$. in paludibus salsis Caroliıx.

uneatus. S. culmo latiuscule folioso : paniculis lateralibus et terminali : spiculis parvulis, oblongiuscule ovatis : squamis lanceolatis, subcarinatis, rufis; linea carinali viridula, prominula.

$O_{B S .}$ Affinis S. sylvatico.

$H_{A B}$, in Carolina.

spathaceus. S. culmo tereti, copiose folioso : foliis proxime alternis, patulis, linearibus, planis : racemis axillaribus et terminalibus, sessilibus; singulorum spiculis 
TRIANDRIA. IIONOGYNIA.

paucioribus, approximatis, alternis, subulato-linearibus, subsexfloris.

Cyperus spathaceus. Wirid. Spec., pl. $28 g$.

$O_{B S}$. Stamina 3 , rarius pauciora : stigmata 2 : setula pistillinæ 5-8, sed plerumque 6 .

HAB. in paludosis sylvaticis a sinu Hudsonis ad Floridam.

syrvaticus. S. culmo triquetro, folioso : spiculis

L. ramulos panicule laxe decomposite glomeratim terminantibus, viridulis, breviovoideis.

$O_{B S}$. Europæo solito dimidio minor.

H.AB. in Canadæ borealibus.

Errophorum. S. altissimus; culmo folioso, triquetro : panicula amplissima, deconposita; spiculis copiosissimis, rufidulis , ovatis, omnibus distincte pedicellatis, setulis pistillinis exertis.

Ertophonum cyperinum. Linn.

$O_{B S}$. A congeneribus differt sctulis genitalia stinantibus cxertis, villiformibus; sed numero definito : unde ab Erıориово discrepat.

HAB. a Virginia ad Georgiam.

I. 
Glumce paleacèx, undique imbricatæ. Cal. o. Stig. 3. Semen lana longissima cinctum.

pozxstachyum: E. culmo elatiore, tereti, folioso:

\&. L. foliis planis, patulis : spicis pluribus pedunculatis.

$H_{A B}$. in Canada.

VIRGINICUix. E. culmo tereti, folioso : foliis an-

L. gusto-planis; caulinis plerumque duobus: spicis pluribus subsessilibus, congestis : floribus diandris : lana fulvescente.

HAB. a Caniada ad Carolinam.

hudsonianum. E. culmo nudissimo, acute triquetro: foliis radicalibus paucis, subtrigone canaliculato-setaceis : spica unica: villis paucioribus.

$H_{A B}$ a a sinu Hudsonis ad lacus Mistassins.

\section{S G H OE N U S. $L$.}

Glumoe paleacer, univalves, congestæ. Cal. o. Stig. bi seu trifidum. Semen 1. subrotundum inter glumas.

albus. S. culmo subtriquetro, folioso, flori-

L. bus fasciculatis; foliis setaceis. $\mathrm{x}$. IIAB. in palndosis Carolinz. 
TRIANDRIA. TONOGYNIA. 35

sp.arsus. S. culmo triquetro, folioso: paniculis axillaribus terminalique, laxe multifloris; spiculis pusillis, ovoideis, omnibus distinctis et pedicellatis : semine, globuloso, tranverse subrugoso - striato ; tuberculo terminali brevissimo.

$O_{B S}$. Habitu proximns S. Surinamensi : stylù bifidus. $H_{A B}$. in umbrosis sylvarum Carolinæ, Georgix.

LoNGIrostris. S. latifolius : umbellis foliosis; spiculis fasciculatis : semine compresso-obovato, longissime mucronato; setulis sex, ipso multo brevioribus.

$O_{B S}$. Majusculus : culmus acute triqueter, foliosus: umbellæ axillares terminalisque : spiculæ sub anthesi subulatx : seminis rostellum subulatun, quadrupla ipsius longiturine ; setnle perispermix subulatæ, rigidulx.

$H_{A B}$. in Virginia et Carolina.

rnexpaxsus. S. anguste foliosus : paniculis remotis; ramulis approximato-erectis; spiculis fusiformibus: semine oblongiusculo, subrugoso, mucrone brevi; setulis sex, duplo longioribus.

$O_{B S}$. Culmus obsolete triangnlns : paniculx remole laterales et terminalis, debiles; ramulis subfasciculatis.

$H_{A B}$. in Carolina.

Rariflorus. S. foliis culmoque folioso setaceis : panicillis laxe rarifloris; spiculis ovatis: 
semine obovato, rugoso; tuberculo apicilari abbreviato; setulis multo brevioribus.

OBS. Folia tenuiter setacea : paniculæ parvula, laterales et terminalis; spiculæ distinctissime pedicclIata, turgide ovatæ: semen hinc planum, inde convexum.

IIAB. in Georgia.

caprtellatus. S. anguste foliosus : capitulis proxime alternis, erectis; spiculis oblongis : semine stipitato, breviuscule mucronato; setulis longioribus, obmuricatis.

OBS. Culmus acutc triqueter, levis : capitu!a breviter pedunculata, interdum geminata : semen compressoobovatum ; mucrone subulato, illo paulo breviore: setulæ retrorsum muricatulæ.

HAB. in Carolina.

crumars. S. foliis linearibus, obtusiusculis : fasciculo terminali; bracteis brevissimis bracteolisque ciliatis : spiculis ovatis : semine lenticulari, lavi; setulis brevissimis, sursum hispidulis.

$O_{B S}$. Culmus compressus, panciter dissiteque foliato: spicularum squanæ medio dorso pubentes: tuberculum epispermium brevissimum. Interdum fasciculus lateralis infra terminalem, multo minor.

$H_{A B}$. in Florida.

DISTANS. S. anguste foliosus : fasciculis subcapitatis, dissite lateralibus et terminali : spi- 
TRIANDRIA. MONOOGYN1 .

culis ovatis, glabris : semine lenticulari; mucrone brevi; setalis illius longitudine.

$H_{A B}$, in Carolina.

Easeicularis. S. angustiuscule planifolius : fasciculis lateralibus terminalique brevi-bracteatis : spiculis pauciusculis, oblongis, glabris; squanis mucronatis : setulis semine lævi duplo longioribus, sursum. hispidulis.

$H_{A B}$, in Carolina.

\section{I G H R O NI E NA.}

$\Delta s s$, bis. Xposec, color : a foliis involucri basĩ discoloribus.

Paleae undique imbricatæ in spicillas sessiliter capitatas. Stamina 3. Stylus bifidus. Semen absque setulis, sublenticulare, rugellosmm, vertice tuberculo stylino cinctum.

Ozs. Huc Scroenus stellatus et affines.

leucocephata. D. erecta, glabella : involucro inferne capituloqué candidis.

$H_{A B}$. in Carolina et Georgia.

\section{F U I R E N A. Rottв.}

Paleae mucronata, in spiculas undique imbricatæ. Stamina et stigmata tria : seminis involucellum tripaleaceum, interjectis interdum totidem setulis. squarrosa. F. foliis ciliatis : spiculis ob squama: 
rum mucrones longos horride squarrosis : paleis pistillinis petiolato-spathulatis, $\mathrm{mu}$ ticis; interjectis totidem setulis brevibus. $H_{A B}$. in paludosis Georgix et Carolinx.

SciRroInea. F. radice repente : culmis aphyllis, vaginis distincte alternis : spica terminali tal. y. subunica, ovata; squamis puberulis, mucrone brevissimo, recto : paleis pistillinis lanceolato-spathulatis; interjectis totidem setulis tenuissimis.

$O_{B S .}$. Caracter FuJIREN ; ; habitus vero diversus.

$H_{A B}$ in paludosis æstate exsiccabilibus Floridæ.

\section{$D I G Y N I A$.}

Obs. Gramina mea huc compuliomnia, juxta methodum jussicenam disposita.

\section{I N N A. $L$.}

Gluma 1-flora, 2-vaìvis. Cal. 2-valvis. Stamen 1.

OBS. Genus certo distinctum ab Agrostide!

ARUndrNacea. C. glabra : panicula magna, mul-

$\boldsymbol{L}$. tiflora, capillari, debili : valvula altera florali infra apicem subaristata.

$O_{B S .}$. Glumæ interioris valvula exterior interdum manifeste aristata; arista dimidiam fere valvulæ longitudinem assequente.

H.B. a sinu Hudsonis ad Canadam, præsertim ad ripas lacuum Mistcssins et in Nova Anglia, Vermont, Ncw-Yorck. 
Tom, 1. Pag. 38

Iab. 7

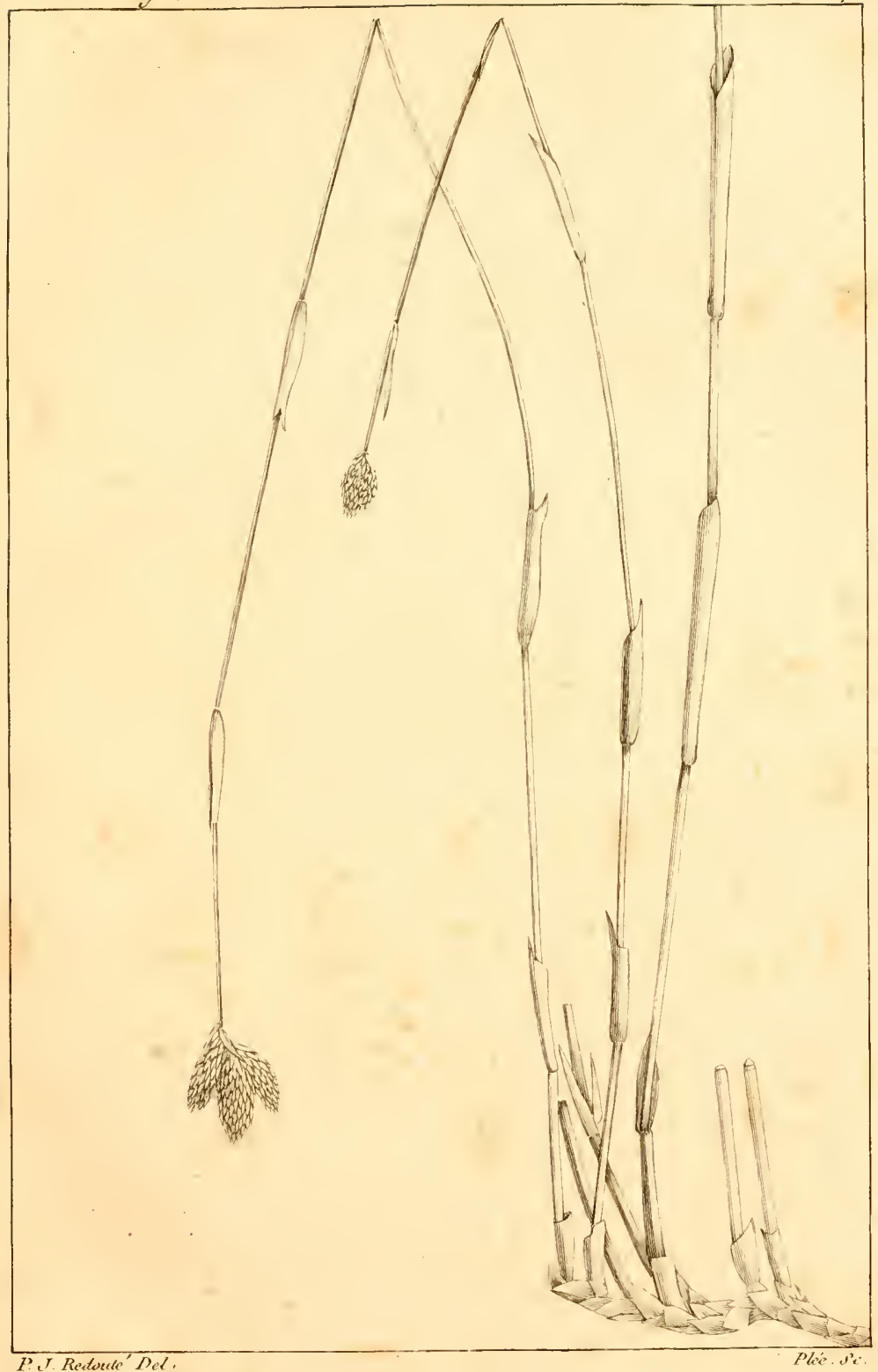

Funkesa simpoidac. 



\section{A N TH O X A N T H U. L.}

Gluma 1-flora, 2-valvis. Cal. 2-valvis Squamula 2-interiores. Stamina 2.

odoratur. A. foliis floribusque pubescentibus:

L. spica ovato-oblonga; e fasciculis sessilibus.

$H_{A B}$. in Pensylvania. Ex Eur opa advena $\mathcal{T}$.

\section{E E R S I A. Sw.}

Glum « o. Cal. 2-valvis, clusilis; valvis compresso-navicularibus, muticis.

oryzoines. L. foliis tenacibus : glumis oblongo-

sw. ovalibus, pubescentibus, carina valvarum ciliatis; triandris.

Lezrsia virginica. Willd.

$O_{B S}$. Variat magnitudine florum; paniculæ ramis paucis et multis; culmo interdum gracili et decumbente. Nullam differentiam spccificam extricare potui.

$H_{A B}$, in Kentucky, Pensylvania et Carolina.

LEATICULARIS. L. panicula ramulis subsolitariis, ramillis secundariis imbricatim spicifloris : glumis lenticulari-orbiculatis, conspicue ciliatis, majusculis.

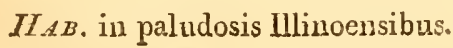




\section{I L E P Y R U M.}

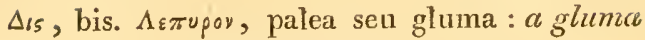
tantumınodo bivalvi.

Habitus Agrostrdis : Flores paniculati, omnes hermaphroditi. Radix perennis.

Guuma simplex, bivalvis : valvis subrqualibus, subulato-linearibus, carinatis; exteriore apice longius recteque aristata. STAM. tria : anthera furcate.

Pisc. styli duo; stigmata penicillata.

Semen arcte inclusum, oblongum.

Ozs. Genus affine Leersir.

Apistosum. D. universe pubens : foliis latis, longolanceolatis : panicula laxa, debili; floril)us majusculis : arista valvis triplo longiore.

$H_{A B}$. in umbrosis sylvis Georgia et Carolinx.

MinUtiflorum. D. culmis gracilibus : foliis planis, linearibus; vaginis collo muticis : panicula capillari, longa, angustissima : floribus minutis; arista longitudine glumx.

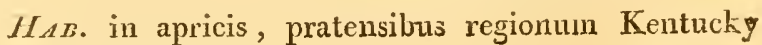
et Illinoensium. 


\section{A R I S T I D A. $L$.}

Gluma 2-valvis. Cal. 1-valvis, apice 3-aristato.

Dichотома A. stricte multicaulis, setacea; culmis dichotomis : floribus parvulis, subspicatis, subuniaristatis : arista gluma breviore et basi contorta; lateralibus brevissimis.

$H_{A B}$. in Carolina superiore, juxta Lincoln, in glareosis.

STRICTA. A. culmis foliisque stricte erectis : foliis pubescentibus : racemo in spicam longam, angustam, non ita confertam coarctato : aristis gluma longioribus.

$O_{B S}$. Variat foliis planiusculis et convoluto-filiformibus. $H_{A B}$. in Carolina inferiore.

OLIGANTHA. A. culmis stricte erectis, subramosis: foliis convoluto-filiformilus, pratongis : floribus ciistanter alternis, solitariis : aristis tribus gluma longa longioribus.

$H_{A B}$. in vastissimis pratensibus Illinoensibus.

\section{T R I C H O D I U M.}

$\Theta_{\rho} \triangleleft \xi$, capillus. E⿺辶。s, forma : Florescentia capillaris.

Flores paniculati.

GLuma exterior subrqualiter bivalvis : valvis lineari-lanceolatis, acutis, muticis. 
GL. interior I-valvis, brevior, ovali-lanceolata, mutica, glabra.

Appendix nullus.

STam. tria.

Pist. ovarium brevi-obovatum : styli duo, origine distantes vixque a stigmatibus distincti : stigmata subsessilia, laxe parceque filosa; filis longis, hispidulis.

SEM.....

LAXIflorum. T. culmis erectis : foliis angustis, breviusculis, suberectis; vagina aspetab. 8. riuscula : panicula brevi, tenuissime capillari, laxissima; summitatibus breviter pauciterque floridis : glumæ valvis lanceolatis.

Cornucory a hyemalis. WaLt.

$H_{A B}$. in humidis et pratensibus a sinu Hudsonis ad Floridam $0^{x}$.

becumbers. T. culmis decumbentibus : foliis vage patulis, longioribus latioribusque; vagina lævi : panicula oblonga, laxa : glumæ valvis lineari-lanceolatis, sensim acutissimis.

Cornucopia perennans. Walt.

$H_{A B}$. a Virginia maritima ad Floridam, præsertim ad ripas amniuu, solo limoso hieme inundato $\sigma^{x}$. 
Tom . 1. Pag, 42 ,

Tab. 8.

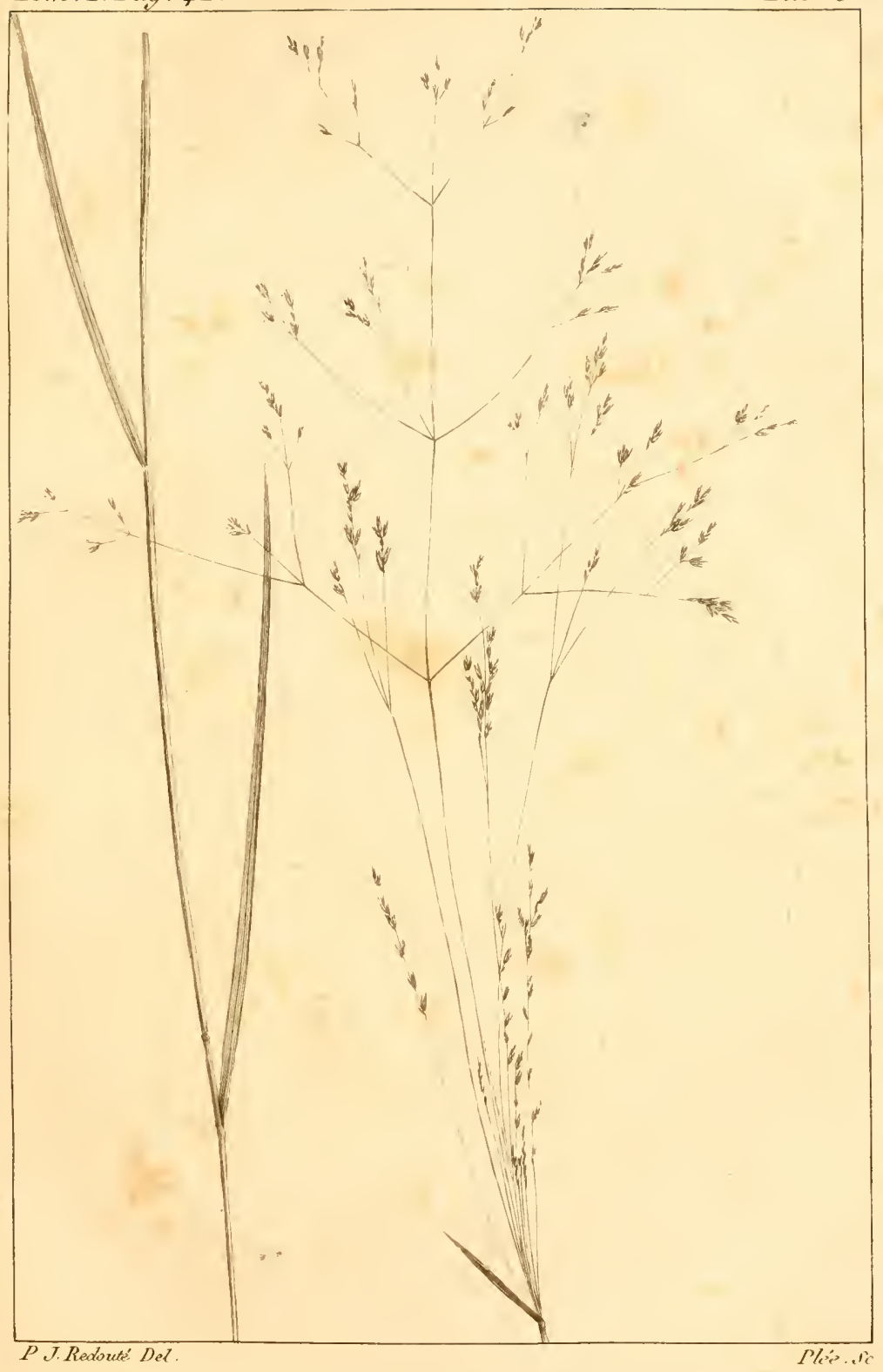

Tricnodum lexiflorem. 

TRIA NDRIA. DIGYNIA.

A L O P E C U R US. $L$.

Gluma 2-valvis. Cal. 1-valvis apice simplici.

ARISTULATUS. A: culmo erecto : glumis ovalibus, obtusis : arista vix exerta.

$H_{A B}$. in paludosis Canadæ.

\section{P H A L A R I S. $L$.}

Gluma 2-valvis, valvis æqualibus, carinatis.

Cal.2-valvis, gluma minor.

arundinacea. P. panicula racemosa : glumis acu-

L. . tissime lanceolatis.

$H_{A B}$. in Canada et Nova Anglia et ad ripas fluviorum Pensylvanix.

villosa. P? panicula stricta : gluma obovatæe valvis exterioribus dense villosis.

$H_{A B}$. in sylvis sabulosis Carolinæ.

$$
\text { P A S P A L U M. } L \text {. }
$$

Gluma 2-valvis, valvisæqualibus, subrotundis, concavis. Cal. 2-valvis, glumæ subæqualis.

SETACEUM. P. strictum, erectum : culmo setaceo: foliis villosissimis : spica unica, gracili : glumis geminis, suborbiculato-obovatis, glabris.

$O_{B S .}$ Sæpe etiam pedunculus monastachyus e suprema vagina erumpit.

$H_{A B}$. in aridis Carolin $x$ inferioris. 
DEEILE. P. culmo debili, summitate setaceo: foliis hirsutis : spica plerumque unica, tenui : glumis uniseriatis, contigue alternis, solitariis, inconspicue puberulis, brevi-obovatis.

$H_{A B}$. in maritimis Carolinæ et Georgiæ.

ciliatifolium. P. foliis latiusculis, pubescentibus, serrulato-ciliatis : culmo summitate I-2stachyo : spicis longis : glumis quasi triseriatis, geminis, suborbiculato-obovatis, obtusissimis, glabris.

H. $A$. in Carolina.

PRECOX. P. erectum, glabrum : foliis angusto$W_{A L T}$ longis : spicis remote alternis : glumis brevibus, obovatis, lavibus, glabris.

$H_{A B}$. a Carolina ad Floridam.

LAEVE.

P. erectum, glaberrimum : foliis breviusculis; vaginis compressis : spicis pluribus, alternis : glumis biseriatis, suborbiculato-ovatis, levibus, glabris.

$H_{A B}$. in Georgia.

rlonidanum. P. erectum : foliis inferioribus pilosis; superioribus glabris et longissime vaginantibus erectisque : spicis paucioribus, erectis : glumis biseriatis, suborbiculatis, glabris, lacvibus, majusculis. $O_{B S}$. Affine P. virgato. LinN. IIAB. in Florida et Georgia. 
Plicatulum. P. erectum, glaberrimum, lave: foliis angusto-longis : spicis pluribus, alternis, erectis : glumis quasi iriseriatis, brevibus, ovatis, subrufescentibus, glabris; valvula plana juxta margines transverse plicatula.

$I_{A B}$. in Georgia et Florida.

\section{I G I T A R I A. HALL.}

Gluma 2-valvis inæqualis, mucronala. Cal. I-valvis. Spicæ filiformes, unilaterifloræ.

sangunalis. D. culmis repentibus, patulis : vaginis punctato-hispidis : spicis plurimis, passim fasciculatis : floribus imbricatis, geminis; glumx valvula extima postica ovali, margine pilosa, cxeteris plusquam semi-breviore.

PanjCum sanguinale. LINN.

Synturarisua precox. Walto

$H_{A B}$. a Pensylvania ad Carolinam; in cultis $\odot:$ in Florida maritima.' 'ఛ.

PILOSA. D. culmis erectis : foliis angustioribus vaginisque pilosissimis : spicis pluribus, setaceis ; floribus minutis, remotiuscule geminis, utroque pedicellato : glume valvula extima postica fere caterarum longitudine.

Syntherisma villosa. Walt.

HAB. in sabulosis sylvarum Carolina, Georgiæ et alibi. 
PASPALODES. D. culmis repentibus, patulis : vaginis glabris, ad collum villosis; foliis directe patentibus : spicis binis, subuncialibus, basi subvillosis; rachi latiuscula, glabella; floribus solitariis, bifariam imbricatis, glabriusculis.

$O_{B S .}$ Affinis P. distachyo. LinN.

$H_{A B}$ in pascuis aridis, juxta Charslton.

sErotisa. D. decumbens : foliis vaginisque molliter villosissimis : spicis pluribus, setaceis : floribus pusillis, binis, (rarius ternis) omnibus pedicellatis : valvula extima minutissima.

Syntherisma serotinc. WaLt.

HAB. in graminosis humidis Carolinæ.

\section{P A N I C U M. $L$.}

Gluma 5-valvis, valva tertia exteriore dorsali, minore. Cal. 2-valvis, persistens.

* Spicata.

GLAUCUM. P. foliis rariter pilosis; spica oblonga,

L. confertim setosa : involucellis multisetis, bifloris : glumis seminiferis undulato-rugosis.

$H_{A B}$, in humidis Pensylvaniæ, Virginiæ, Carolinæ $\odot$.

Crus galli. P. culmo patulo : vaginis foliisque L. glabris : spicis longis, alternis, solita- 
TRIANDRIA. DIGYNIA.

riis geminisque : glumis ventricoso-ovatis, pubescentibus; passin vel rarius om nibus aristatis.

$H_{A B}$. in Carolina $\odot$.

runicatur. P. humifusum : spicis solitarie alternis, simplicibus : glumis turgide ovatis, passiun aristatis, muricato-hispidissimis.

Obs. Affine C. Galli : flores habitu Cexcurr.

H.A. in Canada ad ripas lacus Champlain et ad lacum Ontario $\odot$.

HIRTELlum. P. culmo repente : foliis ovali-lanceoL. latis : spica interrupta; spiculis brevibus, paucifloris, secundis : glumis aristatis; arista valvula extimr longissima.

$H_{A B}$. in umbrosis a Carolina ad Floridam.

MOLLE. P. rachi glumisque dense mollissimeque pubentibus : spicis solitariis, alternis, simplicissimis; glumis solitarie distincteque alternis, ovalibus, muticis, bifloris; flore altero masculo, altero hermaphrodito.

OBs. Habitus Milir punctati. LiNs.

$H_{A B}$. in cespitosis Floridæ.

$$
\text { ** Paniculata. }
$$

Capillare. P. vaginis hirsutissimis : panicula caL. pillari, ramosissima, decomposita, laxa : 
floribus minutis, omnibus pedicellatis, solitariis, oblongo-ovatis, acuminatis , muticis.

$H_{A B}$. in Pensylvania, regione Illinoensi et Virginia.

nichotomiflorum. P. erectum, glabrum : panicula ramos alternos culmumque terminante, dichotome (absque rachi com. muni) ramosissima; ramis prolixis, setaceis : floribus oblongis, acuminatis.

OBS. Habitus fere P. capillaris.

$H_{A B}$. in occidentalibus montium Alleghanis.

vingatur. P. grande, erectum, glabrum : foliis I. longissimis planis, collo subvillosis : panicula erecta ramosissima : glumis ovatis, acuminatis, muticis, bifloris ; flore masculo et hermaphrodito.

Panicun coloratum? W WLT.

$O_{B S .}$ Panicula interdum subvirgatim stricta, initerdum et præsertim cultura laxa.

$H_{A B}$. ad ripas fluviorum Mississipi, etc. a Virginia ad Florillam.

Axcers. P. erectum, longifolium, muticum : vaginis pilosis, valde compressis : paniculae ramis simplicibus, interrupte racemulosis : flore accessorio neutro ; hermaphrodito valvis primariis semibreviore, obtusissimo.

HAB. in Carolinæ herbosis humidis sylvaticis. 
TRIANDRIA. DIGINIA.

scoparium. P. majusculum, totum molliter vil-

Las. losum : foliis lanceolatis : panicula erecta, composite setaceo-ramosissima : glumis turgide obovatis, pubescentibus.

$H_{A D}$. in apricis cespitosis Carolinæ. $\odot$.

LAtrfoliun. P. foliis ovali-lanceolatis, amplexi-

L. caulibus, glabris : vaginis subpilosis; basi circa nodum colloque barbatis : panicula sessili, parce ramosa, glabella : glumis puberulis; valvula extima ovali.

$H_{A B}$. in cespitosis pratensibusque sylvaticis Virginix et Carolinæ.

pubescens. P. erectum, ramosissimum, foliosum,

Lал. molliter pubens : foliis lanceolatis, ciliatis : paniculis minimis, rarifloris, invaginatis : floribus subgloboso-obovatis, puberulis.

HAB. in herbosis sylvarum Carolinx.

NiTinum. P. glabrum, vaginarum collo barbato:

Lax. culmo gracili, simplici, erecto ; foliis paucissimis, remotis, lanceolato-linearibus : panicula capillari, confertiuscula, composite ramosa, glabra : floribus pusillis, obtuse ovatis, minutissime puberulis; valvula extima vix perceptibili.

HAB. in Pensylvania et Carolina.

earbuzatum. P. parvulum : culmo gracili, subI. 
ramoso; nodis annullatim barbulatis : foliis lanceolato-linearibus, nitidule glabris, arl collum sparsim pilosis : panicula parvula, capillari, composite ramosa; floribus brevi-ovatis.

$H_{A B}$. in Carolina.

Ramulosum. P. gracile, debile, rámulosum : cúlmo vaginisque glabris; geniculis nudis, crassiusculis : foliis lanceolato-linearibus, patulis, glabris, inferne pilis longis rarioribus, subciliatis : panicula pusilla, capillari, laxa: floribús minutis, breviter obtuseque ovatis; omnibus longiuscule pedicellatis.

$H_{A B}$. in sylvis Carolinæ.

melicarium. P. debile, glaberrimum : foliis angusto - longis : panicula gracili, longa ; ramulis raris, subappressis : gluma membranaceæ valvis subæqualibus,' lanceolatis : minuto flosculi rudimento inani et stipitato de basi floris hermaphroditi.

HAB. in Carolina, Georgia.

Divaricatum. P? glabrum, erectum : foliis angusto-longis : panicula erecta, pyramidata; ramis paucis, dissitis, plerisque geminis, simpliciusculis, divaricato-patulis etiamque reflexis : floribus muticis, binis; altero pedicellato neutro.

HAB. in excelsis montibus umbrosis Carolinze. 



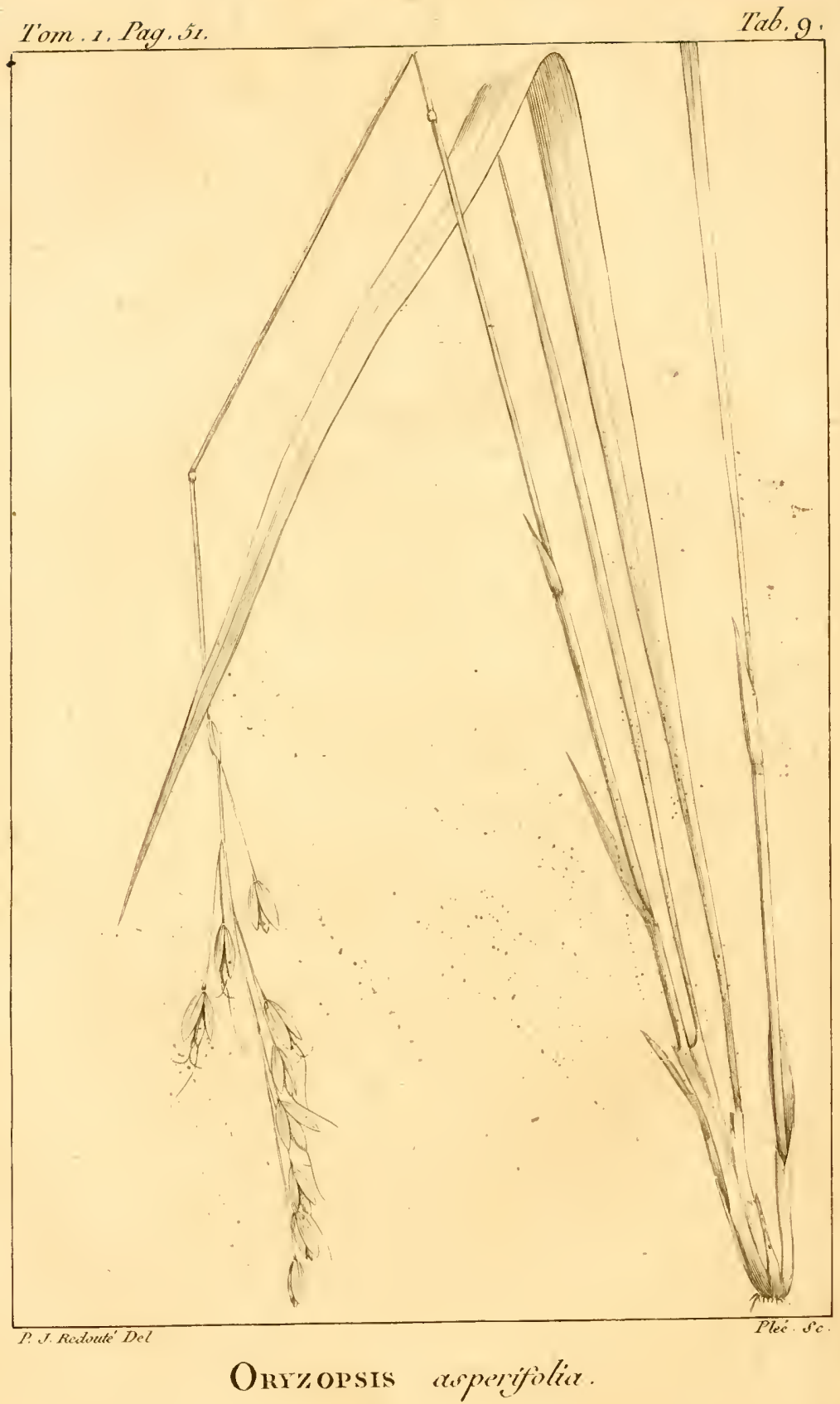


O R Y Z O P S I S.

Oఓ's, facies. OpuZa : Genus Oryzae facie.

Flores majnsculi, paniculati, omnes hermaphroditi. Habitus Oryzae.

Guvma exterior I-flora, interiore latior et tantisper brevior, subxcualiter bivalvis; valvis lato - obovalibus, subcarinato-concavis, nervoso-striatis.

GL. - interior annulo confertim barbulato basi cincta, pubescens : valva exteriore arcte clausa, coriacea, teretiuscule ovoidea, lavi, apice setaceo-aristata : valva interiore prorsus inclusa, multoties an.* gustiore, sublineari, mutica.

Appennices 2, lineares, longitudine ovarii. STAM. tria : anthere per hiantem gluma apicem exertic, longo-lineares, apice barbulatæ, basi leviter bifida.

Pist. ovarium oblongum : stylus partim exertus, compresso-setaceus, marginibus puberulus : stigmata duo, capillaria, minutim glanduloso-puberula.

asperifolia. O. culmo subnudo : foliis rigidule erectis, subpungentibus, asperis.

tab. g. HAB. a sinu Hudsonis ad Quebec, per tractus montium. 


\section{A G R O S T I S. L,}

Clume 2-valvis, valvis acutis. Cal. 2-valvis, gluma major.

1vntca. A. erecta, elatior, glaberrima : foliis Sw.obs. longissimis, sensim setaceo-convolutis; racemo virgatim longissimo : gluma muticæ valvis exterioribus longissimis.

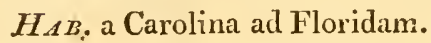

JUNCEA.

A. foliis stricte erectis, convoluto-setaceis, rigidulis; panicula oblongo-pyramidata : floribus muticis; valvula extima duplo minore.

$H_{A B}$. in sabulosis aridis Carolinæ.

DISPAR. A. erecta, majuscula : panicula laxa, subverticillatim pyramidata, multiflora: gluma mutica valvis exterioribus multo majoribus; interiorum altera minima.

$H_{A B}$. in Carolina inferiore. 24.

ASPERA.

A. culmis stricte erectis, ab imo ramosis : vaginis collo villoso-barbatis; foliis longissimis, recurvo-pendulis, asperrimis : racemis lateralibus terminalique coarctatis ; floribus muticis, majusculis : gluma valvis interioribus subtriplo majoribus.

$I_{A B}$. in collibus rupibusque regionis Illinoensis. 
rateriflora. A. culmis erectis, nodosis : foliis linearibus, planis : paniculis lateralibus et terminalibus, pusillis, carctatis, densifloris : gluma muticx et scaberulx valvis acutissimis; interioribus majoribus, basi barbulatis.

$H_{A B}$. præsertim in præcipitibus saxosis fluminis Mis. sissipi et ripariis Illinoensibus.

RACEMOSA. A. culmis erectis : foliis angustelongeque linearibus, erectis : racemo oblongo, e spicis densifloris subinterrupto : gluma exterioris valvis in mucronem aristiformem desinentibus, gluma interiore mutica longioribus.

$U_{B S}$. Affinis A. lateriflorce.

$H_{A B}$. in ripis sabulosis inumdatis fluminis $M$ ississipi.

$$
\text { S T I P A. } L \text {. }
$$

Gluma 1-valvis. Cal. 2-valvis, valva exteriore in aristam longissiman basi articulatam desinente.

BARBATA. S. panicula rariflora; ramulis simplicibus, I-floris, geminis : glume valvis exterioribus majusculis, acuminatis, valvula seminifera stipite densa rufaque barba obsito suffulta; arista longissima, crassa, nuda.

STIPA avenacea. W: $\mathrm{WTT}$.

$O_{B S}$. Interdum infimi paniculæ ramuli biflori. $H_{A B}$. in sylvis Virginiæ et Carolinæ superioris;

Winter green, parcius in maritimis. 
SERICEA. S. glabra : foliis tereti-filiformibus, longissimis; summo paniculam stipante et longitudine subxquante, pungente: panicula longa, debili, tenuissime capillacea sive sericea; floribus exiguis.

$O_{R S .}$ Habitus Aristid.

$H_{A B}$. in sabulosis Carolinæ inferioris. $2 f$.

JuACEA. S. culmis simplicibus setaceisque foliis quasi juncea : panicula parva : gluma glabra; valvis obtuse ovalibus, florem pubentem crassius breviusculeque aristatum requantibus.

$O_{B S}$. Affinis A ven e sibiricae. Linn.

$H_{A B}$. in montibus saxosis, a sinu Hudsonis ad Canadam.

\section{E R I A N T II US.}

Eprov, lana seu villus. Aveos, flos ; flores densissimis villis involucrati.

Panicula composite ramosa : floribus juxta ramulos articulatim solubiles geminatim ordinatis; altero sessili, altero brevi-pedicellato; utroque conformi et hermaphrodito.

GLUma exterior subxqualiter bivalvis, mutica; basi villis densis.involucrata : valvis lineari-oblongis, canaliculatis.

GL. - interior paulo minor, glabra, bi= valvis : valvis linearibus, canaliculatis, tenuius inembranaceis; altera exteriore 
mutica; altera interiore in aristam lon. gam desinente.

STam. duo : anthera oblonga.

Pistovarium obovato-oblongüm styliduo, basibüs contigui, illius circiter longitudine : stigmata oblongo-aspergilliformia. appendices duo, ovario subtriplo-breviores, cuneiformes, truncati.

$O_{B S .}$ Genus $\mathrm{S}_{\text {Accuano }}$ valde affine; numero staminum. et intima valva ariștata præesertim discrepans. Hac antem ultima nota et nommillis aliig forsan ad ANDRopogos, reformato caractere, referéndum!

SACCIAROIDES. E. culmo altissimo : vaginis foliorum ad collum confertissima lạna barbatis : panicula stricta : gluma villis involucrantibus multo breviore; valvis exterioribus juxta margines longe vil. losis.

AXTroxANTU giganteum. WAIT.

$O_{B S}$. Grameil altissimum, 6-9-pedale. Panicula fere Saccilan I officinalis, sed confertiór.

$H_{A B}$, a Carolina ad Floridam, in humidis.

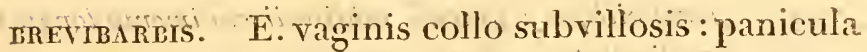
stricta: glumà villis involucrantibusmulto. longiore; valvis acutissimis, nudis. HAB. in collibus. Temussée et Carolino. 


\section{H O L C U S. L.}

Gluma 2-valvis. (interdum 2-flora) Cal. 2-valvis, valvæ exterioris apice aristato. Flores masculi hermaphroditis mixti.

oooratus. H. glaber : panicula parva, ramulis

L. subnutantibus : glumis turgidis, trifloris; masculis valva exteriore ciliata; hermaphrodito diandro; omnibus muticis.

$C_{B S}$. Arista in descriptione et icone Scueuczen tradita, nostro gramini omnino deest.

$H A B$, in pratis humidis, a sinu Hudsonis ad Canadam.

\section{A N D R O P O G O N. L.}

Gluma 2-valvis. Cal. 2-valvis, valvæ exterioris basi aristata in hermaphroditis floribus sessilibus, nuda iil masculis pedunculatis.

* Spiculis ob pennationem rachis et involucella longissime villosis : flosculli additorii rudimento longius pedicellato, minuto, neutro.

MACROURUM. A. vaginis foliorum ad margines manifeste villosis : paniculis lateralibus fasciculato-polystachyis in longam confertamque paniculam constrictis : floribus 
T. RIANDRIA. DIGYNIA.

monandris; arista 4-5-tupla gluma longitudine; valvis interioribus glabris.

Cinna glomerata. Walt.

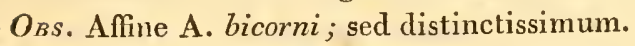

$H_{A B}$. a Carolina ad Floridam, in humidis.

missitiflor Ur. A. vaginis foliorum glabellis : culmis stricte erectis, fere ab imo floridis; spicis dissite lateralibus, rarioribus, erectis : floribus monandris; arista longa , recta; valvis interioribus glabris.

CinNa lateralis. Watt.

HAB. a Carolina ad Floridam, in sylvis.

TERNARIUM. A. ramis remote alternis, solitariis, simplicibus, plerisque tristachyis; spicis distanter alternis, bifidis : villis involucri gluma brevioribus : floribus triandris; valvis interioribus subvillosis, intima ex incisura aristam longam, contortam emittente.

Oss. Habitu accedit A. hirto! rami infmi, interdum tetrastachyi.

HAB. in montosis Carolinx.

** Spiculis non ita villosis.

Scorafium. A. vaginis villosis : ramis ramosis, elongatis, purpurascentibus, in longam paniculam strictis : spicis simplicibus; floribus distincte alternis, triandris; involucellis brevissimis : flosculi additorii rudimento neutró, aristato.

FIA . in aridis sylyarum Carolinæ. 
AVeraceum. A. foliis asperis vaginisque glabris: panicula nuda; sublpyramidatim oblonga, multiflora; floribus 'rufescentibus, triandris ; gluma valva altera villosa ; arista valde contorta.

$\ddot{H} A B$, in vastissimis pratis Illinoensibus.

AmbiguUm: A. foliis amplexicaulibus, subcordatolanceolatis : panicula ramis promisse setaceis, simplicibus, erectis : glumis solitarie alternis, unifloris; flore imberbi, longissime aristato; triandro; floseuli accessorii incremento aristiformi.

HaB. in sabulosis Carolinx,

\section{II I O R,I S. Sw.}

Spicoe unilaterifloré, sjjiculis subsessiliter biseriatis: quarum glumá communis 2-ralris , 2-6-flora : floribus dissimilibus; valva altera (saltem nommulJorum) aristata : uno hermaphrodito, fertili ; cæteris imperfectis, masculis neutrisve; tultimo pedicellato.

perraza. C. glaberrima : culmo compresso : vasw. ginis ancipitibus : foliis obtusis : gluma valvula majore bifida, breviter aristata: flore hermaphrodito submutico, glabello: flosculó accéssorio neutro, obovato, ratundato-obtuso, mutico, univalvi.

$H_{A B}$. in sabulosis maritimis Georgiæ et Floridæ. 
Monostachya. C. spica unica : spiculis sub6-floris; floribus aristatis, ad margines barbatis : singulorum gluma communivalva exteriore juxta nervos scrobiculato-glandulosa et e medio dorso patule aristata.

$O_{B S}$. Sapor recentis plantæ piperitus.

$H_{A B}$ in sylvis Carolinæe inferioris.

mucronata. C. culmis procumbentibus, radicantibus : spicis plerunque 4 , radiátim patentibus; rachi triangulata, in mucronem nudum desinente : spiculis subquadrifloris; glumarum valva extima aristata; -.floribus acuminatis' muticis.

Plucke. tab. 36o. fig. 8. qiiam Linn. ad Cynosurum aegyptium perperam retulil; ad hanc pertinet speciem.

$I_{A B}$, in cultis Carolinx. $\odot$.

cuntupendula. C. racemö-erecto longo; e spicis plurimis, distiche alternis, pendulis, 6-glumibus : glumis singulis 4-floris.

$O_{B S}$. Culmi decumbenti-assurgentes : singularum glumaruni flos hermaphroảitus c basi emittenš rndi'mentum secundi floris inane, promisse aristatum; intra quod bina alia rudimenta quasi in sola arista corrsistentia.

Plantxecultre statnra major; spicx 6-12-glumes.

$\Pi_{A B}$. in aridis regionis Illinocusis ad Wabast et in rupibus ad prairie du rocher. 'T/s. 


\section{T R I P S A U M. L.}

Monoicum. Masculị gluma 2-valvis, 4-flora. Fomineis gluma 2-4-partita, 1-flora, sinibus basi perforatis. Omnibus Cal. 2-valvis, membranaceus.

DaCtYloines. T. maximum : spicis $\mathbf{I}-3$; inferne

I. foemineis, superne masculis.

$H_{A B}$. in regione Illinoensi et Carolina.

CYLINDRICUM. T. foliis angusto-longis : spica cylindrica, hermaphrodita ; in articulos cylindricos, conformes solubili.

HAB. in sabulosis Floride.

R. O T T B OE L L A. $L$.

Gluma, 1-valvis, 1-flora, flosculo hermaphrodito; aut 2-partita, 2-flora, flosculo altero masculo. Utrique Cal. 2-valvis, inæqualis, gluma brevior.

Dimidita. R. radice repente : culmis decumben-

L. tibus : vaginis compressis : foliis obtusis : spicis solitariis; rachi lineari, flexuosa, hinc tantum foveato-florida.

$H_{A B}$. in maritimis, a Carolina ad Floridam. 
Gluma 2-valvis, 2-flora, flosculo, altero hermaphrodito, altero masculo. Utrique Cal. 2-valvis. Involucrum includens tres glumas.

tribulomes. C. vaginis ad margines pubentibus:

L. glumis villosis et spinis longis rigidisque horridis.

$H_{A B}$ a Virginia maritima ad Floridam.

\section{A I R A. L.}

Gluma 2-valvis, 2-flura. Cal. 2-valvis.

Flexuosa. A. foliis setaceis : culmis subnudis :

L. panicula divaricato-laxissima, capillari; ramulis plerumque flexuosis : floribus basi aristatis et brevissime barbulatis; arista recta, exerta.

OBS. Nostrate dimidio humilior, paniculaque vix flexuosa.

$I_{A B}$ in Connecticut, Nova Anglia.

AMeigua. A foliis subsetaceis : panicula ampla, pyramidata : glumis flavescentibus : floribus basi brevissime aristatis barbatisque.

OBs. Ab Arra cespitosa foliis tantum differt etiamque dimidio minor est.

IIAB. circa lacus Mistassins et juxta amnes in lacun S. Joannis delluentes. 
Melicordes. A. erecta, glabra, planifolia : panicula parvula, subracematim coarctata : gluma communi partialibusque majusculis, lineari-lanceolatis, muticis; his basi villis cinctis : minutissimo tertii flosculi rudimento pedicellato.

$O_{B S .}$ Ex secundi flosculi basi nascitur pedicellus longiusculus, villosis, vix perceptibili floris rudimento terminatus.

$H_{A B}$. in Canada.

obrusata. A.gracilis, angustifolia: panicula in racemum oblongum confertiflorum coarctata; glums valva altera angusto-lineari, acuta ; altera lato-obovali, rotundatoobtusissima : floribus muticis, apice compressis.

$H_{A B}$. in aridis, a Carolina ad Floridam.

\section{E L I C A. $L$.}

Gluma 2-valvis, 2-flora. Cal. 2-valvis. Inter flosculos rudimentum tertiifloris pedunculati.

GLABRA. M. glabra, erecta, panicula erecta, laxa; ramulis simplicibus, paucifloris: floribus nudis, majusculis.

Mor1s., hist. 3. S. 8. t. 7. f. 5 1.

$O_{B S}$. Forsan huc referendá sunt $\mathbf{M}$. altissima et mutica. WaLt.

$H_{A B}$, a Virginia ad Floridam. 


\section{T R A G Y N O I A.}

Tpaxus, asper. Nwros, dorsum : a valvis glumae dorso scabris sive asperis.

Habitus arundinaceus : Folia dura.

FLORESCENTIA : spicie plures, alternæ sparsave, lateribus subcompressa; floribus numerosis, hinc juxta rachin setaceam duplici contiguaque serie imbricatim incumbentibus, sessilibus.

Singulorum florum.

Guuma exterior 2-valvis, valva introrsa multo minore; extrorsa omnibus longiore, in acumen setaceum sensim desinente; utraque compressissime carinata, angustolineari, tenui-membranacea, enervi, carina aculeolata.

GL. - interior 2-valvis, valva introrsa gluma exteriori consimili; extrorsa submajore, inermi; utraque etiam lineari.

Appendrx nullus.

Sтам. tria : antheræ longæ, basi levissine bifida, apice indivisæ.

Pist. ovarium sublineari-oblongum, compressum : stylus unicus, ovario multo longior : stigmata 2 , oblonga, glandulis brevibus confertisque quasi spicillata, inferne concrescentia.

SEuEr oblongum, compresso-teres. 
cynosunoidrs. T. foliis longissimis; canaliculatoconvolutis : spicis plurimis, distincte alternis sparsisve.

Dactylis cynosuroides. Linn.

$H_{A B}$. in rupibus juxta sinum Hudsonis.

polystachya. T. altissima : foliis lato-planis, longissimis spicis numerosis, inordinatis, passim subaggregatis.

$O_{B S}$. Forsan varietas prioris, omnibus partibus multo major.

HAB. in inundatis maritimis, a Nova Anglia ad Floridam.

sUnCEA. T. humilis, juncoidea : foliis brevioribus, subdistiche alternis, setaceo-convolutis : spicis paucis, I-3.

$H_{A B}$. in siccis maritimis Carolinæ, Georgix. $\eta_{\kappa}$.

E L E U S I N E. G

Gluma 2-valvis, pluriflora. Cal. 2-valvis, inæqualis. Semen subglobosum.

INDICA. E. glabra : vaginis compressis, collo pilosis : spicis digitatis, strictis, longolinearibus, rectis : spiculis subsexfloris; floribus lanceolatis.

Cynosurus indicus. Linn.

HAB. in cultis, a Carolina ad Floridam. 
TRIANDRIA. DIGYNIA.

JUcronata. E? vaginis pilosis: spicis numerosis, filiformibus, in longam paniculam digestis : spiculis minutissimis; gluma mucronata, quadriflora, flores aquante aut superante; floribus muticis.

$O_{B}$. Species altera Antillana valde affinis; qux tamen differt gluma mutica, breviore et subbiflora. Forsan genus !

$H_{A B}$. in cultis Illinoensibus.

\section{E L Y M U S. $L$.}

Glumae 2-3 in singulo axis dente, 2-valves, 1-2floræ, aut sæpius multifloræ, calycibus 2-valvibus.

virginicus. E. spica crecta; spiculis trifloris; inL. volucro striato.

$H_{A B}$, in maritimis Carolinæ.

\section{B R O M U S. L.}

Gluma 2-valvis. Cal. oblongus, 2-valvis, valvis sub apice aristatis.

canadersis. B. nodis minute barbatis : foliis rariter pilosis : panicula laxa, capillari, pendula : spiculis subsexfloris, cumpressis : florum valva exteriore breviter aristata, versus margines villosa.

H.AB. in Canada.

I. 
Gluma 2-valvis. Cal. 2-valvis, oblongus, valvis mucrouatis.

myuros? F. gracilis : panicula longa, coarctata:

L. $\quad$ spiculis 4-6-floris; floribus subulatis, in aristam longissimam desinentibus.

Frstuca quadriflora? Walt.

$H_{A B}$. in aridis Carolinæ.

BRomornes? F. erectiuscula, gracilis, glabra : foliis L. subcapillaceis : panicula subsecunda, inferne patentiuscula : spiculis subro-floris; floribus lineari-subulatis; arista dimidio breviore.

Festuca octoflora? Walt.

H.AB. in pascuis, circa Chalston.

rluitans. F. glaberrima, decumbens, planifolia:

L. panicula longa, laxa; ramulis simplicibus : spiculis appressis, linearibus, sub12-floris : glumis omnibus muticis, striatis.

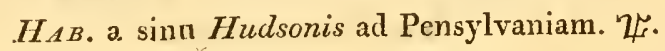

polystacuya. F. erecta, glaberrima : foliis longissimis : panicula erecta, oblonga; ramis numerosis, recte setaceis, plerisque simplicibus, spicifloris : spiculis appressis, oblongis, 8-10-floris : florum valva exteriore brevissime aristata.

$I I_{d B}$, in arvis Illinoensibus. 

Tom.1. Pag. b7 ,

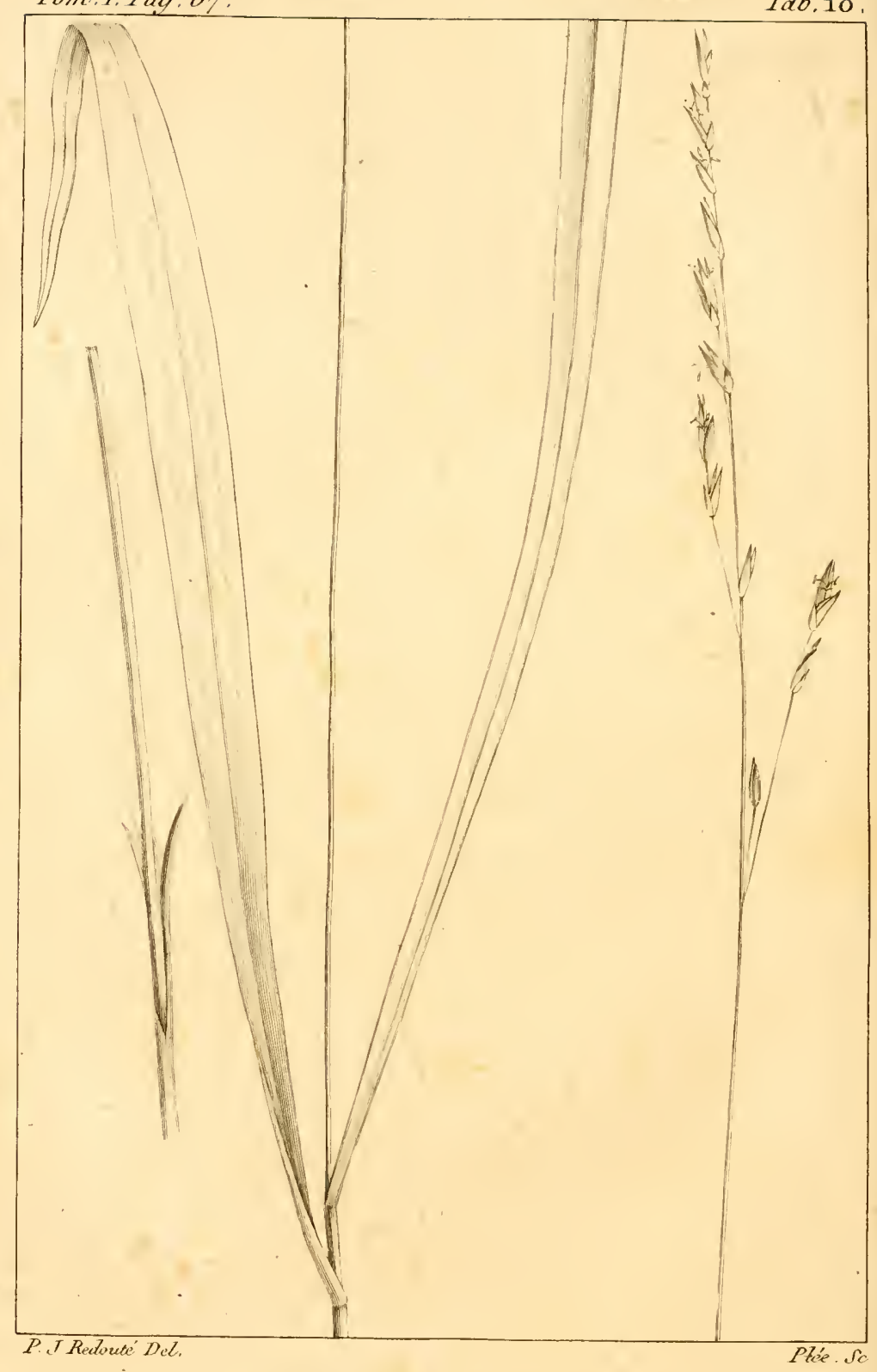

Festuca diendra. 
'T RIA NDRIA. DIGYNIA.

distichiphylla. F. parvula, erecta, glabra : foliis convoluto-subulatis, rigidulis, alternis, distiche erecto-patentiusculis : racemo parvo; vix composito; spiculis approximatis, appressis, sub7-floris, majusculis, muticis.

$H_{A B}$. in maritimis Carolinx.

Pocordes. F. glaberrima, planifolia : culmo sub. binodi, geniculato : panicula confertius cula, ramis inferioribus simplicibus : spiculis proxime alternis, subsessilibus, oblongis , 9-Io-floris ; glumis omnibus muticis.

$H_{A B}$. ad ripas maritimas fluminis S. Laurentii.

DIANDRA. F? culmo erecto, superne asperrimo: foliis latis, planis : panicula racemiformi; tab. 10. ramis simplicibus, sparsis, appressoerectis : spiculis subteretibus, sub5-floris: floribus acuminatis, diandris.

$O_{B S}$. Habitus uniola : sed gl uma spiculæque diversæ. $H_{A B}$. in sylvis antiquissimis regionum Kentucky, Tennassée, \&c. 话.

$$
\text { P O A. L. }
$$

Gluma 2-valris. Cal. 2-valviș, ovatus, valviṣ acutiusculis.

Capillaris. P. culmo ab imo ramoso, erecto: L. foliis angusto-longis : vaginis glabris, 
collo rariter pilosis : panicula ampla, capillari-ramosissima, laxissima ; spiculis 3-5-floris; floribus ovatis, acutis;.valva exteriore glumaque minutim puberulis.

$O_{B S}$. Interdum in eadem panicula spiculæ nonnullæ monstrosæ, oblongæ, multifloræ, steriles.

$H_{A B}$. in Carolina inferiore.

crocata. P. erecta, glabra : collo vaginarun nudo : panicula laxa, patula; spiculis omnibus distincte pedicellatis, ovoideis, 4-5-floris : floribus oblongis, viridibus, apice insigniter croceis, inferne minuta pube marginatis.

HAB. juxta ammes ad lacus Mistassinos aflluentes indeque ad sinum Hudsonis defluentes.

hirsuta. P. culino simplici, crasso, erecto: foliis longissimis, culmo longioribus; vaginis hirsutissimis : panicula amplissima, capillari-ramosissima; spiculis sparsis, omnibus longe pedicellatis, sub5-floris.

$O_{B s .}$ Affinis 1 . capillari : habitus fere Panicr capillaris.

$H_{A B}$. in Carolina inferiore.

SESLEROIDES. P. culmo firmo, erecto : panicula majuscula, erecta; ramis inferne promisse nudis : spiculis in ramulis alternis, subsessilibus, subappressis, sub-6-floris: 

Tom 1. Pag. 69.

Tab.n.

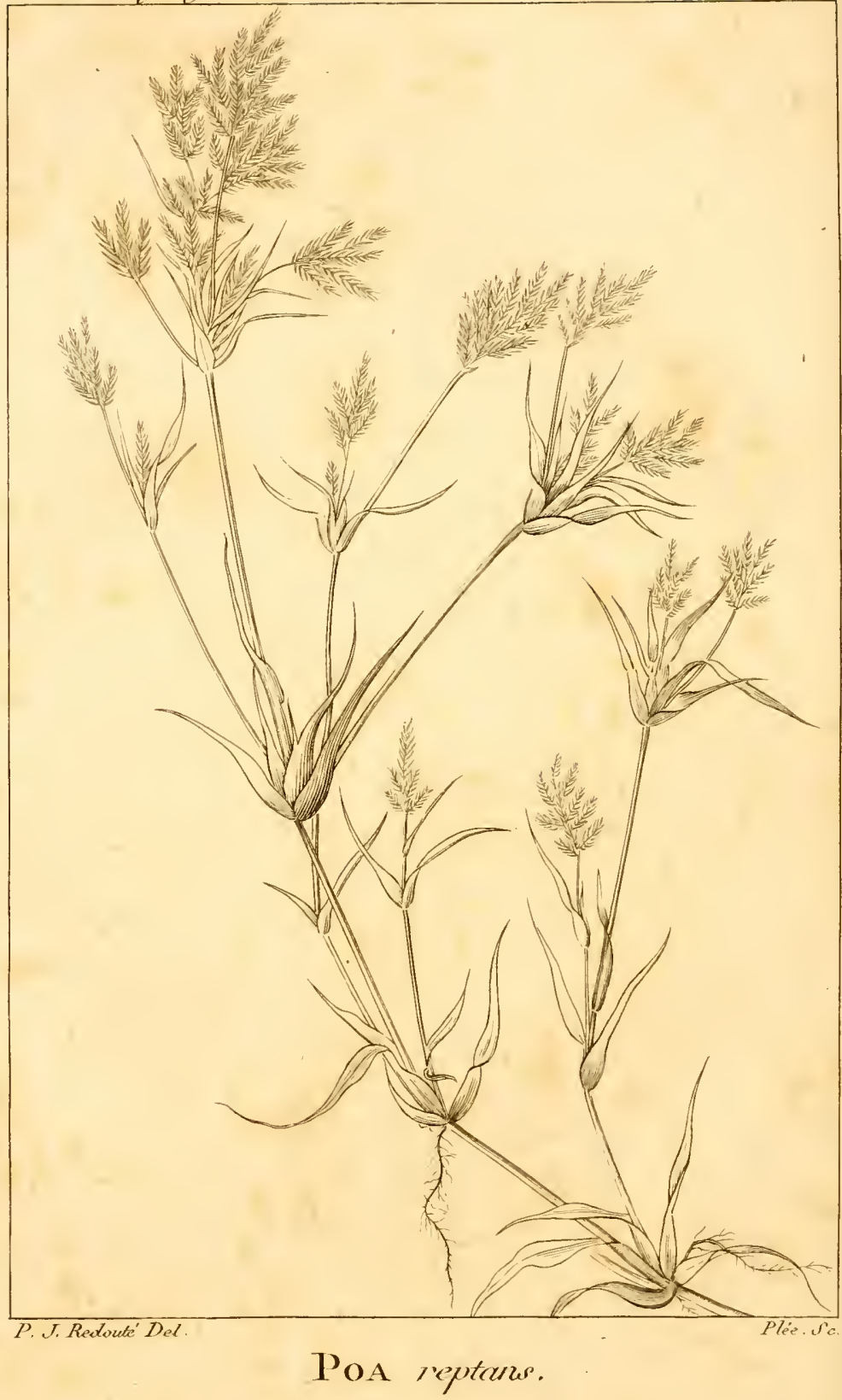


TRIA NDRIA. DIGYNIA.

flosculorum valva exteriore dorso inferne marginibusque villosa, apice quinquefida.

$H_{A B}$. in regione Illinoensi et in montosis Carolinx.

Compress.A. P. glaberrima : culmis geniculatis,

Ł. compressis, panicula parva, racemiformi; spiculis subfasciculato-approximatis, sub5-floris.

$H_{A B}$. in Canada et Pensylvania.

strinta. P. glaberrima, erecta : panicula ramis prolixis, debilibus, pendulis : spiculis subquadrifloris : floribus ovatis, basi nudis, conspicue striatis.

$H_{A D}$. in Pensylvania et Virginia.

Pectinacea. P. erecta, ramosa : vaginarum collo axillisque panicula pilosis : panicula laxa, pyramidatim patula, erecta : spiculis linearibus, subdecemfloris : rachi deflorata valvulis flosculorum interiori! sistentibus pectinata.

OBS. Spiculæ 7-13-flore. GIuma coinmanis brevis. sima, minuta. Flosculorum valvula exterior trinervis, sola decidua.

$H_{A B}$. in arvis lllinoensibus. $\odot$.

REPTANS. P. minutissime pubens : culmo ramoso, reptante : paniculis parvulis, subcapitatab. 1. tim fasciculatis : spiculis longo-linea- 
ribus; floribus subaristato-acuminatis, dioicis.

H.AB. in limosis ripariis amnium regionis Illinoensis. $\odot$.

\section{U N I O L A. L.}

Spiculæ multiflorx, planx, ancipites, subovales : floribus incumbentibus.

Gruma communis tri aut pluri-valvis.

\section{Singulorum florum}

GLuma bivalvis, mutica : valva exteriore lanceolata, acuta, compresse acuteque carinata, subtiliter striata; interiore multo minore, intra priorem recumbente.

Appendices duo, vix dimidia ovarii longitu. dine, cuneiformes, quasi lunulatim emarginati et inde subbicornes.

STAm. I-3; gluma brevius : anthera oblonga, apice integro obtusa.

Pist. ovarium obovatum, compressiuscule teres : styli duo, basi subconnati ; stigmata longa, laxe aspergilliformia, glandulis filisve (sub microscopio) manifeste muricatis.

SeMen....

ratifolia. U. foliis lato-planis; panicula laxa; spiculis omnibus longe pedicellatis : gluma communi trivalvi : floribus sursum sub- 
TRIANDRYA. DIGYNTA.

falcato-angustatis, carina pilosis, monandris.

$H_{. A B}$ in occidentalibus montium Alleghanis.

gracilis. U. vaginis culmoque compressis : foliis planiusculis : panicula longissime graciliterque subspicata, ramis brevibus adpressis : spiculis parvis, subsessilibus : gluma trivalvi : floribus monandris.

U. spicata? LINN.

$O_{B S}$. Folia demum et ariditate convoluta.

$H_{A B}$, in unbrosis sylvarum, a Carolina ad Georgiam. 此

maritrma. U. altissima : foliis convolutis : panicula longa ; spiculis subsessilibus : gluma multivalvi : floribus carina glabris, triandris.

U. paniculata. LiNn.

HAB. in littoribus arenosis, a Virginia ad Ludovisianam.

B R I Z A. I.

Gluma 2-valvis. Cal. 2-valvis, cordatus, valvis ventricasis.

canadensis. B. erecta, longifolia : panicula laxa : spiculis erectis, 4-10-floris : gluma communi parvula : florum valva exteriore ovali, acuta.

$H_{A B}$. in Canada. 
ERAgrostis. B. culmo geniculato, decumbente:

L. collo vaginarum piloso: spiculis erectis, compressis, ovali-lanceolatis, sub2ofloris; floribus subacutis.

$H_{A B}$, in cultis Carolinæ, et Virginiæ.

\section{A V E N A. L.}

Gluma 2-ralvis. Cal. 2-valvis, oblongus, valvis acutis, exteriore dorso aristata.

MOLLIs. A. universe, minutim molliterque puberula : racemo confertiuscule appressospicato : clumis bifloris : floribus imberbibus, aristatis; arista horum longitudine, non contorta.

$H_{A B}$. in Canada.

GLumosa. A. foliis subsetaceis; collo vaginarum villoso: panicula parva, subspicata, pauciflora : gluma communi spiculam sexfloram pubescentem superante; valva florum exteriore ex apice bicorni aristata.

A. spicata. Lrnn.

$H_{A B}$, in Pensylvania, Carolina.

paltstris. A. foliis planis, linearibus : panicula confertiuscula : glumis 2 -floris; floribus glabris, altero mutico, altero ad apicem tenuissime aristato.

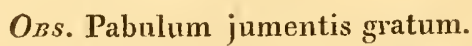

$H_{A B}$. in Georgix et Carolinæ paludosis graminosis: Floret Maio. 
TRIANDRIA. DIGYNIA.

STRIATA. A. panicula coarctata, rariflora: gluma 5-flora; floribus eadem longioribus, subimberbibus; valva exteriore striata, dorso longius aristata : semine nudo.

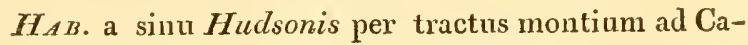
nadam.

\section{A R U N D O. L.}

Gluma 2-valvis. (quibusdam 1-ant 2-flora) Cal. 2-valvis basi lanatus.

Canadensis. A. culmis foliisque lavibus, angustis;

\section{(1)} panicula oblonga : glumis puberulis, lanceolatis, unifloris; floris altera valva dorso aristata.

OzS. Habitu caractereque affinis A. Calamagrosti. $H_{A B}$. in Canada.

arevaria. A. calycibus unifloris; foliis involutis, mucronato-pungentibus. $L$.

$H_{A B}$ ad littora Canadæ.

\section{A R U N D I A R I A.}

Cusm gigantei, perennes. Flores paniculati; spiculis multifloris, hermaphroditis aut masculis.

Gluma conm. inacqualiter bivalvis, brevis, 5- I 2 -flora.

Gr - part. subæqualiter bivalvis, mutica; valva exteriore longo - lanceolata, 
acutissima, dorso convexo, subtereti; inferiore tantisper minore, dorso canaliculata.

Stay. tria, exerto-pendula : anthere longolineares, utrinque brevissine bifida.

A ppendices bini lato-lanceolati, acuti, plani, fere longitudine ovarii.

Tidem in flore masc. ac hermaphrodito. PIST. ovarium oblongum : stigmata tria, subsessilia, oblonga, aspergilliformia, filis longis, numerosis.

Sever nude decidens, maximum, subovoideo-oblongum, subarcuatum, teretiusculum, obtusum, vestigio stigmatorum acuminatum; dorso notatum sulco levi, angusto.

OBs. Habitus Bambois et Nastr.

macrosperma. A. altissima, glabra : foliis linearilanccolatis, subdistichis.

HAB. ad ripas flum. Mississipi : in Carolina, Florida, \&c. Martio flerens.

\section{Z I Z A N I A. L.}

Monoica. Gluma o. Cal. 2-valvis, valva exteriore aristata. Masc. Stam. 6; anth. subsessiles. Foem. Styli 2 aut stylus 2 -fidus. Semen oblongum, nudum.

MLIACEA. Z. crassicaulis : panicula grandi, longa, ramosissima; floribus $o^{x}$ et $q$ permixtis : 
TRIANDRIA. DIGYNIA.

glumis seminiferis subovoideo-ventricosis, brevissime aristatis : semine ovato, lavi.

$H_{A B}$ in aquosis Americæ septentrionalis.

clavulosa. Z. panicula ramosissima; inferne ơ, superne + , ramis virgatis, fulcris florum crassissime clavatis : semine gracili, elongato.

OBS. Huc pertinet Zizania Gronovir, quam Linn. cum Sloanina perperam conjunxit.

$H_{A B}$. in aquosis Americæ septentrionalis.

fluttans. Z. pusilla : culmis gracilibus, ramosis, fluitantibus : foliis natantibus, linearibus, planis : spicis solitariis, axillaribus, setaceis, sub4-floris; superioribus masculis, inferioribus femineis: glumis omnibus muticis.

HAB. ad lacum Champlain.

\section{A N I S U R I S. L.}

Gluma 2-valvis, 1-flora, valva exteriore coriacea, subroturida, basi utrinque emarginata. Cal. minor, 2-valvis. Stylus brevis.

Grandlaris. M. spicis lateralibus, valvulis exte-

Sw. rioribus orbiculatis, punctato-callosis, vaginis pilosis, culmo erecto. Sw.

Cencrirus gramularis. LrnN.

$H_{A B}$, in Carolina, Georgia maritima. 


\section{$T R I G Y N I A$.}

PROSER P I N A A. L.

Cal. 5-partitus, superus. Cor. o. Sem. 1. triloculare.

palustris. P. (a) foliis imis subpinnatifidis vel inciso-serratis : cæteris lineari-lanceolatis, argute serrulatis.

( $\beta$ ) foliis omnibus tenuiter pectinatopinnatifidis.

$O_{B S .}$. Utraque glaberrima; eaulibus herbaceis, assurgentibus, simplicibus : foliis alternis, sessilibus: floribus $1-3$, axillaribus, subsessilibus.

$H_{A B} . \propto$. in fluviorum novæ Cæsareæ ripis ascendente mari inundatis.

$\beta$. in stagnis pratensibus Carolina inferioris.

$$
\text { L E G H E } \Lambda . L \text {. }
$$

Cal. 3-phyllus. Petala 3, linearia. Caps. 3-locularis, 5-valvis : valvulis totidem interioribus. Sem. 1.

major. L. elatior : caule ramisque villosissir. mis : foliis pubescentibus et ad oras/villosis, ovali - lanceolatis; caulinis obtusis cum minuto mucrone; rameis acutis: floribus numerose fasciculatis.

$O_{Z 3 S .}$ Caulis erectus, firmus, 2-3-pedalis, superne panieulato - ramosissimus; ramorum villis subcanescentibus.

$H L A E_{1}$ in apricis aridis Caroline. 
TRIANDRIA. TRIGYNIA.

Racemulosa. L.appresso-pubescens: caule erecto, superne ramis gracilibus paniculato : foliis linearibus, acutis, ciliatis : ramillis in racemulum remotiuscule alterniflorum et nudiusculum desinentibus.

Menandra ramis ternis Gron. virg. 21. $H_{A B}$, in Virginia.

THYMFolia. L. caule erecto, asperiusculo; ramis erecto-paniculatis, latis; floribus foliatofasciculatis.

L. minor? Lins.

$H_{A B}$. in utrius que Carolinæ apricis aridis.

tenuffolia. L. humilis, dumosa : caulibus decumbenti-assurgentibus, ramis patulis: foliis subulato-linearibus : floribus secus ramillos remotiuscule solitarieque alternantibus.

OBs. Capsulæ, ratione plantæ et generis, majusculæ.

$H_{A B}$. in collibus sabulosis juxta amnem Santee. Aprili et Maio florens.

$$
\text { M O L L U G O. L. }
$$

Cal. 5-phyllus. Cor. o. Caps. 3-locul. 3-valvis.

verticillata. M. foliis verticillatis, cuneiformi-

מ. bus, acutis; caule subdiviso, decumbente; pedunculis unifloris. $L$.

$H_{A B}$. ubique in cullis. Aprili ad septembrem florens. 


\section{CLASSIS IV. \\ T E T R A N D I A. MONOGYNIA. \\ §. I. O VA R I O I N F F R O. \\ -A. MO NOPETAL E. \\ G A L I U M. L.}

Cor. 1-petala, plana. Sem. 2, subrotunda.

* Fructu glabro.

Craytoni. G. caulibus procumbentibus, angulis retro-scabris : foliis plerisque quaternis, rarius quinis, lineari-oblanceolatis, obtusis, margine nervoque minutim aculeolatis : fasciculis ramorum terminalibus; floribus paucis, omnibus pedicellatis, minutis, albis : fructu glabro.

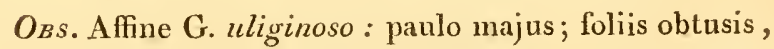
nunquam senis. Videlur esse Aparine $\mathbf{n}^{\circ} .558$ CLAYTONI.

$H_{A B}$, in Canada et Nora Cæsarea. (New-Jersey.)

asprellum. G. caulibus decumbentibus, foliosis; angulis folidrumque margine et nervo manifeste retro-aculeolatis : foliis senis, ovali-lanceolatis, acumine flaccido : ra- 


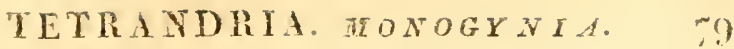
mulis fleriferis rersus summitates pan. cis, foliosis; floribus albis, brevissime pedicellatis, fruetu glabro.

HAs. in septentrionalibus Canadx.

Latrfolum. G. caulibus erectis, lævibus : foliis quaternis, amplioribus, oblongo-ovalibus, sursum sensim angustatis, acutis, planis, membranaceis, trinerviis; margine nervisque (armato oculo) minutissime hispirlulis : pedunculis opposite lateralibus et terminalibus, divaricatis, laxe multifloris.

OBs. Folia 1-2-uncialia, verticillis distantibus : flores violaceo-purpurei : fructus majusculus, slaber, altero lobo plerumque abortiente.

$H_{A B}$ in altis montibus utrinsque Carolinx.

varforum. G. caulibus lavibus; ramis fertilibus assurgentibus, simpliciusculis : foliis quaternis, longo-linearibus, acutis, glabris, subirıermibus : pedunculis ad singulos verticillos solitariis, brevissimis, unifloris; flore albo, cernuo : fructu glabro. Oзs. Affine G. tinctorio LinN.

$H_{A B}$ in Carolina.

$$
\text { * Fructu, Rirsuto. }
$$

IISPIdUlum. G. pumilum, ramosissimum, foliosum; caulibus undique, folis utrinque, 
ovariisque hispidulis : foliis quaternis, subovali-lanceolatis cum minuto acumine, margine revolutis, subrugosis : floribus albis, ramulorum subsolitarie terminalibus.

$H_{A B}$, in Carolina inferiore.

TRIFLORum. G. caulibus procumbentibus, glabriusculis, infra verticillos minutim his. pidulis : foliis senis, ovali-lanceolatis, mucronatis, laevibus, glabellis : (armato oculojuxta marginem nonnihil hirsutis) pedunculis lateralibus et terminalibus verticillo longioribus, trifloris; floribus pedicellatis : fructu hispidulo.

$H_{A B}$, in umbrosis Canadæ sylvis.

puncticulosum. G. caulibus imperceptibili pube asperiusculis : foliis quaternis, ovalibus, obtusis, inermibus, margine nervisque minutim pubescentibus, punctis subpellucidis quasi pertusis : floribus purpureis : fructibus lappulaceis.

G. purpureum. WALt.

Cruclata. no. 313. Cla ${ }^{2}$ ?

$H_{A B}$. in Carolina inferiore.

circezans. G. caulibus erectis, lavibus : foliis quaternis, ovalibus, planis, inermibus ; margine ciliolato nervisque (armato oculo) hirsutulis : pedunculis divaricatis, ple- 
TETRANDRIA. HONOGYNIA. SI risque indivisis, paucifloris : floribus l'cmote alternis, subsessilibus; fructibus cernuis, confertim lappulaceis.

$$
\text { G. boreale? W ALT. }
$$

MAB. in Carolina.

\section{R U B I A. $L$.}

Cor. 1-petala, campanulata. Baccae 2, monosperme.

Browver. R. parce minutimque hispidula : foliis quaternis, ovalibus : pedunculis solitariis, unifloris.

VAlaNtia hypocarpia. Linn.

Rubra peregrina. Walt.

$H_{A B}$. in umbrosis, a Carolina ad Floridam.

D I O D I A. $L$.

Cor. 1-petala, infundibulif. Caps. 2-locularis, 2-sperma.

virginica. D. caulibus procumbentibus, pubesr. centibus : foliis ovali-lanceolatis; floribus axillaribus, solitarie oppositis, sessilibus, fructibus hirsutis.

$H_{A B}$. in humidis, udis Virginix-Carolinx. Estate et autumno floret.

I. 


\section{S PE R M C O G E. $L$.}

Cor. 1-petala infundibuliformis. Sem. 2, bidentata.

DIODina. S. anmua : caule erecto, hirsuto : foliis linearibus vel lineari-lanceolatis, glabris, marginibus minutissimis aculeolis quasi serrulatis; stipulis longissime multisetis: floribus in axillis alternis solitarie sessilibus : fructibus hirsutis.

OBS. Diodia esset, nisi ealyx 4-fidus obstaret?

$I_{A B}$. in aridis sabulosis sylvarum Carolinæ. Augusto et Septembri florens.

GLABRA. S. procumbens; canlibus, foliis fructibusque glabris : foliis ovali-lanceolatis: verticitlis, multifloris.

HAB. ad ripas fluminis Ohio et Mississipi. Julio et Angusto florens.

\section{P O Y P R M U M. L.}

Herbæ, foliis vaginula membranacea connatis :

Flores pusilli, dichotomales et terminales.

CAL. basi tetragonus', 4-partitus; laciniis erectis, sublanceolatis.

Cor. calycis limbo subrqualis : tubus brevissimus; fauce barbata : linibus rotatus, 4-partitus; laciniis rotundatis. 
TETRANDRIA. MONOGYNIA.

Sтам. 4 , inclusa, medio tubo inserta : filamenta brevissima : antherx subrotunda.

PIsT. ovarium ima parte inferum, superne liberum, compressiusculum, ovoideum : stylus brevissimus : stigma ovoideo-capitatum, inclusum.

Cıps. calyce paulo brevior, subobcordata, compressa; 2-locularis; sutura marginali bivalvis; valvis medio septiferis.

SEx. numerosa, angulosa, subrotunda; immediate confertimque adnexa placentx; quie, imo septo inferne connata, intra singulosloculos desinit in processum liberum ascendentem et undique seminiferum.

Linnsi. P. glaberrimum, procumbens : caule sexangulato : foliis angusto-linearibus, acutis : stipulis sinuato-truncatis, indivisis : floribus sessilibus.

Oss. Flos singulus pluribus bracteolis calyci subconsimilibus circumvallatus. Corolla candida.

$H_{1 B}$. in arvis et pascuis aridis Carolinæ, Virginiæ, \&c. Aistate tota.

OL D E N LA N D I A. L.

Cor. 4-partita. Cal. 4 -partitus, superus.

Caps. 2-locularis, infera, polysperma.

gromerata. O. pumila, procumbens, caule foliis calycibusque hirsutior : foliis ovalibus: floribus ad nodos et summitates conglobatis.

$H_{A B}$. in humidis Carolinæ inferioris. 


\section{II $\bigcirc \mathrm{USTONIA.L.}$}

Poinetia. Gumel. Sygst. 263.

Herbulæ rubiaceæ.

CAL. minimus, subsemi-4-fidus, erectus.

Cor. infundibuliformis : tubus calyce longior, angustus : limbus 4-partitus; laciniis patentibus, ovalibus, tubo subbre. vioribus.

Sтам. intra faucem inserta, limbo breviora aut etiam inclusa : filamenta brevissima; antheræ erectæ, oblongae.

PIst., ovarium semiinferum : stylus longitudine tubi aut exsertus : stigmata duo, ligulata.

CAPS. laciniis calycinis versus mediam partem aut infra circumcincta, compressosubglobosa ; emarginata, bigibba ; 2 -locularis, superne semibivalvis; valvis medio septiferis.

SEn. plura, placenta medianæ adnexa; subrotunda, scabriuscula, facie interna scrobiculo umbilicata.

LитдI. II. caule erecto, setaceo, dichotomo; foliis radicalibus et imis spathulatis; caulinis oblanceolatis, paribus dissitis : pe- 
TETRANDRIA. MONOGYNIA. dunculis solitariis, I-floris, longissimis , alternis, lateralibus et terminalibus.

Var, a. elatior : canlis pedunculique suberecti; flores coerulei, multo majores.

ß. minor : magis divaricata, flor, interdum albis.

HAB. \%. a nova Anglia ad Carolinam montosam.

$\beta$. in maritimis arenosis, a Virginia ad Floridam.

serpylemolia. H. cespitoso-multicaulis, procumbens aut etiam repens, filiformis : foliis brevi-ovalibus, abrupte in longiusculum petiolum angustatis : pedunculis terminalibus, solitariis, I-floris, longissimis.

OBS. Habitus fere arenaria balearicae : folia (prasertim junioris planta) minutim ciliata. Cor. cocrulea.

$H_{A B}$. ad fonticulos rivosque excelsornm montium Carolinx. Maio florens. 'Ts.

RotUNDIFolia. H. repens : foliis suborbiculatis, in brevem petiolum abrupte angustatis, crassiusculis : pedunculis axillaribus, solitariis, I-floris.

Oss. Habitus Veronicas mummularifoliae; sempervirens : corolla alba.

HAB. in apricis submaritimis Floridx, et Carolinæ. Martio floret: Wss.

ANGUSTIFolia. H. erecta, opposite ramosissima, glabra : fol. angusto-linearibus, summi 
tatibus confertiuscule fasciculifloris; floribus subimpedicellatis, sxpe ternis.

OBs. Capsula basi minus rotundata quam in cæeteris, potius vero subturbinata : dentibus calycis tantisper supra ejus medietatem. Corolla purpurascens.

$H_{A B}$, in submaritimis Floridx.

variars. H. caulibus erectis, simpliciusculis, præsertim ad nodos subbarbatos pubescentibus : foliis arcte sessilibus, ovalibus vel etiam lineari-lanceolatis : fasciculis corymbulisve florum purpurascentium terminalibus.

H. purpurea? Lins.

$O_{B S}$. Generis maxima : variat foliis lato-ovalibus, lanceolatis et sublinearibus. Houstoniam inter et Heруотим quasi media. Radice perennans, antheræ tubo cor. prorsus exertæ.

$H_{A B}$. in diversis locis utriusque Carolinx et alibi. Floret Julio.

\section{I T C H E L L A. $L$.}

Cor. 1-petalæ, superæ, binæ, eidem ovariv. Stigmata 4. Bacca bifida, 4-sperma.

REPENS. M I T C H E L L A.

I.

$I_{A B}$, in Carolina, Terra Mariana, Virginia. 
TETRANDRIA. MONOGYNYA. 8 -

C E P H.A L A N T H US. $L$.

Cal. communis o : proprius superus, infundibuliformis. Receptaculum globosum, nudum. Semen 1 , lanuginosum.

occinentalis. C. foliis oppositis ternatisque. $L$.

I.

HA $A$. in paludosis, a Canada ad Floridam.

L I N N AEA. $L$.

Cal. duplex : fructus 2-phyllus; floris 5-partitus, superus. Cor. campanulata. Bacca sicca, trilocularis.

BOREALIS. LI N N I A.

I.

H.AB. in Canada et nova Anglia.

-B. POLYPETAL E.

\section{U DWIGI $\lrcorner. L$.}

Cor. tetrapetala. Cal.4-partitus, superus. Caps.

4-gona, 4-locularis, infera, polysperma.

mirida. L. glaberrima, lucidula : caulibus assurgentibus, ima parte radicantibus : fo- liis oppositis, ovalibus, inferne quasi in petiolum promisse angustatis : floribus apetalis, minimis, axillaribus, sessilibus : capsula subovata, brevius coronata.

$O_{B S .}$. Bracteolæ nullæ.

$M_{A B}$. in humidis Carolinæ inferioris. Floret Mlaio 
pencrculosa. L. parvula, repens : caulibus puberulis : foliis oppositis, sessilibus, linearilanceolatis, glabris : pedunculis sparsim axillaribus, unifloris, longissimis , uti calyces pubescentibus : floribus majusculis : capsulis clavato-oblongis, laciniis coronantibus promisse lanceolatis.

$O_{B S}$. Folia sublinearia. Flos, ratione plantre, maximus. Pedunculus infra florem bracteolis 2-setaceis munitus.

HAB. in paludosis submaritimis Carolinæ inferioris. Maio florens.

Mrnocarpa. L. procumbens assurgensve, glaberrima : foliis alternis, spathulato-obovalibus, superne punctis subcallosis remote marginatis : floribus minutis, sessilibus, axillaribus, apetalis : capsulis minimis, brevissimis; laciniis coronantibus rotundatis et acuminatis.

$O_{B S .}$ Folia parvula, plerumque obtusa cum minuto acumine. Bracteolæ 2 sub flore subulatæ.

$H_{A B}$. in humidis Caroline inferioris. Julio floret.

ANGUSTIFolia. L. erecta, elatior, stricte ramosissima, glabra : foliis alternis, angustolinearibus, acutis : floribus axillaribus, sessilibus, petalophoris : capsula oblongiuscule turbinato-prismatica; laciniis 
TETRANDRIA. MONOGYNIA.

calycinis brevioribus, subsemilanceoJatis.

L. ramosissima? WALT.

IIAB. juxta fossas aquosas Carolinæ inferioris. Augusto et Septembri floret.

JUSSI ternis, lanceolatis, decurrentibus : floribus axillaribus, subsessilibus, petalophoris : capsula majuscula, clavatooblonga, laciniis calycinis ovali-lanceolatis.

L. decurrens? WALT.

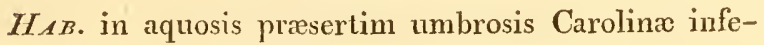
rioris. Floret Julio.

MaCrocanes. L. major, erecta, minutim puberula : foliis alternis, longo-lanceolatis, acutis, subtus subalbicantibus : floribus alternis, brevi-pedicellatis, petalophoris: capsula majuscula, globoso-4-gona, lucida; laciniis calycinis maximis, quasi lato-cordatis, coloratis coronata.

L. alternifolia. LiNn.

$H_{A B}$, in pratensibus Virginize et Pensylvanix.

vingata. L. erecta, elatior, glabra; ramis promisse virgatis : foliis alternis, sessilibus, longo-linearibus, oltusis : floribus in superiore ramorum parte quasi virgatim spicatis; alternis, pedicellatis, petala- 
$9^{\circ}$, TETRANDRIA. MONOGYNIA.

phoris : capsulis globoso-4-gonis, non coronatis, glandulis disci ambitu pubentibus.

ILAB, in aridis sylvis Carolinæ inferioris. Maio florens.

MoLlis. L. erecta; elatior; caule, foliis calycibusque molliter subtomentoso-pubescens : foliis alternis, lanceolato-oblongis; floribus apetalis, in superiore ramulorum parte sessilibus, modo alternis, modo terminaliter congestis : capsulis subrotundis.

$H_{A B}$. in paludosis Carolinæ inferioris. Julio floret.

capitata. L. radice repente; erecta, glabra: foliis alternis, linearibus vel lineari-lanceolatis, acutis; capitulis ramorum terminalibus, petalis calyce brevioribus: capsula sub4-gono-semiglobosa, laciniiz calycinis hujus longitudine, lato-brevibus.

L. suffruticosa. W WLT.

$O_{B S}$. Caules primordiales repentes et pubescentès, vestiti foliis obovalibus : surculorum sterilium folia latiuscule lanceolata.

'HAB. in aquosis apricis Carolinæ inferioris. Septembri floret. 


\section{G O R N S. $L$.}

Involucrum 4-phyllum sæpius. Petala supera 4.

Drupa nucleo 2-loculari.

caradersis. C. radice repente: caulibus herba-

I. ceis, simpliciusculis, assurgentibus : foliis obovalibus, summis quasi seno-verticillatis : involucri magni foliolis ovalibus, acuminatis, fructibus globosis.

$O_{B S}$. Caules ima parte squamosi : ramuli axillares brevissime diphylli; unde folia quasi verticillata. Bacca interdum binuculata.

$H_{A B}$. in sylvis umbrosis Canadx. Maio floret. Junio fruct.

FLORIDA. C. arborea : foliis ovalibus, acuminatis;

. subtus albicantibus : floribus sessiliter capitatis; involucro maximo, foliolis apice deformi quasi obcordatis : fructibus brevi-ovatis.

HAB. in sylvis Virginiæ, Carolinæ, Canadæ, \&c.

Tomentulosa. C. ramis verruculosis : foliis amplis, lato-ovalibus, acuminatis, subtus eximie tomentosis et candicantibus : $\mathrm{cy}$ mis patentissimis.

C. circinata. L'Herit.

$H_{A B}$. in collibus amnium ripariis Canadæ, NewYorck, Connecticut. Junio et Julio floret. 
92 TETRANDRIA. MONOGYNIA.

Landginosa. C. patula : ramulis lanuginosis : foliis ovalibus, acuminatis, plerisque basi subrotundata obtusis, subtus manifeste pubescentibus : cymis confertifloris, lanuginosis.

$O_{B S}$. Folia inferiora interdum subcordata.

Affinis C. sericeae. Lins. discrepans vero ab icone Heritien I.

HAB. in humidis Canadæe et Carolinæ.

stolonifera. C. caule inclinato; ramis debilibus; ramulis glabriusculis : foliis ovalibus, non ita acuminatis, basi obtusiusculis, utrinque minutissime puberulis, subtus albicantibus : cymis parvulis, minutim puberulis.

$O_{B S}$. Frutex incomptus, uberius stoloniferus, ramis purpurcis : Osier rouge Canadensium.

$H_{A B}$. ad ripas amnium rivorumque Canadæ, Novæ Anglix. b.

rastigiata. C. glabriuscula : ramis stricte erectis, fastigiatis : foliis ovalibus, longissime acuminatis : cymis longius pedunculatis.

OBS. Rami cinerei; ramuli fusci, puncticulati, sæpe subquadranguli. Folia subtus dilutiora nec albida. Antheræ sæpe dilnte coerulescentes.

Affinis C. strictae. L'Herıt. sed cyma non paniculata.

HAB. in dumosis, ad ripas rivulorum Virginix, $\mathrm{Ca}-$ rolinx. Aprili floret. 
TETRANDRIA. MONOGINIA. $\quad 9^{3}$ ASPERIFOLIA. C. ramulis cymisque pubescentibus: foliis brevi - petiolatis, ovalibus, acuminatis ; subtus asperiuscule subsemitomentosis; super minuta rigidulaque pube asperis.

$O_{B S}$. Caulis rectissine erectus, solito ramosissimus.

Cyma confertim multiflora.

$H_{A B}$. in sylvis umbrosis Caroline inferioris.

Junio et Julio floret.

aztennifolia. C. foliis inordinate alternis.

L. S.

Var a. ramis cortice obscure rubro.

ß....... pallito virescente.

IIAB. a in Canadæ sylvis.

$\beta$ in sylvis montanis amnium ripariis Carolinx.

Maio floret.

5. II. OVARIO SUPERO.

-A. MONOPETAI。

- alternifoliae.

G E N T U N G L U S. $L$.

Cal.4-fidus. Cor. 4 -fida, patens. Stam. brevia.

Caps. 1-locularis, circumscissa.

LANCEOLATus. C. foliis angustatis, quasi petiolatis; inferioribus ovalibus; superioribus lan. 

ciniis subulatis.

$O_{B S}$. Nostrate gracilior et subelatior : corolla itidem alba.

HAB. in locis udis Carolinæ inferioris; rara. $\odot$. Aprili floret.

$$
\text { P L A N T A G O. } L \text {. }
$$

Cal.4-fidus. Cor.4-fida : limbo reflexo. Stamina longissima. Caps, 2-locularis, circumscissa.

Kentuckensis. P.glabra : foliis lato-ovalibus, subintegris : spicæ floribus sparsis passimque glomeratis : bracteis calycibusque rotundato-obtusis.

$O_{B S}$. Jamdudum culta in hortis gallicis sub nomine

P. canadensis.

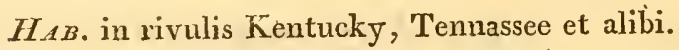

virginica. P. undique subcanescenti-pubentis-

L. sima : foliis ovali-lanceolatis, rariter subdenticulatis : spica oblonga, floribus minus confertis; corollis anguste et subrostratim conniventibus.

$H_{A B}$. in Virginia.

Sparsiflora. P. rariter puberula : foliis lanceolatis, subintegris : spica longa, gracili; floribus solitarie sparsis, glabris.

$H_{A B}$. in sylvis Carolinæ et Georgiæ.

maritima. P. foliis carnosis, subulato-linearibus, L. integris: scapo minutim puberulo, pube 
TETRANDRIA. MONOGFNIA.

incumbente : spica cylindracea; bracteis brevibus, obtusis.

$H_{-1 B}$ ad ripas fluminis $S$. Laurentii mare inmdatas.

aristata. P. foliis subsetaceo-linearibus : spica oblonga, cylindracea; bracteis subulaioaristatis, supra flores longius exertis.

H.AB. in pratensibus Illinoensium.

$$
\text { L Y C I U M. L. }
$$

Cor. Lubulosa, fauce clausa filamentorum barba.

Bacca 2-locularis, polysperma.

CAROLINIANUM. L. inerme : foliis anguste spathulato-oblongis : floribus quadrifidis, tetrandris, coerulescentibus.

L. salsum. Bartram. trav. $5 g$.

HАB. ad littora scirposa Carolinæ, Georgir, Floridx. TF.

- ${ }^{\star \star}$ oppositifolicie.

C A L L I C A R P A. $L$.

Cal. 4-fidus. Cor. 4-fida. Bacca 4-sperma.

AMERICANA. C. ramis pruinoso-tomentosis; foliis

L. lato-ovalibus, utrinque acutis, dentatis, subtus subtomentosis : cymis sessilibus, petiolo brevioribus.

$I_{A B}$. in sylvis et dumosis apricis Carolinæ inferioris. Junio floreris. Septembri fruct. 
F R A S E R A. WALT.

CAL. profunde 4-partitus, patens, laciniis lanceolatis, acutis.

Con. calyce multo major, profundissime 4-partita, patens : laciniis ovalibus, ob utrumque marginem versus summitatem incumbenti-inflexum quasi acuminatis.

Glandula conspicua, orbiculata, convexo-protuberans et eleganter barbata in parte laciniarum media.

Sтам. 4, corolla breviora eique alterna; filamenta subulata; anthera subovatooblonga, inferne subsemibifida, demum reflexæ.

PIst. ovarium oblongo-ovatum, compressum, sensim desinens in stylum ipsius circiter longitudine : stigmata 2, crassa, glandulosa, divergentia.

CAps. majuscula, ovalis, valde compressa, ambitu submarginata, subcartilaginea, rudimento styli mucronata; I-locularis, margine 2-valvis.

Semina pauca, (8-1 2) elliptica, plano-compressa, membranaceo-marginata; ad latera u triusque suturæ immediate longitudinaliter per marginem alterum ita adnexa, ut sibi invicem imbricatim incumbant.

OBs. Genus gentianeum; fructu fere Mrasantuis Nymphoidis. 
TETRANDRIA. MONOGYNIA.

WALteri. P. erecta, altissima : foliis oblongoovalibus, verticillatis oppositisque.

H.\&B. in paludosis Carolinæ.

$$
\text { SW E R T I A. } L \text {. }
$$

Cor. rotata. Nectariferi pori ad basim laciniarum corollæ. Caps. 1-locularis, 2-valvis.

Corniculata. S. floribus 4-fidis, corolla subcamL. panulata; tubodeorsum quadricalcarato. $H_{A B}$, in paludosis Canadæ.

\section{E N T A U R E L L A.}

Plantula Centaurio minori affinis.

Herbulæ annuæ, quandoque aphyllæ; foliis squamiformibus, oppositis. Florescentia subpaniculata.

$\mathrm{C}_{\text {AL. }}$ profunde 4-partitus, appressus; laciniis lanceolato-linearibus, sensim acutis.

Con. subcampanulata, 4-partita; laciniis erecto-patulis vel etiam patentibus, ovalibus oblongisve.

Stay. quatuor, erecta, dimidia limbi corollæ longitudine, tantisper infra hujus incisuras inserta ; filamenta complanatosubulata; antheræ erectx, subcordatx, obtusiusculæ, inferne bifidx, non contortæ.

PIst. ovarium oblongo-ovatum; stylus brevis; stigma magnum, crassum, glan- 

dulosuin, apiee obtuse subbifidum, per utrumque styli latus etiamque ultra hujus basin adnato-decurrens.

Caps. calyce corollaque persistentibus in. volucrata, oblongo-ovata; 1-locularis, 2-valvis.

Semina numerosissima, minuta, globulosa, adnexa placentis duabus crassis, oppoposite juxta utramque suturam longitudinaliter adnatis.

$O_{B S}$. Genus Gextiazs affine.

verna. C. caule superne quasi in pedunculos - raros, r-floros, longiusculos diviso : latab. 12. ciniis corolla oblongis : stylo ovario lonfig. 2. giore.

$O_{B S}$. Vix semipedalis : flores ratione plantæ et prioris speciei majusculi, albidi.

$H_{A B}$. in sphaguosis Carolinæ inferioris. Primo vere florens.

paniculata. C. caule superne ramoso; ramis ramulosis; panicula stricta, multiflora : tab. 12. laciniis corollse ovalibus : stylo ovario fig. 1. multo breviore.

$O_{B S}$. Flores parvuli, albi. Interdum in gracilibus plantis panicula c ramulis simplicibus subunifloris.

$H_{A B}$. in humidis Carolinæ. Autumno florens. 


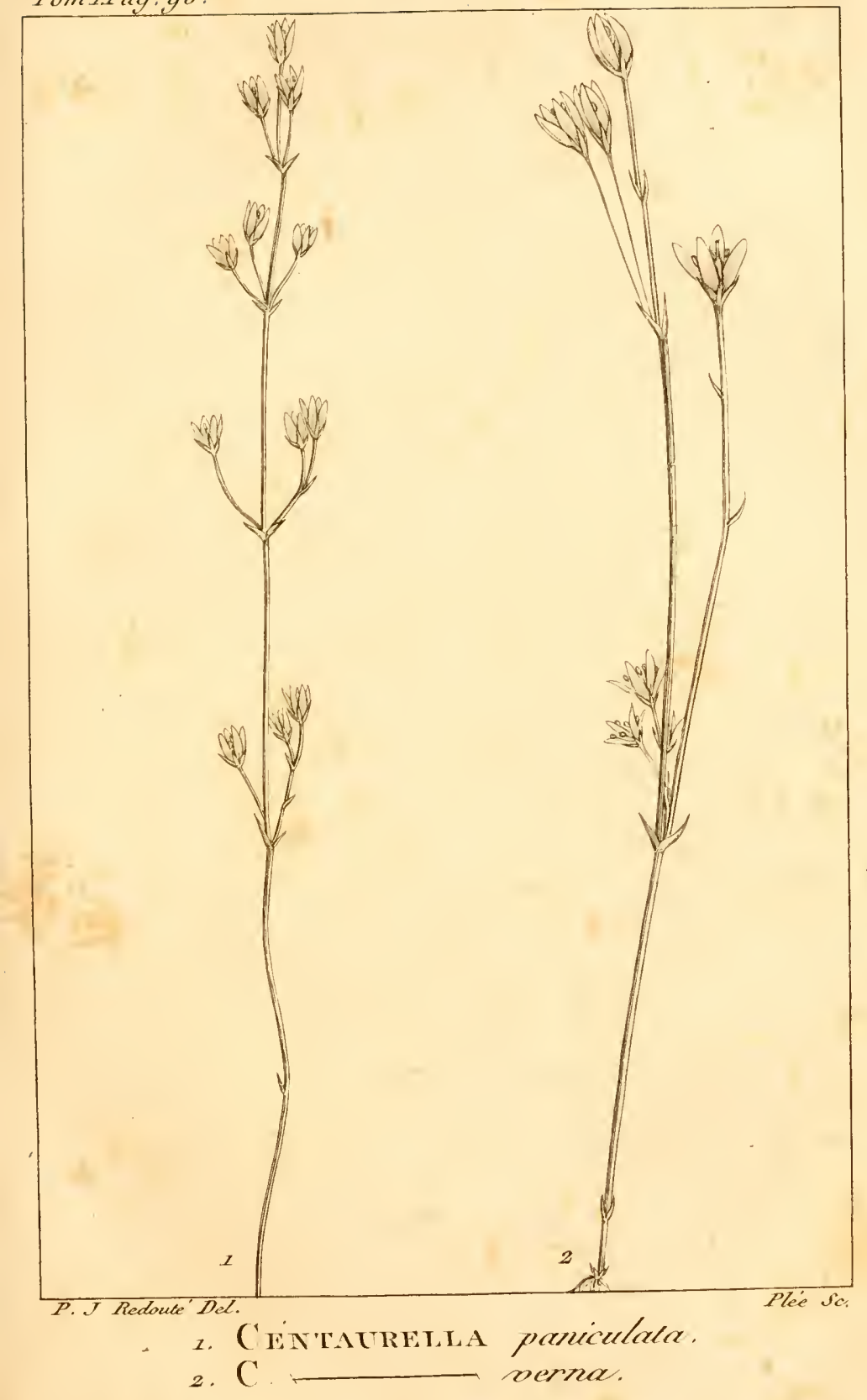



TETRANDRIA. MONOGYNIA.

-B. POL I PETAL $\overparen{E}$.

\section{A M M A N I A. L.}

Cór.4-petala, calyci inserta, vel nulla. Cal. 1-phyllus, plicatus, 8-dentatus, inferus. Caps. 4-locularis.

RAMosion. A. caule erecto; foliis lanceolatis linea-

L. ribusve, basi dilatata subsemiamplexicaulibus: floribus inferioribus compactoverticillatis, superioribus solitarie oppositis : petalis purpureis.

$I_{A B}$. in udis regionis Illinoensis, Virginiæ, Carolinx. Augusto florens.

нuмııs. A. humilis, procumbens : foliis lanceolatis, inferne in petiolum angustatis: floribus petalophoris, solitarie oppositis, arcte sessilibus.

A. ramosior. WALT.

$O_{B S .}$ Affinis A. debili : capsula 4-locularis.

$H_{A B}$. in paludosis Carolinæ septentrionalis. Septembri florens.

$$
\text { P. T E L E A. L. }
$$

Cor. 4 -petala. Cal. 4 -partitus, inferus. Fructus membranaceus, subrotundus, centro nonospermus.

TRIfoliata. P. foliis ternatis. $L$.

,L. 


\section{A L L I O N I A. L.}

Cal. communis oblongus, simplex, triflorus ; proprius obsoletus, superus. Corollulae irregulares. Recept. nudum.

myctaginea. A. erecta, glabriuscula : foliis latocordatis, acutis : pedunculis solitariis; involucro quinquefido, 3 - floro : calycibus fructiferis brevissima pube hirsutulis, involucro ampliato multo minoribus.

$O_{B S}$. Habitus omnino Nrctaginis hortensis (MIlia bitis Jalapae. Linn.)

$H_{A B}$ ad ripas fluminis Tennassée.

\section{$D I G Y N I A$. \\ S A N G U I S OR B A. $L$.}

Cal. 4-phyllus. Ovarium inter calycem corollamgue.

Cara Densis. S. spicis longo-cylindraceis, albidis:

L. staminibus longissimis.

IIAB. in Canada, circa Quebec.

H A M A M E L I S. I.

Involucrum 3-phyllum. Cal. proprius 4-phyllus.

Petala 4. Nux 2-comis, 2-locularis.

VIRGINICA. H A M $\Lambda$ M I L I S.

$\boldsymbol{L}$.

$H_{A B}$, in Virginia. 
TETRANDRIA. TETRAGYIIA. rOT

\section{$T E T R A G Y N I A$ 。}

POTA MOGETON. $L$.

Cal. o. Petala 4. Stylus o. Sem. 4 .

Perfoliatum. P. foliis amplexicaulibus, cordato-

L. ovalibus seu cordato-oblongis : spicis. oblongis, multifloris, floribus alternis.

$O_{B S}$. Differt a nostrate foliis oblongioribus, sursum: sensim angustatis.

$H_{A B}$. in lacubus amnibusque Canadx.

Lucens. P. foliis lanceolatis, subsessilib̄us, bąš

L. quasi in petiolum angustatis : spicis. longo-cylindricis.

$O_{B S}$. Nostrate quadruplo minus : foliis integerrimis, non acuminatis.

$H_{A B}$. in amnibus ad lacus Mistassinos afluentes inde ad sinum Hudsonis defluentes.

IATANS : $\beta$. P. foliis longe petiolatis, natantibus,.

E. sublanceolato - ovalibus; primariis.nonnullis subcordatis.

HAB. in Canadæa amnibus ot in flumine Ohios

HYBRIDUM : $\beta$. P. follis submersis angustissime Grat. linearibus, longis; emersis natantibus, oblongo-ovalibus.

$O_{B S}$. Forsan solnmmodo varietas P. natantis.

Affine P. polygonifolium. Pourr. act. Tolos, In.

$H_{A B}$. in aquis stagnantibus Carolinæ. 
L. gusto-linearibus, planis : spicis capitatim sub4-floris.

OBS. Quasi ambiguum inter P. gramineum et P. $m \alpha$ rinum.

HAB. in rivis afluente mari inundatis Caroline infe. rioris.

marinum? P. caule filiformi : foliis pralongo-

L. subsetaceis, crassiuscule planis, sensim acutissimis : spica terminali, promisse pedunculata, quasi verticillatim interrupta : fructibus turgide ovoideis, majusculis.

$O_{B S}$. P. marinum LiNa er species adhucdum obscura!

$H_{A B}$. in fluminis $S$. Laurentii aquis affuente mari subsalsis.

\section{R U P P I A. $L$.}

Cal. o. Cor. o. Sem. 4 pedicellata.

OBs. Hoc genus, ni fallor, pariter ac Arö̈des, in Monoecia sedem habere debet; staminibus totidem flores $\sigma^{x}$ et pistillis totidem $q$ constituentibus.

MARITIMA. RU P P I A.

L.

OBS. Mea cum Europra onmino convenit; in eo tamen differens ( si qua fides iconi optimi GertNerr) quod fructus ovoideus sit et in colliculum a stylo persistente desinat.

$H_{A B}$, ad ostium fluviorum Americæ septentrionalis. 


\section{CLAS S I S V. \\ P E N T A N D R I A. MONOGYNIA.}

ઈ. I. OV $\Lambda \mathrm{RIO}$ I NFERO.

一A. MONOPETA L 死.

C H I O C O C C A. L.

Cor. infundibuliformis, æqualis. Bacca 1-loctlaris, 2-sperma, infera.

3aCEMosa. C. foliis ovalibus, planis, non rel

I. parum acuminatis; racemis axillaribus, pedunculatis, simpliciusculis.

$O_{B S}$. Folia brevius ovalia quam in Antíllana, et vix acuminata.

$H_{A B}$. in maritimis Florida.

\section{P I N C K N E Y A.}

Caulis fruclicosus. Folia opposita, stipulacea. Flores majusculi, fasciculato-paniculati.

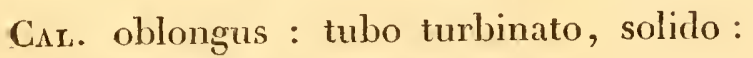
limbo longiore, patentiuscule erecto, 5-partito; laciniis oblongis, raro subxqualibus; una solito (vel etiam altera) in bracteam foliiformem, coloratam apice ampliata. 
roh PENTANDRIA. MONOGYNIA.

Cor. tubus longus, cylindraceus, ima parte paulo arctior : limbus 5-partitus; laciniis oblongis, obtusis, recurvo-patentissimis.

Stam. quinque : filamenta supra faucem exerta, erecta, longa, sctacea, paulisper supra basim tubi corollae inserta : anthera subversatiles, oblongæ, obtusæ.

PIsT. Ovarium tubo calycis concretum sive inferum : stylus longitudine staminum: stigma crassiusculum, obtuse bilobum.

Fruct. Capsula majuscula, subrotunda, modice compressa, opposite bisulca et inde quasi ovato-digastra, apice retuso et areolato nudissima.

- Pericarpium subcoriaceo-carthaceum, 2-loculare, hiatu modico bivalvi; valvis medio semiseptiferis.

-Semina numerosa, horizontaliter acervata, alato-membranacea, circumscriptione irregulariter suborbiculata, basi Iunatim emarginata, qua affixa sunt receptaculo axili.

-Nucleus ovalis, plano-lenticularis, materie subcornea undique includente embryonem rectum, cotyledonibus breviovalibus, obtusis ; radicula compressiuscule tereti, illis paulo breviore.

Genus affine Cinchons. 

Tom, 1. Pag, 1os.

Tab. 15 .

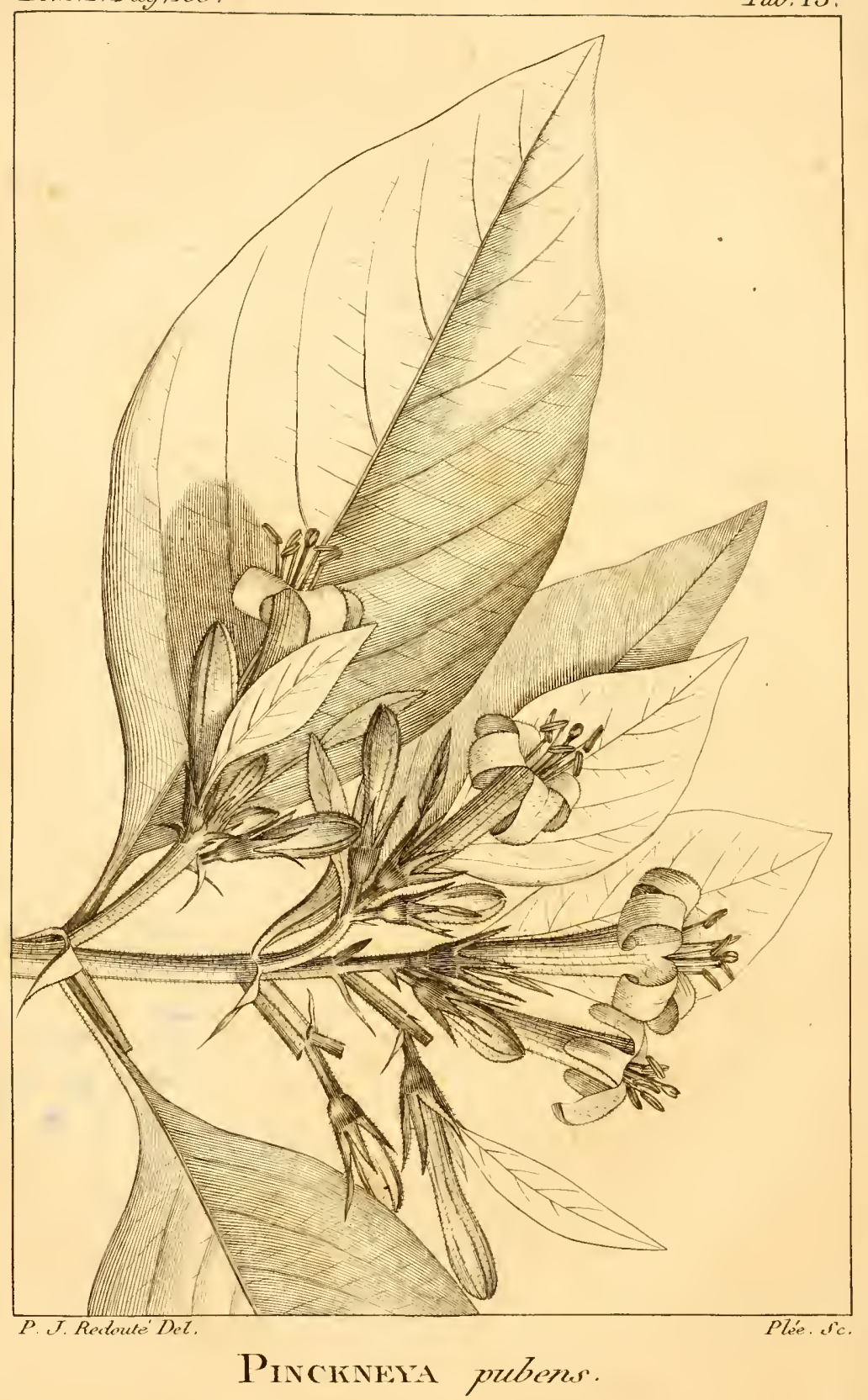


PENTANDRIA. MONOG INA. IO5 pureNs. P. foliis ovalibus, utrinque acutis, subtab. 13. tus subtomentosis.

$O_{B S}$. Frutex subarborescens, erectus, opposite ramosus. Flores majusculi, pallentes et purpureolineati : fasciculis e supremis axillis et terminalibus subpaniculatis.

$H_{A B}$ ad ripas fluvii Sanctae Mariae, in Georgia.

C A P R I F O I I U M. T. Juss.

Cal. 5-dentatus. Cor. tubulosa, 5-fida. Bacca 3-locularis, polysperma.

sempervirens. C. spica verticillis distantibus : corolla subregulari, rutilo-coccinea.

Lonicera sempetvirens. LiNN.

$H_{A B}$. in sylvis Carolinæ; ab Aprili ad Septembrem florens.

eracteosum. C. foliis omnibus connatis : bractea perfoliata floribus multo ampliore; capitulo brevi-pedunculato : corollis breviusculis, basi hinc geniculato-gibbis.

$O_{B S}$. Variat $1^{\circ}$. floribus violaceo-purpurcis et flavescentibus : $2^{\circ}$. capitulo unico et terno.

H.AB. in montibus Carolinæ. 
Flores gemini, singulo pedicello insidentes. Calo singulis 5-deutatus. Cor. 5-fida aut 5-loba subrequalis, ant irregularis bilabiata. Calycibus junctis, baccæ duæ basi comnatæ, 2-loculares, polyspermæ, aut coadunatæ in unican supra bi-um-bilicatam.

tataricum. X. foliis subcordato-ovalibus, glabris, ciliatis : baceis distinctis.

Lonicrra. tatarica. LinN.

$H_{A B}$. in montosis Canadæ, Novæ Angliæ.

villosum. X. ramis villosis : foliis oblongo-ovalibus, obtusis, utrinque subtomentosovillosissimis : pedunculis brevibus; baccis coeruleis.

$H_{A B}$. in præruptis saxosis, per tractus montium, a sinn Hudsonis ad Canadam. b.

S Y M P H O R I C A R P O S. Dill. Juss.

Cal. ti-dentatus. Cor. 5-fida subæqualis. Bacca coronata, 4-locularis, 4-sperma, loculis interdum 2 abortivis.

vUlgaris. S. floribus axillaribus, subcapitato-glomeratis.

$H_{A B}$, in Virginia et Carolina. 
PENTANDRIA. MONOGYNIA. MO nacenosus. S. racemo terminali : corolla inius barbata.

HAB. in montanis, ad lacus Mistassins.

D I E R V I L L A. T. Juss.

Cal. oblongus, 5-fidus. Cor. duplo longior, infundibulif. 5-fida patens. Caps. oblonga, 4-locularis, polysperma.

Tourneforti. D. racemis terminalibus: foliis serratis.

Lonicera. Dievillla. Linn.

HAB. in Canada, Nova Anglia et in cacumine montium excelsorum Carolinx. $\not$.

T R I O S T E U M. $L$.

Cal. 5-fidus. Cor. vix calyce longior, tuluulosa, 5-loba. Bacca 5-locularis, 5-sperma.

masus. T. foliis ovalibus, acuminatis, basi abrupte angustatis, latins angustiusre connatis : axillis uni-plurifloris : corolla obscure purpurea.

T. perfoliatum. LiNN.

$\Pi_{A B}$, in Carolina superiore.

mixus. T. caule hispido : foliis ovali-lanceolatis, subconnatis; axillis unifloris : corolla lutea.

Lonicera humilis, \&c. Grovor.

$I_{A B}$. in Virginia. 


\section{A M P A N U L A. L.}

Cor. campanulata, fundo clauso valvis staminiferis.

Stigma 3-fidum. Caps. infera, poris lateralibus dehiscens.

anplexicaulis. C. caule erecto, simpliciusculo: foliis subreniformi-cordatis, crenatis, concavo-amplexicaulibus : floribus axillaribus, sessilibus, glomeratis.

Campanula perfoliata. Linn.

$\boldsymbol{H}_{A B}$. in cultis, hortensibus Pensylvanix, Carolinæ.

מOTUNDIFOLIA.

C. glabra : radice perenni, repénte:

$\boldsymbol{L}$. cavile procumbente : foliis radicalibus subreniformicordatis, crenatis sive ansulatis; caulinis linearibus, integris: panicula laxe pauciflora, floribus nutantibus.

IIAB. in rupibus montanis Canadæ.

acuminata. C. glabriuscula : caule stricte erecto; foliis lanceolatis, in promissum acumen sensim desinentibus, modice serratis : spica fasciculato-multiflora : corollis subrotatis.

OBS. Ad altitudinem 3 ped. elata.

C. nitida. Dop. mem. 4. p. 119. t. 18.

ILAB. in remotis occidentalibus Pensylvania et Virginix. 
PENTANDRIA. HONOGYNI. IOY

Flexuosa. C. glabra; caulibus erectis, flexuosis, saperne ramulosis; ramulis usque ad summitatem paucifloram foliosis : foliis 1anceolatis, remotiuscule serratis : floribus parvulis, breviter pedunculatis, nutantibus.

$O_{B S .}$ Affinis C. linifoliae: subpedalis.

$H_{A B}$. in montibus altis Caroline.

divaricata. C. glabra, lucidula, erecta : foliis lanceolatis, remote serratis, patulis, membranaceis : panicula ramulis subaphyllis, gracilibus, divaricato-patentissimis, paucifloris; floribus parvulis, nutantibus.

$H_{A B}$, in altis montibus Carolinæe.

\section{S A M O L U S. L.}

Cor. hypocrateriformis. Stam. munita squamulis corollæ. Caps. 1-lucularis, infera.

Vhlerandi. S a M o L U S.

$\boldsymbol{L}$.

-B. P O L Y PET A L E.

\section{R I B E S. $L$.}

Petala 5 et stamina calici inserta. Stylus 2-fidus. Bacca polysperma, infera.

RECURVATUM. R. inerme : ramis recurvatis : foliis ampliusculis, pubescentibus, acute lo- 
batis, glanduloso-puncticulosis : racemis reflexis : calycibus tubulatis, glabris : baccis nigris.

$H_{A B}$ ad ripas amnis Larorum (des Goëlands) juxta sinum Hudsonis.

alergervium. R. inerme : foliis abbreviatis, leviter acuteque lobatis, glabriusculis, nervis exalbidis : racemis recurvatis : baccis glabris, rubris.

$H_{A B}$, in Canada, ad amnem Mistassin.

RIGExs. R. inerme, racemis rectis : foliis super glabris, subtus pubescentibus, reticulato-rugosis, lobis dentibusque acutis : racemis laxiuscule multifloris, etiam fructiferis rigescenti-erectis : baccis hispidulis, rubris.

$O_{B S}$. Baccæ uti racemus erectæ.

H.A. in Canada, ad amnem Mistassin.

TRIFIdum. R. inerme : foliis glabriusculis, modice lobatis : racemis laxe multifloris, pubescentibus; floribus parvis : laciniis calycinis subtrifidis : baccis hirsutis, rubris.

OBS. Foliorum lobi subacuti, inforne non angustati.

Racemi debiles, fere R. rubri, sed floribus minoribus. Calyx viridulo-pallens. Petala purpurea, spathulata, rotundato-obtusa.

Hsв. juxta Quebec et sinum Hudsonis.

rotundfolıu. R. spina subaxillari : foliis minutissime puberulis, suborbiculatis, mo- 
PENTANDRIA. THONOGYNIA. II dice lobatis; lobis subrotundo-olutusis: pedunculis unifloris; limbo calycis tubuloso : bacea glabra.

$H_{A B}$, in montibus excelsis Carolinæ.

HiRtellur. R. spinula subaxillari : ramis breviter rariterque hispidulis : foliis parvis, semitrifidis, lobis pauci-dentatis : pedunculis unifloris : bacca glabra, rubra.

HAB. in saxosis, ad amrem Sagney.

crmosвati. R. passim sub gemmis 2 -aculeatum :

sace. foliis molliter pubescentibus : racemis nutanti-pauciloris : calycibus erectocampanulatis: baccis aculeatis.

HAB. in Canada.

oxyacantho Ines? R. spina subaxillari multiplici:

L. caule aculeolis undique hispidulo : folis ultra medietatem lobatis; petiolis villosis: baccis racemosis, hispidis.

HIAB. ad lacus Mistassin.s.

Gracile. R. spina subaxillari, brevissima : foliis graciliter petiolatis, utrinque pubescentibus; lobis acutis, incisis et acute dentatis : pedunculis capillaribus, erectis, subbifloris : calycibus glabris, tubulatocampanulatis.

IIAE. in montibus T'ennasséc. 
II PENTANDRIA. MONOGYNIA.

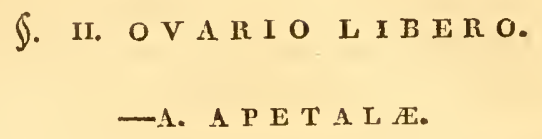

T H E S I U M. $L$.

Cal. 1-phyllus, cui stamina inserta. Sem. ', inferum.

conxubulosum. T. erectum : foliis ovali-lanceolatis, fasciculis florum corymbuloso-terminalibus.

T. umbellatum. Linn.

$H_{A B}$, in aridis Americæ septentrionalis.

\section{A N Y C H I A.}

Herbulæ foliis oppositis, stipulosis. Flores minuti, folioso-fasciculati; singulo sessili, stipulaceo-bracteolato.

CAL. oblongus, connivens, 5-partitus ; laciniis oblongis, pone apicem subsaccatum acuminatis.

Cor. nulla.

Sтал. quinque (interdum et præsertim cultura pauciora) imo calyci inserta, eo breviora, laciniis opposita : filamenta setacea, erecta, distincta : antheræe subcordata.

Setx interpositx nullx. 
PENTANDRIA. MONOGYNIA. II

PIsT.ovarium subrotundum : stylus unicus: stiginata duo, oblonga, recurvata.

Fructus : capsula calyce involucrata, apice areolata, membranacea, non dehiscens, basi sub lapsu rupta semen dimittens.

SEr. unicum, subreniforme, laeve, ad fundum capsule adnexum filamentulo $\mathrm{e}$ sinu laterali descendente.

Genus affine Paronychice.

Dichoтомa. A. caule patulo, dichotome ramosissimo : foliis glabris, lanceolatis, erectis : stipulis floralibus calyci glabro sub requalibus.

Queria canadensis. Linn.

$O_{B S .}$ Caulis interdum erectus et parce ramosus; vegetioris vero plantæe constanter patule ramosissimus. Folia exsiccatione punctis prominulis conspersa. Stamina in planta sylvestri fere semper 5 : in culta srepe tantum duo.

HAB. in collibus calcariis Pensylvaniæ superioris et Kentucky.

meristoldes. A. humifusa, conferta, undique pubens : foliis oblongo-ovalibus, ciliatis, setula terminatis : laciniis calycis subulatis, acumine setaceo patuloque.

$H_{A B}$, in arenosis aridis Carolinæ septentrionalis.

ARCYROCOMa. A. cespitosa, procumbens: caulibus minutim puberulis : foliis linearibus, I. 
J4 PENTANDPIA. MONOGYNIA. acutissimis, subpilosis : capitulis fasciculato-terminalibus, argenteis : calycis pilosi apicibus barbatis et longius acuminatis.

Obs. Habitus Ilteceeri Paronychica, Linn.

$J I_{A B}$, in rupibus montium superioris Caroline.

$$
\text { G L A U X. } L \text {. }
$$

Cal. 1-phyllus. Cor. nulla. Caps. 1-locularis, 5-ralvis, 5-sperma.

\section{MARITHA. G L A U X.}

I.

$I_{A B}$, ad ripam affluente mare inundatam imi fluminis S. Laurentii

一. HO NOPETALA.

- - Fruciu folliculari.

A S C L E P I A S. L.

Contorta. Nectaria 5, ovata, concava, corniculum exserentia.

5. 1. Appendicibus corpusculo genttalifero SUBæQUALIBUS.

* Foliis oppositis.

SYRIACA $\beta$. $\Lambda$. caulibus simplicissimis; foliis lanL. ceolato-oblongis, sensim acutis, sub- 
PEXTANDRIA. MONOGINIA. II tus tomentosis : umbellis subnutantibus.

$O_{B S .}$ Uinbellæ etiam tomentosa.

$H_{A B}$. in pratis vastis Illinoensium.

obtusifolia. A. foliis arcte sessilibus, amplexicaulibus, oblongis, rotundato-obtusis, undulosis : umbella terminali, longius pedunculata, multiflora : corollis glabris; corniculis exertis.

$H_{A B}$, a Virginia ad Carolinam.

нувгіDA. A. caulibus simplicissimis, minutim tomentosis : foliis petiolatis, ovalibus, minutissime puberulis : umbellis aphyllis, terminalibus.

$O_{E S}$. Corollæ limbus et superna appendiculorum pars albent ; cxterum purpurascens.

A. variegata. Walt, nec Linnat.

$H_{A B}$. in Carolina.

incarnata. A. caule erecto, superne ramoso, I. tomentoso : foliis lanceolatis, utrinque subtomentoso-lannginosis : umbellis pluribus, origine geminatis : corniculis appendicum exertis.

OBS. Culta omnibus partibus minor : multo magis pubescit. Folia subsessilia.

$H_{A B}$. in pratis humidis Illinoensibus.

Amplexicn Ulis. A. totaglaberrima glaucaque: caulibus decumbentibus, simplicibus: foliis 
If6 PENTANDRIA. MONOGYNIA.

cordatis, amplexicaulibus, purpurco venosis : corniculis appenrlicum delites. centibus, compresso-ligulatis.

Afluis A. humistralce, WaLt.

$C_{B S}$. Umbella quasi e summis axillis et terminales. Corolla viridescens.

$H_{1} B$. in pascuis aridis, sabulosis, circa urbem $\mathrm{Sa}$ vannah, in Georgia.

Desilss. A.glaberrima: caule debili, erecto, simplici : foliis conspicue petiolatis, ovalilanceolatis, utrinque acutis, membranaceis : pedicellis capillaribus : floribus omnino albis.

$O_{B S}$. Folia interdum latius et quasi ventricose ovalia.

$H_{A B}$. in aquosis umbrosis Carolina.

** Foliis sparsis seu verticillatis.

verticillata. A. caule erecto, simplicissimo, li-

L. neatim puberulo : foliis angustissime linearibus, copiosis, strictis, glabris, plerisque verticillatis : corniculis appendicum promisse exertis.

$\boldsymbol{H}_{A B}$. in pratis Illinoensitus.

LONGIFolis. A. caule decumbente, minutim uti folia puberulo : foliis sparsis, prælongo- 
PENTANDRIA. TONOGYNIA. IT linearibus : appendicibus corollac corpusculo genitalifero brevioribus et cora niculo vacuis.

Affinis A. incarnatae? WALT.

$O_{B S}$. Folia interdum subverticillatim approximata.

$H_{A B}$. in sylvis Georgia occidentalibus.

S. it. Appendicieus corpusculo genitalifero

DUPLO AUT ULTRA ALTIORIBUS.

* Foliis sparsis.

tuberosa. A. caule erectiusculo, summitate diva-

$\boldsymbol{L}$. ricato-ramoso, hirsutissimo: foliis sparsis, lanceolatis, hirsutis : umbellis quasi in corymbum terminalem, patulum dispositis.

$O_{B S}$. Flores anrantiaco-crocei. Folliculi pubescentes.

Caules interdum subdecumbentes.

ß. datıl varietas in aridissimo solo hirsutior, foliis snblincaribus.

HAB. \&. ubique per (Etats-Unis).

$\beta$. in apricis sylvarum sabulosis Carolinx.

** Foliis opposttis.

IAURIfolia. A. caule erecto, glabro : foliis subsessilibus, ovali - lanceolatis, superne sensim angustatis, acutissimis, utrinque 

glabris; supra ad oras minutim asperiusculis : floribus purpureis.

Affinis A. amoence, LinN.

$O_{B S}$. Caulis interdum superne ramosus, et solito versus summitatem minutissime bifariam puberulus. Folia suprema angustins lanceolata. Corolla snbtus subviridescens, snpra pnrpurea : appendiccs purpurascentes. Forsan varietas sequentis?

H.1B. secus amnem Althamaha, in Georgia.

Paupercula. A. caule erectiusculo, glabro, oligophyllo, summitate promisse nudo: foliis longissime linearibus, glabriusculis, umbellis terminalibus, paucifloris.

A. lanceolata? W $\mathbf{\Lambda \mathbf { L T }}$.

$O_{B S}$. Corolla rubella : appendices lutei.

FIAB , in herbidis humidis Carolinæ inferioris.

Ancixa. A. caule simplici, bifariam puberulo: foliis subsessilibus, oblongo-ovalibus, subtus pubescentibus : umbellis termi. minalibus, erectis : petalis purpureis; appendicibus roseis, erectis, tripla genitalium longitudine

$O_{B S .}$. Habitus fere A. syriacae.

$H_{A B}$, in Pensylvania. 


\section{G O NOLOBUS.}

Cor. rotala, profunde 5-partita: Appendix brevissimus, iuclusus. Stylus discoirlco-5-gonns. Corpuscula pollinica subtrunsversa, propter brevitatem styli. Folliculi plerumque costati seu anšulosi. Caelera Vincetoxici seu Cynanchi, quibus valde affinis.-

Macrophrtus. G. sarmentis petiolisque brevihirsutulis : foliis amplis, abruptissime acuminatis, minutim puberulis; laciniis corolla ovali-lanceolatis : folliculis eos tato-angulosis.

Vincetoxicun gonocarpos. W VAtT.

$M I_{A B}$. in sylvis Carolinx.

mmsutus. G. sarmentis petiolisque hirsutissimis: foliis sensim acuminatis, utrinque corspicue pubeseentibess : lacinis corolle? oblongo-ovalibus, olitusis : folliculis. oblongis, sparsim muricatis.

VINcetoxicuM acanthocarpos. WALT.

$I I: B$. in sylvis Carolinx.

izvis. G. sarmentis glabriusculis : foliis quasi conoideo-cordatis, sensin acutis, nervis tantum minutissime puberulis : floribus glabris : corolle Iaciniis ovali-oblongis, obtusiusculis : folliculis lrvibus.

HAB. in dumetosis riparie Fluminis Mississipi. 


\section{G E L S E M I U M. Juss.}

Cal. 5-dentatus. Cor. infundibuliformis, limbo patente, 5 - lobo subæquali. Caps. compressoplana, 2-locul. 2-valvis; Semina plana, valvitlarum marginibus annexa.

nitidum. G. scandens, glaberrimum : foliis lanceolatis : fasciculis axillaribus, paucifloris : floribus luteis, suaveolentibus.

H $\triangle$ z . in Carolina inferiore, Georgia, Florida, Virginia maritima.

\section{E C H I T E S. $L$.}

Contorta. Folliculi 2, longi, recti. Sem. papposa.

Cor. infundibuliformis, fauce nuda.

puberula. E. foliis ovali-lanceolatis, basi acutis, promisse acuteque acuminatis, subtus minutim pubescentibus : floribus parvis, fasciculato-cory mbulosis.

E. difformis? WАLT.

$O_{B S .}$ Folia tenui - membranacca. Corymbulus pedunculatus ; floribus pusillis, obsolete lutescentibus. Folliculi graciles, semipedales et ultra.

$H_{A B}$, in sylvis Carolinæ inferioris. 


\section{A M S O N I A. WALT.}

Folliculi duo, erecti. Cor. infundibuliformis, fance clausa. Semina teretia, nuda, apicibus oblique truncatis.

LAtifolia. A. caule glabriusculo: foliis ovalilanceolatis, superioribus promisse acuminatis, subtus parce puberulis.

Tabernemontana Amsonia. Linn.

$O_{B S}$. Culta folia non ita acuminata, et subglabra.

$H_{A B}$. in umbrosis humidis sylvarum Carolinæ.

ANGUSTIFolia. A. caule conspicue pubescente: foliis angusto-linearibus, crebris, erectis, pubentibus.

Amsonia ciliata. Walt.

$O_{B S .}$ Florum dispositione coloreque a priore non differt.

$H_{A B}$, in sabulosis apricis Georgix.

\section{A P O C Y U M. $L$.}

Cor. campanulata. Filamenta 5, cum staminibus alterna.

androsammifolium. A. caule patentiusculo : foL. liis lato-ovalibus : pedunculis axillaribus et subcymoṣo-terminalibus, pa. 
tule ramosis, glabris : corollis limbo patentibus, roseis.

$H_{A B}$. in Virginia, Canada.

Cannabrnum. A. caule stricte erecto : foliis oblongo-

L. ovalibus, subtus candicanti-subtomentosis : paniculis multifloris, pubescentibus: corollis limbo erectis, subviridulopallentibus.

$I_{A B}$. in Canada.

-__* Fructu 1-loculari:

S I D E R X Y L O N. $L$.

Cor. 10-fida : laciniis alternis, incurvis. Stigma simplex. Bacca 5-sperma.

Vide Swartz Obs. $9^{1}$.

Lycroides. S. spinosum, erectum, foliis lato-

L. lanceolatis, utrinque glabris.

S. laeve. WALT.

$H_{A B}$. in sylvis utriusque Carolinæ:

REclinatum. S. spinosum, dumosum, diffuse reclinatum; ramis sterilibus divaricato-ramillosis : foliis parvulis, obovalibus, glaberrimis.

$H_{A B}$, in dumetosis ripariis Georgix.

rafugrosurr. S. spinosum : ramulis patentissimis, pubentibus : foliis ovali-lanceolatis, 
PENTANDRIA. MONOGYNIA. T23 supra glabris, subtus lanuginosis nec sericeis.

$O_{B S .}$ Sequenti affine.

$H_{A B}$ in dumosis humidis Georgix.

cmirsopHyllomts. S. spinosum : foliis cuneatolanceolatis, plerumque obtusis, subtus: sericeo-nitentibus.

S. tenax. Linv.

$I_{A B}$, in dumetis littoralibus Carolinæ.

D O D E C A T II E O N. $L$.

Cor. rotata, reflexa. Stam. tubo insidentia. Caps. 1-locularis, oblonga.

meadia. D. foliis oblongo-ovalibus, repando-

L. dentatis : unbellis.multifloris, laxis:bracteolis ovalibus.

$H_{A B}$, in Virginia.

intrgrifoliunr. D. foliis oblongo-ovalibus, sulbspathulatis, integerrimis : umbellis paucifloris, strictis : bracteolis linearibus.

Pluck. Alm. tab. 79. fig. 6.

$X_{A B}$. in montibus Alleghanis, juxtarivulos sylvaticos. 
Involucr. umbellulæ. Corollae tubus cylindricus: ore patulo.

sustassinica. P. pusilla, glabra : foliis ovalispathulatis, rariter subdentatis : scapo elongato ; umbella pauciflora : corolla limbo reflexo; laciniis cuneato-oblongis, obtuse 2 -fidis : capsula oblonga, exerta. HAB. ad lacus Mistassins Canadam inter et fretum Hudsonis.

\section{E N Y A N T H E S. $L$.}

Herbulæ aquatiles : folia alterna, subtus puncticulosa ; petiolo basi vaginante. Flores aut axillariter pedunculato - racemosi, aut fasciculatim e ragina petiolari erumpentes.

CAL. subcampanulatus, 5-partitus; laciniis appressis, oblongis : post anthesin connivens, laciniis lateraliter incumbentibus.

Cor. subcampanulata : tubus calyce brevior aut raro longior; limbus 5-partitus; margine attenuato, interdum fimbriato, ante expansionem introflexo; laciniis ovalibus vel oblongis, recurvo-patentibus, nonnunquam interne villosis: marcescens. 
PENTANDRIA. MONOGYNIA.

Aut minuti appendiculi, aut pilorum congeries tubo inter stamina solito adnascuntur.

Sтам. 5, laciniis corolle multo breviora, iis alterna, erecta : filamentis brevibus : antheris sagittato-oblongis, defloratione tortilibus.

PIst. ovarium disco tenuiusculo innatum, ovoideum; desinens in stylum nunc brevissimum, nunc longiusculum : stigma compressiuscule concavo-connivens, glandulari prominentia marginatum, plus minus bilobatum.

Capsula calyce persistente suffulta, ovoidea, stylo acuminata, gibbosa, I-locularis; in speciebus emersis 2-valvis, valvis medio placentiferis; in natantibus (uti solito fit) ruptilis.

Semra plurima, placentis binis opposite parietalibus puncto basilari adnexa, ad. medium cavitatis libere vergentia, planiuscule tumideve lenticularia, lucida, superficie, prasertim versus ambitum, minutis glandulis vesicularibus quasi scaberula, vel rarius pilis cylindrico-tubulosis ciliata.

TRIFOliata. M. assurgens : foliis trifoliolatis; foL. liolis ovalibus, subcrenato-repandis : racemo pedunculoso, subpyramidatim mul. 

tifloro : corolla tubulosa, intus villosissima : stylo longo.

$O_{B S .}$ Parvitate tantum ab Europæa differt. $H_{A B}$. in paludosis Canadic.

tracuysperma. M. habitu nymphoideo : foliorum ora minutim inæquabili : corolla glabra; laciniis integris; appendiculis tubi prominentibus : stylo subnullo : seminibus vesiculis ovatulo-oblongis conspicue scabris.

Villarsia aquatica. Gmel. Syst. $44 \%$. HAB. in aquis Carolinæ inferioris.

\section{Y S I M A C II I A. $L$.}

Vid. Pluck. t. 428. f. 3. et 454. f. 1. 2.

Cor. rotata. Caps. globosa, mucronata, 10-valvis.

\section{* Foliis non punctatis.}

cilita. L. foliis oppositis, longiuscule petioL. latis, subcordato-ovalibus, margine puberulis; petiolo cilioso : pedicellis subgeminis : floribus cernuis : corolla laciniis rolundatis, acuminatis, crenulatis. $H_{A B}$. in New-Yorck et Connecticut.

hyBrind. I. glabra : foliis oppositis, longe petiolatis, lanceolatis, basi sensim acutis; 
PENTANDRIA. HONOGYNIA. 127 petiolo ciliolato : floribus cernuis : $\mathrm{co-}$ rolla laciniis crenulatis.

$\mathrm{O}_{B s .}$ Affinis L. ciliatae.

$H_{\triangle B}$. in Carolina.

HETEROPHYLLA. L. gracilis, glabra : foliis oppositis; imis suborbiculatis et brevi-petio. latis; superioribus linearibus, sessilibus, basi ciliolatis : floribus cernuis.

$O_{B S}$. Flores omnino Lysimachi

Plucr. mantiss. t. 333. fig. I. Affinis.

$I_{A B}$. in Georgia.

** Foliis subtus colorato-puncticulosis.

minsuta. L. caule hirsuto : foliis subsessilibus, plerumque quaternis; ovalibus, cons. picue acuminatis, puberulis, puncticu. losis; pedunculis etiam quaternis; corolla laciniis ovalibus, integris.

L. quadrifolia? Linn.

$O_{B S}$. Folia interdum opposita, nonnunquam terna vel quina : raro ovali-lanceolata.

HAB. in Carolina.

THYPSIFLora? L. glabra : caule simplicissimo, L. punctato : foliis oppositis, sessilibus, latiuscule lanceolatis, acutis, puncticulosis : racemis lateralibus, longiuscule pedunculatis : floribus parvis, subcapitatis.

II.1B. in New? Yurck. 
Axgustifolia. L. glaberrima, ramulosa : foliis oppositis passimque verticillatis, longolinearibus, puncticulosis : racemo caulem terminante, brevi; laciniis corolla rotatie oblongis.

$O_{B s}$. L. stricta ? Aıт. Flores parvuli, lutei.

$H_{A B}$. in Carolina inferiore.

racemosa. L. glaberrima, elata : foliis ovali-lanceolatis, oppositis, puncticulosis : racemo terminali, longissimo, laxe multifloro.

$O_{B S}$. Racemus e pedicellis 1-floris, longiusculis, modo subverticillatis, modo alternis; bracteis lanceolatis. Corolla lutea, rotata; laciniis oblongoovalibus.

Vid. Pluck. t. 428. fig. 4.

$H_{A B}$, in New-Yorck.

__*** Fructu quasi gymnotetraspermo. H E L I O T R O P I U M. $L$.

Cor. hypocrateriformis 5-fida, interjectis dentibus: fauce nuda.

INDICUM. II. annum, erectum, hispidum : foL. liis ovalibus, in petiolum angustatis, asperis : spicis solitariis, fructiferis virgatis : fructibus bifidis.

HAB. in Carolinæ monte calcario, ad fontem Youta dictum. 


\section{Y O S O T I S. $L$.}

Cor. hypocrateriformis, 5-fida, emarginata : fauce clausa fornicibus.

scorproides. M. pumila, undique canescenti-hira. $L$. suta, cespitose multicaulis, procumbens : foliis subspathulato-oblongis : seminibus inclusis, lævibus.

$H_{A B}$. in Pensylvania.

LAPpULA. M. caule erecto, inferne simplici : foliis

I. lanceolato-oblongis, obtusiusculis, pilosis : ramis floriferis terminalibus, subco. rymbosis : fructibus erectis, echinatis, pilis glochidibus.

HAB. in muris urbis Canadensis IMontreal.

VIRGINIANa. M. caule erecto, divaricato, pubes$\boldsymbol{L}$. cente : foliis ovali-lanceolatis : fructibus cernuis, echinatis, pilis glochidibus.

$U_{B S}$. Flores albi.

H.AB. in apricis Virginia et Kentuckr.

$$
\text { B A T S C H I A. GMer. }
$$

$\mathrm{C}_{\mathrm{AL}}$. profunde 5-partitus; lacinïs erectis, linearibus, acutis : solito pilosus.

Con. hypocrateriformis : tubus rectus, calyce longior, intus ad imam basim annulo barbato cinctus : faux nuda : lim. 
bus orbiculatus, 5-partitus; laciniis ro. tundatis.

Stam. 5, inclusa : antheræ infra faucem. subsessiles, erectre, ovata.

PIst. ovarium subrotundo-tetra-gastrum : stylus capillaris, altitudine staminum: stigma minutum, emarginato-bilobum.

Fructus Lithospermi.

OBs. An congener Lithospermum orientale. Lins?

Gmelini. B. caule foliis calycibusque hirsutis: foliis caulinis oblongis, floralibus ovatis; calycibus longis, sublanceolatis.

$H_{A B}$. in aridis sylvis Carolinæ inferioris.

canescens. B. caule foliis presertimque summitatibus molliter candicanti-villosissimis : tab. 14. foliis omnibus oblongis : calycibus brevissimis.

$H_{A B}$, in collibus sylvaticis Temnassée.

\section{I T H S P E R M U M. L.}

Cor. infundibuliformis, fauce perforata, nuda. Cal. 5-partitus.

AĨGUSTIFolium. L. pumilum, procumbens : foliis angusto-linearibus, brevi appressaque pube confertim vestitis : floribus passim lateralibus : seminibus turgide ovatis, 
Tom. z. Pag. 130.

Tab. 14

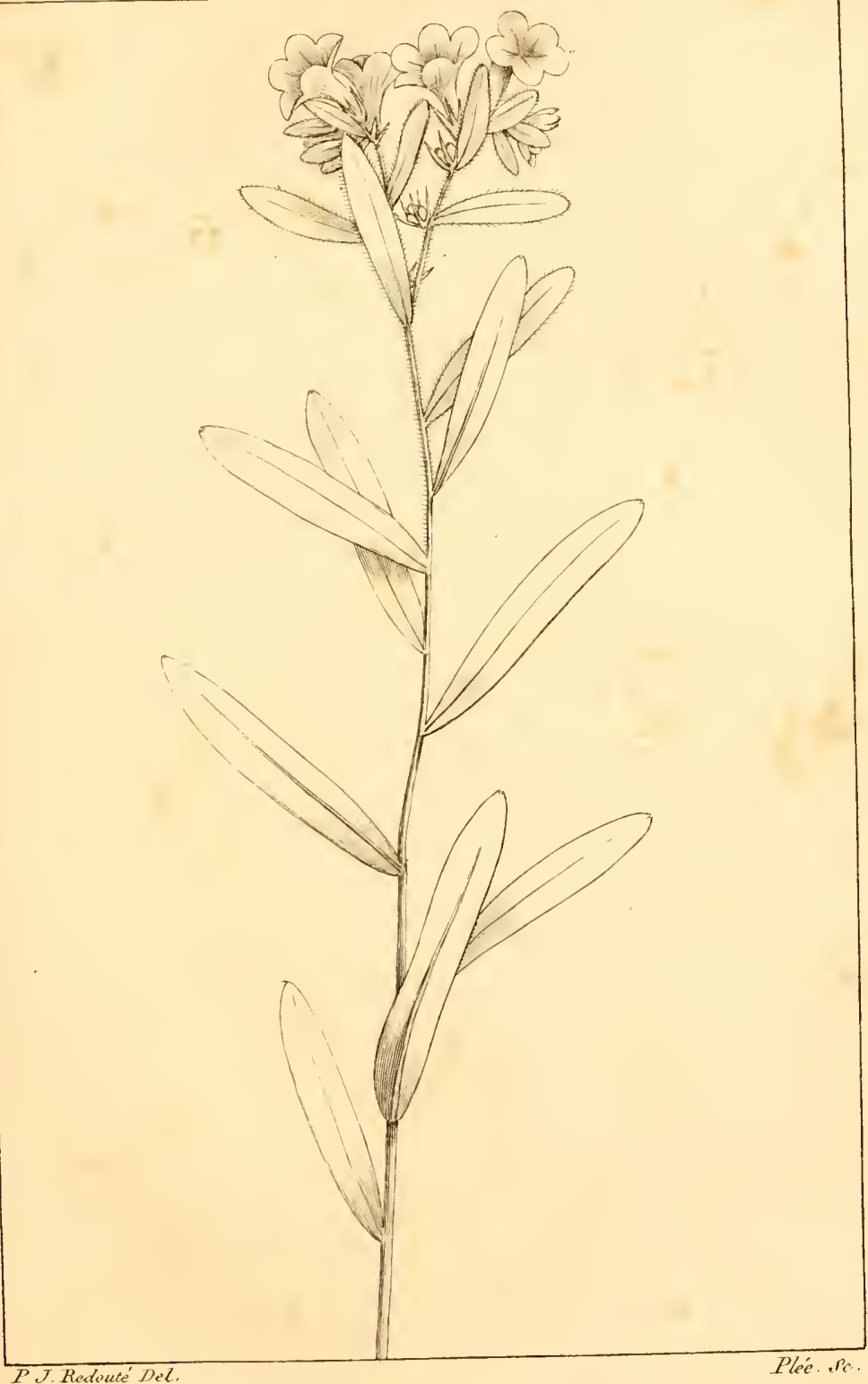

Bitscula canercerner. 

PENTANDRIA. HONOGYNA. Y3I nitidis, undique crebroque cavo-punctatis.

HAB. ad flumen Ohio.

xatifolium. L. foliis lato-ovalibus, nervosis; supra glabriusculis, viridibus et asperis: calycibus fructiferis patulis : seminibus turgide ovatis, lucidis, undique cavopunctatis.

$O_{B S \text {. Affinis L. officinali. Lixn. }}$

$H_{A B}$ in umbrosis sylvis Kentucky.

\section{P U L M O N R I A. L.}

Cor. infundibuliformis, fauce pervia. Cal. prismatico-5-gonus.

virginica. P. erecta, glabra : foliis omnibus ova-

L. libus : fasciculis florum ad summitatem et subpaniculato-terminalibus : corollæe tubo calyce multoties longiore; limbo subintegro.

$O_{B S}$. Folia superiora ramusculis floriferis singulatim innata et inde quasi petiolata.

$H_{A B}$. ad ripas arenosas fluviorum Carolinæ occidentalis et Virginix.

parvirlora. P. glaberrima : caule diffuse procumbente, ramosissimo : foliis ovalispathulatis, minutim acuteque acumi- 
\$32 PENTANDRTA. IONOGYN゙A.

natis, carnosis : pedunculis lateralibus, unifloris : corolla vix dupla calycis brevis longitudine, subcampanulata.

$H_{A B}$ ad littora mari ascendente inundata imi fluminis $S$. Laurentii.

\section{Y N O L O S S U M. L.}

Cor. infundibuliformis, fauce clausa fornicibus. Semina depressa, interiore tantum latere stylo affixa.

AMplexicaule. C. erectum, totum hirsutissimum : foliis ovali-oblongis; superioribus quasi perfoliatim amplexicaulibus : corymbo terminali, longe pedunculato, aphyllo: fructibus obovatis.

HAB. in montibus Alléghanis.

\section{O N O S O D I U M.}

Ilerbæ folïs nerrosis, nervis sublongitudinalibus.

CAL. profunde 5-partitus : laciniis erectis, angusto-linearibus.

Cor. oblongiuscule subcampanulata; fauce nuda : limbo ventricoso, semi-5-fido; laciniis erecto-conniventibus, subsemilanceolatis, acutis; harum et incisurarum margine inflexo. 

Tom 1. Parg, 1.3.3.

Tab.15.

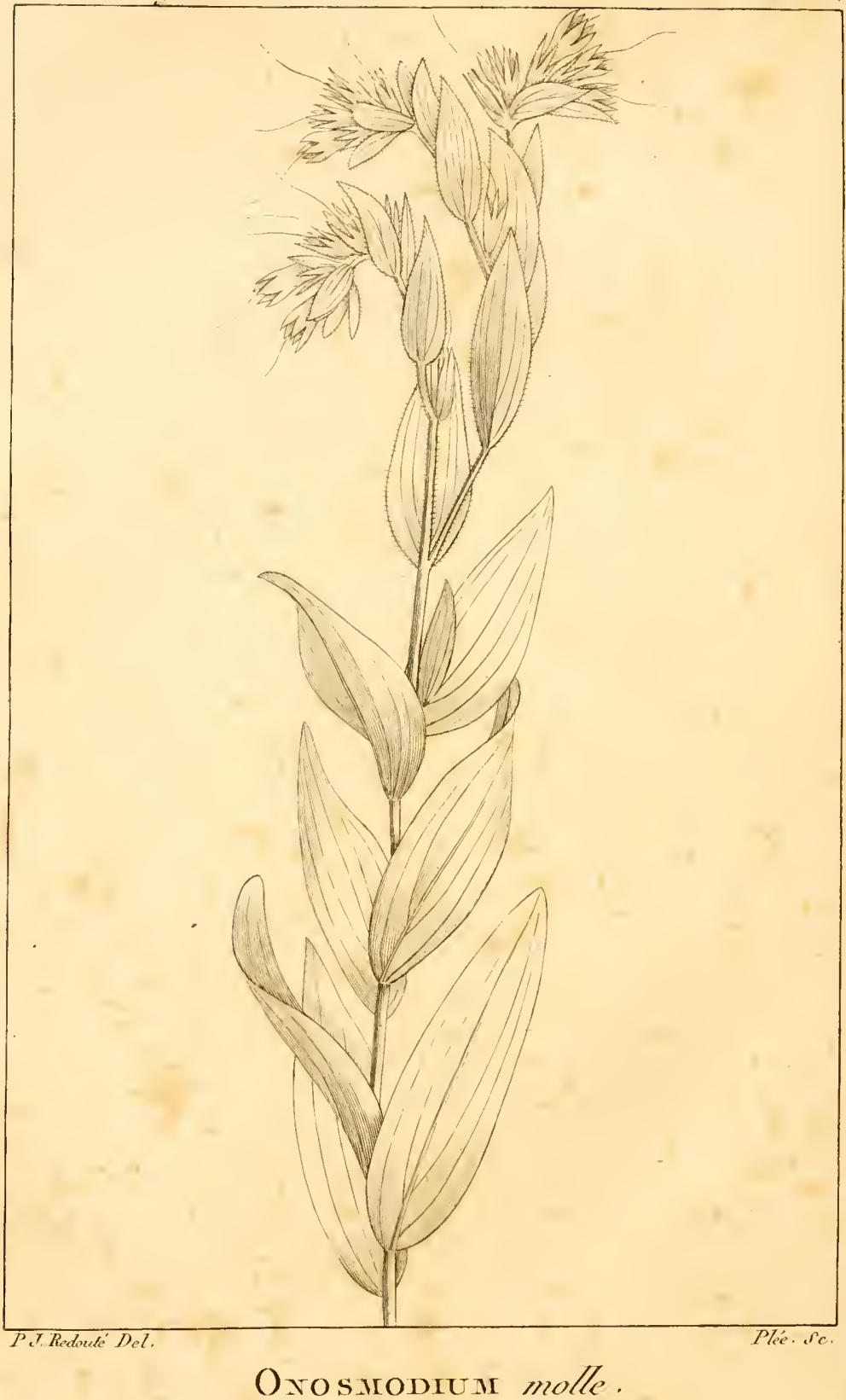


PENTANDRIA. IT NOGYNIA. I33

Sтмm. antheræ sessiles, inclusæ, sagittatæ, acutæ.

Pist. Onosma; stylo promisse exerto.

OBs. Genus affine Oxosme : differt corolla multo breviore; limbo profundius et acute diviso, connivcnte : antheris sessilibus nec ita mucronalis.

urspour. O. omnibus partibus hispidum : foliis obovali-lanceolatis, acutis, supra a papillis piliferis manifeste puncticulosis: laciniis corolla quasi subulato-acutissimis.

Litiospermum virginianum. Line.

IIAB. in Virginia.

MoLLE. O..molliter candicanti-viliosum: foliis oblongo-ovalibus, subtriplinerviis, fere tab. 15. tomentosis : corolla laciniis subovalibus.

$H_{A B}$. in Tennassée, circa Nashville.

___*** Fructu pluriloculari.

H Y D R O P H Y L L U M. $L$.

Cor. companulata, interne striis 5 melliferis longiludiualibus. Stignna 2-fidum. Caps. globosa, 2-valvis.

caranense. L. glabriusculum : foliis lobato-angulosis : fasciculis florum confertis. $H_{A B}$, in sylvis nmbrosis, humidis Canadæ, montiun Alléshanis, \&c. 
I34 PENTANDRIA. MONOGYNIA.

vingivicum. If. foliis pinnatifidis aut etiam pin-

L. natis; laciniis ovali-lanceolatis, incisoserratis : fasciculis florum conglomeratis.

HAB. in sylvis montanis Canadx, Virginia, Alléghanis, \&c.

appendorcutur. H. undique hirsutissimum : foliis radicalibus subpinnatifidis, caulinis sublobato-angulosis : fasciculis florum subpaniculatis : calycis sinubus in totidem appendiculos reflexis.

$O_{B S .}$. Corolla cerulescens : calycis sinus, nonnullarum Campanularum instar, reflexi et in appendiculum. ovalem protracti.

$H_{A} \dot{B}$, in sylvis montanis Tennassée.

\section{P II A C E L I A. Juss.}

Cal. 5-partitus. Cor. subcampannlata 5-fida. Stam. exserta. Styl. brevis. Caps. 2-locul. 4-sperma, 2-valvis, valvis in singulo semiloculo 1-spermis.

mipinnatifida. P. erecta : foliis pinnatifidis; laciniis inciso-lobatis : spicis plerumque tab. 16. bifidis, oblongis, multifloris : corollx coerulex lobis margine simpliciusculis. HAB. in sylvis occidentalibus montium Alléglanis et Kentucky.

mimbriata. P. procumbenti-assurgens : foliis pinnatifidis; laciniis indivisis : spica solitaria, 
Torn.1. Pag. 137.

Tab. 16.

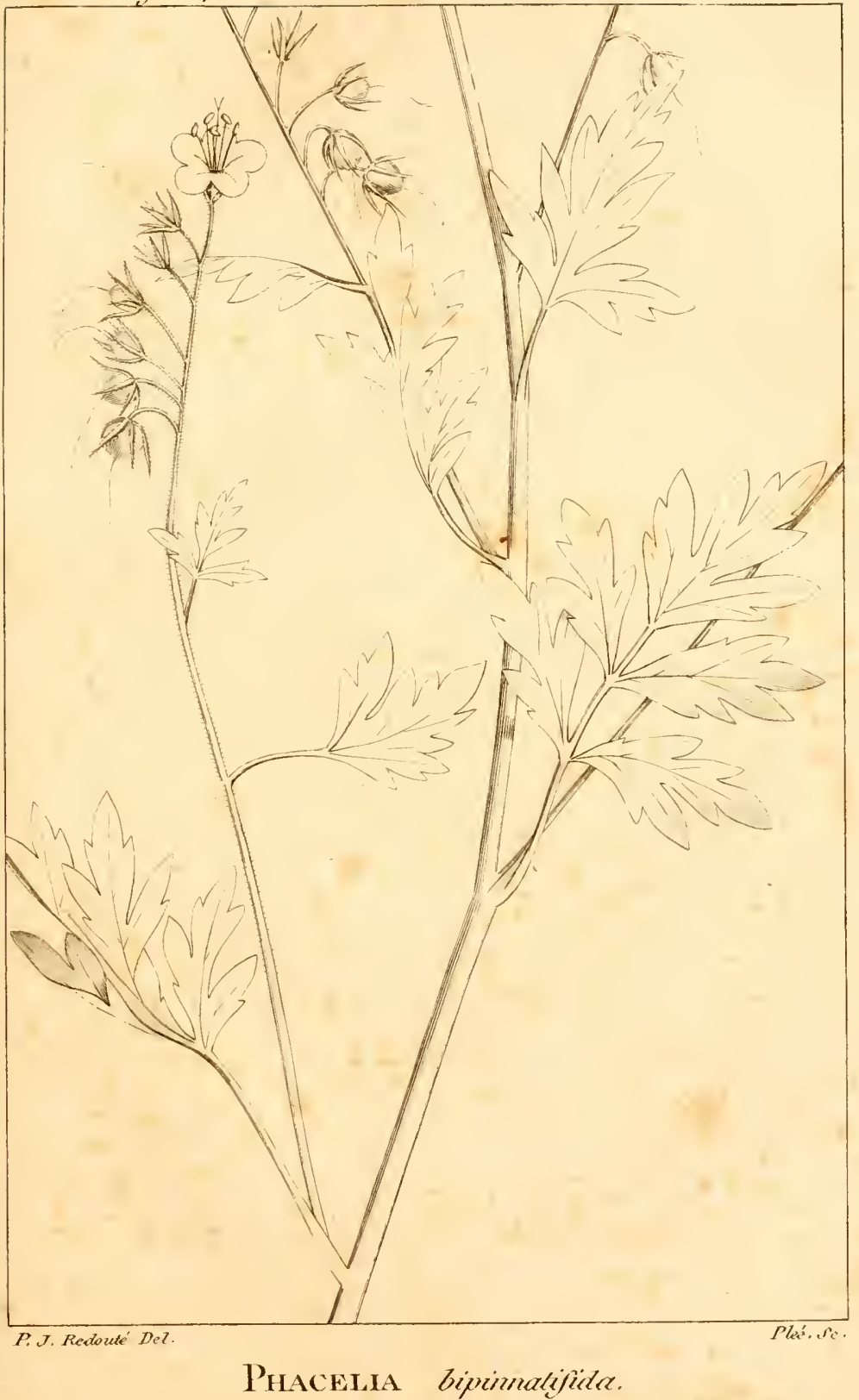



PENTANDRIA. MONOGYNIA. 135 brevi : corolla alba; lobis margine ciliato. fimbriatis.

Pluck. t. 245. fig. 5.

$H_{A B}$, in excelsis montibus Carolinæ.

\section{I G H O N D R A. ForsT.}

Herbula perennes, repentes. Folia alterna.

Pedunculi 1-flori : flos pusillus, cernuus,

Caz.quasicampanulatus, 5-partitus: laciniis subspathulato-oblongis, primum latere incumbentibus.

Cor. calyci subæqualis, abbreviato-campanulata, 5-partita : laciniis ovalibus, patulis, tubo longioribus.

- sub disco hypogyno inserta.

Staм. corolla alterna, paulo breviora, erecta : filamenta subulata : antherx bre. viter cordato-ovate, scaberula. - paulo infra incisuras corollix inserta.

Pist. ovarium disco suborbiculato innatum, subrotundo - bipartitum : stylus ex fundo illius incisure, profunde bipar. titus : stigmata 2, peltato-capitata, glanduloso-scaberula.

CAps. calyce ampliore et eodem compressopatentiore involucrata, bipartito-didyma, bilocularis; septo loculis globosis multo breviore et iis decidentibus persistente. 
SEar. in singulis loculis unicum, sphæroideum, fundo immediate adnexum; te. gumine proprio durissimo et subcorneo.

-Embryo majusculus; pauca materie subcorneo-farinacea involutus : radicula infera : cotyledonibus contortuplicatis; intermissis hic et illic materiei supra dicta processibus.

OBS. Genus convolvulaceum! Evolvulo conterminum.

canozinensis. D. omnibus partibus minute pubens : foliis absque emarginatura reniformibus, utrinque viridibus : calycibus villoso-ciliatis.

Deminofia repens. Gmer. syst. 458.

$H_{A B}$. in Carolina, circa Charlstown, \&c.

$$
\text { C O N V L V U L US. L. }
$$

Cor. campanulata, plicata. Stigmata 2. Caps. 2-locularis : loculis 2-spermis.

STans. C. erectus, totus candicanti-subtomentosus : foliis brevi-petiolatis, subcordato-ovalibus : pedunculis I-floris : calyce inter bracteas multoties ampliores delitescente; laciniis lanceolatis, muticis.

Affinis C. spithamaeo, Walt.

$O_{B S}$. Corolla alba, oblongo-campanulata. Stigmata oblonga.

IIAB. juxta lacum Champlain, Canadx. 
PENTANDRIA. MONOGYNIA. 137 trichosanthes. C. humifusus pubens : foliis lanceolato-oblongis, cum setula obtusis : pedunculis longis, fasciculatim I-5-floris: corolla brevi - campanulata, indivisa, pilosa : stylo bipartito.

C. humistratus et aquaticus. Wa tт.

$O_{B S}$. Variat foliis angustioribus et latioribus; pubentibus et tomentosis : pedunculis $1-5$-floris : calyce glabro et pubescente.

Corolla alba, margine quasi remote 1o-denticnJato. Stylus profunde bipartitus. Capsula ovoidea, pubescens.

$H_{A B}$. in sabnlosis sylvaticis Carolinæ.

cinionarus. C. volubilis, glaber : foliis eximie cordatis, glabris, margine subciliatis: pedunculis longiusculis, I-floris : calycis ebracteati laciniis lato-ovalibus, obtusis : corolla ampla, tubulato-campanulata, alba: stignatibus subglobosis.

$H_{A B}$. circa urbem Knoxville, in Tennassée.

REPENS. C. subrepenti - prostratus, minutim

L. puberulus : foliis subsagittatim ovali-cordatis; sinu angusto; auriculis brevibus, quasi truncatis : pedunculis longiusenlis, $\mathrm{y}$-floris : calycis bibracteati laciniis oblongis.

$O_{B S .}$. Corolla alba, roseo ad ambitum suffusa. Bractere mar,rine purpurascentes, puberulæ, sensim acuninate.

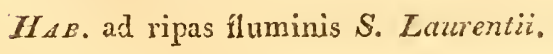


138 PENTANDPIA. WONOGYNTA.

sagrtrfolius. C. volubilis, glaberrimus : foliis profundissimo sinu oblongo-sagittatis; auriculis subacuminatis : pedunculis uncialibus, $\mathrm{r}$-floris : calycis brévis laciniis rotundato-ovalibus : corolla ampla-, infundibuliformi-campanulata, rosea.

C. speciosus? WALT.

Puuck. t. 85. f. 3 .

phindratus. C. radice crasse napacea; caule vo$L_{\eta} \quad$ lubili, puberulo : foliis pubescentibus, lato-cordatis, rarius subtrilobis repandisve : pedunculis longis, fasciculifloris: calycibus glabris, submuticis : corolla tubulato-campanulata.

$O_{B S .}$ Planta junior subtomentosa. Flores breviter pedicellati : bracteæ calycinæ nullæ: corolla $C$. serizum, alba ; fundo purpureo. Stigmata brevia.

$I_{A B}$. in Virginia et Carolina.

Batatas. C. radice tuberosa : repens : foliis

L. glabriusculis, lato-cordatis sinu lato parumque profundo, modo hastatis, modo variabiliter anguloso-lobatis : pedunculis longis, fasciculato-plurifioris; pedicellis brevibus : calycis glabri laciniis lanceolatis, acuminatis : corolla campanulata.

HAB. in Carolina, cultus. 
PENTANDRIA. MONOGYNTA. I 39

Nru. C. caule volubili, hïrsuto : foliis ven-

I. tricoso-trilobis : pedunculis brevibus, $\mathbf{I}$-2-floris : bracteis subulatis : calycibus villosissimis, longissime acuminatis.

$H_{A B}$. in Carolina, circa hortos et agros.

carourvus. C. caule volubili, glabriusculo : foL. liis glabellis, profunde sublanceolato-3lobis : pedunculis sub2-floris : calycis laciniis ovali-lanceolatis, parce pilosis ciliatisque : corolla breviuscula : capsula pilosa.

$H_{A B}$. in sepibus Carolinæ. $\odot$.

ontusilonus. C. prostratus, glaber : foliis crassis, profundiuscule sinuato-lobatis; lobis rotundato-obtusis, impari multo majore, obovali, emarginato: pedunculis I-floris: calycis ebracteati laciniis oblongo-ovalibus, submuticis : corolla brevi-campanulata.

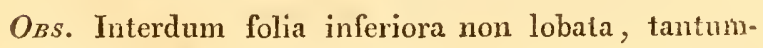
modo pluts minus repanda.

$H_{A B}$, in littoribus arenosis Georgix et Floridx.

Drssectus. C. volubilis : caule et prosertim peL. tiolis imisque pedunculis pilosissimis: foliis glabris, 7-partito-palmatis; laciniis sinuato-lobatis : pedunculis I-floris: 
I to PENTANDRIA. MONOGYNTA.

calycis glabri laciniis lato-ovalibus, mu-

ticis : corolla campanulata, aba.

$I_{A B}$. in collibus calcariis Floridæ.

\section{P O M OE $\Lambda . L$.}

Cor. infundibulif. Stigma capitato-globosum.

Caps. 5-locularis.

coccrnea. I. puberula : foliis cordatis, promisse

$x$. acuminatis, ima parte interdum subangulatis : pedunculis sub5-floris : calyce verruculoso, aristato : limbo corollæ tubulosæ subintegro.

$H_{A B}$. in Carolina, ad ripas fluminis Mississipi, \&c.

LAcunosa. I. glabra : foliis cordatis, inferne obs-

$L$. cure repandis, aut rarius angulatis : pedunculis brevibus, subi-floris : calyce piloso et ciliato : corolla parva, brevi: capsula pilosa.

Alfuis $I$. trilobae. LinN.

$H_{A B}$, in Florida et Carolina.

Bona nox. I. glaberrima : caule sarmentoso,

L. passim scabrato : foliis lato-cordatis, integris seu diverse angulosis; pedunculis I-3-floris : calyce aristato : corolla maxima, alba; tnbo anguste longissimo, virescente, fasciis limbi concoloribus.

$\not I_{A B}$. in sylvis ripariis Floridx. 
PENTANDRIA. HONOGYN:A. I 4 maCRonHza. I. radice crassissima : foliis subtus tomentosis, cordatis, simplicibus lobatisque, plicatis : pedunculis subunifloris: calyce foliolis ovalibus, muticis : corolla alba, grandi : seminibus prolixe lanuginosis.

IL.1B. in maritimis Georgix et Floridx.

\section{P O M O P S I S.}

CAL. oblongo - campanulatus, subsemijfidus : laciniis erectis, subulatis.

Cor. subinfundibuliformi - tubulosa : linebus patens, 5-partitus; laciniis suboralibus.

Sram. inæquali longitudine.

Pist. ovarium oblongum, obtusissimum, 3-sulcatum : stylus subtripla longitudine, erectus : stigma tripartitum; lacinulis longo-linearibus, recurvo-patulis.

CAps. calyce subbrevior, ovata, obtusissima, convexo-trigona, parte styli mucronata.

SEM. in singulis loculis pauciuscula, duplici serie, inæqualiter et oblongiuscule cubica : angulis subprominulis; medio faciei interna adnexa.

Ozs. Genus a Cantua preprimis fructu discrepans. 
I42 PENTANDRIA. MONOGYNIA.

refgans. I. minutim pubescens : foliis linearipinnatifidis.

Iromea rubra. Linn.

CaNTUa coronopifolia. WiLld. spec. 879 .

HAB. in Carolina.

P O L E M O N I U M. $L$.

Cor. 5-partita, fundo clauso valvis staminiferis.

Stigma 3-fidum. Caps.3-locularis, supera.

Reptans. P. foliis pinnatis, septenis, floribus ter-

L. minalibus, nutantibus. $\boldsymbol{L}$.

$O_{B S}$. Variat floribus albis.

$H_{A B}$. in montibus Virginix.

\section{P H L O X. L.}

Cor. hypocrateriformis. Filamenta inæqualia. Stigma

5-fidum. Cal. prismaticus. Caps. 3-locularis, 1-sperma.

gLaderrima. P. cespitosa, assurgens, glabra :

L. foliis lineari-lanceolatis, lrvibus : fasciculis confertifloris subfastigiato - corymbosis : calycibus submuticis.

OBS. Icon Dillexir a Linn zo citata non quadrat.

IIAB. in subhumidis Carolinx inferioris et ultramontanis occidentalibus. 
PENTANDRIA. MONOGYNIA. I43

TrIflona. P. caulibus erectis, puberulis : foliis lanceolatis, glabris : corymborum ra. millis sub3-floris : calyce glabro, dentibus linearibus.

$O_{B S}$. Humilis : folia sensim acuta : rami elongati, laxiuscule corymbosi, ramulis 3-5-floris, sed plerisque 3 -floris. Calyx viridulus : corolla purpurascens, magnitudine figuraque $\boldsymbol{P}$. suaveolentis. IIAB. in Carolina superiore.

IAtrolia. P. erecta, glabra : caule levi : foliis quasi cordato-ovalibus : floribus fastigiato-corymbosis : calycis dentibus lanceolatis, vix acuminatis : corolla majuscula et purpurea laciniis suborbiculatis.

OBs. Affine $P$. carolinae. Folia sæpe alterna.

$H_{A B}$. in unbrosis humidis et solito sphagnosis sylvarum Carolinæ.

Maculata. P. canlibus erectis, pulverulento - as-

L. periusculis : foliis lanceolatis, glabris, margine reasperis : panicula oblonge confertimque multiflora; calycibus muticis.

Var. $\alpha$. purpurea : caulibus purpureis, pallido-guttulatis : corollis amone purpureis, mox ad violaceum vergentibus.

Var. $\beta$. candida : caulibus inmaculatis, - minus elatis : corollis candidis.

l’. suaveolens. Art.

Obs. Affinis PuUck. t. 425. f. 6.

Has. in Virginia, Carolina. 
J44 PENTANDRIA. MONOGYNIA.

paniculats. P. caule prealto, firmo, lævi : fo-

L. liis undulosis, subrhomboideo-lanceolatis, margine asperis : panicula composita, pyramidato-brachiata : calycibus aristatis.

HAB. in Carolina superiore.

aristata. P. viscidulo-pubescens : foliis sublinearibus : panicula e racemis laxis et subgeminifloris fastigiata : aristis calycinis longissimis.

$O_{B S}$. Debilis, erecta : folia a basi ad apicem sensim angustata : pedicelli plerumque gemini : corollæ laciniæ oblongiuscule obovales.

Var. $\propto$. virens : corolla roseo-purpurascente.

Var. $\beta$. canescens : corolla albidorosea.

H.AB. a. in Carolina, ad ripas amnis Santée.

$\beta$. in Tennassée, circa Knoxville.

divaricata. P. humilis, decumbens, pubescens:

$\boldsymbol{L}$. foliis ovali-lanceolatis, plerisque alternis: ramulis paucifloris, subdivaricatim laxis: calycibus subulato-linearibus : corollæ laciniis subobcordatis.

$O_{B S .}$ Folia non acuminata : ramuli floriferi pauciores: corolla coerulescens.

Variat foliis lato-subcordatis.

H.AB. in montibus Virginix. 
PENTANDRIA. IIONOGTN1A. I4

\$ILosa. P. humilis, decumbens, pubescens:

L. foliis lanceolatis, asperiusculis : sum. mitatibus subsessiliter fasciculifloris : calycibus subulato - acuminatis : corolla laciniis rotundato-obtusis.

$O_{B S}$. Corolla dilute purpurascens.

XTAB. in montanis Georgia occidentalibus.

subulata. P. pusilla, cespitosa, candicanti-per

L. bens : foliis fasciculatis, subulatis, pun. gentibus, ciliatis : pedicellis paucis, ter" minalibus.

$O_{B s .}$ Dense crspitosn; caulibus primariis repentibns, floriferis assurgentibus : calycis dentibus setaccosubnlatis: corolla majuscula, carnea; laciniis cuneatis, emarginatis.

$H_{A B}$. in aridis sabulosis Carolinx.

תertars. P. reptanti-stolonifera, pubescens; caulibus fertilibus erectis, simplicibus, oligophyllis : foliis radicalibus et stotonicis obovalibus; caulinis ovali-lanceolatis : corymbulo paucifloro.

OBS. Planta pulchella, liabitu quodanmodo Beictons: flores inter congencres maximi : corolla amoene coerulca; laciniis suborbiculato-obovalibus : calycis dentibus sctaceo-subulatis.

IIAB, in excelsis montibus Carolinx occidentalis. 
I 40 PENTANDRIA. IONOGYNI\%

$$
\text { C II I R O N I A. L. }
$$

Cor. rotata. Pistillum declinatum. Stam. tubo corolla insidentia. Antherae denum spirales. Pericarpium 2-loculitre.

gracilis. C. debilis : ramis laxis, setaceo-clongatis, I-floris : foliis lineari-setaceis : calyce setacco, corollæ subrquali.

C. campanulata? Liss.

OEs. Caules debiles, subdecumbentes : folia inferiora linearia, snperiora setacea : corolla rosea, laciniis obovalibus.

$\not I A E$. in Carolina inferiore.

PANiculata. C. Emmiter erecta : foliis lanceolatolinearibus : panicula multiflora, brachiata, subfastigiata : calyce subulato, corolla semibreviore.

$O_{B S}$. Canlis lineis 4 prominulis quasi quadrangulns: folia inferiora interdum ovali-lanceolata; suprema subulato-setacea. Corolle lacinia oblongre.

$I_{A B}$. in Georgia et Carolina.

Angulanis. C. caule erccto, marginato-quadran-

L. gulo : foliis amplexicaulibus : corymbo multifloro : calyce brevi; laciniis lanceolato-linearibus.

$O_{B S}$. Caules stricte erecti : corymbulus strictus : calyx corolla phus dimidio brevior. Corolla rosea, lacisiis ubovaiions. 
PENTANDRIA. MLNOGYNZA. I4́7 Var, a. latifolia : foliis brevibus, ovalibus seu etian suborbiculato-cordatis.

- B. angustifolia : foliis quasi lanceolatis; supremis etiam linearibus.

ItaB. in uliginosis sabrlosis Carolinæ inferioris.

carrcosa. C. folie oblongo-obovalibus : foribus solitariis, subz-partitis: calyce foliaceo, corollam superante.

C. dichoiona? WaLT.

Uns. Erecta, foliosa; foliis deorsum angustatis. Calyz involncriformis; laciniis lato-oblanceolatis. Corolla dilute rosea; laciniis obovalibus.

$H_{A B}$. in Carolina inferiore.

chlorordes. C. caule lavi : foliis lanceolatis, erectis : ramis paucioribus, I-floris : floribus 7-13-partitis, amplioribus.

Chrorei dodecandra. Lins.

OBS. Canlis ảebilis aut subdecumbens. Calyx corolla brevior; laciniis linearibus : corolla rosea ; laciniis oblongis.

HAB. in Noveboraco et Nova Cresarca.

$$
\text { S P I G E L I A. } L \text {. }
$$

Cor. infundibutif. Caps. didyma, 2-locularis, polysperma.

marilandica. S. perennis; canlibus simplicis- 
I4S PENTANDRIA. ATONOGYNTA.

simis : foliis omnibus oppositis, sessilibus, lanceolato-ovalibus.

IIAE. in Virginia, Marilandia, Carolina.

\section{O P H I O R R II I Z A. L.}

Cor. infundibuliformis. Ovarium 2 -fidum.

Stigmaia 2. Fructus 2-lobus.

Mitreola. O. caule acutangulo : foliis sessilibus:

L. cyma longius pedunculata.

Суnостолum sessilifolizm. Gmet. syst. 443.

Ors. Crnoctonum petiolatum ejusdem, videtur varietas foliis basi angustatis, nec vere petiolatis.

ILAB. in agrestibus, pascuis Carolinæ inferioris.

\section{VER B A S C U M. L.}

Cor. rotata, subinæqualis. Caps. 1-locularis, 2-valvis.

Blattaria. V. foliis amplexicaulibus, oblongis, L. glabris, peciunculis solitariis. $I_{A B}$. in Virgimia.

Chaytoñr. V. glabrum : caule simpliciusculo: foliis caulinis sublanceolato-oblongis, inciso-crenatis, crenis crenulatis : spica blattarina.

FAB. in Carolina. 
PEYTANDRIA. MONOGYNIA. I P II Y S $\Lambda$ L IS. L.

Cor. rotata. Stamina conniventia. Bacca intra calycem inflatum, 2-locularis.

riscosa? P. herbacea, conspicue confertimque L. pubescens : foliis subcordato-ovalibus, leviter repandis, pruinoso-puberulis: calycibus fructiferis pubescentibus.

$O_{B S}$. Affinis DiLx. Elth. t. 10.

HAB. in Carolina.

obscura. P. herbacea, divaricato-ramosissima; foliis quasi cordato-suborbiculatis, acuminatis, inequaliter dentatis; corolla flava, maculis fuscis : antheris coerulescentibus.

Var a.glabra : summitatibus et petiolis vix perecp. bili pube.

— B. viscido-pubescens.

$O_{B S}$. Affinis P. pruinosae.

$I I_{A B}$, in Carolina.

Latceorata. P. perennis, pumila, pubescens: foliis subsessilibus, ovali - lanceolatis, subintegris : calyce villoso.

$O_{B S}$. Caulis dichotomus. Folia gemina, inferne in petiolum sensim angustata, uirinque parce pubsulia et viridia.

II.1L. in Carolins. 
Cor. rotata. Antherae subcoalitæ, apice poro gemino dehiscentes. Bacca bilocularis.

cirolinerse. S. caule annuo, pumilo, erecto, L. aculeato : folin ovali-oblongis, basi acutis, sublobato-sinuosis, utrinque aculeatis, subius subtomentosis, super asperiuseulis : racemo simplici : corolla albido-co-rulescente : baccis cernuis, luteis.

$O_{B S}$. Radix perennis.

$H_{\perp B}$. in agris Carolina.

\section{A Z A L E A. L.}

Cor. campanulata. Stamina receptaculo inserta. Caps. 5-locularis.

carrscens. A. foliis subtus tenui tomento canescentibus, nervo non setigero : floribus roseis, non viscidis : calyce minutissimo: staminibus exertis.

Oss. Solito nudiflora : corolla nudo oculo vị manifeste pubescens; tubo breviore quam in $A$ viscosa. Calycis denticuli brevissimi, rotundato-obtusi. ILAB. juxta rivulos Carolinæ inferioris.

viscosa. $\Lambda$. ramis hispidis : foliis glabriusculis; nervo conspicue setigero : foliis vis- 
IENTANDRIA. MONOGYNIA. YÕ

cidissimis : calycis denticulis rotundatis, brerissimis.

Var. o. virens : foliis utrinque viridibus : ranis solito purpureis. Variat foliis multo minoribus.

- $\beta$. glauca : foliis subtus glancis. Variat ramis hispidioribus; unde $A$. scabra hortulanortum.

$I I_{-A B}$. in Carolina inferiore.

rerrclymeromes. A. subnudiflora : foliis glabel-

lis; nervo supra lanuginoso, subtus setigero: floribus majoribus, non viscosis: staminibus longissime exertis.

$O_{B S}$. Folia utrinque viridia : calyx dentibus brcvibus, ovali-subrotumdis : corolla rosea; tubus hirsutus, limbo brevior; limbus manifeste anplior quam in creteris.

$H_{A B}$. in New-J̄ersey.

Gatexdulacea. A. subnudillora : foliis utrinque pubentibus, perfectis hirsutulis : floribus amplioribus, non viscosis, calendulaceis : calycis dentibus oblongis : corolla tubo hirsuto, laciniis breviore.

Var. «. flammea : floribus flammeo-salendulaceis.

- $\beta$. crocea : Iloribus croceis.

II Aв. a. ad ripas fluvii Savannah, loco dicto Trom sislers.

ß. in sumunis montibus Carolinza. 
Anthera pyxidis instar transverso dehiscens.

Pusilli fruticuli, folies alternis seu suboppositis. Flores terminales.

C..L. bracteis subconsimilibus stipatus; profunde 5-partitus; laciniis incumbentierectis, oblongis, paleaceo-membranaceis.

Cor. abbreviata, campanulata: tubus calyce brevior: limbus 5-partitus, patens; laciniis spathulatis.

- sub disco hypogyno tenaciter inserta.

SтAм. filamenta lacinias alternas corolla mentientia, lamellata : anthera loculis subglobosis, basi appendiculatis, transverse in hemisphæras dehiscentibus.

Prst. ovarium breviter ovoideum, sub3-gonum : stylus crassus, rectus : stigmata tria brevissima.

Ovarium 3-loculare : ovulis pauciusculis, receptaculo axili immediate adnexis.

Fruct....

BARBULATA. P. repens : foliis cuneato-lanceolatis, acutissimis, basi interna confertab. 19. tim barbulatis, ciliatim subdecurren- 


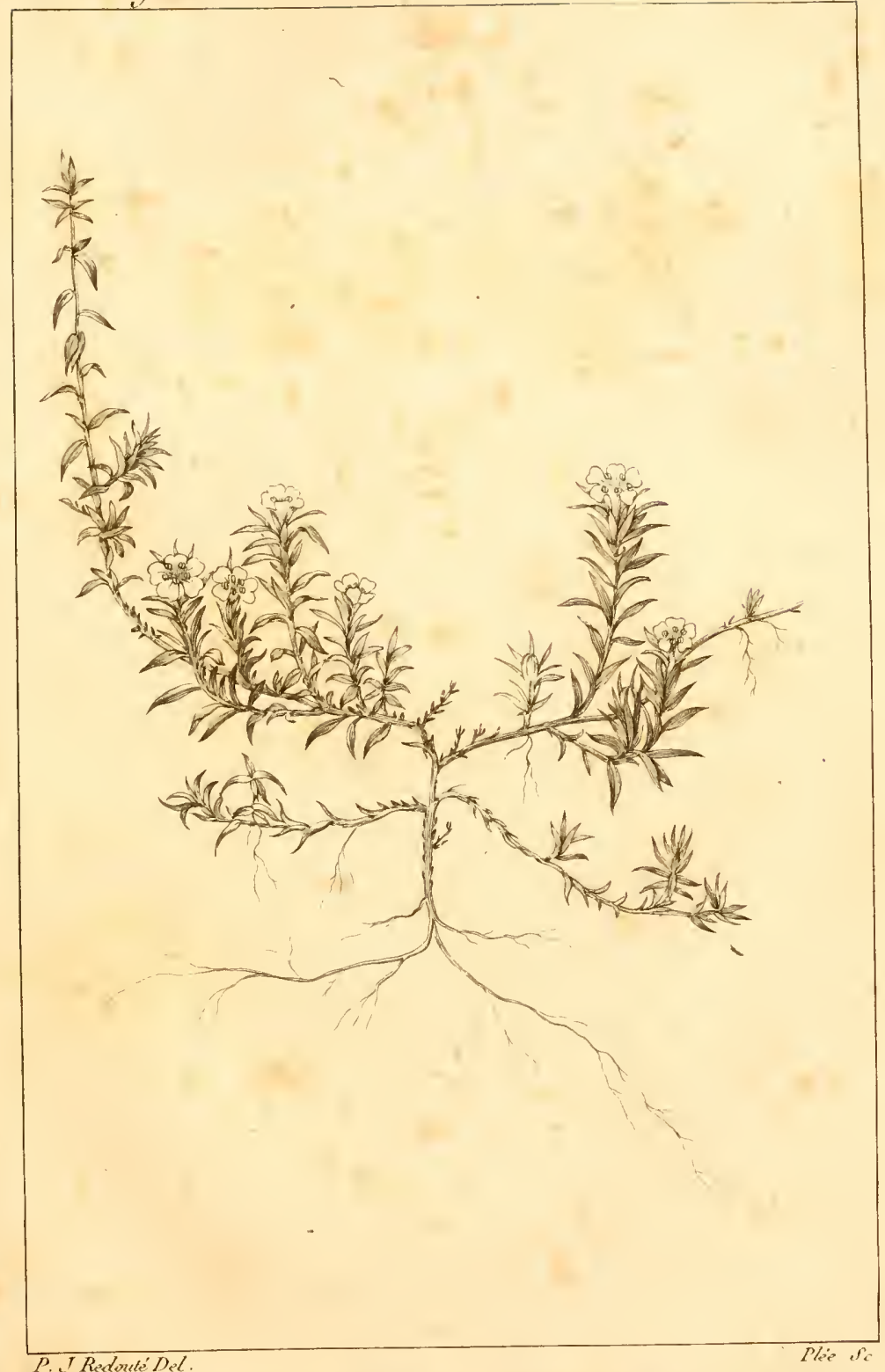

Prxmantmera barluelezta. 

PENTANDRIA. IONOGYNIA. 153 tibus : floribus solitarie terminalibus: calyce ciliolato.

OBs. Habitus Azales procumbentis. Planta pusilla, fruticulosa, repens; ramulis assurgentibus, brevibus, unifloris. Folia $\mathrm{ERJC}_{\mathrm{r}}$, firmiuscula, nudo oculo glabella : summa confertim florem sessilem involucrantia; intimis calyci subconsinilibus.

$\|_{A B}$. in Carolina superiore.

-C. P O L Y P E T A L FE.

R H A M N US. $L$.

Cal. tubulosus : squamis stamina munientibus.

Cor. nulla. Bacca.

Franguloides. $R$. inermis : foliis ovalibus, acuminatis, leviter denticulatis : floribus dioicis; nonnihil fasciculatis : calycibus acutis : fructibus turbinatis.

$O_{B S}$. R. alpino affinis. R. alnifolius? L'IIER1т. HAB. ad lacum Champlain.

carolinianus. R. inermis : foliis ovali-oblongis, L. S. integriuseulis, glabris : umbellulis pedunculatis ; floribus hermaphroditis , 4-andris, I-gynis; stigmate bilobo : fructibus globosis.

$H_{A B}$. in Carolina.

volurilis. $R$ ? inermis, volubilis . foliis ovalibus, I. S. mucronatis, repando-subcrenatis, stria- 
I5/4 PENTANDRIA. MONOGYNIA. tis : floribus dioicis : drupa nuce biloculari.

$O_{B S}$. Folia glabra, ob ncrvos oblique parallelos quasi striata. Raceni subterminales : flores fructiferi staminibus imperfectis. Drupa succosa; nux sæpe sæpius, altero loculo abortiente, 1-sperma.

$I_{A B}$. in Ludovisiana ct Carolina.

Minutiflorus. R. foliis passim oppositis, ovalibus, serrukatis : floribus rainutissimis, dioicis, spicatis, in rachi alterne sessilibus; 5-andris : stylo 3-fido : bacca 3-sperma.

II $A B$. in maritimis, a Carolina septentrionali ad Floridam.

\section{E A N O T II US. L.}

Petala 5 saccata, fornicata. Bacea sicca, 5-locularis, 3-sperma.

americanus. C. foliis ovalibus, serratis, subtus

L. tomentosis : racemis composite confertifloris, ob ramulos aphylios quasi longe pedunculatis.

H.1в. ubique a Canada ad Floridam.

Microphyulus. C.subdecumbens, glabriusculus: foliis perpusillis, passim fasciculatis, obovalibus oblongisve, integriusculis: corymbulis ramulorum terminalibus. $O_{B} S$. Radix, nli precedcutis, crassius tuberosa, rubra. IIAB. in herbosis sabulosis sylvarum Gcorgix et Flurid $x$. 
PENTANDRIA. MONOG NIA. Y 55

C E L A S T R U S. $L$.

Cor. 5-petala, patens. Caps. 5-angularis, 5-locularis. Sem. calyptrata.

scarnexs, C. altissime scandens, volubilis, iner-

L. mis : foliis ovalibus, acuminatis, levite? serratis : racemo terminali.

IIAB. in Canada et Connecticut.

$$
\text { E V O N Y M U S. } L \text {. }
$$

Cor. 5-petala. Caps. 5-gona, 5-locularis, 5-valvis, colorata. Sem. calyptrata.

AMERICanus. F. ramis eximie 4-gulatis : foliis sub.

L. sessilibus; foribus omnibus quinquefidis: capsula verrucoso-muricata.

ILAB. in Virginia et Carolina.

atropurpureus. E. foliis longiuseule petiolatis,

JAce. amplis, ovalibus, subtiliter serrulatis: floribus omnibus 4 - fidis, atropurpureis : capsula lievi.

HAB. in Kentucky ct Tennassés. 


\section{T E A. L.}

Caulis fruticósus. Folia alterna, minutim bistipulata; sub gemmatione utroque margine involuta. Spicæ solitarie terminales : bracleæ deciduæ.

CAr. brevi-campanulatus, basi rotundatoobtusa coneavus, quinquefidus : sinubus obtusis dentes erectos subulatos distinguentibus.

Cor. petala quinque, dupla calycis longitudine, linearia, sensim acuta, superne reflex́-patentia, summitate incurva : summo calycis incrassato tubo, ad hujus sinus, distincte inserta : demum decidua.

Sткм. petalis breviora iisque alterna, erecta : filamentasubulata, tenuilaterum basilari tractu quasi subconfluentia : anthera incumbentes, oblonga, obtusæ, basi subbifida, loculis immediate appositis, introrsa facie longitudinaliter dehiscentibus.

Pist. staminibus sublongius, opposite bisulcatum : ovarium oblongum, teres, sensim desinens in stylum erectum : stigma cras̄sius capitatum, convexo-bilobum, glandulosum.

C.rs. tubo calycis cupulatim stipata, ovata, stylo cuspidata, bisulcata. 
PENTANDRIA, HONOGNN1A. I5

PERrc.immaturum biloculare; dissepimento angustissimo; seminulis axilibus.

-maturum coriaceum, rupto ad axim dissepimento quasi I loculare, 2-valve: valvis tunc utroque margine introflexo seminiferis.

Serr. pauciuscula, (plurimis abortantibus) incqualiter subrotundo-ovata, lavia ; reiiculo vasculari teguminis transpicienda.

Obs. Ordo nat. Saxifragere; licct monostyla!

vIrGinica. I. foliis oblongis, serratis : spicis puL. bentibus.

$H_{A B}$, in Virginia.

\section{Y R I L L A. L.}

Caulis fruticosus seu arborescens. Folia sparsa, solito frondosa : stipula nullæ. Spicæ laterales, multifloræ : pedicellis ad apicem bibracteolatis : floribus pusillis.

CaL. minntus, subturbinatus, appressus, 5-partitus : lacinulis ovali-lanceolatis, acuminatis.

Cor. triplo major : petala quinque, rigidula, stellatim patentia, ovali-oblonga, superne concavula, inferne convexiuscula, bạsibus contigua, hypogynica.

Sтım. petalis alterna, iis subbreviora, erec. tiuscula : filamequta crassiuscule setacea: 
antherx subrotundo-cordatx, obtusæ, inferne bifida; loculis longitudinaliter plano-patentibus, adusque mutuam dorsorum pressionem.

Pist. ovarium disco minuto innatum, obtuse conoideum : stylus brevis : stigmata duo (rarius tria) brevia, obtusa.

Bacc pusilla, floralibus partibus persisten. tibus stipata; conoideo-ovata, obtusa, stylata, lavis.

Pericnrpum firmiuscule carnosum, crasciusculum, exsiccabile, non dehiscens, biloculare.

SEz. in singulis loculis solitaria; ovata; e summo axi appensa, mediante funiculo partim per dorsum decurrente.

$O_{B S}$. Genus nequidem ejusdem ordinis naturalis ac ITEA.

chrominian. C. foliis cuneato-lanceolatis, acutis, membranaceis, nervillosis : spicis gracilibus : petalis pedicello longioribus.

C. racemiflora, Auctorum.

$H_{A B}$, in Carolina.

antullana. C. foliis cuneato-oblongis, obtusis, coriaceis, subtus enerviis : spicis crassioribus : petalis pedicello subbrevioribus. 
PENTANDRA. MONOGXNA. I Tं
A M PEL OPSIS.
A $\mu \pi \varepsilon \lambda_{0 s}$, Vilis. O广is, facies.

Genus Vitrm inter et Cissum medium: a priore distinguitur petalis sub anthesi discretis et reflexo-patulis nee calyptratim cohrentibus; foribus lemmaphroditis; dum vites omnes borealiamericana dioica : a posteriore (cui tamen affinius) quinario staminum numero.

Hac autem tria genera vix ullis floralibus notis inter sediscrepani: nequidem a fruetu, seminibus pluribus vel unico foeto, petita valet differentia; namque omnium ovarium biloculare et intra singulum loculum biovulatum est. Notandx tamen sunt in Cisso et Ampelopside $1^{\circ}$. facilis ramorum juxta nodos solubilitas; $2^{\circ}$. foliorum frequentior compositio prolapsuscue.

condata. A. ramis glabris : foliis sinu lato et parum profundo cordatis, interdum superne subtrilobo - angulatis, dentatis; nervis subtus puberulis : racemis duplicato-bifidis.

ILAR. in dumetosis regionis Illinoensis et ad ripas amnis Savannath. 
Quineulfouı. A. caule radicando - scandente: foliis quinato-digitatis; foliolis petiolatis, ovalibus, acuminatis, superne grandidentatis : racemis subsessilibus, confertiuscule multifloris.

Hedera quinquefolic. Linn.

$H_{A B}$, in Virginia, Canada.

Brpissata. A. foliis duplicato-pinnatis, pinnulis inciso-lobatis : racemis pedunculosis, subduplicato-bifidis.

Vitis arborea. LinN.

$H_{A B}$. in Carolina, Virginia.

$$
\text { C L A Y T O I A. L。 }
$$

Cal. 2-ralvis. Cor. 5-petala. Stigma 5-fidum.

Caps. 5-ralvis, 1-locularis, 5-sperma.

virgivics. C. foliis pralongo-linearibus : flo* ribus albido-roseis.

$H_{A B}$. in lumidis sylvarum Virginix et Novæ Anglix.

carolinana. C. foliis brevi-ovalibus, in petiolum abrupte angustatis : floribus roseis.

Ons. Folia vix semiuncialia; interdum in caulicula paria duo. Flores paulo minores.

$H_{A B}$, in montibus excelsis Carolinæ. Mar tio floret. 
PENTANDRIA. DIGFNIA. 16 .

\section{$D I G Y N I A$.}

6. I. OVARIO INEERO.

- H Y D R OCOTYLE. $L$.

Umbella simplex; involucro 4-phyllo. Pelala

inlegra. Senrina semiurbiculato-compressa.

* Floribus pecunculatis.

vUlGaris. II. foliis orbiculatis, centro peltatis,

L. leviter crenatis : spica pedunculata, interrupte pauciflora.

IА $а$ в. in Carolina et Georgia.

vabellulata. H. foliis peltatis, manifeste crew natis, basi sinu emarginatis : umbellula pedunculata, multiflora, floribus pedicellatis.

H. umbellata. LinN.

$H_{A B}$. in Carolina et Virginia.

FICAROIDES. H. foliis petiolatis, rotundato-corn datis, subanguloso - repandis; petiolo passimque nervis pilosis : capitulo pedunculato, trifloro, villoso.

$O_{B S}$. Folia majuscula, non rotundato-crenata, insolito congenerum more.

Affinis $H$. asiaticae.

H. cordata? W $\mathrm{ALT}$.

IIAB. in udis nec inundatis rivulorum ripis Carolinæ inferioris.

I. 
LINEATA. H. perpusilla, glaberrima : foliis crassiusculis, cuneato.linearibus, transverse et distanter lineatis indeque (adversa luce) quasi articulatis : umbellula pedunculosa.

Ors. Affinis $H$. chinensi, Lins.

$I_{A B}$. in inundatis Carolinæ inferioris. Aprili et Maio floret.

** Floribus sessilibus.

americana. H. glabra : radice tuberosa : foliis

I. quasi peltato-orbiculatis, ad marginem petiolatis, duplicato-crenatis : glomerulis paucifloris, sessilibus.

Var. $\alpha$. flexicaulis : caulibus firmioribus brevioribusque, quasi angulatim flexuosis.

- . gracilis : gracilior, filifarmis, non flexuosa; foliis etiam minoribus.

HAB. a. in Canadæ depressis.

$\beta$. in montibus Carolinx et Canadx.

\section{S A N I C U L A. L.}

Umbellae confertæ, subcapitatæ. Fructus scaber. Flores disci abortientes.

marilandica. S. foliis ad petiolum usque partitis

$\boldsymbol{r}$. sive subdigitatis : capitulorum floribus fertilibus subternis et sessilibus, sterilibus numerosioribus, pedicellatis.

IIAB. a Pensylvania ad Carolinam. 
Flores capitati. Receptaculum paleacertm.

ovalifolium. E. simplex : foliis ovalibus, den. tatis : capitulis omnibus pedunculatis, involucro paulo brevioribus : paleis parvulis, subæqualiter tricuspidatis.

E. americanum? WALT.

$H_{A B}$. in subhumidis sylvaticis et pratensibus Caro. linæ. Floret Julio.

Toetrnuxr. E. pumilum, graveolens : foliis spi-

r. nuloso - serratis ; radicalibus cuneatooblongis : capitulis dichotomalibus, ses. silibus : paleis longissimis, lineari-lanceolatis.

$O_{B S .}$. Excluso Groxovin synonymo.

$H_{A B}$. in campestribus, pratensibus aridis Antillarun et Floridx.

aquaticur. E. prealtum : foliis longissime lanceolato-linearibus, serratis; rameis lineari-multipartitis : foliolis involucri, capitulo ovoideo longioris, 3-5-fidis.

E. aquaticum, Lins. admisso solo GroNovir synonymo.

$O_{B S}$. Caulis conspicue fistulosus : folia inferiora lanceolata et parve dentata; superiora linearıa el in- 
16 PENTANDRIA. DIGYN1A.

ciso-serrata. Paleæ florales minutæe, subtricuspidatæ.

$H_{A B}$. in paludosis ascendente mare inundatis; presertim ad pontem Goose-Creck.

yuccifoliun. E. elatius : foliis radicalibus longissime gladiatis, remote arisiato-ciliatis; caulinis rameisque subconsimilibus: foliolis involucri, capitulo globoso brevioris, indivisis.

$O_{B S .}$ A Linnæo cum præcedente confusum : caulis inferne simplicissimus. Capitnla pedunculata : paleæ breves, indivisæ, lanceolate.

$I_{A B}$, in paludosis Virginiæ.

\section{A U C U S. $L$.}

Corollae suljudiatæ, ommes hermaphroditæ. Fructus pilis hispidus.

pUsillus. D. retrorsum hispidulus : foliis lacinulis minimis sublanceolatis : umbella pusilla; umbellulis oliganthis : fructibus 8-fariam cristato-muricatis. $H_{A B}$. in campestribus Carolinæ.

\section{A. MI M I. L.}

Involucre pinnatifida. Corollae radiatæ:omnes hermaphroditæ. Fructus lievis.

capillaceur. A. caule pumilo, ab imo ramoso: foliis omnibus composite capillaceo-mul. 
PENTANDRIA. DIGYNIA. Y65

tipartitis : involucris umbella subsemibrevioribus, etiam multipartitis : seminibus glabratis.

OBS. Statura A. coptici, paulo minor. Folia tenuissine capillacea, laciniis numerosis.

$I_{A B}$. in campestribus Carolinx.

$$
\text { C I C U T A. } \boldsymbol{L} \text {. }
$$

Fructus subovatus, sulcatus.

bULmetrd. C. foluis fœniculaceis : ramis vertiL. cillatim bulbiferis.

$I L A B$. in aqnis Canadæ.

S ELI N U M. $\boldsymbol{E}$.

Fructus ovali - oblongus, compresso - planus, in medio striatus. Involucrum reflexum. Peíalco cordata, æqualia.

CANADFNe. S. glaberrimum, lucidulum : foliis bipinnatis; foliolis multipartitis, lacinulis lanceolatis : fructibus ovalibus.

Athamantha chinensis? Linn.

HAB. ad ostium fluminis S. Zaurentii。 
Fructus ellipticus, emarginatus, compressus, striatus, marginatus. Cor. difformis, inflexo-emarginata. Involucrum caducun.

LAmatUr. H. foliorum petiolo nervisque subtus lanato-villosissimis; foliis trifoliatis, foliolis omnibus petiolatis, amplis, subro- tundo-cordatis, subpalmato-lobatis : fructibus orbiculatis.

$\not H A B$, in Canada.

\section{I G U S T I C U M. L.}

Fructus oblongus, 5-sulcatus utrinque. Corollae æquales, Petalis involutis, integris.

scoticum. L. foliis caulinis biternatis, summis

L. trifoliatis; foliolis lateralibus trapezinis, terminali rhumbeo : umbellis strictis; involucro invocellisque lineari-polyphyllis.

$H_{A B}$. juxta flumẹı S. Laurentii, ad Tadoussack.

Actzifoliun. L. foliis petiolo duplicato-tripartito, partitionibus secundariis 3-5-foliolatis; foliolis ovalibus, æqualiter dentatis : involucellis setaceis : fructibus oblongo-ovalibus, subalato-ro-costatis. OBS. Planta 3-pedalis et ultra. Umbellæ laterales solito steriles, infra terminalem subverticillatæ. HA. A ad ripas fluminis S. Laurentii, juxta Tadoussack. 
PENTANDRIA.DIGYNIA. I67 MLRsinode. L? caule lævi glabroque, nodis sive foliorum insertionibus confertim barbulatis : foliis plerisque biternatis, juxta marginem et nervos puberulis : fructibus ovalibus, utrinque margine subdipteris.

$O_{B S .}$. Fructum maturum non vidi; ideoque de gencre dubius hæreo.

$H_{A B}$. in Carolina superiore.

\section{S I U M. L.}

Eructus subovatus, striatus. Involucrum polyphyllum. Petala cordata.

LixeARE. S. erectum : foliis pinnatis, foliolis longis, sublanceolato-linearibus, minutis denticulis remotiusculis leviter serratis : involucro oligophyllo; involucellis lineari-polyphyllis : umbella breviter ra= diata.

$O_{B S}$. Affine $S$. rigidiori!

$\angle H_{A B}$, in aquosis Canadx.
A N G E L I C A. L.

Fructus subrotundess, angulatus, solidus, stylis. reflexis. Corollae aquales; petalis incurvis.

TRIQUinata. A. petiolo tripartito; partitionibus pinnato-quinquefoliolatis; foliolis in. 
ciso-dentatis; terminalium impari rhombeo, sessili, lateralibus decursivis.

$O_{B S}$. Glabra : pedunculo pedicellisque minutissima pube subcandicantibus.

$H_{A B}$. in Canada.

\section{S I S O N. $L$.}

Frucius ovatus, striatus. Involucra sub-4-phylla.

Jusillur. S. annuum; foliis biternatim multipartitis : umbellulis 3-5-floris : fructibus scaberulis.

OBs. Affinis Duvcus divaricatus. WaIT.

$I I_{A B}$. in sabulosis aridis Carolinæ.

cananense. S. foliis plerisque trifoliatis; foliolis

c. lato-ovalibus, duplicato-dentatis : pedunculis geminis : fructibus oblongis.

$I I_{A B}$, in Canada.

TRrfoliatum. S. foliis omnibus trifoliatis, foliolis dentatis, inferioribus ovalibus, 2-3-lobis, superioribus ovali-lanceolatis : umbella terminali, solitaria, promisse pedunculata : fructibus subrotundis. II $\boldsymbol{t}$. in Carolina superiore.

aAREITAlUM. S. foliis pinnatis, superioribus quinatis; foliolis omnibus sessilibus, lan- 
PENTANDRIA. DIGYNIA.

ceolatis, integerrimis, albido-marginatis : involucro involucellisque nullis.

$H_{A B}$. in udis Carolinæe.

вUlbosum. S? pusillum : radice globoso-bulbosa: caule debili, simplicissimo, diphyllo, solito uniramulato : folio laterali tripartito, partitionibus subpinnatis, pinnulis divisis; terminali subbiternato : umbellulis terminalibus, solito tribus, 3-5-floris.

Ons. Planta 3-5-nncialis, erecta. Caulis inferne nudus, ad basim juxta bulbum quasi squamulis stipatus; versus medietatem emittens unicum folium, solito cum ramulo florifero; terminatur folio sessili, cujus e vaginula oriuntur 2 sen sæpius 3 pedunculi terminati umbellula subsessili, 3-5-flora, parvulo folio oligotomo involncellata : flores omues hermaphroditi : caly $x$ integer : petala ovalia, alba : stamina petalis longiora; antheris atro-purpureis: ovarium compresso-turbinatım, striatum; styli longinsculi. Fructum maturum videre non licnit; ideoque de genere hæreo et tantummodo quadam cum Siso inundato affiuitate, huc plantam forsan proprii generis referre moveor.

HAB. ad rupes arduas, prope Knoxville. Martio, nivoso solo, florens. 
Umbella composita. Involucrum nullum. Fructus oblongus, subrostratus. Nucleus longitudine seminis.

Clayton. M. petiolo tripartito, partialibus 3-5foliolatis; foliolis oblongo-ovalibus, subpinnatifido-lobatis : umbella pauci-radiata, divaricata : fructibus elongatis, teretibus, laevigatis.

$O_{B S .}$ Planta subbipedalis, erecta. Folia absque canitis pubentia. Pedunculi geminatim terminales : umbellæ et umbellulæ sub fructificatione divaricatolaxæ; radiis paucissimis, 3-5, longissimis; umbellulis subdicarpis.

HAB. in montibus Aileghanis.

$$
\text { S M Y R N I U M. } L \text {. }
$$

Fructus oblongus, striatus. Petala acuminata, carinata.

CORDATUr. S. foliis radicalibus suborbiculatoWALT. cordatis, crenatis; caulinis petiolatis, trifoliatis; supremis tripartitis : imbella radiis brevibus.

OB́s. Folia radicalia sinu profundo cordata : canlino rum foliola petiolata, subcordato-ovalia, dentata. Fructus angulis eminentioribus.

$I_{A B}$. in sylvis montanis Carolinie. 
A UreUr. S. foliis biternatis, partialium interme-

L. dio sape subquinato; foliolis ovali-lanreolatis, serrulatis : umbella brevi-radiata.

$O_{B S}$. Folia radicalia pleraque biternata : inferiorum partiali petiolo intermedio sub5-foliolato, ob fo. liolum impar tripartitum : suprema trifoliata. Flores plerique, congenerum more, etian abor tiunt.

HAB. in montibus Carolinæ.

mprgennmum. S. glaberrimum : caule lævi : fo-

L. liis glaucis; inferioribus triternatis; superioribus biternatis; foliolis ovalibus, integris: umbella radiis paucis, setaceoelongatis.

THAB. in collibus Connecticut et Yellow-Montain Caroline.

: S. Ir. OVA R X O SEMIINEERO.

II E U C E R A. $L$.

Petala 5. Caps. 2-rostris, 2-locularis.

Contusa. II. viscido-pubescens; scapo foliisque asperinsculis : foliis modice et rotundatim lobatis : fasciculis paniculae confertiusculis : petalis purpurascentibus.

H. americana. Lins.

$H_{1 B}$. in variis locis Pensylvanix, Caroline, \&c. fiequcnitus in regione Illinoensi. 
villosa. H. villosissima : foliis acute lobatis: fasciculis paniculac capillaribus, laxifloris : petalis albis.

$O_{B S}$. Præcedente minor et gracilior : petiolis imoque scapo villosissimis, non viscidis : foliis profundius lobatis, lubis acutangulis : floribus pusilies, albis. $H_{A B}$. in altioribus montibus Carolinæ borealis.

5. III. OVARIO S U PER C.

$$
\text { U L M U S. } L \text {. }
$$

Cal.,5-fidus. Cor. o. Capsula compresso-membranacea.

FULVA.

U. foliis plerunque ovali-oblongis, rarius cordato-ovalibus, longissime acuminatis, utrinque pubescentibus et juxta nervos subtomentosis : gemmis, sub explicatione, densa fulvaque lana tomentosis: floribus sessilibus.

OBS. Succus sub cortice manifeste viscosus, unde nomen triviale sliperi elm. Folia figura et serratura multum variant; scd magis quam cæterarum pubent. Stamina 5-7. Stigmata purpurascentia. Fructus fere $U$. campestris, minor et tantisper, prasertim ante maturitatcm, utraque facie pubescens.

HAB. in Canada, Vermont, Connecticut, montibus Alleghanis, \&c. frigid. Anıericæ regionibus.

ANIERICANA. U. ramis lavibus : foliis subuniforI. miter serratis; dentibus uncinato-acu- 
PENTANDRIA. DIGYNIA. I 3 minatis : floribus (elapsa gemma) manifeste pedicellatis : fructibus densissimo villo fimbriatis.

Oss. Pamuli solito quasi vininatim virgati, spadicci. Folia subtus minutim pubentia; dentibus plurimis 1-2-denticulatis; interdum obtusiusculis. Stamina 5-8 : stignata alba. Membrana fructus glabri pube densissina eanescenteque eleganter cincta.

$H_{A B}$. in Pensylvania, Virginia, Carolina inferiore, \&c.

ALATA. U. ramis passim ex ulroque latere in alam suberosam corticalem dilatatis : foliis oblongo-ovalibus, sensim acutis, (nec acuminatis) basi subrequalibus : fructu pubescente et confertim cilioso.

$V \cdot$ pumila? WALT.

$O_{B S}$. Arbor mediocris : folia carpinea. Fructificatio fere Unn anericanae.

H. $_{\text {AB. }}$ in Virginia cí Carolina inferiore.

G H E N O P D I U M. L.

Cal. 5-phyllus, 5-gonus. Cor. o. Sem. 1, lenticulare, superim.

Anthelminticum. C. perenne, erectum : foliis

L. ovali-lanceolatis, rariter dentalis : spicis simplicibus, gracilibus, longis, aphyllis: floribus trigynis.

IIAB. in ruderatis, canpestribus Kentucky. 
Cal. 5-phyllus. Cor. o. Caps. 1-sperma. Sem. cochleatum.

caroliniana. S. herbacea, decumbens, glabra: $W_{A L T}$ foliis breviusculis, dilatato-subulatis, spinescentibus, lævibus : floribus digynis : gemmis fructificantibus valde turgidis : calycibus fructiferis latius explanato-alatis.

$O_{B S}$. Affinis $S$. rosaceae.

$H_{A B}$ ad littora Carolinæ.

SALSA? S. herbacea, érectiuscula, ramosisL. sima : foliis linearibus, muticis, carnulosis : glomerulis florum quasi in spicas interfoliaceas approximatis : calycibus fructiferis depresso-subrotundis.

Obs. A. SAlsola qua maritima circa Hâure de Grace et Dieppe incolit, in eo tantum differt, quod humilior sit et subdecumbens, floribus confertioribus.

$I_{A B}$ ad ostium fluminis $S$. Laurentii.

platiphylla. S. caule herbaceo, diffuse ramosissimo : foliis ovali-oblongis, inæuualiter acuteque angulato-dentatis : ramulis floridis paniculatis : floribus trigynis : ca- 
PENTANDRIA. DIGYNIA.

lycibus fructiferis ala horizontali denti. culata cinctis.

$O_{B S .}$. Habitus a genere diversus et fere Cimenopodr. Sub floratione foliosa; sub fructificatione demum, elapsis foliis, prorsus aphylla et tnnc quasi se diversam exhibens. An potius proprii generis?

HAB. in regione Illinoensinm, he alluvientibus Mississipi aquis allata.

C U S G U T A. $L$.

Cal. 4-fidus. Cor. 1-petala : Caps. 2-locularis.

americana. C. floribus pedicellatis, pentandris.

L.

$H_{A B}$. in Carolina inferiore, Virginia.

\section{G E N T I A N A. $L$.}

Cor. monopetala. Caps. 2-valvis, 1-locularis. Receptaculis 2, longitudinalibus.

$O_{B S .}$ An potius I-gyna?

AMAreLLOInes. G. caule quadrangulo : foliis semiamplexicaulibus, ovalibus : floribus terminalibus, subternis, pedicellatis : corolla 5-fida, laciniis' lanceolatis, setaceoacuminatis.

OBs. Habitus G. amarellae, paulo minor, itidem ramosa : rami summitate sub3-flori. Corolla minuta, obsolete lutea, fauce glabra, plicis muticis, H.AB. in monticulis Kentucky. 
I 6 PENTANDRIA. DIGYNIA.

Pneumonanthe. G. foliis lineari-lanceolatis : flo-

L. ribus majusculis, terminalibus etiamque solitarie lateralibus : corollæ 5-fidx laciniis rotundatis; plicis interioribus in denticulum acutum desinentibus.

$H_{A B}$. in montibus altioribus, Canadam inter et sinum Hudsonis.

Saponaria. G. caule cylindrico, asperiusculo:

L. foliis ovali-lanceolatis : floribus sessilibus, fasciculatis : corolla 5-fida, laciniis cum acumine obtusis.

$O_{B S .}$ Habitus G. cruciatae : flores majusculi, terminales aut etiam laterales; interdum unicus. Calycis láciniæ foliaceæ, lanceolatæ. Corollæ plicæ internæ in lacinulam subintegram desinentes.

HAB. in herbosis sylvarum, a Canada ad Floridam.

puberula. G. caule asperiusculo : foliis linearilanceolatis, undulosis, uti calyces ciliolatis : floribus sessilibus, terminalibus, 5-fidis.

$O_{B S}$. Quoad habitum affinis $G$. pneuinonanthe. Folia inferne sensim angustata, minuta pube ciliolata. Flores majuscnli, coerulei. Calycis laciniæ cuneatolanceolatæ, vix longitudine tubi. Corollæ laciniæ brevissimæ, obtusæ, muticæ; plicæ internæ in lacinulam denticulatam desinentes.

$H_{A B}$. ad confluentem fluviorum Olio et Mississipi; prope propugnaculum Cheroquis. 
Arrestroura. G.caule simplici, gracili, unifloro:

foliis angusto-linearibus, patulis : corolla 5-fida; laciniis ovalibus; plicis in laciniam laceram desinentibus.

$O_{B S}$. Caulis erectus, cylindricus, superne dissitis foliis quasi nudus. Folia deorsum angustata. Corolla magna, cœrulea.

$I_{A B}$. in pratis Caroline inferioris.

Acuta. G. caule 4-gono : folis sessilibus, subamplexicaulibus, oblongo-ovalibus, acttissimis; floribus fasciculatis, terminatlibus et lateralibus : corolla 5-fida; laciniis lineari-lanceolatis; fance ciliata.

OBs. Canlis erectins : folia arcte sessilia, erecta. Florcs parvuli, viridi-lutei : ramuli floriferi brevissimi.

H. $E$. in altis montibus Carolinæ et in Canada, prop̣e Tadoussack.

\section{H Y D R O L E A. L.}

Cal. 5-phyllus. Cor. rotata. Filamenta hasi. cordata. Caps. 2-locnlaris, 2-valvis.

c.spolinava. H. foliis longo-lanceolatis: floribus quasi subsessilibus, axillaribus.

H. quadrivalvis. W W Lt.

Obs. Habitus, pubescentia, armatura foresque H. spinosce. LINN. sed non ita ramosa ; fulia angustiora et multo longiora : flores 1-5, fasciculati, quasi axillares, ob brevitatem ramusculorum 1loridorum. Capsula glabra.

$I I . \& B$. in aquis stagnantibus Carolina inferioris. 


\section{$T R I G Y N I A$.}

§. I. OVA I I O IN FERO.

V I B U R N U M. $L$.

Cal. 5 - partitus, superus. Cor. 5 - fida. Baccs 1-sperma.

PRUNifolium. V. glabrum; ramulis subtransverse L. patentissimis : foliis subrotundo-ovalibus, obtusis, serrulatis; petiolis lavibus : floribus majusculis.

$H_{A B}$. in utraque Carolina.

Lentago. V. glabrum : petiolis subscabrosis; I. foliis ovalibus, conspicne acuminatis, argute et subuncinatim serrulatis : cymis sessilibus.

$O_{B S}$. Folia sxpe rentricoso-ovalia; interdum ovalioblonga. Flores minores quam in prunifolio.

HAB. in Carolina, Virginia.

AUnUm. V. glaberrimum : foliis ovalibus rel L. ovali-lanceolatis, margine revoluto integris : cymis ebracteatis, pedunculatis.

$O_{B S}$. Interdum folia subdentata. Variat foliis plus minus lucidis; deciduis et lryeme persistentibus.

$H_{A B}$. in Carolina inferiore; foliis deciduis : in montipus Genroir; foliis persistentibus. 
Cassinomes. V. glaberrimum : foliis parvulis,

L. cuneato-obovalibus, crenato-dentatis, coriaceis : cymis arcte sessilibus.

HAB. in umbrosis sylvarum, juxta rivos Carolinæ inferioris et Georgix.

Lantanoines. V. petiolis nervisque pulverulentotomentosis : foliis amplioribus, suborbiculato-cordatis, abrupte acuminatis, inæcualiter dentatis, dentibus muticis: cyma arcte sessili : fructibus ovatis.

OBs. Affinis Lantancae, sed distinctissima species: frutex humilior, caulibus surculisque subprocumbentibus.

$H_{A B}$ in rupestribus opacarum sylvarum Canadæ.

oелtatum. V. foliis plicato-sulcatis; basi subcorL. datis; modo suborbiculatis, modo ovalibus; inciso-dentatis serratisve : fructibus subglobosis.

Var. $\propto$ :'glabellum; majus; foliis suborbiculatis sen brevi-ovalibus, glabriusculis.

$\beta$ : semitomentosum; minus; foliis ovalibus, subtus tomentosis.

$O_{B S .}$ Utrumque in patrio solo colui et in vivo comparavi : nullam essentialem differentian deprehendere potui.

HAB. $\alpha$. in altis montibus Carolinæ.

$\beta$. in Carolinæ inferioris dunetosis. 
180 PENTANDRIA. TRIGYNIA.

MOLle, V. foliis suborbiculato cordatis, pli. cato-sulcatis, dentatis, subtus mollissima pube subtomentosis; petiolis subglandulosis : cymis radiatis? fructibus oblongo-ovatis.

$O_{B S .}$ Opulus foliis indivisis : cortice quotamnis laceratim deciduo.

$H_{A B}$, in Kentucky, circa Danville.

Opurus. V. foliis lobatis; petiolis glandulosis, L. cymis floribus sterilibus radiatis.

Var. a. europeanum.

ß. Pimina : foliis tricuspidatis; lobis sursum angustatis, promisse acuminatis.

$\gamma$. edule : pumilum, strictum, multicanle foliis brevissime lobatis, denticulato-serratis, denticulis acuminatis; fructibus ednlibus.

$I_{A B}$, in Canada.

ACERIFOLIUM. V.ramulis petiolisque pilosis; eglanL. dulosis : foliis lobatis, parce dentatis, subtus pubescentibus, axillis nervorum hirsutis : cyma longe pedunculata.

$H_{A B}$. in montanis Pensylvaniæ, Virginix, Caroline superioris, \&c. 


\section{S A M B U C U S. L.}

Cal. 5-partitus. Cor. 5-fida. Bacca 5-sperma.

canadersis. S. humilior; ramulis petiolisque gla-

L. berrimis : foliolis oblongo-ovalibus, nitidis, glabris, nervo medio vix pubescente; longissime angusteque acuminatis : cyma laxa.

$O_{B S}$. Foliola inferiora interdum geminata rariusque ternata. Flores inodori. Fructus senșim ac sensim saturatins purpurascentes, demunı plena maturitate atri.

Tantan- cum 3. nigra liabet affinitatem, ut inter utramque eomparative in lorto americano cultam, vix ullam differentiam observaverim; americanz tamen semper humilis; curopæa vcro arborescens.

$I_{A B}$ a Canada ad Carolinam.

Puners. S. cortice verruculoso : foliis etiam. terminalibus, quinatis; foliolis suЂtus pubescentibus, ovali-lanceolatis : cyma confertiuscule racemosa.

OBs. Affinis. S. racemosae, presertim ffornm dispositione et fructibns itidem rubris, etiangue cortice. Folia vero nunquam trifoliolata et angustiora, interdum subtus subtomentosa. Folia caulinm steriJium quandoque septentita; foliolis oblongo-ovalibus, serratis, adjesto nonnunquam ad basin nonnullarum foliolo multoties minore.

IfAB. in altis montibus Pensylvania, Canadx, Carolinx. 
S. 11. OVARIO SUPERO.

R H U S. $\dot{L}$.

Cal. 5-partitus. Petala 5. Bacca i-sperma.

rYPHINUM. R. arborescens; ramis petiolisque vil-

r. losissimis : foliis pinnatis, multijugis; foliolis lanceolato-oblongis, argute serratis : racemo fructifero conferto; fructibus purpureis, velutinis.

$H_{A B}$. a Canada ad Pensylvaniam.

CLABrum. R. prorsus glabrum : foliis pinnatis, L. multijugis; foliolis lanceolato-oblongis, serratis, subtus plus minus albicantibus: floribus dioicis : fructibus holosericeis.

$H_{A B}$. in sepibus arvensibus Virginiæ et Pensylvaniæ.

rumuer. R. humile : ramis petiolisque brevi pube vestitis : foliis pinnatis, multijugis ; foliolis ovalibus, vix acuminatis aut muticis, inciso-dentatis, subtus subtomentosis : fructibus holosericeis.

$O_{B S .}$. Frutex pedalis et vix ultra.

IIAB. in Carolinæ superioris comitatu Mecklenbourg.

COPALIMUM. R. foliis pinnatis, multijugis; peL. tiolo alato; foliolis ovali-lanceolatis, in- 
PENTAIDRIA. TRIGYNIA.

tegris : floribus dioicis; racemo ses. sili.

$O_{B s}$. Rami puberuli, sparsim punctati. Foliola supra lucide glabra, subtus puberula. Fructus lucidi, cum pube vix couspicua.

$H_{\mathcal{A B}}$, in utriusque Carolinæ et Virginiæ sylvis.

Vernix. R. arborescens, glaberrimum : foliis L. pinnatis, multijugis; foliolis ovalibus, abrupte acuminatis, integris : panicula laxa; floribus dioicis : fructibus albis, glabris.

$O_{B S}$. Foliola interdum subangulato-parce-dentata .

H.s. a Canada ad Carolinam.

Toxiconendron. R. radicans, trifoliatum, leu-

L. cocarpum : foliolis ventricoso-oralibus, integris aut sinuato-crenatis : racemis rameis et axillaribus, sessilibus, dioicis.

Var, a. vulgare : radicando-scandens : foliolis amplis, integris seu rariter dentatis.

- ß. quercifolium : non scandens, hrmilius: foliolis varie lobato - sinnosis, sub floratione tomentosis.

- $\gamma$ microcarpon : foliolis oblongo-ovalibus, longius acuminatis, sæpius rhomboideis : fructu multo minore.

$I_{A B}$, in Carolina inferiore et Georgia. 
Aromaticun. R. fructiculosum, quasi amentaceum, nudiflorum : foliis trifoliatis; foliolis pubentibus, rhombeo-ovalibus, dentatis.

$\dddot{H}_{A B}$. iṇ Carolina superiore et Kentucky,

$$
S T \perp \text { P II Y L E A. L. }
$$

Cal. 5-parlitus. Petala 5. Caps.1-locularis, 5-ralvis. Semina papposa.

2nIFola. S. foliis trifoliatis : racemis pendulis: L. petalis inferne ciliatis : fructu ovato. $H_{A B}$. in New-Yorck et Carolina superiore.

\section{$T E T R A G Y N I A$.}

PA R N A S I A. L.

Caulis unifolius, I -llorus. Petala 5 : appendices perigynicæ 5, setaceo-5-multisetæ. Stigmata sessilia. Caps. 1-locularis, polysperma.

parrstris. P. foliis rarlicalibus cordatis : appen-

L. dicibus perigynicis, multisetis.

canolnuan. P. foliis radicalibus suborbiculatis: appendicibus trisetis. $O_{Z s} S$. Magnitudo hạbitusque prioris.

IIAB in undis Caroline. Prior detexit clariss. Bosc. 
PENTANDRIA. PENTAGINTA. 185

\section{$P E N T A G Y N I A$. \\ 5. I. OVARIO INFERO.}

\section{A R A L I A. L.}

Involucr. umbellula. Cal. 5-dentatus, superus. Cor. 5-petala. Bacca 5-sperma.

Nudicaulrs. A. caule subnullo; surculis unifolia-

L. tis : folio triternato vel triquinato; foliolis oblongo-ovalibus : scapo nudo, unico, folio breviore; umbellulis paucis.

$I_{A B}$, in iisdem locis ä $A$. racemosa.

R.ıcruosa. A: herbacea, divaricato-ramosa : pe-

L. tiolis tripartitis, partitionibus $3-5-$ foliolatis; foliolis plerisque cordatis : ramulis axillaribus foliosis et multi-umbellulosis; terminalibus paniculatis, subaphyllis.

$H_{A B}$. in Canada et altis Alleghanis montibus.

IISPIDA. A. humilis, ima parte fruteseens : caulibus foliisque setis rigidis hispidis : foliis duplicato-pinnatis; foliolis inciso-serratis : umbellulis paucissimis, longiuscule pedunculatis.

II.AB. in montibus arduis saxosis, Canadam inter et sinum IIudsonis. 
186 PENTANDRIA. PENTAGYNIA.

spinosa. A. caule arborescente foliisque spinoL. $\quad$ sis : foliis duplicato-pinnatis; foliolis leviter serratis : panicula ramosissima, umbellis numerosis.

$H_{A B}$. in sylvis fertilibus Carolinæ inferioris et Illinoensibus.

$$
\begin{aligned}
& \text { 5. II. OVARIO SUPERO. } \\
& \text { DROSERA.L. }
\end{aligned}
$$

Cal. 5-fidus. Petala 5. Caps. 1-locularis : apice 5-valvis. Sem. pluxima.

LONGrFolia. D. scapis radicatis, brevibus : foliis $I_{4}$. cuneato-obovalibus. $H_{A B}$. in Canada.

RotUNDIfolia. D. scapis radicatis, elongatis : foL. liis cuneato-rotundatis. $H_{A B}$. in Carolina inferiore.

\section{Z A N T H O R H I A. L'HrRIT.}

Cal. o. Petala 5. Nectaria 5, pedicellata. Capsulae 5 , monospermæ.

A PIFOLIA. ZaNTHORHIZA.

L'HERIT.

$H A B$. in nova Georgia et Carolina. 
HEXANDRIA. MONOGYNIA. 187 CLASSIS VI.

\section{H E X A N D R I A.}

\section{MONOGYNIA.}

6. I. OVARIO I NFERO.
A G A V E. $L$.

Cor. erecta, supera. Filamenta corolla longiora, erecta.

VIRGINICA. A. foliis integris, mucronatis : scapo

I. simplicissimo, spicifloro : ovario subrotundo-triquetro: staminibus exertis.

$O_{B S}$. Flores odoratissimi, obsolete virentes.

$H A B$, in herbosis Carolinæ et Virginix.

\section{A M A P Y L I S. $L$.}

Cor. 6-petala, campanulata. Stigma 3-fidum.

Atanasco. A. foliis angusto-linearibus : scapo

L. I-floro: calyce aquali; stigmatibus linearibus, recurvatis.

HAB. $_{A}$ in nmbrosis humidis sylvarum Carolinz. 
Petala 6 : Nectario 12-fido. Stam. nectario imposita.

mexicanur. P. scapo bifloro: staminibus calycem L. subrequantibus.

$O_{B S .}$ Plantæe cultæ scapus 2-5-florus; sylvestris constanter biflorus. Processus nectarii longitudine calycis, et stamina paululum superantes.

$H_{A B}$, in inundatis Carolinæ.

\section{If Y P O X I S. $L$.}

Cor. 6-partita, persistens, supera. Caps. basi angustior. Cal. gluma 2-valvis.

carolinensis. H. foliis subulatis, gramineis : scapis $\mathbf{I}$-4-floris; pedicellis flore et bracteis longioribus : ovario laciniis ovali-lanceolatis quarlruplo et ultra breviore.

OBs. Diversa vidctur ab $H$. erecta. Linn. ex icone Puuchn.

H.AB. in cultis et pascuis aridis Carolinæ, Virginia et Pensylvaniæ. 


\section{A L E T R IS. ”.}

Folia gladiata, exsucca. Scapus radicalis, simplex, spiciflorus; floribus parvulis.

Caz. petaloideus, :tubulosus, breviter 6fidus, seabriusculus. : laciniis subecqualibus, acutis.

Srar. summo tubo, infia laciniarum basim insería, iisdem breviora, erecta : filamenta brevissima : anthera subsagittatx.

Pist. ovarium semiinferum; sensim attenuatum in siylum longíusculum, triquetrum : stigma obtusum, trigonum.

Caps. calyce marcido et paulisper ancto vestita ; inferne infera et rotundato-obtusa ; superne majoreque pro parte libera, trigono-pyramidata, stylifera : 3-locularis, apice 3-valvis.

SErr. numerosa, minutissima, oblonga , arcuata, striata; ad axim adnexa, inani utraque loculorum extremitate.

OBs. Inter species ad Aletrim a $L_{I N N_{A}}$ o relatas, unica $A$. farinosa vere huicce pertinet generi. Habitus NartheciI : fructus fere Pittcalraia.

ILES. A. floribus manifestius pedicellatis 
oblongo-tubulosis : calycibus fructiferis laviusculis, farinosis.

A. farinosa. Linn:

$H_{\& B}$. in America septentrionali.

AUREA. A. floribus subsessilibus, breviter tuWALT. bulatis, subcampanulatis : calycibus fructiferis rugosis, scaberrimis.

OBs. Synonyma Plock. et Moris., a Linnezo ad. Heloniam bullatam relata, huic pertinent. $H_{A B}$, in Carolina.

ઈ. II. ovario SUPERO.

-A. C A P S U L A T $\mathbb{E}$.

J U N G U S. L.

Cal. 6-phyllus. Cor. o. Caps. 1-locularis.

Campestris. J. culıno folioso : foliis planis, vilL. losis : capitulis sessilibus pedunculatis. que.

$I_{A B}$. in montibus Carolinæ.

MELANOCARPUS. J. culmo folioso : foliis sublanceolato-latiusculis, glabris : panicula capillari, laxissima; floribus distincte pedicellatis : capsulis nigricantibus.

HAB. in montibus sinum Hudsonis inter et Canadam, juxta lacum Cycnorum. 
HEXANDRIA. RONONONIA.

$\lg$

BUFONIUS. J. annuus : culmo foliato : foliis subse-

L. taceis : panicula dichotoma; floribus solitariis, alterne sessilibus.

HAB. in Carolina.

REPENS. J. culnis repentibus, foliosis: foliis planis, angusto-granineis : capitulis paucissimis, sessilibus pedunculatisque, paucifloris : calycibus viridulis, subulatis, 3-andris.

$H_{1}$ s. in Carolina et Georgia.

Frmitans. J. culmis capillaribus, surculis nume-

LAM. rosis, reptantibus, inundatione fluitantibus; floribus paucissimis, fuscis, quasi ramillos terminantibus.

IIAB. in amnibus Canadæ.

FILIFORMis. J. culmo nudo, filiformi, erecto, r. superne sæpe subcurvo et debili, media parte laterifloro: floribus paucis, fasciculatis, distinctis, pedicellatis sessilibusque : calycibus pallidis, acutissimis.

HAB. ad sinum Hudsonis.

BICORNIS. J. foliis radicalibus, subsetaceis, canaliculato-planis : culmo erecto, nudo : involucro setaceo-2-phyllo, erecto, paniculam terminalem parvulam superante: 
I92 HEXANDRIA. IO NOGYNIA.

floribus distinctis; calyce lineari-lanceolato, acutissimo, viridulo.

J. tenuis. Rostк. 2't. t. 1. f. 3. Moris, hist. 3. s. 8. t. 9. f. 15.

$H_{A B}$. in Georgia et Cárolina.

Acumatus. J. culmo foliato, erecto : foliis quasi nodoso-articulatis : panicula terminali composita : glomerulis subtrifloris, pedunculatis sessilibusque : calycibus gracilibus, acuminatis , 3-andris.

$O_{B S}$. Habitus omnino $J$. articulati.

$H_{A B}$. in Carolina inferiore.

ARISTUlatus. J. radice bulbosa : culmo foliato, erecto, compresso : foliis anguste canaliculato-planis : panicula composita; glomerulis trifloris, fuscis : floribus triandris; bracteolis et foliolis calycis exterioribus aristatis.

OBs. Habitus J. bulbosi.

$H_{A B}$, in Georgia et Carolina.

polycephalos. J. culmo oligophyllo, firmiter erecto : foliis quasi nodoso-articulatis : capitulis globosis, compacte multifloris , subpaniculatis : calycibus linearibus , 3-andris.

J. nodosus ? Rostк. 38. t. 2. f. 2. et Reicir. syst. 2. pag. $9^{6}$. exclusis synonymis qux ad J. bicornem pertinent. 
IIEXANDRIA. MONOGYNIA.

Var. o.cressifolius : major, foliis multo cras. sioribus et conspicue compressis.

- . tenuifolius : foliis subfiliformibus.

HAB. in Georgia et Carolina.

\section{T R A D E C A N T I A. L.}

Cal. 3-phyllus. Petala 5. Filamenta villis articulatis. Caps. 5-locularis.

Roses. T. foliis gramineis, pralongis : peduns culis elongatis, umbellatim paucifloris: calyce glabro, roseo.

$H_{A B}$. in subudis sabulosis Carolinæ.

riranica. T. erectiuscula: foliis elongatis : flo L. ribus pubentibus, sessilibus, congestis, $H_{A B}$. in Vịginia et Carolina superiore.

\section{P O N T D E R A. $L$.}

Cor. 1-petala, 6-fida, bilabiata. Stam. 5 , apici, 5 , tubo corolla inserta. Caps. 3-locularis.

condita. P. erecta : foliis oblongo-cordatis :

L. spica oblonga, confertim muliflora. $H_{A B}$, in aquosis, a Canada ad Floridam. 
I94 HEXANDRIA. MONOGYN1A.

\section{A C O R U S. $L$.}

Spadix cylindricus, tectus flosculis. Cor. 6-petalæ, nudx. Stylus nullus. Caps. 3-locularis.

Calamus. Acorus.

I.

H.AB. a Canada ad Carolinam.

\section{O R O N T I U M. $L$.}

Spadix cylindricus, tectus flosculis. Cor. 6-petalee, nudæ. Stylus nullus. Folliculi 1-spermi.

aguaticum. Órontium.

L.

$O_{B S}$. Aquatilis, acaulis, glaberrima : folia ereeta, petiolata, ovalia vel lanceolata : scapus radicalis, cylindricus, spica nuda terminatus.

$H_{A B}$, in aquosis , a Canada ad Floridam.

\section{A L L I U M. $L$.}

Cor. 6-partita, patens. Spatha multiflora. Linbella congesta. Caps, supera.

CANADENSE? A. foliis planis, canaliculatis, longe L. angusteque linearibus :..scapo nudo, foliis paulo altiore, compresso : involucro brevissimo : umbellula pauciflora; (vix ultra 8 ) pedicellis erectis, elongatis : 
HEXANDRIA. IIONOGYTIA. Igä calycis laciniis lanceolatis, cum nervo viridi albis : staminibus simplicibus.

FIAB, in Carolina inferiore.

MUtabile. A. bulbo subrotundo; tunicis fibril. losis : foliis scapo cylindrico brevioribus, plano canaliculatis, superne subsetaceoconvolutis, flaccidis : involucro brevi; umbella multiflora aut cum bulbulis pau* cillora : calycis exalbido - rosei laciniis ovali-lanceolatis : staminibus simplicibus.

$O_{B S}$. Interdum capitulum totum bulbiferum.

$H_{A B}$. in Georgix meridionalibus. Ineunte Maio floret.

\section{T I L L I A N D S I A. $L$.}

Cal. 3-fidus, persistens. Cor. 5-fida, campanulata. Caps. 1-locularis. Sem. papposa.

In cunvata. T. parvula, cespitose radicata, prui-

$\boldsymbol{l}$. nosa : foliis subulatis, recurvatis, scapo setaceo, foliis longiore, summitate subbifloro.

$I_{A B}$. in Florida.

usneordes. T. pusilla, filiformis, intorta, prui I. nosa : floribus solitariis, sessilibus.

ITAB. in arboribus littoralibus Carolinz. 


\section{P II A L A N G I U M. Juss.}

Cal. patens aut connivens. Stam. filamentis filifor: mibus, nudis. Semina angulata.

croceur. P. bulbosum : scapo foliis gramineis multo breviore : spica pyramidali; bracteis convoluto-amplexantibus, pusillis, obtusis; floribus croceis : seminibus subglobosis, lavigatis, nigris, nitidis.

IIAB. in herbosis humidis sylvarum Georgix.

\section{Y U C G A. $\boldsymbol{L}$.}

Cor. campanulato - patens, Stylus nullus. Caps. 5-locularis.

FILAMENTOSA. Y. acaulis : foliis latiuscule JanceoI. latis, margine passim filamentosis.

$I_{A B}$. in littoralibus et remotis occidentalibus Carolinæ et Virginiæ.

aloirolia. Y. caulescens : foliis lineari-lanceolaL. tis, minutis denticulis callosis quasi serrulatis.

$H_{A B}$, in littoralibus Carolinæ, Floridæ, \&c.

Groniosa. Y. caulescens : foliis latiuscule lanL ceolatis, integerrimis. $I_{A B}$. in littoralibus Caroline. 
Cor. 6-petala, campanulata : linea longitudinali nectarifera. Caps. valvulis pilo cancellato connexis.

Caradense. L. folin distincte verticillatis, lineari-

$\boldsymbol{L}$. lanceolatis : ramulis pedunculiformibus, plerumque ternis, summitate reflexis : calyce recurvo-complanato; laciniis lanceolatis, maculosis.

IAB. in Canada; montibus Alleglanis Caroline ct Virginix.

caroliniandr. L. glaberrimum : foliis enerviis, plerumque verticillatis, late subcuneatolanceolatis sive obovalibus : ramis floriferis crassis, ternato-terminalibus: (rarius binis aut unico) calycibus valde reflexis, maculosis.

OBS. Affine L. Martago : flores dupla circiter magnitudine; dispositione diversa.

IIAE. in herbosis liunidis Carolinæ inferioris.

Catesвer. L. foliis paucis, sparsis, erectis, lineaIF $A L T$ vibus : flore unico, terminali, erecto: calycis laciniis erectis, ungue longo an. gustoque quasi petiolatis.

II. 1 . a Pensylvania ad Carolinam, locis herbosis lu midis. 
IgS HEXANDRIA. MONOGYNIA.

E R Y T R O N U M. $L$.

Cor. 6-petala, campanulata : Nectario tuberculis 2 petalorum alternorum basi adnatis.

Dexs carrs. E. foliis lanceolato-oblongis : flore I. flavescente.

$M_{A B}$. in frigidioribus America septentrionalis.

\section{U V U L A R I A. $L$.}

Radix fibrosa, aphylla. Caulis herbaceus, inferne vaginatus, superne dichotomus. Folia plana, membranacea, non vaginantia. Flores solitarii.

Cir. petaloideus, ad basim usque 6-partitus : laciniis erectis, campanulatis, longo-lanceolatis, acutis ; unguibus canaliculatis, nectariferis.

Stam. imis laciniarum basibus inserta, erecta, iisdem multo breviora : filamenta brevissima : antheræ longissime lineares, acuminatæ.

PIst. ovarium subrotundum : stylus setaceus, trisulcatus, triqueter : stigmata tria, longa, subsetacea.

CAp. calyce deciduo nudata, trigona, angulis compressis; trilocularis, trivalvis, valvis medio septiferis. 
HEXANDRIA. MONOGYNIA.

SEr. plura, abortatione solito paucissima; irregulariter subglobosa; ad hilum arillata.

PERFoliata. U. foliis perfoliatis : calycis laciniis L. intus granulosis : capsula truncata.

Var. a. major : omnibus partibus major : calyce luteo, intus vix granulato.

- . minor : calycis pallido-exalbidi laciniis undulosis, confertius granulosis : truncatula capsulæ multo minoris depressiore.

Anonymos Erytironio affinis ? Walt. Car. 122.

$H_{A B} \alpha_{0}$ in Canada et altissimis montibus Carolinæ.

$\beta$. in montibus mediocribus Carolinæ et Virginix.

sESSILIFOLIA. U. caule glabro, summitate bifido;

L. ramulo altero sterili, altero unifloro: foliis sessilibus, lanceolato-ovalibus, subtus glaucescentibus : calycis laciniis planis, intus lævibus : capsula ovoidea,. stipitata.

II $A B$. a Canada ad Carolinam, et circa Charistowrs:

PUberula. U. caule puberulo : foliis ürinque concoloribus, ovalibus, basi rotundatis .. 
subamplexicaulibus : capsula ovoidea, sessili.

$O_{B S}$. Affinis procedenti, sed distincta : calyx paulo major, laciniis etiam intus levibus, superne sensim angustatis, acutis.

$H_{A B}$ in altissimis montibus Carolinz.

-B. B A C C A T 压。

\section{S T R E P T O P U S.}

Erpertos, tortuosus. Movs, pes : pedunculiss

distortus.

Pist. stigmata brevissima.

BAcca subglobosa, lævigata; cortice carthaceo; 3-locularis.

Sem. plura, aut abortatione paucissima; ovoidea; hilo nudo.

\section{Cetera Uvularia.}

OBS. Genus Convaluaria proximum.

Distortus. S. glaber : foliis amplexicaulibus : pedicellis solitariis, medio distorto-geniculatis.

Uvularia amplexifolia. Linn.

OES. Antheræ filamentis multo longiores, acumine bifido.

ILAB, in Canadeo sylvarum umbrosis, 


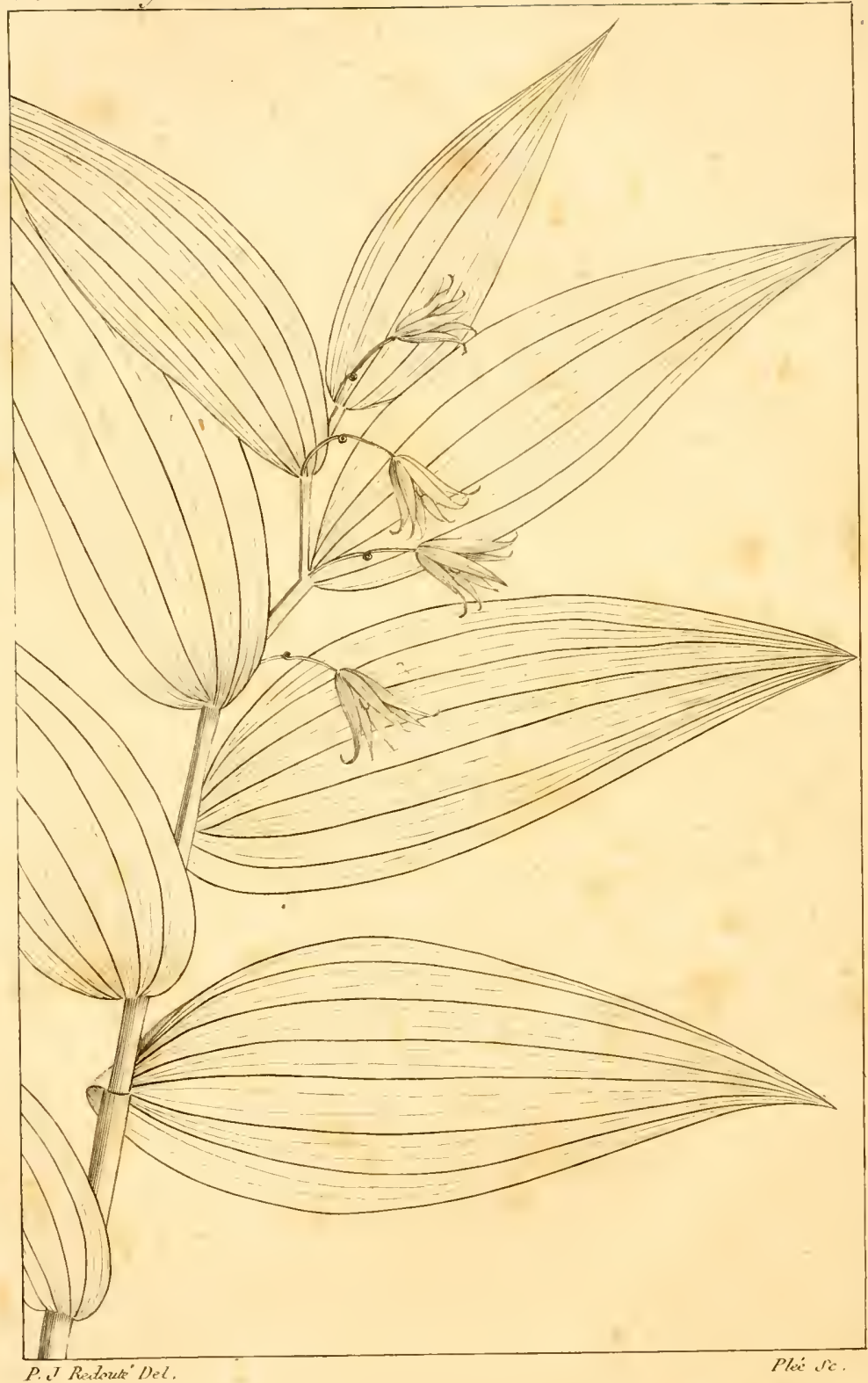

Struptopus posent. 
IIEX N D RIA. MONOGYNIA. 20T

roseus. S. glaber; lucidus : foliis amplexicaulibus, serrulato-ciliolatis : floribus rotab. 18. seis; antheris brevibus, bicornibus.

$H_{A B}$. in cxcelsis montibus Carolinæ septentrionalis et in Canada.

LANUGinosus. S. subcandicanti-lanuginosus: foliis sessilibus, basi vix cordatis : pedicellis in brevissimo stipite geminatis; floribus majusculis, virescentibus.

$O B S$. Folia abrupte longiusque acuminata. Flores tripla congenerum magnitudine, quasi Uvularis. Bacca loculi abortatione 1-2-spermi.

$H_{A B}$, in altis montibus Carolinæ meridionalis.

C O N V A L A R I A. L.

Corolla 6-fida. Bacca maculosa, 5-locularis.

fifolia. C. scapo bi-trifoliato : foliis cordatis : L. floribus tetrandris.

$O_{B S .}$ Folia interdum vix cordata aut etiam oblongoovalia.

Pudckn. tab. 434. fig. 4. hujus varietatem refert.

$H_{\mathcal{A} B}$. in Canada.

majalis. C. scapo radicali, nudo: spica floribus. I. cernuis, breviter campanulatis. IIAB. in altissimis montibus Carolinæ. 
202 IIEXANDRIA. MONOGYNIA.

trifolia. C. caule pumilo, alterne trifoliato:

L. foliis ovali-lanceolatis : spica simplici; floribus erectis.

$H_{A B}$. in rupibus et montosis, a sinu Hudsonis ad Queber.

Uabelulata. C. foliis radicalibus, oblongo-ovalibus : scapo radicali, nudo, pubescente: umbellula terminali, nuda, multiflora.

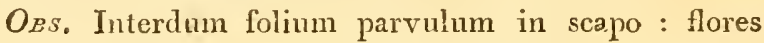
albi, rarins intus purpureo maculati, odorati: plante canadensis umbella sæpe prolifera. Barca majnscula, coerulea, ante maturitatem non punctata.

$I_{A B}$, in montibus Alléghanis.

multiflora. C. foliis oblongo-ovalibus : pedunL. culis axillaribus, multifloris.

$O_{B S}$. An solummodo varietas C. Polygonati? LiNN. $H_{A B}$. in montibus Americæ septentrionalis.

stellata. C. foliis lanceolatis seu ovali-lanceoL. latis, subamplexicaulibus, plurimis : spica simplici, terminali.

$O_{B S}$. Planta sylvestris affinior Polygonato spicato sterili Connutr.

$H_{A B}$. in Canada.

Racerrosa. C. tota pubescens : foliis subpetioL. latis, oblongo-ovalibus, longissime acuminatis : racemo terminali, ramoso. $H_{A B}$, in Canada et in montibus Carolinæ. 

Tom 1. Pag an

Tizb. 20

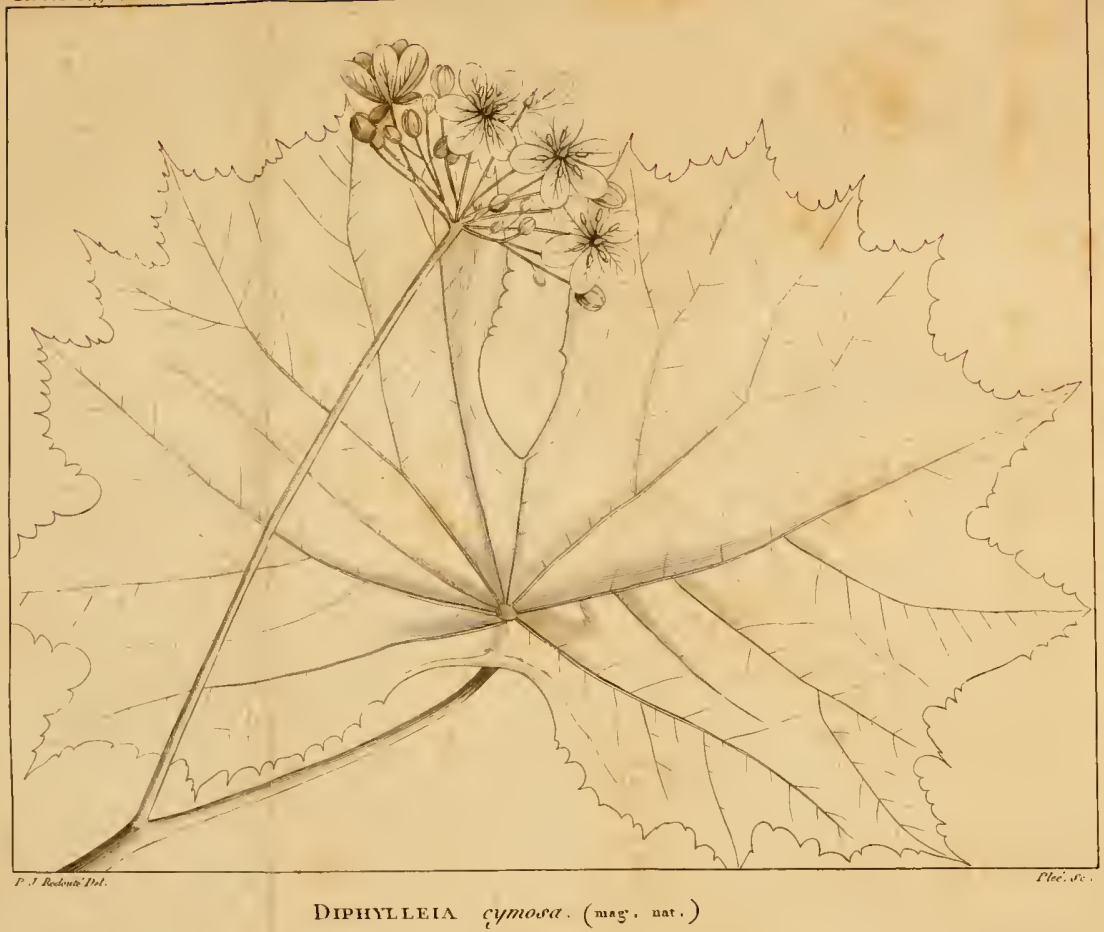





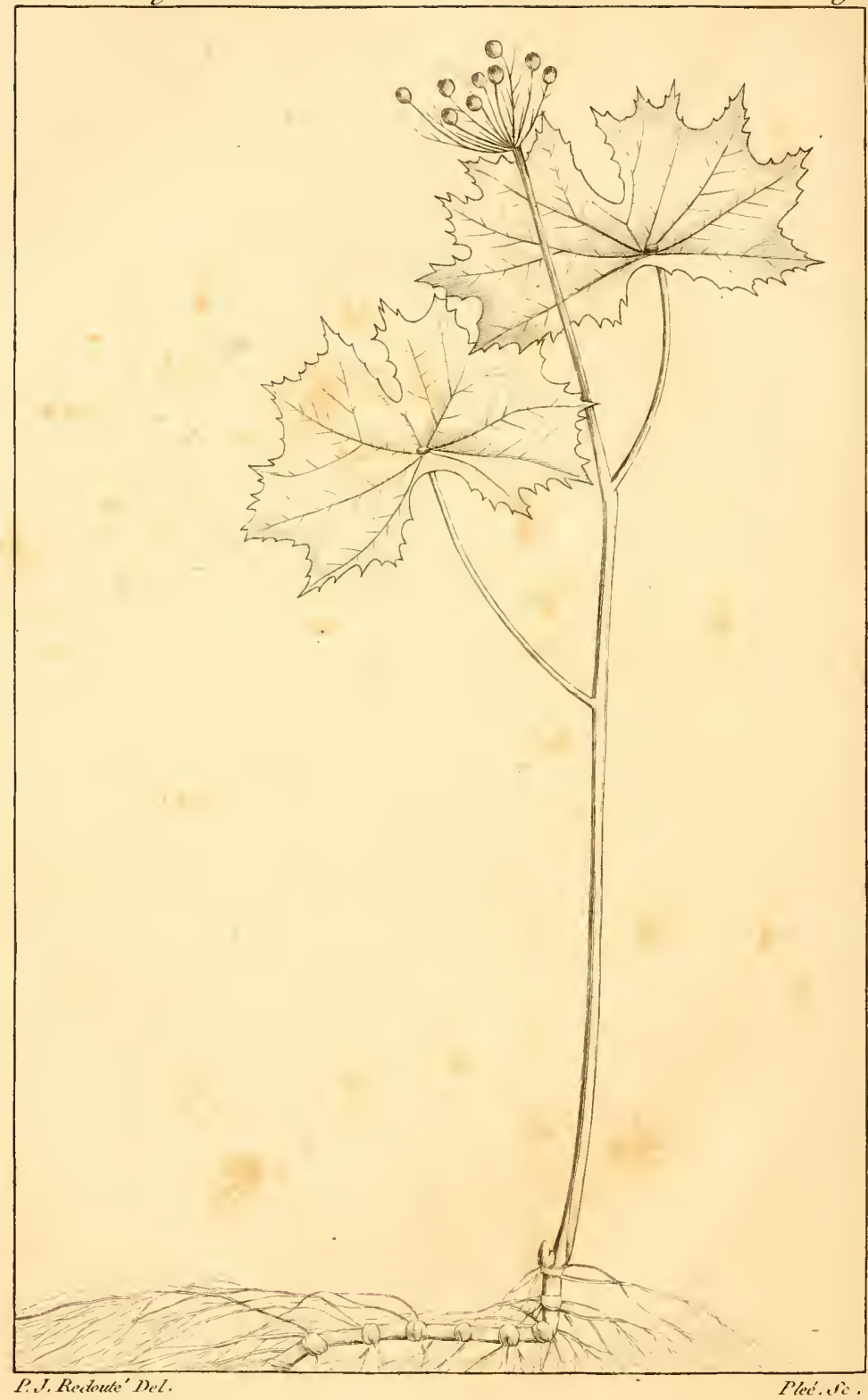

DIPHIT.T.EA cymorit. 
HEXANDRIA. MONOGYNIA. 203

D I P H Y L L E I A.

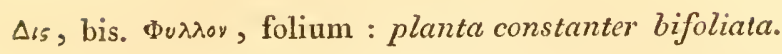

Herba Podophylu peltati; foliis tamen alternis et remote a margine peltatis. Pedunculus terminalis, cyma simplici.

CaL. triphyllus; foliolis ovalibus, concavis, deciduis.

Cor. petala sex, calyce majora, patula, ovalia, concava, decidua.

Stam. sex, petalis dimidio breviora, hypogyna : filamenta brevia, plana : anthera oblonga; loculis membrana a basi ad apicem junctis, eadem soluta dehiscentibus.

PIST. ovarium ovatum : stylus vix ullus: stigma capitatum.

Bacca subglobosa, f-locularis, sessilis. Semina $2-3$, subrotunda.

$O_{B S .}$ Genus affine $\mathrm{C}_{A u}$ uopnyluo.

cymosa. D. glaberrima : foliis subpalmatis, anguloso-lobatis, serratis; lobis acuminatab.19.20. tis : cyma multiflora.

$U_{B S}$. Planta statura Podophy l.r peltati. Flores candidi. Baccæ atro coeruleæ, seminibus purpureis.

$H_{A B}$. in rivulis excelsorum montium Carolinx septentrionalis. Ineunte Maio floret. 


\section{A U L O P H Y L L U M.}

Kav liformi quasi continuo.

Caulis simplex, petioli vicem gerens; terminatus folio composito, basi pedınculifero.

CaL. 6-phyllus, patens, foliolis lanceoJatis.

Cor. calyce multo major eique opposita, 6-petala; petalis obovali-oblongis, obtusis, basi introrsum appendiculiferis, longitudinaliter venosis.

Stam. sex, petalis opposita, his multoties breviora; utraque ad contactum basis ovarii inserta : filamenta brevissimá: antherx iis longiores, oblongo-cordata, 2-loculares; loculis margine exteriore dehiscentibus.

Pist. ovarium obovatum : stylus brevissimus, excentricus : stigma obtusum.

Frucr. drupa stipitata, globosa; molliter carnosa; nux globosa, cornea, crassissima, cavitate centrali minima, monosperma.

Skm. erectum, oblongum. •

-Embryo erectus, albumine tenui, corneo inclusus.

OBS. Genus affine Epimiedic. 


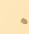


Tom 1. Pay. 20s.

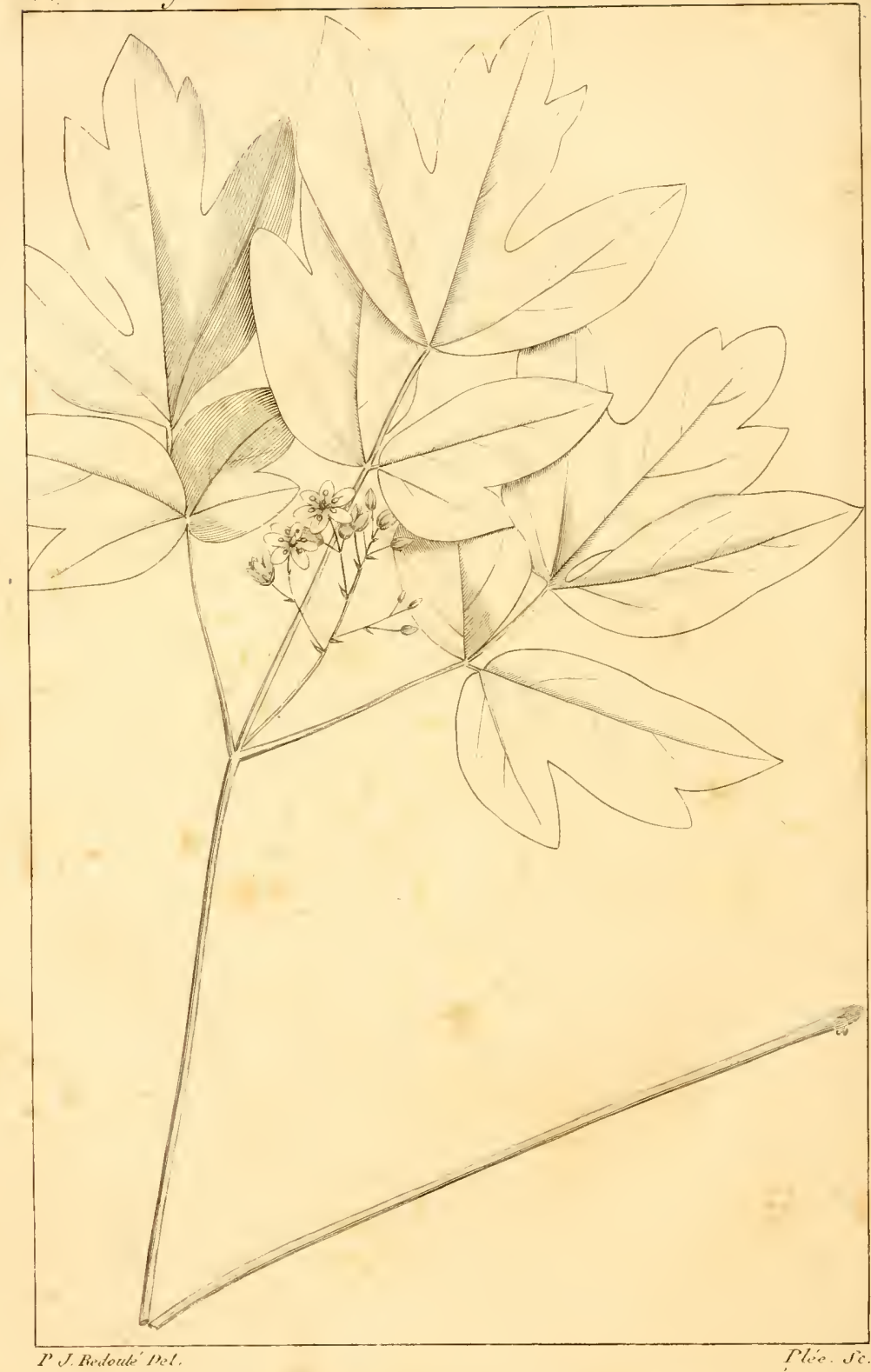

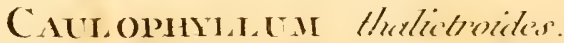


HEXANDRIA. MIONOGINIA. $20 \tilde{3}$

\section{Tinalctromes. C A U L O P H Y L L U M.}

Leontice Thalictroides. Linn.

tab. 21.

Planta subpedalis, glaberrima : herba florescentiaque Eminedi. Interdum caulis nitra folium producitur quasi in ramum terminatum altero folio biternato; tuncque florescentia a basi hujus posterioris folii locum habet. Petioli partiales tres, quinato-pinnati, foliolis ovalibus, inferioribus petiolatis et lobatis, extremo trilobato. Pedunculi solito gemini, altero interiore multo minore : Flores pallido-viriduli. Drupa circiter crassitie fructus Pruñ spinosae, atro-corulea, stipite ipsius longitudine suffuita.

IIAB. in umbrosis regionum frigidiorum et montosarum America septentrionalis.

B E R B E R I S. $\boldsymbol{L}$.

Cal. 6-phyllus. Petala sex : ad ungues glandulis 2. Stylus o. Bacca 2-sperma.

VULGARIS: B. ramis confertim punctatis : foliis

L. rarius serratis : racemis subcorymbosis, abbreviatis : drupis parce carnosis.

$I_{A B}$. in Pelsylvania, Virginia. 


\section{$D I G Y N I A$.}

C A B O M B A. Aubl.

Cal. subæqualiter 6-partitus. Pistilla duo, oblonga.

Capsulae binæ, non dehiscentes , 1-2-spermæ. Semina globosa.

Aubleti. C $\Lambda$ B o $\mathrm{M}$ F $\Lambda$.

Oss. Plantam meam cum Aubletiana attente comparavi; nullamque deprehendere differentiam potui.

$I_{A B}$. in aquosis Carolinæ et Georgiæ.

\section{TRIG YNIA. \\ C. II A M AE R O P S. L.}

Hermapir. Cal.5-partitus. Cor.5-petala. Stam.6. Pist 3. Drupae 3, monosperma.

Mascul. dioici, ut in hermaphrodito.

$O_{B S .}$ Ovarium 3-loculare, loculis 1-spermis, dnobus solito abortantibus.

Palmetro. C. caule arboreo : stipitibus inermibus.

Corypha Palmetto. Whalt.

$H_{A B}$. in maritimis, a Carolina ad Floridam.

SERrulata. C. caule repente : stipitibus minutim aculeato-serrulatis : drupis ovoideis.

$I_{A B}$, in maritimis Georgiæ Floridæque. 
HEXANDRIA. TRIGYNIA.

acauls. C. stipitibus inermibus scapisque lateralibus.

Corypha pumila. Warto

HAB. in Carolina et Georgia.

\section{N O L I N A.}

Folia undique rersa, coriaceo-graminea. Scapus racemiflorus, ramosus : ilores parvuli.

CAL. petaloideus, 6-partitus, patens : laciniis subrqualibus, ovalibus.

Stגim. sex, calyce breviora : filamenta brevia, subulata : antheræ subcordatooblonga, apice leviter emarginata.

Prst. ovarium trigonum : stylus brevissimus : stigmata tria, brevia, recurva, obtusa.

Fruct. capsula membranacea, circumscriptione subrotunda, trigona, trilocularis; loculis I-spermis, unico solito fertili, rarius 2 : septis bipartibilibus dehiscens.

SEM. loculo minus, ad hujus basim adnexum, erectum, brevi-obovatum, exterius convexo-incurvum, interius foveatim excavatum, superficie inæquabili.

P. C. Nolin, Gallus; acer plantarum præsertin Amerieanarum cultor, non mediocri bolanices et agriculturæ emolumesto. 
Grorgians. N. glaberrima : foliis angustissimis, longis, coriaceo-gramineis : scapo inferne foliis subulatis sparsim vestito, remote laxeque ramoso, ramis raccmifloris: pedicellis aggregatis.

$O_{B S}$. Bulbus tunicatus, perennis. Folia 5-9-uncialia , lineam lata, striata, aride et crasse graminea, margine scabra. Scapus 2-pedalis et ultra. Flores minuti, albidi. Planta hinc Phalang ro inde HeLonisis affinis. $H_{A B}$. in Georgia.

\section{T R I G L O C If I N. $L$.}

Cal. 5-phyllus. Petala 3, calyciformia. Stylus o. Capsula basi dehiscens.

manitimum. T. floribus 6-andris : capsulis breviL. bus, ovatis, 6-locularibus.

$H_{A B}$. in littoribus inundatis fluminis $S$. Laurentii.

triandrum. T. foliis subsetaceis, scapum spicamve subaquantibus : floribus breviter pedicellatis, trifidis, triandris : capsulis trigono-subrotundis.

$I_{A B}$. in inundatis, circa Charlstown. 
İEXANDRIA. TRIGYNIA. -209

S C IIEUCIIZERIA. $L$.

Cal. 6-partitus. Cor. o. Styli o. Caps. 3 , inflate, 1-sperm:e.

PALUSTRIS. SCHEŨC II ŹERIA.

L.

$\not \dot{L}_{A B}$. in palndosis Canadx.

NAR T JPE I U M. Juss.

Cal. wqualis, calyculo minimo, 5-partito cinctus. Caps. polysperme, basi junclie.

pusillum. N. lave glabrumque : foliis brevissimis : scapo filiformi : spica pauciflora, conglobata : calyculo rachi adnato : capsula globosa.

OBs. Affine N. alpino sive Antuerico calyculato; omnibus partibus minus : calyculo non immediate sub calyce, sed rachi innato é́ basim pedicelli cingente.

iHAB, ad lacus Mistassins.

pubers. II: scapo, rachi pedicellisque quasi pulverulento-pubentibus et asperiusculis : spica oblonga, fasciculis plurinis interrupta : capsula subglobosa, vix calycem superante.

Metanthium racemosum. WALt.

Anthericum calyculatum. Gron. nec Linn.

II.1S. in Carolina inferiore, circa Charlstown.

r. 
grutirosum. N. scapo pedicellisque scabris et glutinosis : spica fasciculis paucis alternantibus : capsula ovoidea, calyce duplo longiore.

Obs. Habitus Antmerici ossifragi.

H.AB. a Quebec ad usque lacus Mistassins.

\section{E R O P I YL L U M.}

Radix fihrosa. Folia arida, angusta, quasi graminea, sparsa. Spica racemiformis, pedicellis unifloris.

CaL. petaloideus, patentissimus, profundissime 6 -partitus : laciniis ovalibus, planis; tribus alternis tantisper minoribus.

Stam. 6, fere longitudine calycis, crecta : filamenta subulata, basibus inter se et ovario contigua : antherx subrotunda, utrinque emarginatre.

PIST. ovariunı subglobosum, obtuse trigonum : stigmata 3 , angusto-ligulata, introrsum sulco glandulari canalicülata, inferne erecta, superne revoluta.

Capsula calyce marcido multoties major, oblongiuscule subglobosa, convexo-trigastra seu quasi tricocca, subtestacea, 3-Iocularis, superne mediis ventriculis trifariam dehiscens.

Semina in singulis loculis bina, basi interna 
HEXANDRIA. TRIGYNIA. 2IT ima cavitati adnexa, erecta, oblonga, compressa.

$O_{B S .}$ Genus Helonite affine.

setifolium. $\mathrm{X}$. foliis subulato-setaceis。

Helonias asphodeloides. Linn.

H E L O N I A S. $L$.

Folia debiliter recurva, ad radicem undique suljsvaginanti-congesta. Scapus simplicissimus, basi plus minus tunicatus, bulbescens, ima parle foliosus, cætero sparsim distanterque squamosus. Spica terminalis, simplex, breviuscula, multiflora; floribus pedicellatis, crebris; bracteolis brevissimis.

CAL. petaloideus, patens, profundissime 6-partitus : laciniis subrqualibus, oblongo-ovalibus, planiusculis.

Sтмм. 6, calyci subecqualia aut paulo longiora; ad contactum ovarii inserta : filamenta sefacea, basibus non dilatatis dis tinctissima : antherx cordato-reniformes $\mathrm{ab}$ apice rotundato patule bivalves.

PIsT. ovarium irigonum; angulis in totidem stylos setaceos sensim desinentibus.

Capsula calyce marcido basim cingente conspicue major, membranacea, apice trifida, tricornis; trilocularis, olygosperma. 
Semin i in singulo loculo paucissima, (1-2, rarius 3) assurgentia, forma varia nec tamen complanata.

Obs. Genus hinc Nartiecio, inde Vtratro cognatum. Promissiones ovarii, in his aflinibusque generibus styli dictæ, rectius forsan stigmala appellandæ.

ratrfola. II. foliis lanceolatis, acuminatis : scapo subaphyllo : spica purpurascente, con . ferta; floribus brevissime pedicellatis: antheris coerulescentibus.

II. bullata, Linn. Amcen. acad. III. pag. I2.t. I. fig. 1. mala.

Veratrum \&c. Mird. Ic. 181.t. 272. foliis multo brevioribus quam in planta sylvestri : squamis sćapi etiam justo multoties majoribus.

OBs. Nomen billata ex aliena Plucknati phrasi manifeste dedurerat Linnsers.

$H_{A B}$. in Pensylvaniæ et Marylandiæ palndosis.

Jr YTIROSPERMA. H. foliis lineari-longissimis : scapo folioso : floribus virescentibus : antheris pallido-albidis : capsula abbreviata, lobis divaricatis, turgidis : seminibus ovatis, tegumine carnoso rubentibus.

An Mecantinum muscaetoxicum. Walt. Car. 125?

$H A B$. in umbrosis rivulis Caroline inferioris.

Argustrfolis. TI. foliis longissimis angustissimisque : scapo inferne folioso: spica laxius- 
HEXANDRIA. TRIGYNIA. 2I? cula; floribus exalbidis : antheris luteis: capsula oblongiuscula : seminibus angusto-linearibus.

$I_{A B}$. in herbosis et fruticetis sylvarum humidis

Carolinæ inferioris.

busla. H? foliis angustissime, longissimeque gramineis: scapo nudo : spica gracili, floribus parvis, sessilibus.

$N^{2} \cdot 2-2 \frac{1}{2}$ pedalis : an genere distincta? fructus ignotus.

$H_{A B}$. in sabulosis Georgix et Florida.

\section{Z I G A D E N U S.}

Jerba Semapie : florescentia Melantmir. Flores ommes fertiles.

CaL. petaloideus, patentissimus, profundissime 6-partitus; laciniis aqualibus; sub. ovalibus, oblongis, supra basim paulisper sensimque angustatam biglandulosis.

Stam. 6, ad contactum ovarii inserta : catera Melanthir.

PIst. ovarium triquetrum, oblongum, sursum sensim angustatum; styli 3 , contigui, obtusi.

Frucit. capsulacalyce connivente et appresso brevior, membranacea, conoideo-ovata, acuta, stylis contiguis, persistentibus 
terminata, rotundata, subtrigona, leviter trisulcata : trilocularis; loculis polyspermis.

Sem. plurima, lineari oblonga, angulosa : tegumine nucleo ampliore, membranaceo nec alato.

OBS. Genus hinc stiminum sitn et calycis figura $\mathrm{V}_{\mathrm{E}-}$ Tiatro affine, inde glandulis Melanthio: ab utroque floribus omuibus hermaphroditis et præprimis fructu discrepans.

claberrmus. Z. glaberrimus : folïs longo lanceolatis, recurvis, canaliculatis : laciniis ₹ab.22. calycis acuminatis.

$O_{B S .}$. Caulis subpedalis; folialio Serapia augustifoliae: flores albidi, magnitudine Veratri albi.

$H_{A B}$. in herbosis, humidis, Carolinæ inferioris.

$$
\text { M E D E L A. L. }
$$

Cal. o. Cor. 6-parita, revoluta. Bacca 3-sperma. Na. Mrneola asparagoides, $L$. generis diversi.

vraginica. M. caule lanugine decidua vestito : foL. liis in medio caule 6-8-verticillatis, in summitate ternis; ovali-lanceolatis : pedicellis aggregatis, terminalibus.

HAB. per totam Americam septentrionalem. 
Tom 1. Pag.214

Tab. 22

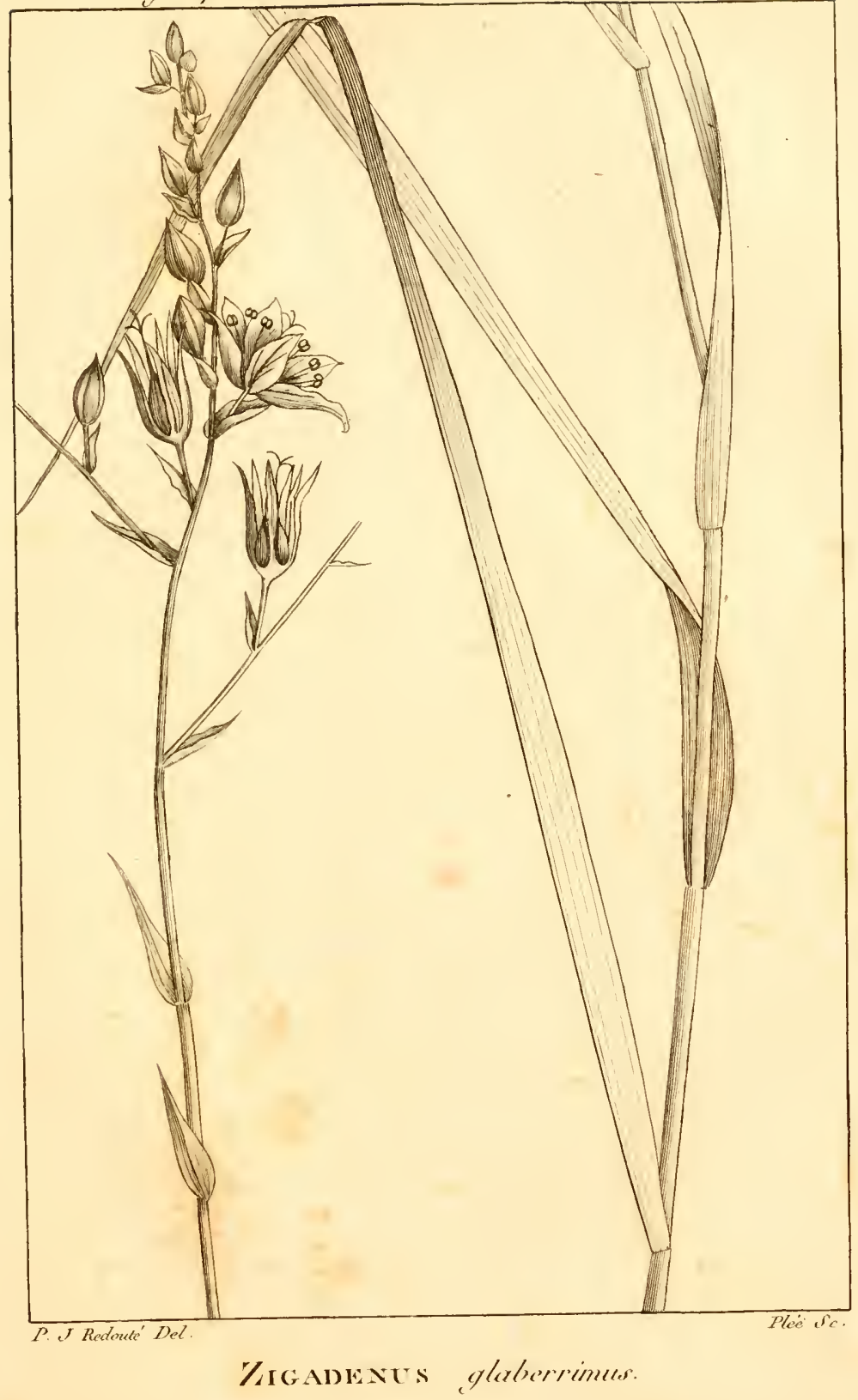





\section{T I I L I U M. $L$.}

Cal. 6-phyllus patens, laciniis 5 alternis exterioribus angustioribus. Bacca 5 -locularis.

SESSILE. T. foliis sessilibus, lato-ovalibus ; flore

$\boldsymbol{L}$. sessili : laciniis calycis interioribus duplo longioribus, erectis, sublanceolatis : bacca depressa, globosa, violacea.

HAB. in umbrosis sylvis Pensylvanix et utriusque Carolinæ.

pusillur. T. pumilum : foliis ovali-oblongis, obtusis, sessilibus : pedunculo erecto : calycis laciniis interioribus vix longioribus.

$O_{B S}$. Laciniæ calycis petaloideæ dilute caruex.

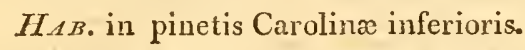

nromnomeur. T. foliis lato-rhomboideis : pedunculo inclinato : calycis laciniis omnibus longitudine subrqualibus, rectis; exterioribus ovali-lanceolatis; interioribus plus minus ovalibus : bacca subglobosa, nigricante.

1. erestum. LINN.

Var. a. atropurpureum : flore majore; laciniis petaloideis atro-purpureis.

- . album : flore dimidio circiter minore; 12ciniis petaloideis albis, obtusis, acuninatis. 
- $\%$ grandiflorum : flore maximo; laciniis potaloideis amplissimis, exalbidis.

$I_{A B}$. in excelsis montibus Carolinæ.

cernuur. 'T. foliis lato-ovalibus, basi angustatis :

t. pedunculo recurvato: laciniis petaloideis multoties amplioribus, recurvatis, patentibus, dilute roseis.

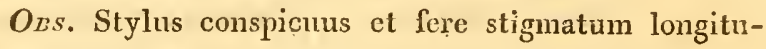
dine!

$H_{A B}$. in montosis Carolinæ supcrioris.

RaYTHROCARPUM. T. foliis basi rotundatis, subcordatis, abrupte subpetiolatis : flore erectiusculo: laciniis petaloideis subduplis, ovali-lanceolatis, recurvatis, albis, inferne purpuirascentibus : bacca oblonga, coccinea.

HAB. in excelsis montibus Carolinæ septentrionalis et Canada, ad sinum Hudsonis.

\section{R U M E X. L.}

Cal. 5-phyllus. Pelala 33, conniventia. Sem. 1, triquetrum.

acetosella R. floribus dioicis : foliis lanceolato-

L. hạstatis.

$I_{A B}$ in America septentrionali. 
crispatulus. R. hermaphroditus : foliis inferio. ribus ovalibus, superioribus lanceolatis; omnibus margine crispatis, undulosis : spicis aphyllis : calycis fructiferi valvulis obtuse cordatis, utrinque éristatis, tridentatis; una nuda, binis inæqualiter graniferis.

$O_{B S .}$ Affinis R. persicaroideo. Habitus $R$. acuti; calycibus fructiferis multo majoribus. Folia suprema minutim crenulata.

$H_{A B}$. in Kentucky.

verticillatus. R. aquatilis, hermaphroditus : fo*

t. liis longo-lanceolatis, margine æequalibus; vaginis promisse tubulosis : spicis aphy!lis ; floribus omnibus longiuscule pedi. cellatis : calycis fructiferi valvulis integris et graniferis.

HAB. in aquosis Canadx.

Britanyica. R. aquatilis, hermaphroditus : foliis I. latiuscule lanccolatis, planis, lavibus : vaginis obsolete laceris : panicula spicis aphyllis : calycis fructiferi valvulis omnibus integris et graniferis.

Oss. Habitu quodammodo $R$. Patientiae; sed multo minor.

HAB. in Carolinæe aquosis. 


\section{$T E T R A G Y N I A$. S A U R U R U S. L.}

Cal. amentum squamis 1-floris. Cor. o. Ovaria 4. Baccae 4 , monospermæ.

cernous. S. caule folioso, polystachio. $\boldsymbol{L}$.

$\boldsymbol{L}$.

Mattuscina, Gmer. Syst. $58 \mathrm{~g}$.

$$
P O L Y G Y N I A \text {. }
$$

A I I S M A. $L$.

Cal. 5-phyllns. Petala 3. Sem. plura.

Plintaco. A. foliis ovalibus cordatisve : umbellis

L. composite verticillato-paniculatis : capitulis fructualibus obtuse trigonis.

- $H_{A B}$ in Canada.

subulata. A. perpusilla : foliis linearibus : um-

๘. bellis subsimplicibus : floribus oligogynis.

$O_{B S}$. Plantula $2 \cdot 3$-uncialis : affuis $A$, ranunculoidi.

$H_{A B}$, in Florida. 
HEPTANDRIA. MONOGYNIA. 213

\section{CLASS IS VII. \\ H E P T A N D R I A. \\ MONOGYNIA.}

E S C U L U S. $L$.

Cal. 1-phyllus, 5-dentatus, ventricosus. Cor. 5-patala, inæqualiter colorata, calyci inserta. Caps. 5-locularis.

Pavis. $\therefore$ E. floribus rubris : racemo laxo, fas-

L. ciculis bi-trifloris : calyce glabriusculo, tubuloso.

$O_{B S}$. Stamina sylvestris plantæ sæpius 7 : petala sæpe 4. Frutex 2-5-pedalis.

$\mathrm{N}^{\mathrm{a}}$. Ominium specierum stamina numero variabilia.

HAB. in Carolina.

LUtEA. E. floribus luteis : racemo fasciculis multifloris : calyce campanulato, subtomentoso: petalis 4 : staminibus plerumque 7 .

OBs. Arbores sylvestres in Kentucky et excelsis Carolinæ montibus, solo pingui, ad altitudinem Hippocastani europæi assurgunt.

$H_{A B}$. in Kentucky et Carolina superiore. 
macrostachya. E. foliolis subtus subtomentosis : racemo pyramidato, longissimo, multifloro; floribus albidis, tetrapetalis, plerumque heptandris.

A. parviflora. WALT.

$O_{B S}$. Arbuscula humilis, quandoque tamen FscuxuxI rubrum superans; plerumque vero ujerius stolonifera.

$H_{A B}$ ad ripas ammis Savannah, juxta urbiculam S. Augusti.

Cal. 7-phyllus. Cor. 7-partita, æqualis, plana, Bacca exsucca.

EUROPEA. T. folis angusto-lanceolatis: cæteris $L$. omnino europex.

$H_{A B}$. in sphagnosis, cupressetis Novæ Angliæ et in Canada. 


\section{CLASSIS VIII.}

OCTANDRIA.

\section{MONOGINIA.}

6. I. OVARIU INIERO.

R H E X I. $L$.

Cal.4-fidus. Petala 4, calyci inserta. Antherae declinats. Caps. 4-Iocularis, intra rentren calycis.

miariata. R. caule ruf́escente, hirsutissimo:

L. foliis hirsutis, basi subpetiolatis, angustatis, ovali-olslongis vel lanccolatis, vel etiam linearibus : calyce longe tubuloso, glabriusculo.

Var. c. purpurea : foliis angusto-lanccolatis : floribus saturate purpureis.

- . rubella : foliis ovali-lanceolatis, vel oblongis : floribus dilute rubellis.

- $\gamma$ exalbida : foliis linearibus : caule hirsutiore : floribus pallidis : quæ $R$. lanceolata, WALT.

ciliosı. R. caule sub4-gulato, glabro: foliis parvulis, subpetiolatis, ovalibus, subtus glabris, supra rariter hispidulis. 
margine promisse et distincte ciliatis : floribus paucioribus, involucratis : antheris breviusculis.

Affinis $R$. petiolata. WALT.

$O_{B S}$. Flores violaceo-purpurei.

$H_{A B}$, in Carolina inferiore.

Lutea. R. caule quadrangulo, hirsuto : foliis $W_{\Perp L}$ ', rariter longiuscule que hirsutis; inferioribus cuneato-oblongis, obtusis; superioribus lanceolatis : floribus luteis : antheris breviusculis.

HAB. in Florida et Georgia.

virginica. R. caule alato-angulato, pilis rarioL. ribus adsperso : foliis sessilibus, ovalilanceolatis, denticulis setaceis distinctis. que ciliolato-serratis, hirsutie sparsa utrinque hispidulis.

$O_{B S}$. Multum statura variat, 1-2 ped.; etiamque 3-4 ped. in inundatis et tuue folia 5-7 nervia : unde septemnervia W WLTERI.

Calyx floridus lrispidulus : petala purpurea, uti in plerisque hujus generis speciebus.

$H_{A B}$. in Virginia Marylandia, Carolina, nova Ccsarea.

GLAbelra. R. caule cylindraceo, glabro : foliis sessilibus, erectis, lanceolatis, lævibus, glabris, integris : floribus brachiato-sub- 
UCTANDRIA. MONOGYN1A. 223 paniculatis : calycibus brevissima hirsutie glutinosis.

OBs. Afmin R. Alifanus, W glauca, superne vix perceptibilibus rarioribusque denticulis prædita. Flores majusculi, dilute purpurascentes.

$H_{A B}$. in sylvis Caroline et Georgize.

\section{E P I L O B I U M. $L$.}

Cal. 4-fidus. Petala 4. Caps. oblonga, infura. Sem. papposa.

tetragonum. E. caule lineis prominulis subqua-

L. drangulato : foliis oppositis, supremis alternis, serrulatis.

$O_{B S .}$ Variat foliis ovalibus et lanceolatis. Flores pusilli.

$X L_{A B}$. in Canada et in excelsis montibus Carolinx.

oliganthum. E. pusillum : eaulibus simplicissimis, apice suburifloris : foliis oppositis, linearibus, iniegerrinis.

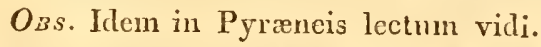

HAB. ad sinum Hudsonis et lacus Mistassins.

ANGUSTIFoliur. E. foliis sparsis, lanceolatis : ra-

I. cemo multifloro, candicante; floribus inxqualibus.

$H_{A B}$. in Canada. 
Cal. E-fidus. Pelalce 4. Caps. cylindrica, inferaSem. nuda.

* Fructu siliquato.

вIENnis. $\quad$ E. caule valido, villoso, passim scaL. bro : foliis crebris, latiuscule lanceolatis, manifeste dentatis : floribus in supremis ramis axillaribus, majusculis: capsula crassius siliquata, sessili.

HAB. in campestribus, circa culta et habitata loca Pensylvanii.

sinuata. $\mathbb{E}$. decumbens, tota molliter pubens :

L. foliis ovali-oblongis, plus minus sinuatodentatis : floribus axillaribu's, villosissimis : capsula siliquata.

$H_{A B}$, in Virginiæ et Carolinæ pascuis aridis.

** Truetu ientricoso, aculangulo.

GLAUCA. $\%$. glaberrima : foliis lato-ovalibus, repando-subdentatis, lævigatis, glaucis : capsula ovato-tetragona.

IIAB. in sylvis remotis et occicentalibus flumini MTississipi confinibus, Tersus regionem Illinoensitum. 
OCTANDRIA. IIONOGINIA. 225

IYYBRIDA. E. caule erecto, villoso: foliis utrinque pubescentibus, lanceolatis, remote subdentatis, undulatis : capsulis subspicatis, breviter stipitatis, ovato-tetragonis.

$H_{A B}$. in Carolina superiore.

xinearis. E. tota pubescens, gracilis : foliis linearibus, integris : capsulis longiuscule stipitatis, subrotundo-tetragronis, villosis.

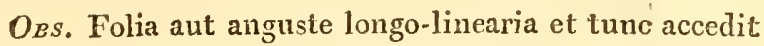
icon Pluckn. t. 426. f. 6 : aut lineari-oblonga et in. terdum utrinque candicanti - subtomentosa; quavidetur affinis Onagrce n $1^{\circ} 491$. Claytoni.

HAB. in Carolini superiore.

chrysantha. (E. caule debili, minutissime pu. bente : foliis lanceolatis, obtusiusculis, planis, integris : floribus parvis, aus reis : calycis tubo laciniis duplo bre. viore : capsula clavata, acutangula, ses. sili.

Ozs. Planta subpedalis et infra. Flores magnitudine Epı́овir palustris, petalis pulchre luteis.

HAB. a Quebec usque ad sinum Hudsonis.

pusilla. E. minutim pubescens : caule pumilo, simplici; foliis lanceolato-oblongis, obtusiusculis, integris : floribus ad sum-

I,

15 
mitatem axillaribus : capsulis sessilibus, clavato-turbinatis, subrqualiter 8-gonis.

$O_{D S}$. Plantula 4-6-uncialis, erecta. Capsulà a nervo seu. costula mediarum facierum conspicuius eminente quasi 8-angulata et usque ad basim profundius 8-sulcata.

HAB. in rupibus, ad lacus Mistassins.

$$
\text { G A U R A. } L \text {. }
$$

Cal. 4-fidus, tubulosus. Cor. 4.petala, adscendens versus latus superius. $N u x$ infera, 1 -sperma, 4-angula.

biennis. G. foliis lanceolatis : spica conferta :

L. fructibus subrotundo-4-gonis, pubescentibus.

OBs. Icon Plucks. non quadrat!

$H_{A B}$, in Virginia.

ANGUSTIFOLIA. G. foliis crebris, linearibus, repando-undulosis : spicæ fructibus dissitis, oblongo-4-gonis, utrinque acutis , subcandicantibus.

$O B S$. Flores duplo minores.

$I I_{A B}$. in Carolina inferiore. 


\section{A C C I N I U M. L.}

Cal. superus. Cor. 1-petala. Filcmenta receptaculo inserta. Bacca 4-locularis, polysperma.

§. I. COROLLA SUBCAMPANULATA SIVE NON URCEOLATA.

* Antheris exertis.

stamneur. V. foliis ovalibus, albicantibus : pe-

L. dicellis solitarie axillaribus : corolla brevi, campanulata : antheris exertis, dorso aristatis : bacca pyriformi.

$O_{B S}$. Variat canie humili et elatiore : ramulis foliisque pubentibns et glabellis; foliis subtus modo vix albicantibus, modo candidis; floribus minoribus ct antheras breviter exerentibus, majoribus et staminibus eminentibus. Folia integra : cor. alba: bacca virescens.

HAB. a Pensylvania ad Floridam.

erttirocarpum. V. foliis ovalibus, acuminatis, serrulatis ciliatisque : pedicellis solitarie axillaribus : corolla longa, lineari-4-partita, dethum revoluta: antheris exertis, dorso muticis.

$O_{B S}$. Frutex ercctus ; ramis solito divaricatis flexuosisque : folia majuscula, tenui-membranacea, juxta merros utrinque hirsutula. Calyx minutus, agnt: 
4-fidus : corolla ante explicationem longa, conoidea. Bacca globosa, nitida, coccinea.

$H_{A B}$. in altis montibus Carolinæ septentrionalis.

Oxycoccus. V.repens; foliis ovalibus oblongisve, I. integerrimis, margine revolutis, glabris, subtus albicantibus; pedicellis elongatis : corolla 4-partita; laciniis ovali-lanceolatis, reflexis : antheris exertis, dorso muticis.

Var. a. ovalifolizes : fol. ovalibus, subacutis: corollæ laciniis ovalibus.

- . oblongifolius : foliis oblongis, obtusis: corollæ Jaciniis lanceolatis : fructu paulo majore.

V. macrocarpon. Ait. Hort. Kew.

$O_{B S .}$ Numerosa, quæ in diversis Americæ regionibus legi et examinavi, conferens specimina; invenio multa europæa prorsus similia, aliaque parumper discrepantia. Etiam vero occurrunt intermedia; ideoque ea omnia ad eandem speciem referre operæ prætium duxi. Fructus magnitudine variabilis.

'IIAB, in Canada.

** Antheris inclusis.

IISPIDUlum. V. repens, hispidulum : foliis subI. rotundo-ovalibus, acuminatis : floribus tab. 23. solitarie axillaribus, subsessilibus : ca- 


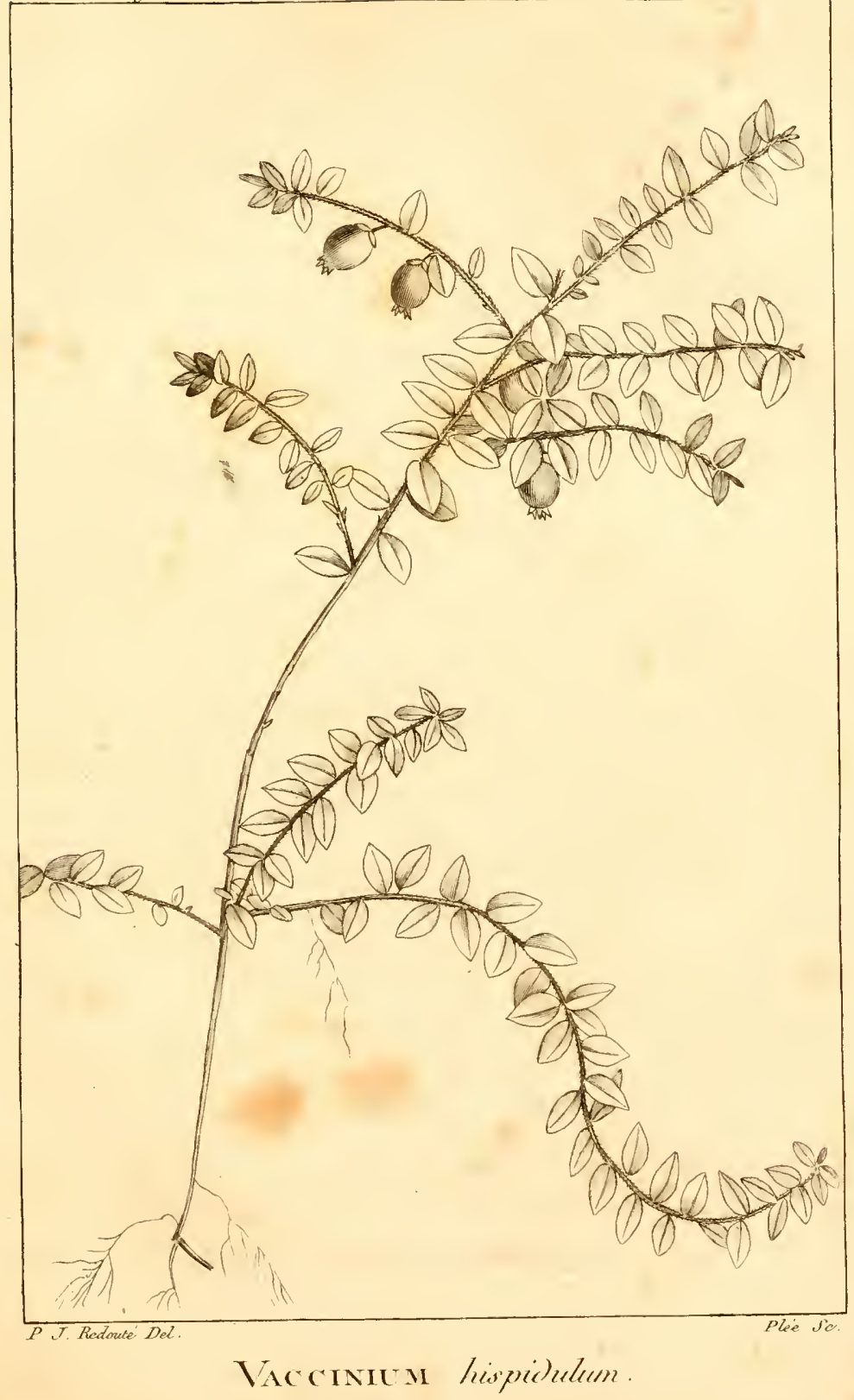


OCTANDRIA. MONOGYNIA. 229 lyce calyculato : corolla brevi-campanulata , 4-fida.

Arburus thymifolia. Ait.

A. filiformis. Lam. dict. $\mathrm{n}^{\circ} .8$.

$O_{B S .}$ Oxycocco paulo minor; caulibus ferrugineo-hirsutis. Folia margine subtusque passim hirsuta. Flores minuti : calyx bracteolis binis involucratus. Ovarium semiinferum. Bacca subgloboso-ovata, nivea, infra verticem convexum coronata, suavitcr edulis.

$I_{A B}$. in cupressetis humidis novæ Angliæ et Canadæ. Aprili florens.

MYRTIFOLIUm. V. repens, glaberrimum : foliis petiolatis, ovalibus, lucidis : margine recurvo rariter denticulatis : fasciculis axillaribus, subsessilibus, paucifloris: corolla subgloboso-campanulata, brevissime 5-denticulata.

OBs. Antheræ dorso muticæ. Baccæ pusillx, subpedicellatæ, globosæ, coronatæ, nigræ.

$H_{A B}$, in Carolina.

Vitis Id

I. tibus, cæteris erectis, puberulis : foliis obovalibus, apice subemarginatis, lucidis, glabris, subtus punctatis : racemulo terminali, subsessilifloro : corolla patulocampanulata, semi5-fida.

OBȘ. Interdum stamina 8 : folia plerumque integra; 
raro subdentata; margine semper recurvo. Bacca rubra.

$H_{A B}$. in rupibus maritimis America borealisa

Fronnosur. V. ramulis, foliis racemisque glan-

L. duloso-puberulis': foliis oblongo-obovalibus, integriusculis : racemis laxe alternifloris, folioso-bracteatis : corolla campanulata, 5-fida.

OBS. Frutex humilis, erectus; ramis inferne nudis; infra, inter aut supra ramulos florifer. Calyx viscido-glandulosus. Bacca globosa, nigra.

HAB. in pinetis, aridis, a Virginia ad Floridam.

ARBoreun. V. foliis petiolatis, obovalibus, muMARSI. cronatis : racemis bracteatis : corolla campanulata, acute 5 - fida : antheris dorso aristatis.

Ö́s. Arbor 15-20-pedalis, speciosa. Folia lncida, punctis glandulosis rariter serrulata; subtus minutim pubentia; supra glabra, interdum suborbiculatt. Stylus exertus. Bacca globosa, nigra, parum succosa.

$H_{A B}$. in sylvis subaridis, a Carolina ad Floridam.

S. II. COROLLA URCEOLATA.

* Racemis distincte multifloris.

RESINOSUM. V. foliis tenuibus, oblongo-ovalibus, Alx. muticis, integris, subtus atomis resino* 
OCTANDRIA. IIONOGYNIA. $23 \mathrm{r}$ sis irroratis : racemis lateralibus, deorsum secundis : corolia 5-gono-ovata.

$O_{B S .}$ Folia petiolata, plerumque obtusinscula, rarius acuta :raeemi confertiusculiflori, pedicellis brevibus. Corolla pallide virescens, obsoleto rubore tincta, fauce conspicue coarctata.

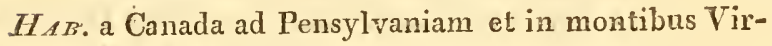
ginix et Carolinarum.

GLAUCUM. V. foliis oblongo-obovalibus vel cuLAM. neato-sublanceolatis, apice muticis, integerrimis, dilute glaticis, subtus copiose resinoso-atomiferis : racemis vage laxifloris : corollis globosis.

OBS. Affine $V$. resinoso, præsertim corolla distingnendum. Folia plerumque obtusa, interdum acuta et sublanceolata; subtus (præsertim vetula) reticulato-venosa. Bacca globosa, cæsia sive glauco-nigra, edulis.

$H_{A B}$ a Pensylvania, ubi rarissimum; ad Carolinam, in qua frequentius occurrit.

** Glomerulis fasciculisve gemmaceo - multisqua mosis.

DisomorpIUm. V. ramulis angulatis : floratione subaphylla : foliis oblongo-ovalibus, acutis, subserrulatis : fasciculis squamoso-bracteatis : corolla oblongo-ovata, 

sura dehiscentibus.

$O_{B S}$. Frutex modo humilis, modo subarborescens; cortice ramorum scaberulo. Folia sub floratione novella aut rarius uulla; minute mucronata, subtus pubentia : interdum integriuscula. Squamæ gemmaceæ et florales purpurascentes. Pédicelli modo squamis occultati, modo manifesti. Calycis laciniæ subrotundæ, obtnsinsculæ. Corolla albido-purpurascens, oblonga, ovoideo-turceolata; denticulis brevissinis, subacutis. Antheræ inclusæ.

Iuc, ni fallor, referenda $V$. corymbosum. Lins. et $V$. amonum. AIr.

galezans. V. foliis sessilibus, cuneato-lanceolatis, subserrulatis, pubentibus : fasciculis sessilibus : calyce acuminato : corolla ovata, fauce valde coarctata, 5 -clentata : stylo exerto.

\section{$V$. tenellum? Aıт.}

$O_{B S}$. Fruticulus habitu $M$. Gale; ramis ramulisque puberulis. Folia venosa. Fasciculorum pedicelli e gemma acervatim multisquamosa quasi ex uno puncto breviter erumpentes, floribus breviores. Corymbuli fructiferi nudi; baccis parvis, globosis, demum nigricantibus, coronatis.

$H_{A B}$, in umbrosis Carolinæ.

pexsyluancum. V. ramis angulosis, cortice viLAM. ridi : foliis sessilibus, ovali-lanceolatis, mucronatis, serrulatis, utrinque luci- 
OCTANDRIA. MONOGYNIA.

dis : fasciculis confertifloris, subterminalibus : corolla ovata, 5-dentata.

$O_{B S .}$. Frutex ramosissimus. Folia plana, membranacea. Calyx virens : corolla subalbida aut pallide rubens. Baccæ corymbosæ, glauco-nigræ.

$H_{A B}$. in New-Yorck, Pensylvania et Georgia.

IIGUSTRINum. V. ramis angulatis : foliis subsessi-

I. libus, erectis, lanceolatis, mucronatis, serrulatis : fasciculis gemmaceis, sessilibus; pedicellis vix ullis : corolla oblongiuscule ovata, 5-dentata.

$O_{B S}$. Frutex stricte erectus : folia membranacea, pubentia, conspicue venosa, venis sæpe purpurascentibus. Squami florales purpurascentes; corolla purpurea : fasciculi modo aphylli, ramei, modo axillares.

$H_{A B}$. in Virginia.

MYrsinites. V. erectum, ramosissimum, micro-

$L_{A M}$. phyllum : foliis myrti, sessilibus, ovalibus, mucronatis, subserrulatis, supra lavigatis, subtus punctatis : fasciculis gemmaceis, subsessilifloris, rubellis.

$O_{B S}$. Fruticulus, ramulis puberulis. Folia subtns glandulosa, punctata : intcrdum sublanceolata. Fasciculi axillares, squamis purpureis. Calycis laciniæ coccineæ. Corolla amoene purpurea, oblongiuscule ovata, 5-dentata.

$H_{A B}$, in sabulosis aridis Floridae. 
BRACHYCERUM. V. pumilum : foliis $B u x i$, obovalibus, rariter manifesteque crenatis : fasciculis subsessilifloris : corolla'brevi : staminibus flamentis glandulosis; antheris brevissime corniculatis.

$\Pi_{A} B_{0}$ in Virginia, circa Winchester.

\section{*** Floribus subsolitariis.}

cesprtosum. V: pusillum, cespitose multicaule, glaberrimum : foliis cuneato-obovalibus, rotundato-obtusis, conspicue serratis, membranaceis : floribus raineis, solitariis, subsessilibus : corolla breviter urceolata.

$O_{B S}$. Fruticulus 2-4-uncialis : flos sæpins unicus ad imos singulos ramulos. Bacca vix pedicellata, globosa, glauco-nigra.

$H_{A B}$. in borealibus Americæ, præsertim circa sinum Hudsonis.

myrtillordes. V. habitu Myrtilli: foliis angustolanceolatis, integris : subtus juxta ner-vos et margine pubescentibus, membranaceis : floribus sparsim subsolitariis, brevissime pedicellatis : bacca glauconigra.

Bluets Canadensium.

II $\triangle B$. a Canadia ad sinum HIudsonis. 
OCTANDRTA. IIONOGYNIA. 235

uliginosum. V. foliis parvulis, obovalibus, roI. tundato-obtusis, integerrimis; supra lavibus; subtus venosis, pubescentibus glaucisque : floribus subsolitariis : corolla brevi, urceolata : antheris dorso aristatis.

$O_{B S .}$ Variat staminibus 8-10.

$H_{A B}$, in borealibus Americæ regionibus, præsertim - juxtá lacum Cycnorum dictum.

$O_{B S .}$ Species 3.4.5.6. 15. 16. semper virent.

5. II. OVARIO SUPERO.

M E N Z I E S I A. Smith.

Capsula calyce scutellato basi suffulta, ventricoso-ovata; 4-locularis, 4-valvis; valvis margine semiseptiferis.

Semina minutișsima, numerosa, oblonga, utrinque acuta placcntx axili, crassæ, altero apice adncxa.

$O_{B S}$. Genus valdeaffine ANDromed $x$; habitu et fructu. Azalex.

SHithi. M L N Z IES IA. 
Cal. o. Cor. tubulosa, limbo obsoleto. Stam. tubo longiora. Bacca 1-sperma.

palustris. Dirca.

$\boldsymbol{L}$.

\section{J E F F E R S O N I A.}

Acaulis. Folia conjugata : pedunculus radicalis, nudas, i-florus.

Cac. 5-phyllus; ( rarius 3-4) foliolis lanceolatis, concavulis, coloratis, deciduis.

Con. petala 8, calyci subconformia, incurvo-patentia.

Stam. 8 , petalis multo breviora et itidem hypogyna, ovarium ambientia : filamenta brevissima : antheræ iis longiores, oblongæ.

Pist. ovarium majusculum, oblongo-obovatum : stylus brevis : stigma peltatum, concavulum, crenulatum.

CAPs. turbinato-obovata, breviter stipitata; coriacea; I-locularis; infra apicem semi circumscisse dehiscens.

Sem. plura, ( 12 - 20) juxta lineam medium capsula dorsum longitudinaliter percurrentem affixa; obovoideo-oblonga, 
OCTANDRIA. TRIGYNIA.

teretia, tenuiter arcuata, hinc ad basim arillata : arillo demum lacero.

BARTONis. JEFFER ONIA.

Podophyluum diphyllum. Linn.

HAB. in montibus occidentalibus Tennassée.

\section{$T R I G Y N I A$.}

P O Y G O N U M. L.

Cal. o. Cor. 5-partita, calycina. Sem 1, angulatum.

\section{* Floribus axillaribus.}

Aviculare. P. caule herbaceo, multistriato, hu-

I. mifuso, ramosissimo, multinodi; stipulis brevibus : foliis oblongis seu ovalibus, glabris : floribus axillaribus, subsessilibus, 8-andris, 3-gynis.

Var. a. angustifolium : foliis pusillis, lanccolato-oblongis.

- . latifolium : foliis lato-ovalibus, obtusis : quasi buxifolium.

$H_{A B}$. in Kentucky et regione Illinoensi.

RAMosissimum. P. herbaceum, erectum, elatius, multicaule : caulibus stricte ramosissimis, multistriatis : stipulis abbreviatis, 
margine laceris; foliis lanceolatis : ramis interrupte multifloris: floribus triandris, trigynis.

$O_{B S}$. Habitus $P$. avicularis.

$H_{A B}$, in regione Illinoensi.

Trnde. P. annuum, pumilum : caule gracili, erecto, ramoso, acutangulo : stipulis anguste tubulosis, castaneis, apice villosis : foliis longe linearibus, stricte erectis, acuminatis : floribus in superna ramulorum parte virgulata remote alternis, subsolitariis.

$H_{A B}$. in Canada.

\section{** Spica gracili.}

virgininum. P. erectum : foliis lato-ovalibus: spicis longissime virgatis : floribus inæqualibus, pentandris, digynis.

'HAB. in sylvis umbrosis, a Canada ad Floridam.

Hydropiper. P.stipulis laxis, glabris, apice ci-

L. liatis, maculatis : foliis lanceolatis, omisso margine glabris : spicis filiformibus, debilibus, subcernuis; bracteis remotiuscule alternis; floribus albidis, octandris, semitrigynis.

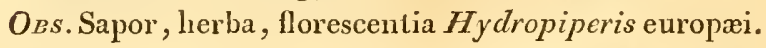
Flores semel vidi 7 -andros, nunquam vero stamina panciora.

HAB. in Pensylvania, Kentucky, regione Illinoensi et Carolinis. 
mYDropiperomes. P. stipulis undique hirsutis, promisse ciliatis : foliis angusto-lanceolatis, sessilibus, minutim asperiusculeque hirsutulis : spicis linearibus, debilibus; bracteis subimbricatis, ciliatis; floribus octandris, semitrigynis.

$O_{B S .}$ Habitus Hydropiperis : non acre ; folia angustiora : flores purpurascentes, raro 7 -andri.

HAB. in Pensylvania, Virrinia, Carolina.

minsutum. P. assurgens, undique conferta proWALT. missaque pube hirsutissimum : foliis sessilibus, lanceolatis : pedunculo subterminali, elongato, plerumque distachyo: spicis linearibus; floribus approximatis, octandris, semitrigynis.

$H_{A B}$. in herbosis udis et submersilibus Carolinæ inferioris.

*** Spica obeso-confertiflora.

Pensicaria. P. stipulis glabriusculis, apice ciliaL. tis : foliis lanceolatis, quasi glabellis : spicis confertifloris, oblongis; floribus hexandris, semidigynis.

$O_{B S}$. Nostrati vulgari prorsus consimilis !

$H_{A B}$. in Kentucky. 
pensylvanicum. P. caule tumide geniculato : $\mathrm{sti}^{2}$ I. pulis glabris nudisque : foliis lanceolatis: ramulis pedunculisque pube brevi, conferta, rigida et apice glandulifera asperrimis : spicis oblongis, confertifloris; floribus roseis, majusculis, octandris, semidigynis.

$O_{B S}$. Habitus Persicariae : flores triplo majores.

$H_{A B}$. in regione Illinoensi, juxta rivulos pratenses.

Amphinium. P. foliis petiolatis, oblongo-ovalibus

$\boldsymbol{L}$. seu lanceolatis : stipulis nudis : spica terminali, erecta, confertiflora, ovata oblongave; floribus 5-andris, semidigynis.

Var. a. natans : foliis natantibus, oblongo-ovalibus : spica ovoidea, glabra.

- $\beta$. emersum : foliis ovali-lanceolatis, erectis, minutim pubentibus : spica oblonga.

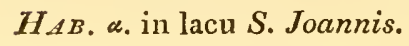

ß. ad ripas fluminis Ohio.

**** Floribus racemulosis : foliorum basi, sinu vel angulo recedente, cmarginata.

scanoens. P.glabriusculum : caule volubili : foliis L. sinu profundo late cordatis : stipulis truncatis, nudis : floribus 8-andris, trigynis : calycibus fructiferis majusculis, tripteris.

$H_{A B}$, in sylvis Kentucky. 
Convolvurus. P. caule asperiusculo, anguloso,

L. divaricato - prostrato vel volubili : foliis oblongis, hastato-cordatis : calycibus fructiferis apteris.

$H_{A B}$, in cultis Carolinæ.

crlirone. P. minutissime puberulum : caule anguloso, prostrato aut scandente : stipulis subacutis, basi extrorsum serie cilio. rum circumdatis : foliis cordatis; calycibus fructiferis apteris.

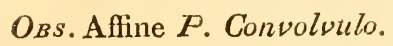

$H_{A B}$. in Canada.

Sagrtatum. P. caule retrorsum aculeolato: foliis

L. sagittatis : floribus capitatis, 8-andris, semitrigynis.

$H_{A B}$. in humidis apertis, herbosis, a Carolina ad Floridan.

ARIFOLIUM. P. caule retrorsum aculeato : foliis

L. hastatis : spicis paucifloris; floribus dis" tinctis, 6-andris, semidigynis.

HAB. in Carolina et in montibus Virginiæ, MaryLandia et nova Casarex.

I. 
242

CA R D IOSPRR MUN. L.

Cal. 4-phyllus. Petala 4. Nectarium 't-phyllum, inæquale. Caps. 3 , commatæ, inflate.

Halicacamum. C. caule glabello : foliolis profun dius et acute inciso-lobatis, imparibus rhomboideis.

$H_{A B}$. juxta amnem Kaskaskica, ab occidente in flumen Mississipi deflnentem.

\section{S A P I N D S. $L$.}

Cal.4-phyllus. Petala 4. Caps. carnosæ, connatæ, ventricosæ.

Saporiaria. S. folius glabris, abrupte pinnatis;

I. foliolis ovali-lanceolatis; fructibus sphxricis, terebinthinaceis.

$\Pi_{A B}$. juxta littora, in Georgia. 
ENNEANDRIA. MONOGXNA. 243

\author{
C L A S S I S IX.
}

\title{
E N N E A N D R I A.
}

\section{$M O N O G Y N I A$.}

\author{
L A U Ii U S. $L$.
}

Cal. o. Cor. calycina, 6-partita. Nectarium glandulis 5 , bisetis, ovarium cingentibus. Filamentc6 interiora glandulifera. Drupa r-sperma.

OBs. Omnes spccics frigidioris Americæ sunt nudiflore; floribus squamis gemmaceis involucratis et plerumque dioicis.

nrospyroines. L. humilis, virgata, nudiflora: foliis oblongo-ovalibus, subtus subtomentosis : floribus glomerato-umbellatis, dioicis : squamis gemmalibus pedicellisque villosis.

$$
\text { L. melisscefolia? WALT. }
$$

$U_{B S}$. Affinis L. Pseudo-Benzoin : multo humilior. Promiscue cum $L$. geniculata liabitans.

Pseuno-Benzoin. L. ramis virgatis, sub floratione aphyllis : foliis cuneato-obovalibus, sub. tus subalbicantibus, puberulis : floribus 
244 ENNEANDRIA. MONOGYNYA. glomerato-umbellatis, dioicis : squamis gemmalibus pedicellisque glabellis.

L. Benzoin Linn. ex synon. Plucknetr.

$\tilde{H}_{A B}$. juxta rivulos et in udis, a Canada ad Floridam.

geniculati. L. ramis divaricatis, flexuosis : fo$M_{A R S H}$. liis deciduis, lanceolatis, obtusiusculis, WAL T' glabris, basi subtus barbatis; sub floratione nullis : floribus umbellatis, polygamis.

$O_{B S}$. Frutex aquatilis, gracilis. Flores lutei, breviter pedicellati, subglomeratim umbellulati : plerique masculi , staminibus novem, calyci æqualibus ; paucissimi hermaphroditi perfecti prioribus inmixti. Bacca subglobosa, coccinea.

LaURUS foliis lanceolatis enerviis, annuis. Growov. Virg.

$H_{A B}$. in aquis stagnantibus Carolinx.

Sassafras. L. foliis deciduis, integris lobatisL. que : floribus dioicis.

$O_{B S}$. \& Stamina 9 , longitudine calycis.

o Staminum imitamenta 6 , brevissima.

$H_{A B}$. a Canada ad Floridam.

Catesbyana. L. foliis perennantibus, lato - lanceolatis ramulisque glabris : paniculis breviuscule pedunculatis : calycis albi 
ENNEANDRIA. MONOGYNA. 245 et subrotati laciniis oblongis, obtusis subaequalibus, deciduis.

Catesb. 11.t. 28 .

$O_{B}$ s. Frutex 6-9-pedalis. Superstes calycis fructiferi pars parva, quasi crenata. Bacca ovata nigra. Stamina. perfecta 6 . Nectarium trifidum circa ovarium.

$H_{A B ;}$ in Florida calidiore et Bahama..

Caroliniensis. L. foliis perennantibus, ovali-lanC.LAESB. ceolatis, subtus subglaucis : pedunculis simplicibus, fasciculo subcapitato, paucifloro terminatis : ealycis laciniis exterioribus duplo brevioribus.

OвS. Perperam a LiNn Folia interdum obovata. Variat ramulis foliisque glabris, iisdemque pubescentibus. Calyx fructife: margine vix mulato : bacca subglobosa, atro coerulea.

HAB. in Carolina, Ludovisia. 


\section{ENNEANDRIA. MONOGYNIA.}

\section{E R I O G O N U M.}

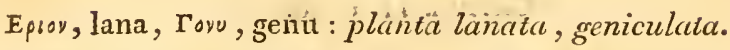

Caulis herbacens, dichotomus. Folia terna, verticillata, sessilia, basi subconiátá. Flores singulorum fasciculorum e communi involucro subcampanulátô êrumpéntés.

CıL. subcampanulatỉis, 6-partitus : laciniis ovalibus, obtusis; tribus interioribus paulo majoribus.

Star. 9 : filamenta capillaria; callyce paulo longiora : anthera bréves; ovata.

PIsT. ovarium 3-quetrum : stylus brevissimus : stigmata 3, longiora, subfiliformia.

Frucr. semen calyce tectum, acute triquetrum, apterum.

$O_{B S}$. Genus inter Polygoneas defectu vaginæ stipularis insolitum.

томтатолшм. E. erectum; partibus omnibus totab. 24. mentosis : foliis ternis, cuneato-obovalibus.

$O_{B S}$. Flores candicantes.

$H_{A B}$. in aridissimis, pinetis Carolinæ et Georgix. 
Tom. 1. Pag. $=46$.

Tab. 24 .

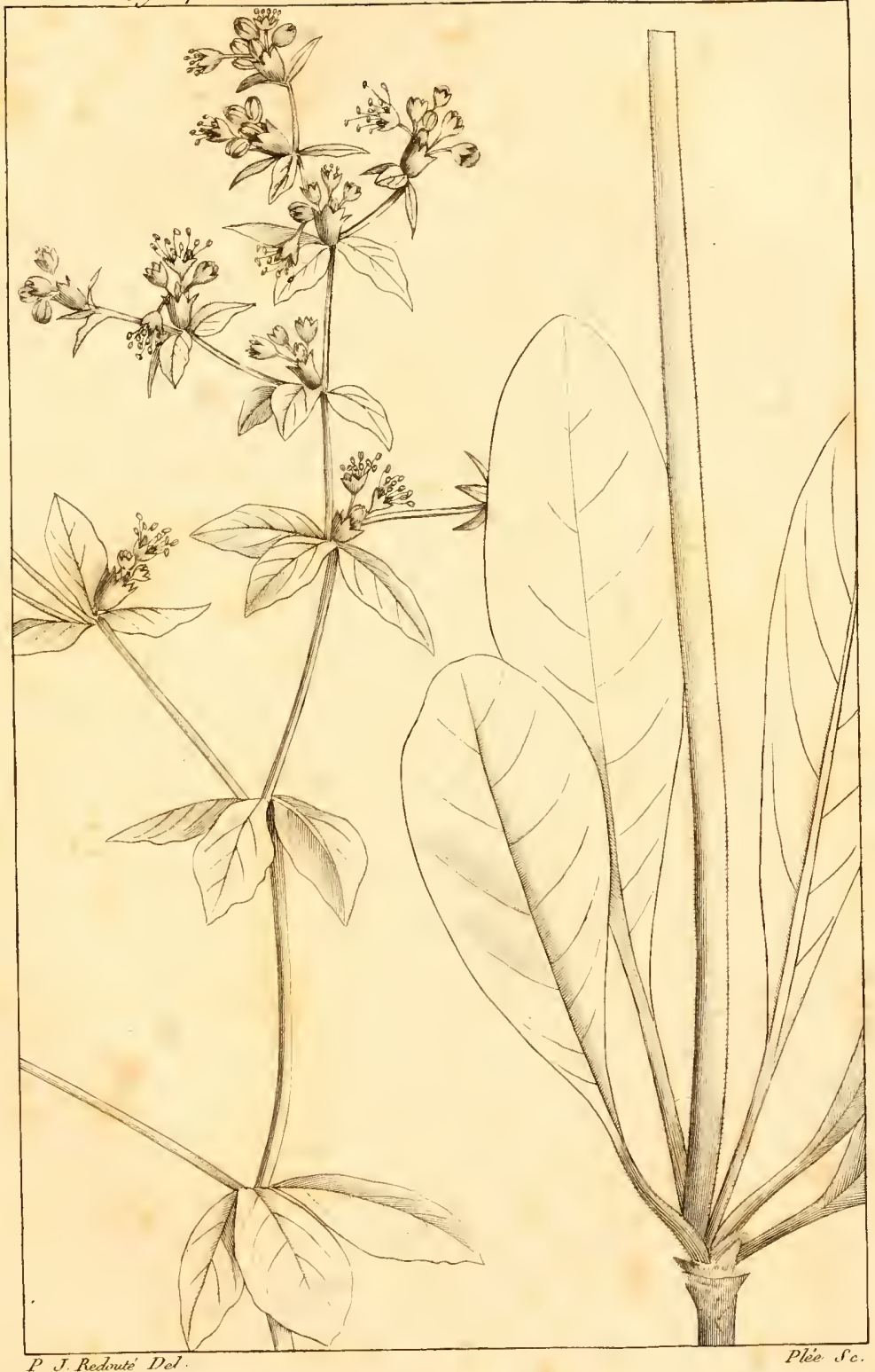

Friogonem tomentosum 



\section{$T R I G Y I I A$}

Hèrba juncoidéa. Spica termithalis; spanthis convom luto-aínplexántibus, oblongis, unilloris.

Cat. petaloideus, 6-partitus, stèllatim patentissimus : laciniis subrequalibus, lineari-lanceolatis, acutis.

STAm. novem, calyce breviora, eidemque ad contactum ovarii inserta : filamenta subulato-setacea : anthere oblongre, obtusx; loculis post dehiscentiam dorso ad dorsum appresso-patentissimis.

Pist. ovarium superum, oblongum , trigonum : stigmata 3 , sessilia, linearia, obiusa.

Caps. calyce persistente et appresso paulo brevior, subrotundo-trigona seu trigastra; absque manifesta septatione trilocularis, loculis ad axim immediate connexis ibique longitudinaliter dehiscentibus, apice bipartibilibus.

Sнм. numerosa, oblonga, teretia, leviter arcuata; margini valvarum ad axim 'peculiari stipitulo adnexa.

OBs. Genus Nartincio affine; insolito staminum numero ab aflnibus facile dislinguendum. 


\section{ENNEANDRIA. TRIGYNIA.}

tenuffolia. P. glaberrima : foliis angustissime tab. 25. ensiformibus, sensim acutissimis.

OBS. Radix perennis, iridea. Scapus subsesquipedalis, oligophyllus; raginis longis, infra apicem folium emittentibus. Spicæ raginis seu spathis proxime alternis, totidem pedicellos unifloros involncrantibus. Flores flavo-rufi. Stipitulus quo singula semina adnexa sunt, hinc longitudinaliter iis adnatus, ultra ipsorum apicem in filum longius contortum desinit.

$H_{A B}$, in udis apertis sylvarum Carolinæ inferioris. 
Tom. 1. Pag, $2\{8$.

Tab. 25.

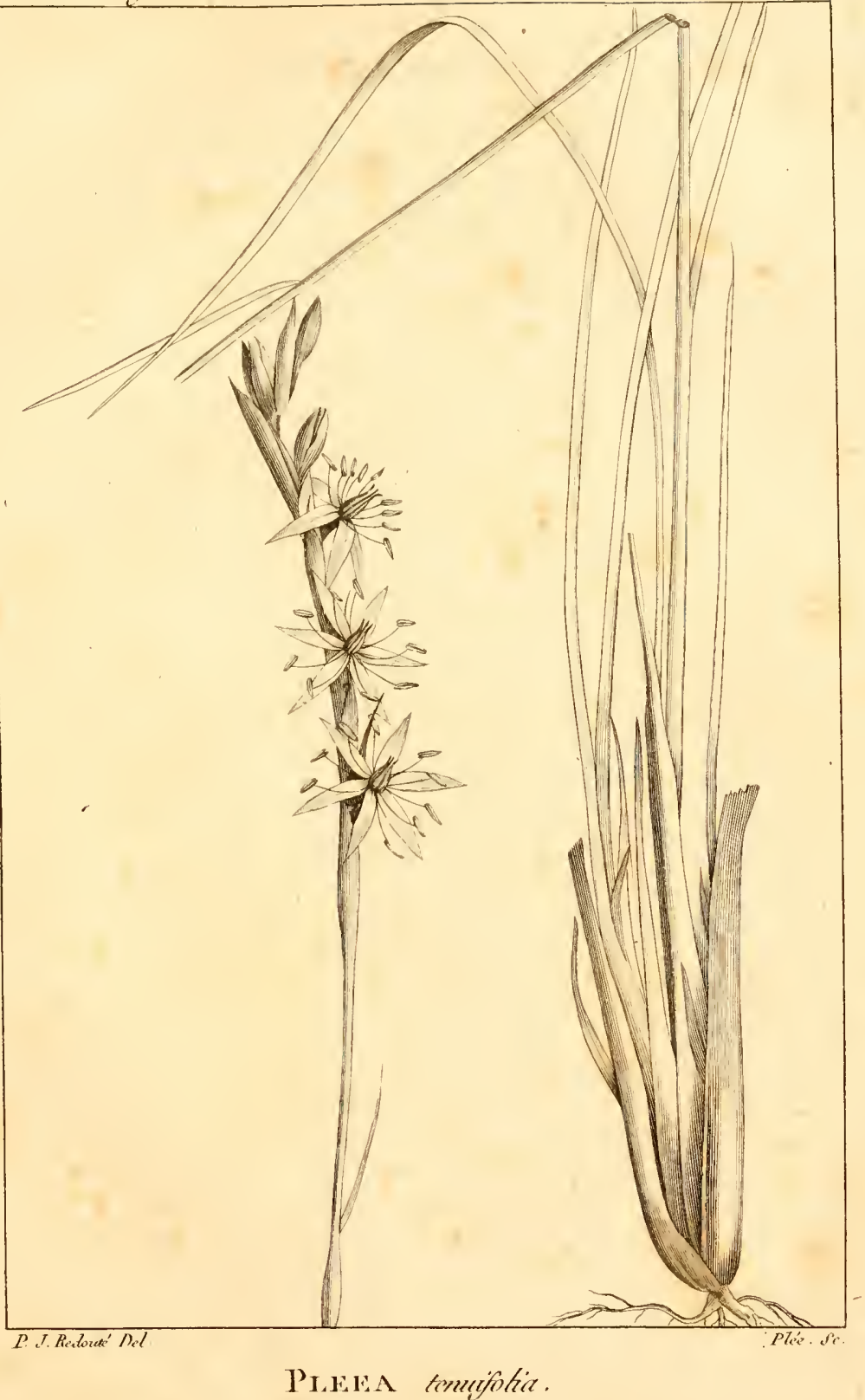



DECANDRIA. HONOGYNIA. 249

C L A S S I S X

\section{E C A N D R I A.}

MONOGYNIA.

ઈ. ร., M O N O I E T A L N.

A R B U T U S. $L$.

Cal. 5-partitus. Cor. ovala : ore basi pellucida. Bacca 5-locularis.

Uva vrsi. A. caulibus procumbentibus : foliis

L. cuneato-obovalibus, integris, margine convexis, coriaceis : floribus fasciculatis : baccis rubris, 5-spermis.

ORs. Interdum folia subdentata.

$H_{A B}$. in rupestribus montanis Canadx, Acadia et Novæ Anglix.

$$
\text { G A U L T H E R I A. } L \text {. }
$$

Cal. exterior 2-phyllus: interior 5-fidus. Cor, ovata. Nectarium inucronibus 10. Caps. 5-locularis vestita calyce baccato.

Procumezps. G, repens: foliis ovalibus, basi acuI. 
tis : calycis brevissimi laciniis subrotundo-ovalibus.

OBs. Caulium summitas, 'petioli et nervus medius supra pubescentes : foliorum dentes aristati, arislis deciduis. Flores plerumque solitarii, rarius racemosi.

$H_{A B}$, in montibus Álléghanis et Canada.

\section{E P I G A. L.}

Cal. exterior 5-phyllus ; interior 5-partitus. Cor. hypocrateriformis. Caps. 5-locularis.

Rrpens. E. ramis, petiòlis nérvoquue hîrsutisL. simis : foliis cordatis, ciliatis.

$O_{B S .}$ Flores omnes in nomullis individuis abortivi.

HAB. in montosis, a Canada ad Carolinam.

$$
\text { P Y R O A. L. }
$$

Cal. 5-parlitus. Petala 5. Caps. 5-locularis, angูulis dehiscens.

SECUNnA. P. foliis subrotundo-ovalibus, manifes-

L. tius dentatis : spicae fioribus secuindis: pistillo recto.

$O_{B}$. Datur varietas minor foliis orbiculatis.

HAB, in Canada. 
DECANDRIA. MO NOGYNIA. 25 I RotUNDIFOLIA. P. foliis rotundatis sive subroI. tundo-obovalibus : spica floribus undique versis : pistillo declinato.

$H_{A} \dot{B}$. in Canada.

ASARIFOLIA. P. foliis reniformibus : scapo squamis nonnullis convolutis, vaginantibus remote vestito : spica floribus undique versis : pistillo declinato.

UNIFlora. P. foliis suborbiculatis, membrana-

L. $\quad$ ceis : scapo unifloro : stylo recto : stigmate radiatim 5-partito.

maculata. P. foliis lanceolatis, rigide serratis,

L. fascia longitudinali discolore notatis : scajo bi sive rarius trifloro : flamentis lanuginosis : stigmate sessili.

OBs. P. maculata et umbellata forsan constitnunt. gènus a Pyrola discrepans habitu, stigmate sessili et indiviso, antheris breviter rostratis et foramine subbivalvi dehiscentibus.

MA

umbellata. P. foliis cuneato-oblongis, argute

L. serratis : scapo corymbifero: stigmate sessili.

HAB. in Canada et Nova Anglia. 
Cal. 5-partitus. Cor. ovata : ore 5-fido. Caps. 5locularis.

* Foliis peremnantibus.

FERruginea. A. foliis coriaceis, subcuneato-obovaWALT. libus, integerrimis, subtus puncticulosis : fasciculis axillaribus, furfuraceoferrugineis : corollis brevibus, globosis: antheris muticis.

$O_{B S}$. Capsula ovoideo-trigona, suturis prominulis.

Var. a. arborescens : foliis confertioribus, revolutis, convexis, floribus numerosis.

- $\beta$. fruticosa : ramis sxpins flexuosis : foliiis distanter altenis, acutioribus, planinsculis, suhhns prominule reticulatis; floribus pauciovibus.

Jinn ista varietates etiam cliltura persis. tunt. Prior floret Aprili; posterior Junio.

His. in Tlorida et Georgia.

zumpa. A. glaberrima: ramis subtriquetris, \#3RTR. acutangulis : foliis ovalibus, integerrimis, levigatis ; vena marginem deflexum percurente : fasciculis axilla. 
DECA D DIA. MONOGYNIA. 253 ribus : corollis cylindraceis : antheris basi appendiculatis.

A. lucida Lani. Dict. $\mathrm{n}^{\circ} \cdot 9$.

A. coriacea. Hort. Kew.

Oss. Folia coriacea, lacidissima, vix perceptibiliter punctata. Flores breviter pedicellati. Calyx majusculus. Antheræ muticæ, ad basim dorsi 2-corniculatx.

HAB. in Carolina inferiore et Florida.

axillaris. A. foliis oblongo-ovalibus, acuminaLAM. tis, serratis, lucide glabris, coriaceis: spicis axillaribus, sessilibus, confertifloris : corollis cylindraceis, ovatis : antheris muticis.

A. Calesbori. Watt.

Catesb. t. 52. icon pessima.

$O_{B S .}$ Folia uti pracedentis punctata; interdum sublanceolata. Spicæ breves, squamoso-bractcatæ; floribus subsessilibus, albidis. Capsula depresso-globosa, 5-cocca.

$H_{A B}$. in montosis Virginiæ, Carolinæ et Georgiæ.

LAUrina. A. glaberrima: foliis oblongo-ovalibus, superne sensim angustatis, integris serrulatisve : racemulis axillaribus, nudis: 

corolla cylindracea : antheris muticis, basi postice gibbis.

A. formosissima. BART.

A. reticulata. W $\mathbf{\Lambda \mathrm { LT }}$.

A. populifolia. Lıм. Dict.

A. acuminata. Art.

A. lucida. J Ace.

$H_{A B}$ in Florida.

calyculata. A. foliis lanceolato-oblongis, obso$\boldsymbol{L}$. lete subserratis, leprosis : ramulis foliose, racemifloris; floribus secundis, solitarie axillaribus : calycibus calyculatis : corollis ovatis : antheris muticis.

HAB. a sinu Hudsonis ad Pensylvaniam.

polifolia. A. foliis lineari-lanceolatis, convexis, L. subtus albicanti-glaucis : floribus aggregato-terminalibus : corollis subglobosis: antheris versus apicem aristatis.

$H_{A B}$. in montibus sinui Hudsonis adjacentibus.

** Foliis deciduis.

Paniculata. A. racemis quasi paniculatis, modo L. nudis, modo foliosis : corollis parvulis, depressiuscule globosis, puberulis : antheris brevibus, ovoideis, obtusis, muticis.

A. racemosa. LuM. Dict. $\mathrm{n}^{\circ}$. 12, et WaLt. Car. 138. 
DEGANDRIA. IIONOGYNIA. 255

Var. 1. nudiflor, : racemis uudis.

A. floribus manifeste pedicellatis el laxinsculis.

8. Aloribus congiobatis, subscssilibus.

- 2. foliosiflora : racemis foliosis.

A. Aloribus glabellis.

в. - subtomentosis.

OBs. Folia membranacea, nerrosa, solito utrinqne minutim puberula, sxe obscurc serrulata.

Magnițudine êt figura admodum variant.

HAE. 1. in frigidioribus, per Etats-Unis.

2. $\mathrm{A}$. in sylvis Carolinæ inferioris.

B. in stagnosis.

AnsoneA. A. ramis teretibus : foliis majusculis,

I. oblongo-ovalibus, acutissine acuminatis, argute serrulatis : panicula terminali, polystachia : corollis pubentibus, ovoideo-cylindraceis : antheris linearibus, muticis.

$O_{B S}$. Arbor altitudinem 50-6o pednm assequens.

$H_{A B}$. in montịus Alléghạnis, a Pensylvania ad Floridam.

RACEMOSA. A. foliis ovali-lanceolatis, rarius obo-

L. valibus, serrulatis, membranaceis : spicis nudis, secundis, elongatis, simplicibus ramosisve : corollis cylindraceis : 
antheris apice geminatim quadriaristatis.

A. paniculata. WALT.

Huc synonymon Catesbei, quod Lineaus ad A. paniculatam retulit.

$O_{B S}$. Calyx infra bibracteolatus, fere instar $A$. $c a=$ lyculatce.

HАB. a Pensylvania ad Floridam.

spreciosa. A. foliis ovalibus, subrotunidis, obtusis, crenatis serratisve : ramis terminalibus nudatis, quasi racemifloris : corollis majusculis, campanulatis : antheris apice geminatim quadriaristatis.

Var. a. nitida :

- B. pulvernlenta : BART. ramis, foliis floribusque pulvere albo inspersis; qui candor certo morbus est.

$O_{B S .}$. Dispositio flurum $A$. mariance.

$H_{A B}$, a. in Carolina septentriouali, circs FaysteVille et Wilmington.

- $\beta$. in Carolinæ utriusque staguosis.

mirnas. A. foliis ovalibus seu lanceolatis, inL. tegerrimis : ramis nudata summitate fasciculoso - racemifloris : corolla subcylindracea : antheris muticis : capsula conoidea.

ILAB. a Pensylvania ad Floridam. 
DECANDRIA. MONOGYNI. 2.57

K A L M I A. L.

Cal. 5-partitus. Cor. hypocrateriformis : limbo subtus quinquecorni. Caps. 5-locularis.

mirsuta. K. ramis, foliis calycibusque hirsuWALT. tissimis : foliis parrulis, subsessilibus, oblongo-ovalibus, sparsis et suboppositis : floribus solitarie axillaribus. K. cilicata. Bartran's Travels, pag. 18.

H.A. in sylvis, Georgix.

GLAUCA. K. ramulis ancipitibus : foliis oppoA1\%. sitis, subsessilibus, oblongis, giaber. rimis, subtus albido-glaucis : corymbis terminalibus, bracteatis.

$I_{A B}$. in remotis borealibus Canadx.

cuneata. K. foliis sparsis, sessilibus, cuneatooblongis, subtus pulbentibus, apice minutim aristatis : corymbis lateralibus, paucifloris.

$O_{B S}$. Affinis $K$. angustifolice sed distinetissima : herba Aza LE: X. Corolla albida, fundo purpurea. $H_{A B}$, in Carolina.

angustifolia. K. foliis ternis, conspicue petio-

L. latis, sublanceolato-oblongis, obtusis, subtus plus minus ferrugineis : corymbis lateralibus.

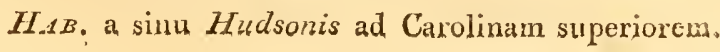

I. 
latifolia. K. foliis longe petiolatis, ovalibus,

L. utrinque lævigatis et subconcoloribus, sparsis ternisque : corymbis terminalibus, viscido-puberulis.

HAB. in montibus Alléghanis, adusque fines Canadæ.

\section{RHODODENDRON. L.}

Cal. 5 -partitus. Cor. subinfundibuliformis Stam. declinata. Caps. 5-locularis.

catawbiense. R. foliis brevi-ovalibus, utrinque rotundato-obtusis : corolla campanulata : calycis laciniis angusto-oblongis.

$O_{B S}$. Affine $R$. maximo, calycis laciniis insolite elongatis.

$H_{A B}$. in montibus excelsis Carolinæ scptentrionalis, juxta originem amnis Catawba.

minus. R. foliis ovali - lanceolatis, utrinque sensim acutis, subtus ferrugineo-punctatis : floribus brevissime pedicellatis, infundibulo-campanulatis : capsulis elongatis.

$O_{B S}$. Aff. $R$. ferrugineo, multo omnibus partibus majus et præprimis capsula discrepans.

$H_{A B}$. in montibus Carolinæ superioris et versus originem amuis Savannah. 
DECANDRIA. HLO NOGYN1A. 250 maxmuar. R. arborescens : foliis subcuneatoL. oblongis, abrupte acuminatis, crassius coriaceis, glabris : calycis laciniis ovalibus, obtusis : corolla subcampanulata.

$O_{B S .}$. Affine $R$. pontico, cujus calycis dentes brevissimæ, acutæ; corolla amplior, subrotata, laciniis longioribus.

$H_{A B}$, a nova Anglia ad Carolinam superiorem montosam.

\section{RHODORA. L.}

canadensis. Rhodora.

I.

OBs. Vix differt a Ruododendro.

$H_{A B}$. in fruticetis Canadx, circa Sorel.

S. II. POLYPETALE.

L E D U M. $L$.

Cal. 5-fidus. Cor. plana, 5-partita. Caps. cularis, basi dehiscens.

Palustre: L. foliis subovali-oblongis, margine latifolinm. revolutis, subtus tomentosis.

$H_{A B}$. in borealibus sphagnosis Cand $x_{\text {. }}$ 
260 DECANDRIA. HONOGYNIA.

Buxmolnur, L. foliis pusillis, convexis, ovalthus, Alt. glabris, lucidis : capsulis apice dehiscentibus.

IIAB. in sunmis montibus excelsis Carolinx.

$$
\text { C L E T H R A. L. }
$$

Cal. 5-partitus. Petala 5. Stigma 5-fidum. Caps. 5-locularis, 5 -valvis.

ALnfolda. C. foliis cuneato-obovalibus, superne L. serratis : spicis subsolitariis : bracteis flore expanso plerisque brevioribus et persistentibus.

Var. a. glabella : foliis glabellis, utrinque viridibus.

- . tomentosa : foliis subtus incano-tomentosis.

$H_{A B}$. a. in Pensylvania.

ß. in Carolina.

acumivata. C. folits ovalibus, acuminatis, basi obtusis, serratis, subtus glabris glaucisque : spicis subsolitariis : bracteis flores superantibus.

$O_{B S .}$ Arborescens : folia ampliora, nunquam cnneatim angustata, longiusculc petiolata. Florescentia C. alnifolice. Spicæ nondum floridæ undique promisse exertis horrent bracteis, quæ solito cul, tura decidunt.

HAT. in excelsis montibus Carolinr. 
DECANDRIA. MONOGYNIA. 26I C A S S I A. L.

Cal. 5-phyllus. Petala 5. Antherae superno 3 steriles; infima 5 rostrata. Legumen.

occidentalis. C. herbacea, glabra : foliis sub-

L. 5-jugis, lanceolato-ovaibus, márgine asperiuscule puberulis; glandula basilari : pedunculis multifloris, axillaribus et subpaniculato - terminalibus : leguminibus angusto-linearibus, falcatis.

If $A B$. in cultis Caroline inferioris, circa Charlsiomn.

Lrnearis. C. herbacea, glabra : foliis sub6-jugis, ovali-lanceolatis, angustatis, acutissimis; glandula basilari : pedunculis subbifloris, axillaribus et terminalibus : legumine lineari, recto.

Ozs. Valde afininis C. occidentali; floratione precociol. ILAB. in Carolina.

marilandica. C. herbacea, glab̉riuscula : foliis

L. 3-jugis, sublanceolato-oblongis, utrinque obiusiusculis; glanduía petiolari obovata : spicis axillaribus et paniculatoterminalibus : antheris atro-fuscis.

OBS. Foliola mucronata. Legumen angusto-lineare, arcuatum, glabrum.

HAB. a Pensylvania ad Carolinam montosam et is regione Illinoensi. 
Chamecrista. C. annua : foliis multijugis; glanL. dula petiolari, subpedicellata : floribus subgeminis, conspicue pedicellatis, majusculis : petalis duobus maculatis : leguminibus pubentibus.

Oss. Variat hirsutissima et glabriuscula : stamina subpurpurata.

Chamaecristarum flores distanter supra axillares. IIAB. in Carolina inferiore et Virginia.

Fasciculata, C. chamacrista, glabriuscula : folis ad summum 9-jugis; glandula petiolari sessili, submedia : fasciculis multifloris, lateralibus: petalis staminibusque luteis : leguminibus glabellis, arcuatim ascendentibus.

Oss. Flores minores quam in Chamaecrista.

$H_{A B}$, in Pensylvania et Virginia.

Nictrons. C. herbacea, patula, tota pubescens:

I. glandula petiolari pedicellata: foliis multijugis, linearibus : floribus minutis, su. pra axillas subsessilibus, pentandris, immaculatis.

OBs. Calyx interdum quadripartitus, laciniis duabus coalitis.

HAB. in Carolina, Virginia et Pensylvania. 
DECANDIIA. MONOGYNIA. ${ }_{2} 63$

POD A I R I A. LaA. Willd.

Caulis herbaceus : folia trifoliata, raro simplicia. Flores axillares ant spicato-terminales.

CaL. campanulatus, breviter 4-dentatus; dentibus 3 xqualibus, superiore latiore.

Con. papilionacea, calyce multoties major: rexillum latum, incumbens, demum lateribus retroflexum, carina paulo brevius : ala lato-obovales, incumbentes carine, hujus latitudine; sed tantisper breviores : carina valde compressa, latoobovalis.

Sтим. 10, distincta, inclusa, fere longitudine carina.

Pist. inclusum.

Lrgumen stipitatum, ovoideum, inflatum, lieve, polyspernum.

perfoltata. P. glaberima; folits suborbiculatoperfoliatis : foribus solitarie axillaribus, lntescentibus : leguminibus subglobosis.

Sophora? perfoliaza. WALT:

Crotalaria perfoliato. Linn.

$H_{A B}$. in aridis Carolinx.

urirzora. P. caule foliis calycibusque pubescentibus : stipulis minutissimis, setaceis: 
foliis sessilibus; foliolis lanceolatis, obtusis : floribus solitarie axillaribus, pedunculatis, lutescenibus.

Soruora? lanceolata?" Waxt.

$H_{A B}$. in Carolina et Gcorgia.

vrucosa. P. caule, folibs subtus et margine calya cibusque pubentibus : stipulis linearibus: foliis subsessilibus; foliolis ovali-oblongis, obtusis : spica terminali, floribus pallidis : calycibus subsemi 4 -fidis.

Soriora? villosa? WatT.

HAB. in Carolina septentrionali.

cervlea. P. glabra : stipulis majusculis, lanceolatis : foliis brevissime petiolatis; foliolis oblongo-cuneatis : spica elongata, floribus coeruleis : leguminibus sensim acuminatis.

$H_{A B}$. in sabulosis inmulatis fluminis Ohio.

azra. P. ramis divaricato-patulis, flexuosis, glabris : stipulis minutis, subulatis : foliolis glabellis, ovali-lanceolatis vel subcuneatis : spica elongata, floribus candidis : leguminibus obovatis.

Sopiona alba. Linn.

HAs. in occidentalibus Virginia et Carolinæ.

mozris. P. canle, foliis calycibusque minutim pubentibus : stipulis foliaceis, lanceolatis : foliolis subrhomboideo-lanceolatis: 
DECANDRIA. TIONOGYNIA. 265 spica terminali, floribus saturate luteis: calycis dentibus acutis.

IHAs. in comitatu Mecklenburg Carolinæ superioris.

Tirctoria. P. glabelrima, ramosissima, microphylla : stipulis setaceis : foliis subsessilibus; foliolis cuneato-obovatis, rotundato-obtusis : floribus spicatis, terminalibus, luteis : leguminibus parvulis, brevi-ovatis, longius stipitatis.

SOPHORA tinctoria. LinN.

II $A B$, a Canada ad Floridam.

\section{E P C I S. L.}

Cal. 5-dentatus, inferne gibbus. Cor. papilionacca: vexillo sub ais brevi. Legumen.

CANADENSIS. C. foliis subrotundo-cordatis, acuI. minatis, ad axillas nerrorum villosis: floribus parvalis : leguminibus brevistipitacis.

IHAR. in America septentrionali. 


\section{ONOTR OPA. $L$.}

Cal. o. Petala 10 ; horum 5 exteriora basi excavala, mellifera. Caps. 5-valvis. Quinta pars numeri quibusdam excluditur.

Hyрортияs. M. caule spicifloro, squamis et floL. ribus extus glabris.

$O_{B S}$. Europæa duplo minor.

$H_{A B}$ ad Canada fines meridionales.

ranuginosa. M. caule spicifloro, bracteis et floribus undique lanuginosis.

OBs. Habitus Hypopithyos; omnibus partibus minor ; squamis bracleisque subacutis. Variat spica cernua et erecta floribus secundis.

$H T_{A B}$. in sylvis Carolinæ superioris.

viriflora. A1. caule breviore, crasso; squamis L. approximatis : flore unico, maximo, cernuo.

HAB. in sylvis umbrosis Carolinæ inferioris.

Monisoniana. II. caule elongato, rectissimo; squamis distantibus : flore unico, erecto. OBs. Flos constanter erectus. Capsula gilobosa. $H_{A B}$. in umbrosis sylvis Carolinx. 
DECANDRIA. MONOGYNIA.

DION A. $L$.

Cal. 5-phyllus. Petala 5. Caps. unilocularis, gibba, polysperma.

Muscipula. Di O N

I.

$H_{A B}$. in uliginosis Carolina septentrionalis, circa Wilmingfon.

\section{JU S S I A. $L$.}

Cal. 4-5-partitus, superus. Petaía 4-5. Caps. 4-5-locularis oblonga, angulis dehiscens. Sem. numerosa, minula.

GRATDIFLRA. J. iabice perenni, repente : canilibus erectis, pedunculis calycibusque villosis : folis integerrimis, inferioribus spathulatis, cuprionibus lanceolais : floribus maximis, decantris.

$H_{A B}$, in palunosis Georgix, circa Sarannatı. 


\section{$D I G Y N I A$.}

H Y D R ANGEA. L.

Caps. 2-locularis, 2-rostris, circumscissa.

VULGarts. H. foliis cordaţo-ovalibus, subtus głabriusculis : floribus omnibus conformibus.

H. arborescens. LinN.

$O_{B S}$. Fruticans nec arborescens.

HAB. in montosis occidentalibus, juxta rivulos $\mathrm{Ca}$ rolinæ.

sives. H. foliis cordato-ovalibus, subtus niveo-tomentosis : floribus exterioribus sterilibus, amplissimis.

H. radiata. WALt.

Oss. Cultura variclatem foliis subtus glabellis et tunc (omissis sterilibus floribus) $H$. vulgari fere - similem obtinui.

IAB. versus originem amnis Sutannah.

$$
\text { S A X I F R A G A. } l \text {. }
$$

Cal. 5-pari. Cor. 5-petala. Caps. 2-rostris, 1-loczlaris, polysperma.

s.eucaitrumarolia. S. hirsutissima : foliis elonIA Pryr. gato-spathulatis, acute dentatis : caumonog. libus divaricato-dichotomis : paniculis capillaribus, laxis : calyce reflexo : petalis inæqualibus.

$I_{A B}$. in excelsis montibus Carolina. 
DECANDRIA.DICYNIA.

virginensis. S. tota minutim pubens : folih ovalibus, obtusis, quasi petiolatis, crematis: caule subaphyllo, paniculato; ramulis subsessiliter alteruifloris : calycibus erectis.

Pluckn. t. 222. f. 5. panicula noudum rite explicata.

OBs. Almin S. punctatae : habitus fere S. stellaris.

$I_{A}$ B. in rupibus Pcnsylvanix, Virginia et in montibus Caroline.

pensylvaxrca. S. elatior, lanuginoso-pubens :

L. foliis ovali-oblongis, denticulatis : caule nudo; panicula oblonga, ramis summitate fasciculifloris : floribus parvis, viridi-luteolis.

$O_{E}$. Excluso Plucknitr synonymo. Variat floribus in ramis panicule conglobatis et corymbosis.

$H_{A B}$. in pratensibus Pensylvania.

\section{CHRYSOSPLENIUM. L.}

Cor. campanulata, 10-fida : laciniis alternis, patulis. Bacca 10-sperma.

oppositoforrum. C. foliis oppositis, subrotundis,

L. basi non sinuatis, levissime crenatis: floribus octandris.

HAz. in montosis Novæ Anglix et in altis montibus Carolinæ. 
Cal. 5-fidus. Cor. 5 -petala, calyci inserta : petalis pinnatitidis. Caps. 1-locularis, 2-valvis; valvulis aequalibus.

Diphycla.' M. foliis sublobato-acutangulis, denL. tatis : caule erecto, superne opposite diphyllo.

$H_{A B}$. in Canada et in montibus Alléghanis.

cormfolia. M. foliis orbiculato-reniformibus,

L.x. subduplicato-crenatis, lucidis : scapo setaceo, aphyllo.

HAB. in Canada, circa Quebec.

prostrata. M. radice repente; caulibus prostratis, alterne foliosis : foliis rotundatocordatis, subacutis, obtuse sublobatis. $I_{A B}$ ad fines meridionales Canadæ.

\section{T I A R E L L A. $L$ 。}

Cal. 5-partitus. Cor. 5-petala, calyci inserta: petalis integris. Cops. 1-locularis, 2-valvis : valvula altera majore.

cornfrola. T. foliis cordatis, acutis, sublobatis, L. dentatis; dentibus acuminatis. $H_{A B}$. in Canada et in nontibas Alléğhanis. 


\section{$T R I G Y N I A$.}

B $\mathrm{R} U \mathrm{~N} N \mathrm{I}$ C H I A. G ERT.

Ca7.5-fidus. Cor. o. Caps. non dehiscens, 1-sperma; inclusa calyce valde aucto, coriaceo, pedicello ensiformi-dilatato suffulto.

OBs. Stamina interdum 8. Genus Polycovo affine.

cirriosa. B. glabra, scandens; foliis oblongoGERT. cordatis, acuminatis : racemis multifioris : floribus secundis.

$$
\text { C U C U B A L U. L. } L \text {. }
$$

Cal. inflatus. Petala 5, unguiculata, ahsque corona ad fancem. Caps. 5-locularis.

Benex. C. glaber, glaucus, caulibus decum-

$\boldsymbol{L}$. bentibus : foliis oblongo-ovalibus, acutis, enerviis : calycibus inflato-membranaceis, venosis.

HAB. in Canada, circa Quebec et loca habitata.

stellatus. C. totus pubescens, erectus : foliis

L. quaterno-verticillatis, ovali-lanceolatis, in longissimum acumen angustatis.

$H_{A B}$. in Nova Anglia et in montibus Alléghanis. 


\section{S I L E N E. L.}

Cal. ventricosus. Petala 5, unguiculata : coronata ad faucem. Caps. 5-locularis.

Quireuevulnera. S. hirsuta: foliis cuneato-oblon.

L. gis, summis linearibus : petalis pusillis, rotundatis, integris : calycibus fructiferis subspicatim alternis, erectis.

Ors. Humılis, ab imo dichotome ramosa Petala carmesina, limbo pallido.

HAB. ad littora maris, juxta Charlstown.

penstlvanica. S. viscido-pubens : foliis cuneatis, caulinis lanceolatis : cauliculis in summitate paucifloris : petalis leviter emarginatis, subcrenatis.

$O_{B S}$. Affinis $S$. Virginicce : humilis, cauliculis simplicinsculis : petala obtusissima, purpurascentia.

H.AB. in Pensylvania.

virginica. S. decumbens, tota viscoso-pubens: L. foliis oblongis, margine asperiusculis: panicula dichotoma : petalis bifidis, saturate rubris : genitalibus exerlis.

$O_{B S}$. Legi varietatem foliis lato-ovalibus, rarissimam. Variat interdum canle erecto, paniculæ coarctatie floribus subfasciculatis.

$I_{A B}$. in regione Illinoensi. 
Cal. pentaphyllus, patens. Petala 5, bipartita. Caps. 1-localaris, polysperma.

pudera. S. tota minuta lanugine pubens : foliis ovalibus, ciliatis : pedicellis erectis, breviusculis : petalis calyce longioribus.

$O_{B S}$. Habitus fere Arsinns mediae. Calycis lacinixa ovales.

$H_{A B}$. in montibus sylvalicis Carolinæ septentrionalis.

A R E N R I A. L.

Cal. pentaphyllus, patens. Petala 5 , integra. Caps. I-locularis, polysperina.

situra. A. tota puberula : caulibus filiformibus, paniculatis, multifloris : foliis setaceo-subulatis, patentibus : petalis sul\}emarginatis, calyce acutissimo et striato paulo longioribus.

OBS. Habitus $A$. tenuifoliae.

$H_{A B}$. in rupibus circa Knoxville.

SQUARrosa. A. foliis imis squarroso-imbricatis, canaliculatis, glabris : cauliculis simplicissimis, olygophyllis : floribus termina-

x. 
274 DECANDRTA.TRIGYNIA.

libus, paucis, erectis : petalis calyce subrotundio multo majoribus.

$O_{3 s}$. Affinis $A$. saratili.

$M_{A B}$. in sabulosis, pinetis Carolinæ, juxta amnem Saritée.

StRrcta. A. glabra, erecta, stricte multicaulis; foliis subulato-linearibus, erectis : panicula rariflora : petalis, calyce ovali-lanceolato, conspicue striato multo longioribus.

$O_{B S}$. Affinis $A$. striatae, multo major.

$H_{. A B}$. in rupibus Nove Anglix, Canadr.

GLAfRA. A. glaberrima, erectiuscula, filiformimulticaulis : foliis subulato-linearibus, planis, patuilis : peciicellis unifioris, elongatis, divaricatis : calycis laciniis ovalibus, obtusiusculis, levibus, corolla brevioribus.

OBs. Affinis Steldarta uniflora. Watt.

$H_{A B}$. in rupibus Carolinie septentrionalis.

SERPYLLfFolia. A. foliis ovalibus, acuatis, subL. ciliatis : floribus sparsis: petalis calyce substriato acutoque brevioribus.

HAB. in cultis Pensylvaniæ et Carolinæ.

RUBRA $\beta$ : A. humifusa; foliis linearibus, carc. nosis, stipula vaginante, membranacea 


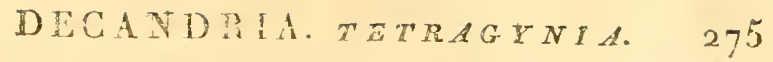
connatis : staminibus quinque : capsulis globosis.

H. B. in Canada, ad ostium fuminis S. Laurentii.

\section{$T E T R A G Y N I A$.}

SPERGULASTRUM.

Habitus et calys Stelciniz.

Cor. petala aut nulla aut calyce conspicue minora, inlegra.

STAII. IO.

PIsT. stigmata 4, sessilia, ligulato-setacea.

Cisps. ovata, calyce longior, q-valvis, àe.

OES. Numero stigmatorum et rariore petalorum ủefoctu a Speroula differt; genus hoc in postermu forsan delendum, reformatis affiniun caracteribus hucusque obscuris.

Layugrostri, S. caulibus tenuissima densaque lanugine restitis : foliis latiuscule lanceolatis, in petiolum angustatis : floribus apetalis.

HAE. in meridionalibus Americ septentrionalis.

Lanecolatum. S. glabrum : foliis utrinque angustato-lanceolatis : floribus petaliferis.

$O_{E S}$. Interdum stigmata 3. Petala brevissima, ovalia. HAB. in borealibus America septentrionalis. 
276 DECANDRA. PENTAGYNTA.

Gramineun. S. glaberimum : foliis linearibus, erectis : noribus peialiferis.

Ozs. Similis ŚTH:Larie graminecé.

ILAB. in Pensylvania.

\section{$P E N T A G Y N I A$. \\ S P E R G U L A. L.}

Cal. 5-phyllus. Petala 5, integra. Caps. ovata, 1-locularis, 5-valvis.

5.tgrnordes. S. pusilla, filiformis, humifusa :

L. foliis oppositis, lineari-subulatis : pedunculis solitariis.

HAB. in cultis Carolinx.

\section{S E D U M. L.}

Cal. 5-fidus. Cor. 5-petala. Squanæ nectariferæ 5, ad basin ovarii. Caps. 5.

pusillija. S. I-2-unciale, erectum, glabrum : foliis alternis, teretiusculis, oblongis : floribus ad summitatem paucioribus, alternis, subpedicellatis.

$O_{B S}$. Flores albi, octandri.

HAB. in Carolina septentrionali, loco dicto Flatrock. 
DECANDTIA: PENTANYNA. 277 vercmelum. S. glabrum : caulibus assurger. tibus : foliis sparsis, planiuscule linenribus, obtusis : cyma polystachya; floribus sessilibus.

$O_{B S}$. Afmis S. reflexo. Spicæ floridx patentissimæ et: recurvatx ; fructiferæ virgatæ. Folia ima oblongooralia. Flores octandri, purpurascentes.

IR. 1 B. in rupibus, circa $K$ noxville.

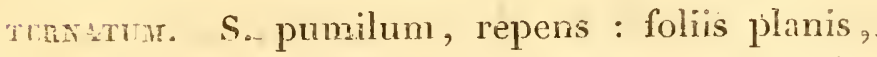
rotundato-spathulatis, ternis; cyma subtristachya; floribus albidis.

Sendr saxatile fl. albis \&c. CLart. Fl, Virg.

Oss. Flos, in summo canle, ad originem spicarum solitarius, decander; cæteri 8-dri.

$H_{A B}$, in rupibns occidentalibus Pensylvanix, Visginire et Carolinæ.

1: impmornes. S. foliis latis, planis, oralibus, utrinque subacutis, dentatis : corymbo multiplici, fasciculato.

Ozs. Florescentia S. Telephiil, folia diversa; floribus dilute purpurascentibus.

$H_{A} P$. in rupibus altissimis America septentrionalis. 
278 DECANDRIA. DECAGYNIA.

PENTIORUI. $L$.

Ca1. 5-fidus. Petala'nnlla vel quinque. Capsula 5-cuspidata, 5-locnlaris.

SeDoines. Plenthon U M.

I.

HAB. a Canada ad Carolinam, in aquaticis.

$$
\begin{gathered}
D E C A G I N I A . \\
\text { PHYTOLACCA. } L .
\end{gathered}
$$

Cal. o. Petala 5, calycina. Bacca supera, 10-locularis, 10-sperma.

Decanna. Phy tol a C CA.

I.

$H_{A B}$, in Virginia. 


\title{
CLASSIS XX.
}

\section{DODECANDRIA.}

\section{$M O N O G Y N I A$.}

\author{
A S A R U M. L.
}

Cal. 3-4-fidus, ovario insidens. Cor: 0. Caps, coriacea, coronata.

GiNA DEnse. A. foliis lato-reniformibus, gemi-

L. natis : calyce lanato, adusque receptaculum tripartito; laciniis sublanceolatis, reflexis.

A. caroliniann!n? WALT.

OBS. Vix dislinctum ab Etropaeo.

HAB, in Canada, montibus altis Americre septentrionalis ct in rupibus sipariis ammis Santée.

virginicurs. A. folihs solitariis, rotundato-cor-

I. datis, glabris : flore subsessili : calyec extus glabro, breviter campanulato.

$O B S$. Folia maculata. Legi varietatem flore maximo, plus quam pollicari, cælcro omnino similcm.

$H_{-A B}$. in Virginia.

imforme. A. foliis subhastato-cordatis : calyee 
280 DODECANDRIA. WONOGYNIA.

tubuloso, infra limbun brevissime trifidum coarctato.

A. pirginicum. WaLt.

$O_{\text {Bs }}$. Folia albido - maculosa. Calyx forma a cæteris diversus.

$\Pi_{\Delta B}$. in umbrosis sylvis Carolinæ inferioris.

\section{B E F A R I A. L.}

Cal. 7-fidus. Peiala -. Stamina 14. Caps. 7-locularis, polysperma.

pariculata. B. ramis hispidissimis : foliis ovalilanceolatis, glabris : panicula subaphylla, tab. 26. multifiora, glutinosa.

$O_{B S}$. Frutcx pulchellus, 3-4-pedalis, erectus, resinoso-glutinosus. Folia subsessilia, utrinque acuta erecta, nervo medio parcius hispido, subtus dilute glanca, Flores magnitudine R Ronor $\approx$, interdum racemo simplici, elongato. Capsula depressiuscule globosa, stylifera, 7-sulcata, 7-locularis, 7-valvis; valvis margine semiseptiferis et apice bipartibilibus.

HAR. in Florida arenosis.

\section{Y T H R U M. L.}

- Cal.2-fidus. Petala 6, calyci inserla. Caps. 2-locularis, polysperma.

LINEARE. L. glabrum, caule virgatim panicuL. lato, tetragono: foliis suboppositis, li- 
Tom, 1, Pry, $28 \%$.

Tab. 26

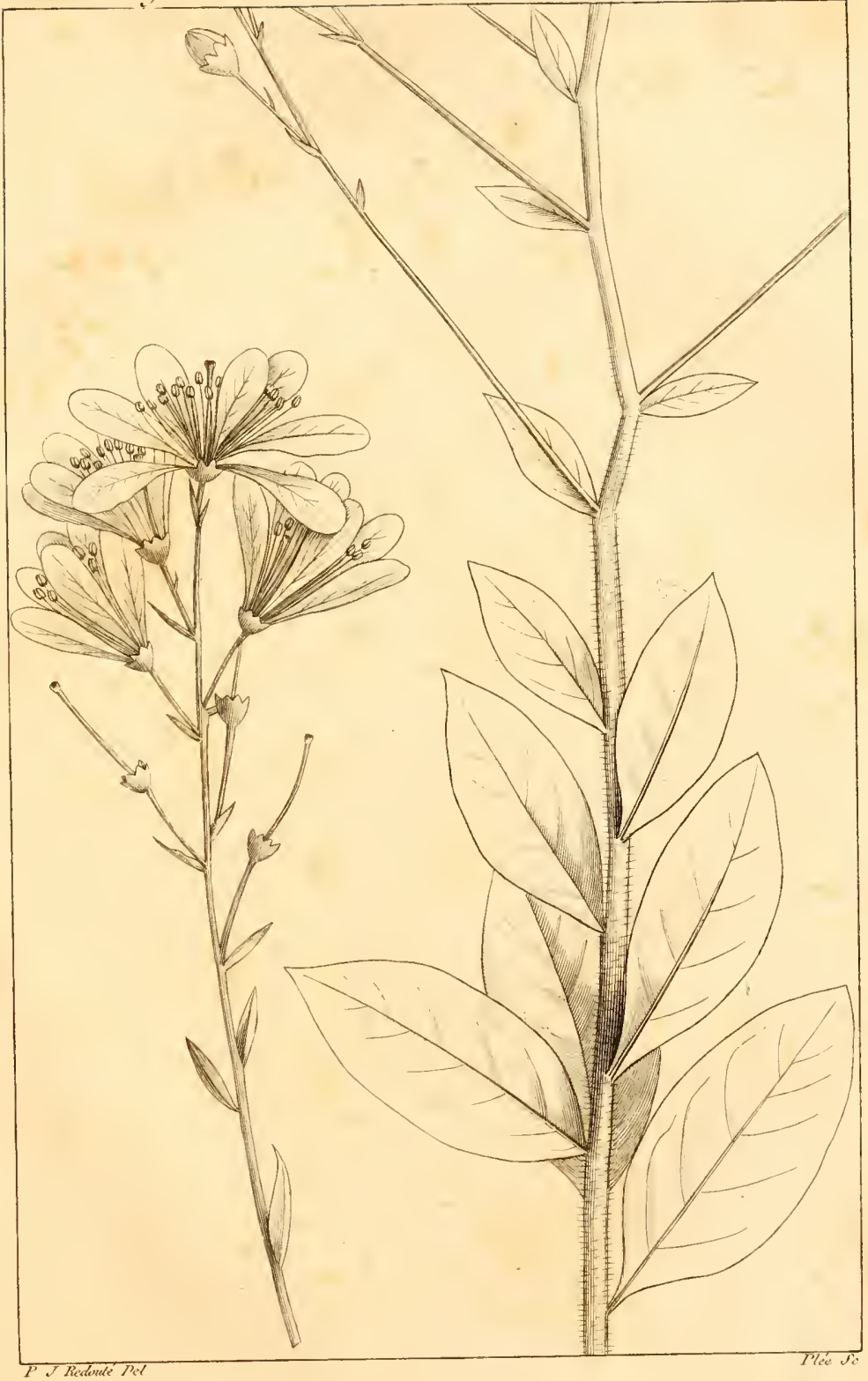

Beraria pormiculute? 

DODECANDRIA. MONOGYNIA. 28I nearibus : floribus solitarie axillaribus, hexandris.

HAE. in paludosis submaritimis Virginiæ et Carolinæ.

venticillatur. L. foliis lanceolatis, oppositis,

L. petiolatis : floribus axillaribus, subver'ticillatim aggregatis : fructibus globosis.

Deconox. Grex. Syst. 6y).

HAB. in paludosis, a Canala ad Floridam.

C U P H E A. Brown.

Cal. tubulosus, 6-dentatus, dente superiore latiore. Petala 6 , inæqualia, 2 superiora majora. Stam. insertione inrequalia. Caps. 1-lacularis calyce tecta. Semina lentiformia.

Viscosissraid. C U I' II I A.

GRRT.

$H_{A B}$. in montibus Virginiae et in crelaceis Kentucky. 
282 ICOSANDRIA. MONOGYNI.

\section{CLASSIS XII. \\ I COS A N D R I A. MONOGYNIA. \\ G A C T U S $L$.}

Cal. 1-phyllus, superus, imbricatus. Cor. multiplex. Bacca 1-locularis, polysperma.

Opuntra. C. articulato-prolifer; articulis comL. presso-ovoideis: spinis setaceis : floribus luteis.

$H_{A B}$. in submaritimis Pensylvaniæ, Carolinæ, New Yorck. Floret Junio.

D E C U M A R I A. $L$.

Cal. laciniis 8-12, superis. Petala totidem. Stam. triplo illorum numero. Caps. 7-10-loc. polysperma.

"Fonsthia. D. sarmentis radicando-scandentibus: foliis lato-ovalibus, superne rariter dentatis, Incidis, glabris; petiolo nervisque subtus puberulis.

Decumania barbara. Lins.

Forsythia scandens. Walt.

Decumaria sarmentosa. Act. soc. nat Paris. t. 13.

$H_{A B}$. in umbrosis humidisque sylvis Carolinze. 
ICOSANDRIA MONOCYNIA. 283

P II I L A D E L P H U S. L.

Cal. 4-5-partitus, superus. Petala 4-5. Caps. 4-5-locularis polysperma.

INonorus. P. calyce viridi; laciniis superne senIF $A L T$. sim angustatis, longius acuminatis : petalis candidissimis, amplissimis, patentibus, subovalibus : stylo staminibus longiore, adusque stigmata indiviso sive solido.

OBS. Phinadelphi coronarii styli 4 , imissimis basibus concrescentes!

HAz. in Caroliṇa.

C II R Y S O B O L A U S. L.

Cal. 5-fidus. Petala 5. Drupae nux 5-sulcata, 5-valvis.

onLoNcrforres. C. foliis subcuneatim oblongis val etiam oblanceolatis : petalis subrotundoobovalibus : staminibus glabris.

OBS. Variat foliis oblongo-obovalibus, subtns lanuginoso-incanis. Fructus oblongo-ovatus seu oliveformis.

$H_{A B}$. in sabulosis sylvarum Georgix et Floridæ. 
P R U N U S. Tourn. Juss.

Cal., petala stamina et ovarium. Cerasi. Drupa major, foeta nuce 1-2-sperma, ovata, subcompressa, prope margines angulatos sulcata.

sph Ærocarpa. P. fruticosa : foliis brevi-ovalibus, serrulatis, basi plerumque biglandulo.sis : calycibus puberulis : drupa sphærica; nuce subrotundo-ovoidea.

$O_{B S}$. Ramuli juniores pedunculique pubentes : fructus breviter pedunculatus, fusco-purpureus, acerbus.

$H_{A B}$. in maritimis Novæ Angliæ.

ıcuminata. P. fruticosa, ramulis glabris : foliis oblongo-ovalibus, longiuscule acuteque acuminatis; calyce glabro : drupa longiuscule pedunculata, ovata, acuminata.

$H_{A B}$. in Virginia.

niemalis. P.arborea; stipulis setaceo compositis: foliis oblongo - ovalibus obovalibusve, abrupte promisseque acuminatis : pedicellis aggregatis, glabris : calycis laciniis lanceolatis; fructu subovato.

Oss. Fructus nigricans, acerbas, hieme edalis.

HAB. in Canada, Virginia et in umbrosis Carolina.

Chicasa. P. frutex, ramis subspinescentibus, glaberrimus : foliis oblongo-ovalibus, 
ICOSANDRIA. MONOGYNIA. 285 acutis acuminatisve, minutissime scrrulatis : gemmis aggregatis, singulis subbifloris : pedicellis brevissimis : calycis glabri laciniis obtusis : fructu subgloboso.

$O_{B S}$. Fructus flavus, parvus; æstate edulis, sub nomine Chicasas.

$H_{A B}$. in Carolina. Ab Indis introducta.

\section{E R A S U S. Tourn. Juss.}

Cal. campanulatus, 5-lobus, deciduus. Petala 5. Drupa subrotunda, camosa, glabra, foeta nuce levi, subrotunda, 1-2-sperma.

virginians. C. glaberrima, foliis deciduis, ovalioblongis, acuminatis, serratis, nitidis, subencrviis : racemis terminalibus, elongatis: fructibus globosis.

Prunus virginiana. Linn.

Var $\beta$. humilior : ramis divaricatis; foliis minoribus, ovalibus : racemis fructiferis puberulis.

HAB. a Canada ad Carolinam.

- 6. in sylvis montanis Temassée et occidentalibus Carolinæ.

Caroliniani. C. foliis perennantibus, breviter AIn. petiolatis, lanceolato-oblongis, mucronatis, lævigatis, subcoriaceis, integris ; 

racemis axillaribus, brevibus : fructu subgloboso, acuto, subexsucco.

$O_{B S}$. Arbor formosa, fastigiata, ramis strictis : fructibus hieme persistentibus.

$H_{A B}$, a Carolina ad Floridam.

Bonealis. C. arborescens : foliis ovali-oblongis, acuminatis, membranaceis, glabris : floribus subcorymbosis; pedicellis longiusculis : fructu subovato.

Prunus nigra? Hort. Kew.

$O_{B S}$. Folia quasi eroso-denticulata. Fructus pusillus, ruber, dulcis.

$H_{A B}$, in America boreali et in altis montibus Novæ Anglix.

pUmila. C. foliis subcuneato-lanceolatis, rarius serratis, glabris, subtus glaucescentibus: pedicellis aggregatis : fructu ovato.

$O_{B} s$. Fruticulus prostratus. Fructus partyus, niger, edulis.

Prunus pumila. Linat. nec Walt.

$I I_{A B}$ ad ripas arenosas lacuum Americx borealis. 


\section{$D I G Y \perp I A$.}

A G R I M ON I A. $L$.

Cal. 5 -dentatus. Petala 5. Sem. 2, in fundo calycis.

Euratoru. A. spicis virgatis : floribus subsessi-

x. libus : fructibus basi brevissime obconica sublavibus, divaricato-hispidis.

$H_{A B}$. in Carolina superiore.

striat.. A. spicis virgatis : fructibus reflexis, turbinatis, sulcato-striatis, apice tantum et quasi coronatim hispidis.

OBS. Flores albidi.

HAB. in Canada.

C R A T $\mathbb{E}$ G US. L.

Cal. 5-fidus. Petala 5. Bacca infera, disperma.

Ampozid. C. spinosa : foliis deltoideis, incisolobatis; lobis acutis, inciso-dentatis : corymbi pedicellis subsimplicibus : calycis laciniis subserratis.

$O_{B S}$. Folia molli et candicanti lanugine conspersa.

Calycis tubus oblongus.

$H_{A B}$. in humidis sylvarum Carolinæ. 
clandulosa. C. spinosa : stipulis, calycibus imaque foliorum parte margine glandulosis; glandulis globularibus, sessilibus : foliis subrotundis, breviter lobatis, subpubentibus : floribus subsolitariis.

$O_{B S .}$ Junioris plantæ stipulæ, majusculæ, foliacex, subreniformi-orbiculatæ; folia minus lobata, basi abrupte in petiolum brevem, alatum angustata.

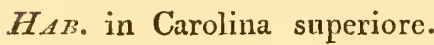

spatiulata. C. ramulis spinescentibus, fasciculatim foliosis : foliis (adultæ plantæ) parvulis, longissime deorsum angustatis, subspathulatis, trifidis.

$O_{B S .}$ Affinis Oxyacanthae.

$H_{\triangle B}$, in Carolina utraque et Virginia.

coccinea. C. arborea : foliis longe petiolatis, sub-

L. cordato-ovalibus, inciso-angulosis, acutissime serratis, membranaceis, demum glakellis : corymbis pubescentibus : calycis laciniis linearibus, subserratis : petalis suborbiculatis.

$O_{B S}$. Fructus rubri.

$J_{A B}$, in Canada et in excclsis montibus Carolinæ septentrionalis.

Crus Gallt. C. glaberrima, spinis longissimis z. passim armata : foliis oblonge cuneato- 
I COSA NDRIA. DIGXNIA.

obovalibus, luciris : cnrymbis compo-

sitis : calycis laciniis !inearibus.

MLE. in Carolina superiore.

puxctata. C. arborca; foliis majusculis, subpli$J_{-4}$ cQ catis, breviter subcuneato-obovalibus, superne duplicato-dentatis, subtus juxta nervos villosis : corymbo lanuginoso : la. ciniis calycis subulatis.

Ors. Folia petiolata : fructus lutei, punctati.

$H_{A B}$, in Carolina superiore.

tomentosa. C. spinosa : ramis foliisque utrinque L. . lanuginosis : foliis sessilibus, rotundatocuneatis, superne dentatis : floribus subsolitariis : calycis laciniis incisis : fructu flavo.

Mespilus xanthocarpus. Lins. Suppl. 25\%. M. laciniata. W $\mathbf{\text { LxT, }}$

$H_{A B}$, in Carolina inferiore. 


\section{$T R I G Y N I A$. SOR BUS. $L$.}

Cal.5-fidus. Petala 5. Bacca infera, 3-spama.

aucuparia. S. foliis pinnatis : fructibus dense

L. corymbosis, parvulis, globosis, rutilis. Var. $\alpha$. foliis acuminatis.

- $\beta$. foliis sensim aculis.

$O_{B S .}$ Utraque variat foliis pubescentibus et glabellis.

$H_{A B}, \alpha_{0}$ in excelsis montibus Carolinx.

- $\beta$. in Canada et circa lacum Ontario. 


\title{
$P E N T A G I N I A$.
}

\author{
M E S P I U S. L.
}

Cal. 5-fidus. Petala 5. Bacca infera, 5-sperma.

cananensis. M. foliis subovalibus, acutissime ser-

L. ratis, subacuminatis; adultis glabris: racemo simplici, elongato; forifero lanuginoso; fructifero glabro : pelalis oblongis : fructibus atropurpureis, edulibus.

Var. a. obovalis : humilior ; foliis oblongiuscule obovalibns.

- B. cordala : arborea : foliis cordato-ovalibus, conspicue acuminatis.

- $\%$ rotundif lia : arborescens; foliis suburbiculato-ovalibus, utrinque rotụ. datis.

- ঠ. oligocarpa: frnticosa : foliis oblongoovalibus, basi acutis, subtiliter serru.latis, brevi-petiolatis : fructibus subsolitariis.

HAB. a. in Carolina inferiore. $\beta$. a Canada ad Virginiaı et in montibus Carolinæ. $\%$ in Canada. $\delta$. in America boreali.

arbutifolra. M. inermis foliis oblongo-ovalibus, I. acuminatis, subtilissine serrulatis, sub- 
292 ICOSANDRIA.PENTAGNIA.

tus subcanescentilus : corymbo composito.

Var. a. erythecarpa : foliis subtus tomentosis; fructibus rubris.

- - melanocarpa : foliis subtus glabriusculis; fructibus nigris.

Oss. Fructus crassitie Oxyacantitae.

$H_{A B}$, a. in Virginia et Carolina.

- $\beta$. in Canada, a sinu Hudsonis ad Virginiam et in montibus altis Carolinæ.

$$
\mathrm{M} \Lambda \mathrm{I}, \mathrm{US} \text {. T. Juss. }
$$

Cal. 5-fidus. Petala 5. Styli basi connati et villosi; stigmata 5 , distincta. Pormum sphæioideum, basi circa pedunculum concava, umbilicata, medio 5 -loculare, loculis cartilagineis, 2-spermis; Semina cartilaginea.

coromaria. M. foliis lato ovalibus, basi rotunMıx. datis, subangulatis, serratis, nitide glabris : calycibus extus glabris : pedunculis corymbosis : fructu parvo, lacvigato.

HAB. in Pensylvania, Virginia.

ANgustifolia. M. foliis lanceolato-oblongis, basi Aır. acutis, leviter crenato-dentatis, glabris: pedunculis corymbosis.

$O_{B S}$. Aflinis priori : fructus minor. Folia ill America decidua.

HAs. in Carolina. 
ICOSANDRIA. PENTAGYNTA: 293: S P I $\mathbb{R}$ E.A. L.

Cal. 5-fidus. Petala 5. Capsilae polysperma.

saliciforia. S. fruticosa : foliis lanceolatis, ara L. gute serratis, membranaceis, nervosis, subtus nudis : racemo terminali com: posito, subpaniculato : floribus albis, pentagynis.

Oss. Variat foliis ovalibus, late dentatis etiamque sublobatis; foliis oblonge cuneato-obovalibus; modio acutissimis, modo obtusis, \&c.

H.tB. a sinu Huclsonis ad Pensylvaniam et in montibus Carolinæ: ?

aomentosa. S. fruticosa : foliis ovalibus sen sub-

I. lanceolatis, inæqualiter serratis, subtus tomentosis : racemo terminali, compo. sito, confertiflora :.. foribus pusillis, carneis, pentagynis.

HAB. in Canada et occidentalibus montosis America septentrionalis.

opulffols. S. fruticosa : foliis lobatis, dupli-

x. cato-dentatis crenatisve : corymbo terminali, subumbellato, confertion multifloro: floribus trigynis : capsulis inflatis.

Ilaв. a Canada ad Carolinam, juxta montes. 
294 ICOSANDRIA. PENTAGYNIA.

TRIFOliata. S. herbacea : foliis trifoliatis; foliolis

I. lanceolatis : floribus laxe subpaniculatis, pentagynis : calyce tubuloso-campanulato.

FAB. a Canada ad Floridam.

довата. S. herbacea : foliis pinnatis; pinnis JAce. lateralibus imparique maximo subpalmato-lobatis; lobis lanceolatis, duplicato-serratis : cyma composita; floribus roseis, 3-5-gynis.

$H_{A B}$. in Virginia et Carolina septentrionali.

Anuncus. S. herbacea : foliis 2-3-pinnatis : floL. ribus minutis, dioicis, trigynis, paniculatis.

$O_{B S .}$ Panicula compositæ numerosis gracilibusque spicis.

Var. '. hermaphrodita : foliis lucidioribns : floribus in spicis minus crebris et hermaphroditis-fertilibus.

$H_{A B}$, in montibus Virginiæ, Carolinæ et Georgiæ. 
ICOSANDRIA, POTYGYNIA. 20S

\section{POLYGYNIA.}

R O A. L:

Pelala 5. Cal. urceolatus, 5-fidus, carnosus, coillo coaretatus. Sem. plurima, hispida, calycis interiuri lateri aflixa.

conominara. R. pumila : caule levi; aculeis sti-

ᄂ. pularibus binis, acicularibus, patulis: petiolis aculeatis; foliolis ovalibus lanceolatisve : fructibus globosis, hispidulis.

OBS. Foliola parvula, plerumqute acuta.

$H_{A B}$. in Georria et Carolina.

SETICERA. R. ramis glabris, gemino-aculeatis :ioliis 3-5-foliatis, petiolo nervoque aculeolatis : calycis glolosi lacinis subpen -natim setigeris.

Oss. Foliola glabra, acuninata. Proter aculeos infra folia geminatos, interdum nonnulli etiam hic et illic rarissime sparsi sunt in ramis.

Datur varietas elatior, aculeis inordinatis; foliolis. subtus, presertim juxta nervos, puberulis; laciniis. calycinis rarius setigeris.

HAB. in Carolina inferiore.

дxvianta. P. glaberrima: subgemination ackleata : foliis 3-5-foliatis, subenervis: stipule anguste mucronibus subalatis: 
calyce ovato, promisse hispidissimo, laciniis integris.

Oss. Aculei in ramis passinı geminati, recurvi; uno

in petiolis : foliola lanceolato - ovalia, lævigata: calycis tubus spinis gracilibus longisque hispidus.

IIAB. in Georgia.

Pressluatica. R. caule glabro, passim uncinulis geminatis : foliolis 5-7, oblongo-ovalibus, subtus subincanis; fructu depresso-globoso.

$O_{\bar{s} S}$. Petioli interdum passim aculeolati.

$H_{A B}$. in paludosis Pensylvanix et Novæ Anglix.

\section{R U B US. $L$.}

Cal. 5-fidns. Péala 5. Bacca composita acinis monospermis.

* Frrticosi.

marrazis. R. sarmentoso-procumbens : stipulis subulatis : foliis $3-5$-digitatis ; foliolis oblongo-ovalibus, non acuminatis, sub æqualiter serratis, glabriusculis :pedicellis subsolitariis, elongatis.

$R$. fiuticosus. WaLt.

OBS. Sarmenta diffuse procumbentia : petioli et pedunculi hispidi aculeatique : petala majuscula, suborbiculata. Fructus niger, edulis.

HAB. in Carolina et Pensylvania, ubique frequens. 
ICOSANDRIA. POLTGYNIA. 297 occidentalis. R. ramis peliolisque glaucis el acuI. leatis : foliis trifoliatis; foliolis ovalibus, promisse acuminatis, sublobatim duplicato-serratis, subtus cano-tomentosis.

HAB. a Canada ad Carolinam, per continuam seriem montium Alléghanis.

rillosus. R. pubens, hispidulus aculeatusque: Axt. foliis 3-5-digitatis; foliolis absque albedine pubentibus : stipulis setaceis : calyce breviter acuminato : racemo laxo, pedicellis solitariis, longiusculis.

R. hispidus? WaIt.

H.AB. in utraque Carolina.

strigosus. $R$. inermis, rigide hispidissimus : foliolis 3 aut pimnato-quinis, oralibus. basi obtusis, subtus lineatis et candidotomentosis; impari sxpius subcordato.

$O_{B S}$. Rami, petioli, nervi, pednuculi calycesque Jispidissimi ncc antem aculeati. Foliola sensin et acute acuminata, sæpius tria; si quinque, non digitata, sed bijuga cum impari.

$H_{A B}$. in montibus Pcnsylvaniæ et in Canada.

oDoratus. R. stans, viscido-hispidulus, inermis:

L. subcorymbose multiflorus : fructu velutino : foliis simplicibus, acute lobatis. $H_{A B}$. in Canada ct in excelsis montibus Alléglaanis. 
Cumsuonus. R. herbacea, inermis; cauliculis

L. erectis, subdiphyllis, I-fldris : sipulis ovalibus, obtusis : foliis simplicibus, subreniformibus, rotundato-lobatis.

$I_{A B}$. in sphagnosis ripariis amnium in sinum Hudsonis defluentium.

sixituls : R. herbaceus, trifoliatus : foliolis canadensis.subrhombeis, acutis, inciso-dentatis; impari petiolato : floribus subternis.

OBS. Pubescens : stipulæ ovali lanceolatæ : flores solito tres; inferiore solitario, terminalibus genninis; longiuscule peciicellati.

HAB. a sinu Híudsonis ad fines meridionales Canadx.

ogorals. R. frulicescens, pilis rigidis hispiduLus : loliis trifoliatis; foliolis rotundatoobovalibus : pedunculis composite multifloris.

H.AB. in vallibus exeelsorum montium Carolinæ septentrionalis.

acicis. R. Lerbaceus, pusillus : foliis omnibus subradicalibus, trifoliatis; foliolis sessilibus, lateralibus subtrapezoideis, impari rhombeo : flore unico, brevipedicellato.

$O_{B S}$. Afünis $R$. arctico; sed diversa.

II $\mathrm{E}$. in sphagnosis sinui IIudsonis adjacentibus 



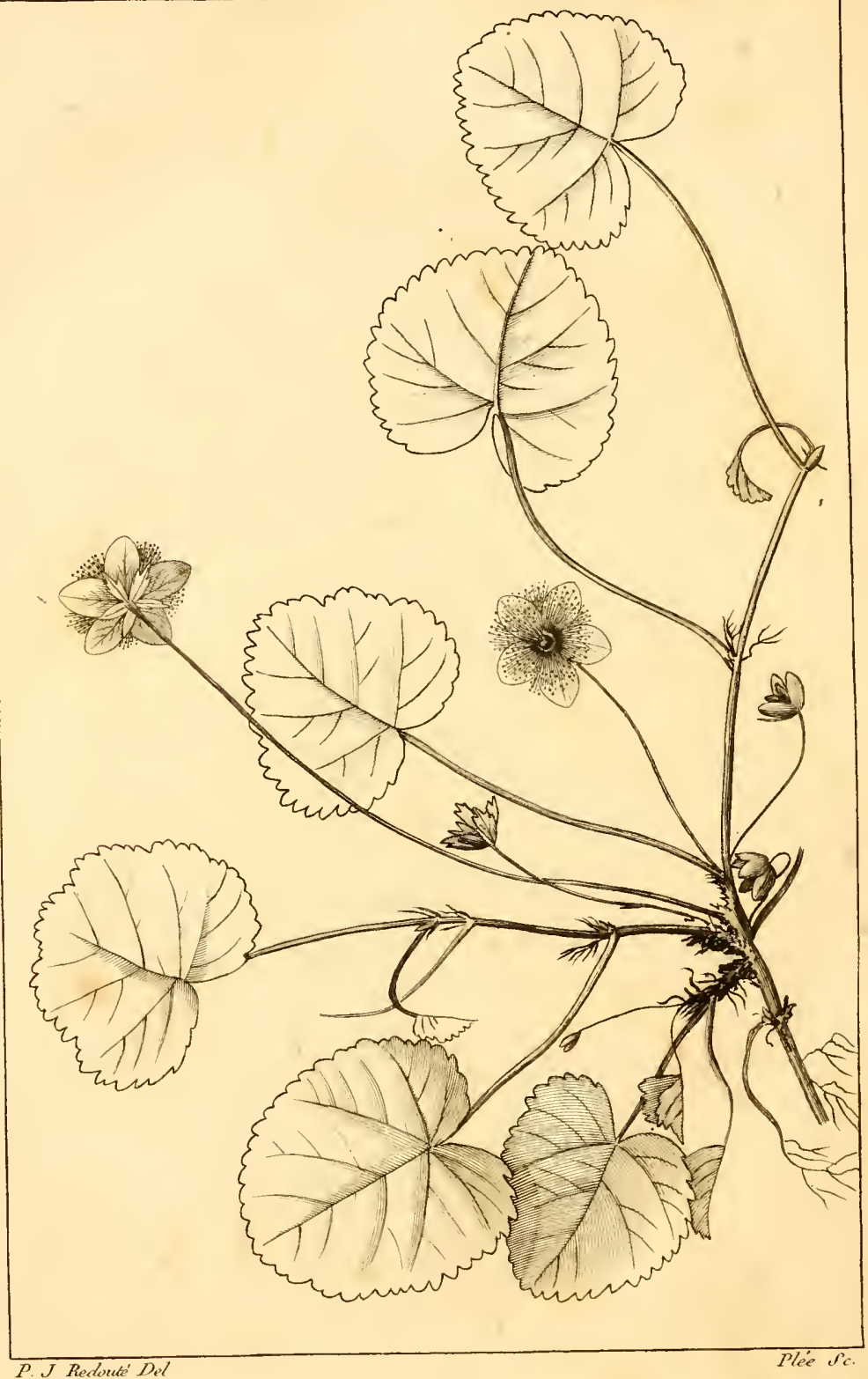

DAIIBARDA violaeoides. 
ICOSANDRIA. POLYGYNIA. 299

I R A GA R I A. L.

Cal. 10-fidus. Petala 5. Receptaculum seminum ovatum, baccatum, deciduum.

cananensis. F. major : foliolis amplo-ovalibus;

lateraibus manifeste petiolalis : pedicellis longis, recurvo-pendulis : receptaculis seminum globosis, favoso-scrobiculatis, villosis.

HAB. in montosis et sylvis, a sinu Hudsonis ad Floridem.

D A L I B A R D A. L.

Genus a Rebo discrepans qualiter fere Potrantifia a Fragaria.

Herbula radice repente perennes, subacaules, cligophyllæ.

CAL. 5-partitus.

Pistulla 5-8 : styli longi, filiformes, decidui.

Semina exsucca.

violromes. D. villosa : stoloniluus reptantibus: foliis simplicibus, cordatis, crenatis: tab. 2\%. pedunculis unifloris.

Ruevs Dalibarda. Smitu. 1c. xx. optime, calyce petalisque tamen nimis acutis.

Oss. Calycis lacinix interdum apice dentatio. Hizs. in Canada. 
Fiaganones. D. folits trifoliatis; foliolis brevibus, cuncatis, superne rotundalis, tab. 28. crenato-lobatis, glabriusculis, ciliatis : pedunculis multifioris : calycis tubo acute obconico : filamentis staminum persisa tentibus.

\section{G E U M. L.}

Cal. 10-fidus. Petala 5. Semina arista geniculata.

Gananensf. G. hirsulissimum : foliis eaulinis pinMURR. natis : stipulis multifidis : pedunculis. fructiferis rigide divaricatis; capitulis squarrosis; ariștis nudis, uncinatis. G. strictum. Hort. Kew.

$O_{B S}$. Petala lulea, orbiculata, calyce majora. Has. in Canada.

gexiculatum. G. subpaniculatim multiflorum: foliis caulinis subsessilibus, tripartitis : petalis cuneato-obcordatis : aristis prorsus pubentibus, medio geniculatis.

Ors. Caulis superne ramosus. Stipula subintegra. H.x. in Canada.

nadatur. G. hirsutissimum; caule simplici : foliis radicalibus pinnatis; impari amjlissimo, reniformi, radianti-nervoso: 


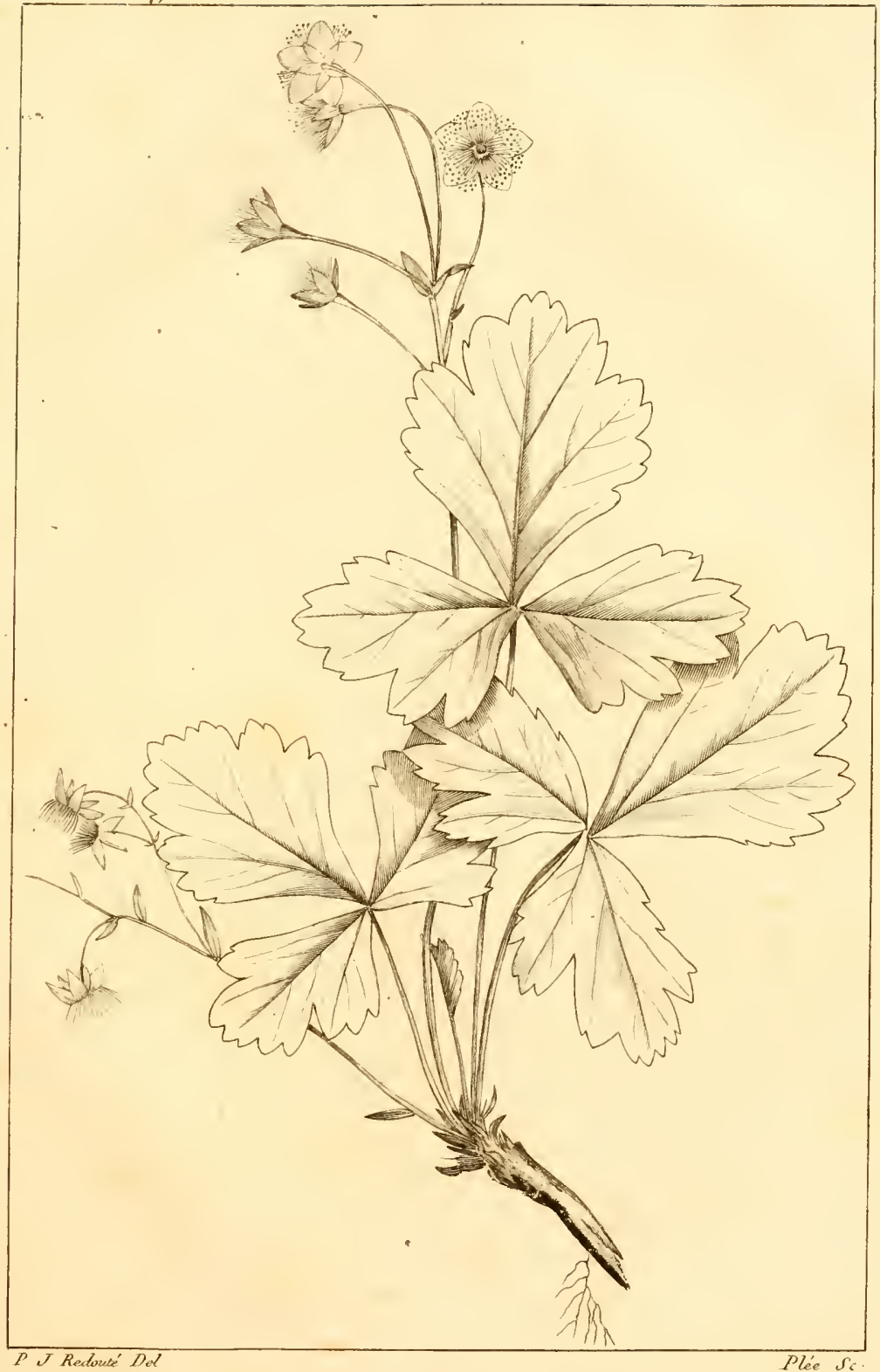

DAIABARDA frectarioides. 

IC.OSANDRIA. POLYGYN1A. 301 caulinis amplexicaulibus, inciso-laceris : aristis glabris, apice simplici.

Oss. Planta pulchella, caulibus simplicibns, erectis: folia radicalia pinnata, pinnulis pancioribus minimisque; caulina simplicia. Petala cuneato-obcordata, lutea basique fulva.

$I_{A B}$. in excelsis Carolinæ montibus.

nuáe. G. caule simplici : foliis radicalibus inL. terrupte pinnatis; caulinis trilcbis : floribus nutantibus : capitulis squarrosis, hirsutissimis; aristis superne nudiusculis, minutissime uncinatis.

HAB. in Canadie borealibus.

vinginianum. G. foliis radicalibus caulinisque tri-

L. foliatis : floribus nutantibus : capitulis globosis; seminibus hispidulis; aristis nudis, apice tortilibus:

OBs. Modice pubens : folia caulina pleraque trifoliata et petiolata : stipulx parvulx, ovali-lanceolatx, subintegræ. Flores pusilli, petalis albis.

HAB. a Canada ad Virginiam. 


\section{O M A R M. $L$.}

Cal. 10-fidus. Petala 5, calyce minora. Receptaculum seminum ovalum, spongiosum, persisiens.

palustre. C O M A $R$ U M.

$\boldsymbol{L}$.

OBs. Europæo omnino simile.

HAB. in Canada, a Quebec ad sinum IIudsonis.

$$
\text { POTENTIILA.L. }
$$

Cal. 10-fidus. Petala 5. Semina subrotunda, recepiaculo parum exsucco affixa.

trinentata. P. assurgens, glabriuscula : stipulis Aır. subulatis : foliis trifoliatis, oblongocuneatis, apice subtridentatis : panicula laxa.

$O_{B S}$. Foliola interdum 4-5-dentata; omissis nervo subtus et margine glabra. Flores albi.

$H_{A B}$. in rupibus Canadæe tin summo monte dicto Grandfather Caroline.

nonvegica. P. erecta, ramulosa; parce pubens :

L. foliis trifoliatis, subrhombeo-lanceolatis, inciso-dentatis : stipulis ovalibus, dentatis : petalis calyce majusculo brevioribus.

$O_{B S .}$ Flores quasi foliose paniculati ; pedicellis breviusculis. Petala pallida.

IIAB. in Canada. 
ICOSANDRIA. POLIGYNTA. 303 nirsura. P. pilis rigidulis hirsutissima, erecia, simplex : foliis trifoliatis, obovalibus, sublaciniaio-incisis : panicula pauciflora, pedicellis brevibus : petalis albis, calyee minoribus.

OES. Tota virens, habitu aflinis P. hirta?. Stipulx sublanceolatæ, erectæ, integræ.

IIAB. in Canada, a Quebec ad ostium fluminis S. Lazm rentii.

carancasis. P. fragaroides, candicanti-sericea :

L. foliis quino-digitatis, cuneato-obovalibus, inciso-dentatis : calycis laciniis lineari-lanceolatis : petalis subintegris, orbiculatis.

$O_{B S}$. Habitus Fragarye sterilis : affinis $P$. vernae.

Radix repens : caulicnli procumbenies, uni-biramulati. Flores lutei ; pedicellis longis, solitariis.

H.A. a Canada ad Carolinam superiorem.

smplex. P. erecta, simplex, hirsuta : foliis 5 digitatis, oblongo-ovalibus : pedunculis lateralibus, solitariis, clongatis, unifloris.

$O_{B s .}$ Caulis angulosus, asperinsculus : foliola incisodentata, nervis pilosis. Incrementum ramuli et folium unicum petiolațm ex axillis foliorum subsessilium 1-floris : pedunculus setaceus, elongatus. Petala lutea, rotundato-obcordata, calyce longiora.

H.AB. in Canada, Pensylvania et Carolina. 
3O4 ICOSANDRLA. FOLYGYNIA.

rruticosa. P. caule fruticoso, erecto : foliis pin-

L. nato-trifoliatis; impari profunde tripartito; lateralibus simplicibus aut bipartito-geminatis.

HAB. ad ripas amnium rivulorumque Am ricæ borealis.

pensylvanica. P. erecta, mollissime subcandi-

L. canti-villosa : foliis pinnatis; foliolis oblongis, obtusis, subsemipinnatifidis, tomentosis : panicula stricta, multiflora: calycis tomentosi laciniis semiovalibus.

$O_{B S .}$. Flores sulphurino-lutei, visciduli.

$H_{A B}$. in Canada.

supina. P. procumbens, dichotoma : foliis pinL. natis; pedunculis lateralibus, solitarie alternis, brevibus, patulis, I-floris.

$H_{A B}$. in arenis ripariis inundatis fluminis Missousi.

Anserina. P. foliis numerose interruptopinnatis,

L. inciso-serratis : caulibus repentibus : pedunculis solitariis, $\mathrm{x}$-floris.

HAB, ad ripas lacus Champlain. 
ICOSANDRIA. POIYGYNIA. 305

C A L Y C A N T II U S. L.

Cal. 1-phyllus, urceolatus, squarrosus, foliolis coloratis. Cor. calycina. Styli plurimi stignate glanduloso. Sem. plurima, caudata, intra calycem steculentum.

rLorinus. C. foliis lato-ovalibus, subtus ramuL. lisque tomentosis : floribus rarissime fertilibus.

HAB. in Carolina.

FERAX. C. ramis stricte erectis, sxpe virgatis : foliis ovalibus vel sublanceolato-ovalibus, subtus glabris, sensim acuminatis : floribus fertilibus.
C. fertilis. WALT.

IIAB. in altis montibus Carolinæe et Virginix. 


\title{
CLASSIS XIII.
}

\section{P O L Y A N D R I A.}

\section{$M O N O G Y N I A$.}

\author{
T I L I A. $L$.
}

Cor. 5 -petala. Cal. 5 -partitus. Bacca sicca, globosa, 5 -locularis , 5 -valvis, basi dehiscens.

LAXIFLORA. T. foliis cordatis, sensim acuminatis, rariter dentatis, membranaceis : paniculis laxifloris : styio petalis longiore.

$H_{A B}$, in maritimis Carolinx, Virginix.

CANADENsis. T. foliis suborbiculato-cordatis, abrupte acuminatis, crassiusculis : paniculis confertiusculifloris : stylo petalis subrequali.

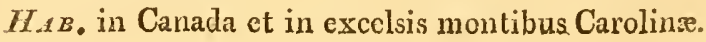


POLYANDRIA. MONOGYNA. 307 HE L I A N T H EMU M. Juss.

Cal. nunc æqualis, nunc sæpius inæqualis, laciniis 2 extimis minoribus. Caps. 1 - locularis, 5 -valvis; membrana valvas intus vestiens, medio exarata linea seminifera.

RAMULIFLoRUm. H. exstipulatum, erectiusculum, minutim pubens : foliis alternis, oblongis, subtus tomentosis : ramusculis brevibus, summitate subtriftoris : calycibus fructiferis globosis.

$O_{B S}$. Folia obtusiuscula. Calyces læves et absque manifesta pube pulverulenti.

$H_{A B}$, in Georgia et Carolina.

corymbosum. H. exstipulatum, fruticescens, pumilum, erectum, ramosum, minutim pubens; foliis alternis, lanceolatis : corymbo subfastigiato, e fasciculis confertim multifloris.

$O_{B S}$. Folia snbtus subtilissime incano - tomentosa。 Flores parvnli, lutei.

$I_{A B}$. in maritimis Carolinæ et Georgix.

Carolinianum. I. perenne, exstipulatum, hirsutum : caulibus erectis, simpliciusculis : foliis alternis, oblongo-ovalibus seu sublanceolatis, subdenticulatis; imis ob- 
308 POLYANDRIA. WONOGYNIA.

ovalibus : pedunculis calycibusque villosissimis, in summitate paucioribus.

Cistus carolinianus. WVatt.

$O_{B} s$. Folia inter Helianthema najuscula : flores etiam majusculi, Jutei.

$H_{A B}$. in Carolina.

Caraderse. H. perenne, exstipulatum, erectum: foliis alternis, erectis, lanceolatis, subtus minution tomentosis : floribus paucioribus, pedicellis solitariis.

Cistus canadensis. IīNN.

$H_{A B}$. in Pensylvania et Nova Anglia.

\section{A C T EA. L.}

Cor. 4-petala. Cal. 4-phyllus. Bacca 1-locularis. Sem. semiorbiculata.

racemosa. A. folïs decompositis; racemis virL. gatim longissimis : floribus monogynis : capsula ovoidea.

$H_{A B}$ a Canada ad Floridam, per tractus montium.

spicata. A. foliis decompositis : racemo abbre$L$. viato : floribus monogynis : baccis globosis.

Var. $\alpha$. rebra: fructibus rubris.

- . alba : fructibus albis : foliolis oblongisribus, magisque in acuturn angustatis.

II.AS. \%. in Canada.

- $\beta$. in Canada et in montibus Virginix. 
POLYANDRIA. MONOGYNIA: 309

G I E I I D O N I U M. Juss.

Stigma parvum, bifidum. Capsula longa, tenuis, 2-Falvis, 1-locularis dissepimento nullo.

DIPIYLLUM. C. caulibus in summitate geminatim diphyllis : foliis sessilibus, lobato-pinnatifidis : pediunculo ex foliorum dichotomia solitario, unifloro : capsula oblongoovata.

Obs. Hre species Chemidonium Sanguinatia quasi connectit.

HAB. in umbrosis occidentalibus Tennassée et Ken n tucky.

\section{S A N G U I N A R I A. $L$ 。}

Cor. 8-petala. Cal. 2-pliyllus. Capsula orata, 1 -locularis.

cananersis. S. foliis subreniformibus, sinuatoL. lobatis : scapis unifloris.

$H_{A B}$ a Canada ad Floridam.

\section{P O.D O. P I Y L L U M. $L$.}

Cor. 9-petala. Cal. 3-phyllus. Bacca. 1-localaris, coronata stigmate.

pectarum. P. foliis peltatis, lobatis.

L. 
3ro POLYANDRIA. MONOGYNYA.

\section{S A R R A C E N I A. L.}

Cor. 5-petala. Cal. duplex, exterior 3-phyllus int. 5-phyll.Caps. 5-loc., stylo stigmate cly peato.

pUrmurea. S. foliis brevilbus; tubo ventricoso-

L. gibbo, fauce coarctato; ala ventrali arcuatim elatiore; appendice erecta, subreniformi-cordata, mutica, sessili : flore purpureo.

Puuckn, t. 37 6. f. 6.

HHA. a sinu Hudsonis ad Carolinam, præsertim in sphagnosis.

flava. S. foliis strictis, longissime infundi-

I. bulatis; fauce patula; ala ventrali subnulla; appendice erecta, basi coarctata, ima parte lateribus retroflexis; mucrone subulato.

$$
\text { Ps.ucke. t. } 376 \text {. f. } 5 \text {, }
$$

$H_{A B}$. in humidis apertis, a Carolina ad Floridam.

VArIolaris. S. foliis elongatis; tubo superne dorso maculoso, in appendicem fornicatim incurvatam, brevem desinente; ala ventrali lineari-lanceolata : flore flavo.

HAB, a Carolina ad Floridam. 
POLYANDRIA. TONOGYN1A. 31I PSTtTacina. S. foliis brevibus, superne coloratis, venoso-reticulatis; ala veutrali sursum subcuneatim latescente; tubo sensim in appendicem recurvatam, rotundatim for nicatam, mucronatam : flore purpureo.

OBs. Appendix quodam modo caput Pistlaci imitatux. HAB. ab urbe Augusta Georgix ad Floridam.

$$
\text { N Y M P II A A. L. }
$$

Cor. polypetala. Cal.4-5-phyllus. Bacca multilocularis, truncata.

$\triangle L E A$ N. foliis orbiculato-cordatis, integris;

L. sinu basis angusto, lateribus subrectilineis : flore albo : petalis calyci $/$ phyllo equalibus.

$$
\text { N. odorata? AI }
$$

HAE. a Canada ad Carolinam.

Lutea. N. $\beta$ - Kalmiana.

L.

$O_{B S .}$ Differt a $N_{0}$ luter foliis subbiuncialibus, flore vix ultra semiunciali.

Quamvis differentiam specificam verbis notare non possim ; diversa tamen videtur.

HAB. in Canada.

Advina. N. foliis erectis : calyce 6-phyllo. AIT.

OBs. Cætera ommino $N$. luteae.

I1AB. a Nova Anglia ad Carolinam, 
zongrodia. N. foliis elongatis, sagittato-cordatis, obtusis : flore lu teo : calyce 6-phyllo, petalis nullis : antheris subsessilibus. N. sagittifolia? WaLt.

FAB. in amnibus Carolinæ sept. et merid.

\section{$D I G Y N I A$.}

F O T II E R I L L A. $L$.

Caulis fruticosus : folia alterna, stipulata. Spica, squamulis sessilibus, 1-fluris. Foliatio conduplicativa : pubes fascicularis.

Cac. pusillus, abbreviato-campanulatus, margine leviter 5-6-crenatus.

Cor. o.

Stan. plurima; summo calycis tubo contigue et unica serie inserta; decidua : filamenta longissima, recta, subclavata: anthera erectæ, subcordata; loculis dorso oppositis, angustata filamenti summitate connexis.

Prst. ovarium calycis fundo innatum eliamque tantisper immersum; subconoideum, fissum, desinens in 2 stigmata setaceolongissima, glabra, recurvata.

CAPS. calyce quasi cupulatim semitecta, ovoideo-subglobosa, bicornis : 2-locularis : superne 2-valvis; moxque partibi- 
POLYANDRIA. DIGYZTA. 313

litate valvarum quadrifariam dehiscens et quadricornuta : loculis cartilagineis a communi cortice sponte secedentibus.

SEM. in singulis loculis unicum; summæ fere columella, hilo lateraliter subterminali appensum; oblongo-ovatum, lievigatum.

Tegumen durum, testaceum.

Albumen carnosum, albidum, undique includens. Embryonem uti semen inversum, rectum : radicula lonģiuscula, cylindrica : cotyledonibus ovalibus, facie ad faciem appressis.

$O_{B S}$. Genus pluribus notis Euphorbiaceis affine.

Garnert. F. foliis subovalibus, superne crenatox. dentatis, subtus subcanescentibus.

Oss. Foliorum figura ludit; modo suborbiculata, modo subcuneata, modo et sæpius obovali : frutex plerumque nudilorus; interdum frondescentillorus,

ILAB. ill Carolina. 


\section{$T R I G Y N I A$. \\ DE L P H I N I U I. $L$.}

Cal. o. Petala 5. Nectarium bifidum, postice cornutum. Capsulae 3 seu 5.

AzUreum. D. caule stricto : foliis lineari-multipartitis : spica floribus breviter pedicellatis, amonissime azureis : cornu sursum arcuato; petalis villosissimis : eap. sulis ternis.

$I_{A B}$, in Carolina et Georgia.

Tridactruum. D. caule glabro : foliis tripartitopalmatis; laciniis lanceolatis, integris parceve divisis : spica stricta : cornu recto, calyci breviusculo subacquali : capsulis ternis.

D. carolinianum? WАLT.

Ozs. Caules erecti, simpliciusculi : folia glabriuscula; inferiora sub5-partita, laciniis 2-3-fidis. Spica pulverulenta; floribus solitarie alternis, breviter pedicellatis.

HAB. in montibus Virginiæ et Carolinæ.

rrrconne. D. pumilum, simplicicaule : foliis palmato-multifidis; laciniis sublanceolatis, 
POLYANDRIA. TRIGYNIA. 315 obtusiusculis: fasciculo paucifloro : calycis majusculi cornu recto : capsulis tribus, compressis, arcuatis, ab ipso receptaculo subreflexo-patulis.

$I_{A B}$. in altissimis montibus Carolinx.

\section{A C O N I T U M. L.}

Cal. o. Petala 5 : supremo fornicato. Nectaria 2 , pedunculata, recurva. Capsulae 3 seu 5.

Excinatur. A. caule flexuoso : foliis 3-5-partitoL. palmatis; lobis rhomboideo-lanceolatis: capsulis ternis.

$O_{B S .}$ Lobi foliorum acute incisi : galea promisse rostrata : flores coerulei.

$H_{A B}$. in rivis altissimorum montium Carolinæ. 
3 I6 POLYANDRIA. PENTAGYNIA.

\section{$P E N T A G Y N I A$. \\ C I M I C I F U G A. $L$.}

Cal. 1-phyllus. Petala 4 , urceolata, cartilaginea.

Capsulae oblongæ, sutura laterali dehiscentes, polyspermi.

OBs. Cimicifugae rectius habendx sunt pro speciebus Aсте. fructu multiplici; quales in DeLfHiNio aliisque affinibus occurrunt.

ampricata. C. foliis decompositis : floribus pis-tillisque longiuscule pedicellatis : ovariis glabris.

$O_{B S}$. Habitns Acte s racemosae. Pistilla interdum 6. HAB. in opacis sylvaticis altium montium Carolinæ.

almata. C. foliis simplicibus, palmatis : floribus dichotome subpaniculatis, polygynis.

$O_{B S}$. Pistilla ultra duodecim, discreta, in capitulum subrotundum collecta.

$\not L A B$. in rivulis excelsorum montium Carolinæ.

$$
\text { A Q U I I, E G I A. } L \text {. }
$$

Cal. o. Petala 5. Nectaria 5 corniculata inter petali. Caps. 5, distinctx.

Cana densis. $\Lambda$. florum cornibus rectis : staminibus

L. exertis.

OBS. Flores rubelli.

$I_{A B}$. a Canada ad Carolinam, per tractus montium. 
POLYANDRIA. POLYGYNIA. 317

\section{$P O C I N G \quad Y \quad Y \quad N I A$.}

N E L U M B I U M. Juss.

Cal. et Stam. Nynpurez. Ovarium apice truncatum, stylos plurimos et stigmata totidem supra exerens. Fructus turbinatus, totidem foreis supra excavalus monospermis. Semina magna, ovata aut subrotunda.

Luteum. N. flore luteo : antheris acute lineariacuminatis : calycis foliolis duobus extimis multo minoribus.

$H . A B$. in regione Illinoensi et in Carolina.

\section{H Y D R A S T I S. $L$.}

Cal. o. Petala 3. Nectaria o. Baccae plures.

\section{catamensis. II I D R A S T I S.}

I.

Fructus. Bacce plures, arcte densatre in capitulum globosum, superficie communi convexo-gibbulosum et persistentibus stylis sparsin scabratum; mutuo pressu difformcs, abdita parte, minus teneriusque carnosx ; 1-loculares. - Semina duo (aut abortatione unicum), altero supra alterum, obovoidea, lavigata, nigricanti-fusca.

HAB. in traetu montium Alléshanis, a Canada ad Carolinara. 
Cal. o. Petala 4. Rarius 5 vel 6. Sem. caudata.

virginiana. C. foliis trifoliolatis; foliolis lato cor-

$\boldsymbol{L}$. datis, inciso-dentatis lobatisque : floribus dioicis.

OBs. Corymbi pauciflori.

$H_{A B}$ a Canada ad Virginiam.

RETICUlata. C. foliis compositis; foliolis oblongoovalibus, utrinque obtusis, omnibus integris petiolatisque : floribus solitariis.

$O_{B S}$. Flos fere $C$. viornae; calyce minus crasso. Foliola aride menbranacea, utrinque prominule reticulato-venosissima.

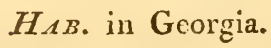

Viorr.. C. foliis divaricato-compositis; foliolis

I. plerisque ovali-lanceolatis, utrinque acutis; nonnullis trifoliatis aut trilobis: floribus solitariis.

DBs. Calyx crassissine coriaceus.

$H_{A B}$. in Virginia.

CRispa. C. foliis divaricato-compositis; foliolis

L. ovali-lanceolatis, acutissimis, integerrimis : floribus solitariis.

Oss. Flores majusculi, purpurascentes; calycibus undulosis, superne fimbriato-crispis, Cauda seminum non plumosa.

$H_{A B}$. in Virginia, Carolina. 
POLYANDRIA. POLFEXIA. ЗंI sfrices. C. caule erecto, pubentissimo : foliis simplicibus, ovalibus; junioribus calycibusque extus incano-sericeis : pedunculo terminali, solitario; flore cernuo.

C. ochroleruca? Aiт.

$O_{B s}$. Affunis C. integrifolice ; flore conspicue minore; calyce angustiore. Folia scssilia, opposita, pubescentia.

$H_{A B}$. in Virginia et in montanis Carolinx.

\section{A NEMONE. $L$.}

Cal. o. Petala 6-g. Sem. plura.

Ilepatica. A. foliis trilobatis, integerrimis : sca-

L. pis unifloris : involucro calyciformi.

$O_{B S}$. Variat foliorum lobis rotundatis, obtusis, ovalibus, acutis.

$H_{A B}$. a Canada ad Carolinam, per tractus mon. timn.

Nemorosa. A. caule unifloro : foliis biternatis;

L. foliolis inciso-lobatis, acutis : seminibus ovatis, siylo brevi uncinatis, puberulis.

$O_{B S .}$ A. quinquefolia Liss. hujusce rarietas, foliis minus incisis; lateralibus profunde bipartitis, unde quasi quinque evadunt.

$H_{A B}$, a Cauada ad Virginiam et in altis montibus Carolinix.

parviflora. A. caulibus simplicissimis, unifloris : foliis simpliciter trifoliatis; foliolis 
sessilibus, cuneatis : pedunculo longissimo, nudo : seminibus lanatis, muticis.

$O_{B S}$. Foliola glabriuscula, summitate obtruse incisa.

HI.AB. ad amnes in sinum Hudsonis defluentes.

virginiana. A. caule ramoso : petiolis trifoliatis;

$\boldsymbol{L}$. foliolis inciso-lobatis, serratisque : pedunculis virgatis : seminibus capitulo oblongo-ovato, lanatis.

IHAB. a Canada ad Carolinam.

Aconitirolia. A. caule ramoso : foliis radicalibus palmatis : caulinis amplexicaulibus; lobis acute lanceolatis, inciso serratis: seminibus capitulo globoso, lenticularibus, nude rostellatis.

A. pensylvanica. Lisw.

A. dichotoma, ejusd.

$H_{A B}$. in Canada et Nova Anglia.

\section{R A N U N C U L U S. $L$.}

Cal. 5-phyllus. Petaliz 5 intra ungues poro mellifero. Capsulae numerosæ.

niliforans. R. perpusillus, glaber : caulibus filiformibus, reptantibus; distanter geniculatis, quasi aphyllis : geniculis uni- 
POLYANDRIA. POLYGYNIA. 32I floris ; flore pedicellato : foliis subulatolinearibus, obtusis.

OEs. Affinis R. reptanti.

$H_{A B}$. ad ripas fluminis $S$. Laurentii et sinum Hudsonis.

Framula. R. glaber, decumbens : foliis petio-

L. latis, subdentatis ; inferioribus ovali-lanceolatis; superioribus sublinearibus.

$H_{A B}$. in Carolina inferiore.

mISPIDUS. R. erectus, hirsutissimus : foliis trifoliatis ; foliolis acute lobatis : caulibus infra primum pedunculum nudis, paucifloris : calyce appresso.

$H_{A B}$. in umbrosis sylvis Carolinæ inferiozis.

rulbosus. R. radice bulbosa : foliis radicalibus

$\boldsymbol{L}$. trifoliatis ; foliolis varie incisis : pedunculis elongatis, sulcato-striatis, unifloris : calyce villoso, reflexo : capsulis lentiformibus, globoso-capitatis.

$H_{A B}$. in pratis humidis Pensylvaniæ.

MURicatus. R. glabellus, diffusus : foliis simpli-

I. cibus, subrotundis, tripartito-lobatis : calyce reflexo : capsulis majusculis, utraque facie muricatis.

$F_{A B}$, in Carolina.

r. 


\section{T H'A L I C T R U M. $L$.}

Cal. o. Petala 4 seu 5. Sem. ecaudata.

AYEMONOIDES. T. pusillum : foliis radicalibus biternatis : involucro petiolatim sub6-phyllo et pedicellis aggregatis scapos aphyllos terminantibus.

Anemone Thalictroides. Linn.

$O_{B S .}$ Involucrum fit ex binis foliis contigue sessilibus;

foliolis capillaribus, petiolatis.

$H_{A B}$, a Canada ad Virginiam.

x evrgatum. T. caule lævigato : foliolis suborbiculatis, sublobato-crenatis, subtus glaucescentibus, lævibus : floribus dioicis; calyce 4-phyllo : filamentis capillaribus : umbellulis paucifloris, pedunculatis, sessilibus.

Affine $T$. dioico. Liss.

$O_{B} S$. Plures quidem hujus generis species vidi et legi ; quas tamen silentio premere satius duxi, quam species forsan jam notas pro novis statuere : namque species hujus generis (in posterum prorsus elaborandi) ita male fuerunt hucusque definite, ut eas dignoscere nequiverim.

Thalictra Americana fere omnia dioica : unicum tantum submonoicum observavi.

$H_{A B}$. in Pensylvania et montibus Carolinæ. 
POLYANDRIA. POLYGYNIA. 3.3

H Y D R O P E L T IS.

$\Upsilon \delta_{o p}, \Pi_{\varepsilon \lambda \tau \eta}:$ planta aquatica foliis peltatis.

Herba aquatilis; foliis simplicibus, alternis ; pe-dunculis unifloris.

CAI. profunde 6 -partitus seu sub6-phyl. lus, petaloideus, modice et quasi campanulatim patens; laciniis lanceolatooblongis; tribus alternis paulo longioribus, tenuioribus et saturatius coloratis, summitate subrecurvis.

Cor. o.

Star. numerosa (circiter 36), hypogyna, fere longitudine calycis : filamenta capillaria : anther:e lineares, obtusa, filamento continux.

Pist. plura, (15-18) distincta, approximata, erecta : ovaria singula oblonga; in stylum filiformem, incurvum, apice obtusum desinentia.

Froct. capsula plures, intra calycem vegetum ipsis longiorem, erectæ, oblongoovata, vestigio styli mucronatæ, introrsum sutura quidem longitudinali donata, sed subcarnosæ nec dehiscentes, I-loculares. 
324 POLYANDRIA. POLYGYNIA.

Semina duo, subglobosa, suturæe adnexa; srepe unicum.

$O_{B S}$. Genus affine $\mathbf{C}_{A \text { Lthes. }}$

purperea. H. foliis centro peltatis, ovalibus, . $a$ ab. 29. integerrimis : floribus purpureis.

$O_{B S}$. Planta Hydrocharidea; floribus extensione subuncialibus, obscure purpurcis, ad violaceum exsiccatione tendentibus.

$H_{A B}$. in aquis tranquillis Carolinæ inferioris et Provinciæ Tennassée.

\section{A L T H A. $L$.}

Cal. o. Petala 5. Nectaria o. Caps. plures, polyspermæ.

palustris. C a l t h a.

$\boldsymbol{I}$.

$H_{A B}$. in Pensylvania, Virginia 
Tom 1 Pag. 32x.

Tab. 29 .

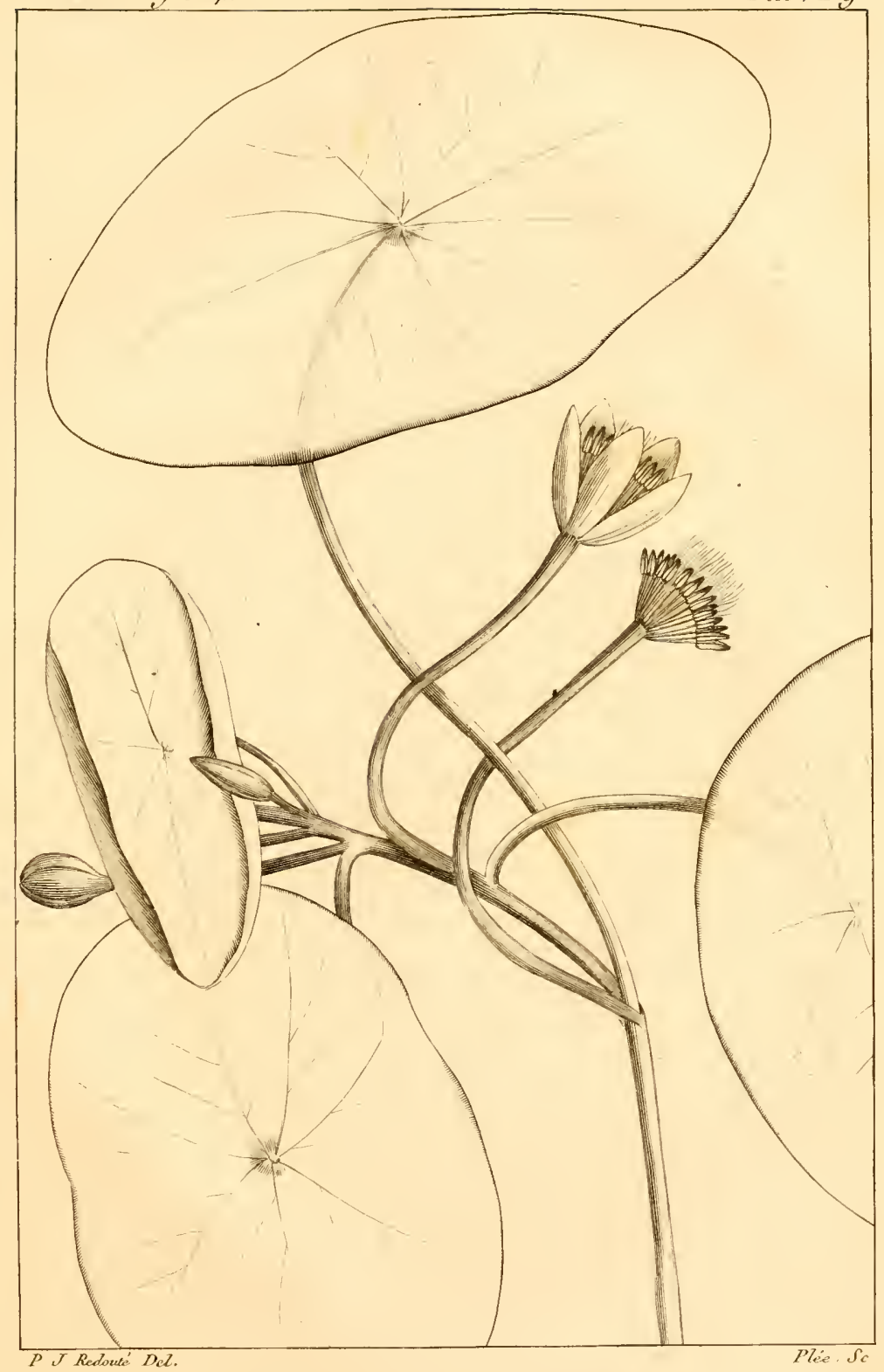

Hydropeits purpurea. 

Cal. o. Petala 5. seu plura. Nectaria bilabiata, tubulata. Caps. polyspermæ, erectiusculæ.

TRIFolius. H. pusillus : foliis trifoliatis; foliolis

L. rotundato-obovalibus, duplicato-crenatis, crenis acuminatis : scapo unifloro: calyce deciduo : petalis pluribus gracilibus, spathulatis : capsulis umbellulatopedicellatis.

$O_{B S}$. Habitus generi alienus. Flos pusillus, tribus circiter lineis amplus, albus. Calyx 5 -phyllus. Petala numero variantia, difformia; limbo-rotundato, oblique introrsum saccato; ungue longo et gracili. Stamina numerosa, alba. Pistilla 2-6, stipitata : capsulæ longitus stipitatæ, nmbellulatin erectæ, ovoideo-oblongæ, curvatim rostratæ, polyspermæ.

$H_{A B}$ a sinu Hudsonis ad Pensylvaniam, in cupressetis sphagnosis.

Ti-savoyanne jaune Canadensium. 


\section{L L I C I U M. $L$.}

Cal. 6-phyllus. Petala 27. Caps. plures, in orbem digestæ, bivalves, monospermæ.

rLORIDANUM. I. foliis acuminatis : floribus atroL. purpureis; petalis numerosis, oblongis linearibusque.

$H_{A B}$. in Florida occidentali, juxta flumen Mississipi.

parviflordu. I. foliis obtusis : floribus pusillis, obsolete flavis : petalis calyceque rotun. datis, concavis.

Illicium anisatum. Bartram's Journal. pag. 24. Lond. $176 \mathrm{~g}$.

$H_{A B}$, in Florida orientali, juxta amnem S. Joannis.

L I R I D E N D R O N. L.

Cal. 3-phyllus. Petala 9. Sem. imbricata in strobilum.

Tulipifera. L. foliis abscisso-truncatis , 4-loL. batis.

Var. $\propto$ : acutiloba : lobis acutis acuminatisque.

- $\beta$ : obtusiloba : lobis rotundato-obtusissimis.

$H_{A B}$. a. a Canada ad Virginiam et a Carolina ad Floridam, per tractus montium.

- $\beta$. in Pensylvania. 
Cal. 5-phyllus. Petala 9. Caps. bivalves, imbricatæ. Semina baccata, pendula.

Grandiflora. M. foliis perennantibus, ovalibus,

$\boldsymbol{u}$. rigide crasseque coriaceis : pistillis lanatis : petalis dilatato-obovalibus, abrupte in unguem angustatis.

НАB. a finibus septentrionalibus Carolinæ ad Mississipi.

GLAUCA. M. foliis aequaliter ovalibus vel ovali-

L. oblongis, subtus glaucis.

$H_{A B}$. a Nova Cæsarea ad Floridam.

Macrophylla. M. ramis medullosis, fragilibus: foliis omnium amplissimis, oblonge subcuneato-obovalibus, basi sinuata subauriculatis; subtus glaucis.

$O_{B S}$. Folia 1-2 $\frac{1}{2}$ ped. longa, figura fere $M$. auriculatae. Caulis arborescens; ramorum substantia fere tota medullosa. Petala sex, alba; inferiora basi purpurea.

$H_{A B}$. in regionibus occidentalibus fluvio Tennassée trajectis.

tripetala. M. foliis amplioribus, oblonge subL. cuneato-obovalibus; junioribus densissime holosericeis : calyce reflexo.

$O_{B S .}$ Petala solito novem.

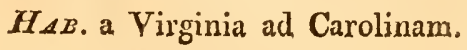


328 POLYANDRIA. POXYGYNIA.

acuminata. M. foliis ovalibus, acuminatis, sub-

L. tus pubentibus : floribus flavo-coerulescentibus.

$I_{A B}$. a Pensylvania ad Carolinam, in montibus altissimis.

Cordata. M. foliis cordatis, subtus subtomentosis : floribus flavis.

$O_{B S .}$ Affinis $M$. acuminatae.

$H_{A B}$. in collibus apricis Carolinæ superioris et Georgix.

auriculata. M. foliis subrhomboideo-obova$B_{\triangle R T}$. libus, inferne angustatis, basi profundo sinu quasi auriculatis, membranaceis, utrinque viridibus.

M. Fraseri. WaLt.

$H_{A B}$. in montibus altissimis Carolinæ. 


\section{O R C H I D O C A R P U M.}

Fructus Orchidomorphus.

Flos Unone seu Uvarize.

Fruct. Bacce plures, aut abortatione subsolitariæ, sessiles, majusculæe, ovoideo-subreniformes.

Semina plura, juxta suturam internam simplici serie adnexa, arillata.

$O_{B S}$. Genus hoc novum proponere satius duxi, quam ad affinia liuc usque obscura referre.

Arietinum. O. foliis glabriusculis, oblonge cuneato-obovalibus : petalis exterioribus orbiculatis : fructibus maximis, crassius carnosis.

Annona triloba. Tinn.

HАB. a Virginia ad Floridam, juxta inundatas amnium ripas.

parviflorum. O. ramulis, foliis petalisque rufopubentiluus : foliis cuneato-obovalibus, basi acutis : floribus parvulis; subsessilibus : fructibus pruniformibus, parce carnosis.

Obs. Petala omuia ovalia, intus obsolete atropurpurea.

$H_{A B}$. in Carolina et Georgia. 
33o POLYANDRIA. POLYGYNIA.

pygmaeum. O. foliis prelonge lanceolatis cuneatisve, glabellis : petalis exterioribus multoties majoribus, obovali-oblongis.

Annona pygmaea. Bartr. Trav.

$H_{A B}$. in Georgia et Florida.

GRANDIFLORUM. O. ramulis foliisque rufo-pubentibus : foliis cuneato-obovalibus, basi obtusis : petalis exterioribus multoties amplioribus, obovalibus; interioribus oblongis.

Annona grandiflora. BArtr. Trav. 18.

HAB. in Georgia et Florida.

FINIS TOMI PRIMI. 





